\title{
Algoritmos evolutivos multi-objetivo para a reconstrução de árvores filogenéticas
}

\author{
Waldo Gonzalo Cancino Ticona
}

Orientador: Prof. Dr. Alexandre Cláudio Botazzo Delbem

Tese apresentada ao Instituto de Ciências Matemáticas e de Computação - ICMC-USP como parte dos requisitos para obtenção do título de Doutor em Ciências, na área de Ciências de Computação e Matemática Computacional.

"VERSÃO REVISADA APÓS A DEFESA"

Data da Defesa :

$11 / 02 / 2008$

Visto do Orientador:

USP-São Carlos

Março de 2008 

Algoritmos evolutivos multi-objetivo para a reconstrução de árvores filogenéticas

Waldo Gonzalo Cancino Ticona 



\section{Dedicatória}

A minha família, especialmente aos meus pais e a minha irmã, pela compreensão, carinho e incansável apoio ao longo do período dos meus estudos de pós-graduação.

Aos meus queridos amigos, pelos momentos de convívio, trocas e afetos. 



\section{Agradecimentos}

Ao Prof. Dr. Alexandre Cláudio Botazzo Delbem, que, no decorrer deste doutorado, contribuiu para meu crescimento científico e intelectual.

Ao Prof. Dr. André C.P.L.F. Carvalho, pela atenção e apoio durante as etapas inicias do meu trabalho.

À Fundação de Amparo à Pesquisa do Estado de São Paulo pela concessão da bolsa de doutorado e pelo apoio financeiro para a realização desta pesquisa (Número de Processo: 02/13846-0).

Aos meus professores e colegas, sem distinção, sou-lhes muito grato. 



\section{Resumo}

O problema reconstrução filogenética têm como objetivo determinar as relações evolutivas das espécies, usualmente representadas em estruturas de árvores. No entanto, esse problema tem se mostrado muito difícil uma vez que o espaço de busca das possíveis árvores é muito grande. Diversos métodos de reconstrução filogenética têm sido propostos. Vários desses métodos definem um critério de otimalidade para avaliar as possíveis soluções do problema. Porém, a aplicação de diferentes critérios resulta em árvores diferentes, inconsistentes entre sim. Nesse contexto, uma abordagem multi-objetivo para a reconstrução filogenética pode ser útil produzindo um conjunto de árvores consideradas adequadas por mais de um critério.

Nesta tese é proposto um algoritmo evolutivo multi-objetivo, denominado PhyloMOEA, para o problema de reconstrução filogenética. O PhyloMOEA emprega os critérios de parcimônia e verossimilhança que são dois dos métodos de reconstrução filogenética mais empregados. Nos experimentos, o PhyloMOEA foi testado utilizando quatro bancos de seqüências freqüentemente empregados na literatura. Para cada banco de teste, o PhyloMOEA encontrou as soluções da fronteira de Pareto que representam um compromisso entre os critérios considerados.

As árvores da fronteira de Pareto foram validadas estatisticamente utilizando o teste SH. Os resultados mostraram que o PhyloMOEA encontrou um número de soluções intermediárias que são consistentes com as soluções obtidas por análises de máxima parcimônia e máxima verossimilhança realizados separadamente. Além disso, os graus de suporte dos clados pertencentes às árvores encontradas pelo PhyloMOEA foram comparadas com a probabilidade posterior dos clados calculados pelo programa Mr.Bayes aplicados aos quatro bancos de teste. Os resultados indicaram que há uma relação entre ambos os valores para vários grupos de clados.

Em resumo, o PhyloMOEA é capaz de encontrar uma diversidade de soluções intermediárias que são estatisticamente tão boas quanto as melhores soluções de 
máxima parcimônia e máxima verossimilhança. Tais soluções apresentam um compromisso entre os dois objetivos. 


\section{Abstract}

The phylogeny reconstruction problem consists of determining the evolutionary relationships (usually represented as a tree) among species. This is a very complex problem since the tree search space is huge. Several phylogenetic reconstruction methods have been proposed. Many of them defines an optimality criterion for evaluation of possible solutions. However, different criteria may lead to distinct phylogenies, which often conflict with each other. In this context, a multi-objective approach for phylogeny reconstruction can be useful since it could produce a set of optimal trees according to mdifficultultiple criteria.

In this thesis, a multi-objective evolutionary algorithm for phylogenetic reconstruction, called PhyloMOEA, is proposed. PhyloMOEA uses the parsimony and likelihood criteria, which are two of the most used phylogenetic reconstruction methods. PhyloMOEA was tested using four datasets of nucleotide sequences found in the literature. For each dataset, the proposed algorithm found a Pareto front representing a trade-off between the used criteria.

Trees in the Pareto front were statistically validated using the SH-test, which has shown that a number of intermediate solutions from PhyloMOEA are consistent with solutions found by phylogenetic methods using one criterion. Moreover, clade support values from trees found by PhyloMOEA was compared to clade posterior probabilities obtained by Mr.Bayes. Results indicate a correlation between these probabilities for several clades.

In summary, PhyloMOEA is able to find diverse intermediate solutions, which are not statistically worse than the best solutions for the maximum parsimony and maximum likelihood criteria. Moreover, intermediate solutions represent a trade-off between these criteria. 



\section{Sumário}

Lista de Figuras $\quad$ vi

Lista de Tabelas $\quad$ viii

Lista de Abreviaturas $\quad$ ix

Lista de Símbolos $\quad$ xi

1 Introdução 1

2 Reconstrução filogenética $\quad 7$

2.1 Introdução . . . . . . . . . . . . . . . . . . . . 7

2.2 Seqüências e grafos . . . . . . . . . . . . . . . . . . 9 9

2.3 Reconstrução filogenética . . . . . . . . . . . . . . . . . 11

2.4 Máxima parcimônia . . . . . . . . . . . . . . . . 15

2.4.1 Estratégias de busca da árvore ótima . . . . . . . . . . . . 18

2.4.2 Heurísticas para busca da árvore de máxima parcimônia . . . . . 22

2.5 Máxima verossimilhança . . . . . . . . . . . . . . . . 24

2.5.1 Modelos de substituição de seqüências de DNA . . . . . . . . . 24

2.5.2 Cálculo de verossimilhança para uma árvore . . . . . . . . . . . . . 27

2.5.3 Heurísticas para busca da árvore de máxima verossimilhança . . . . 30

2.6 Comparação de métodos de inferência filogenética . . . . . . . . . . . . 32

2.7 Avaliação de clados e árvores alternativas . . . . . . . . . . . . . . 34

2.7.1 Análise de bootstrap . . . . . . . . . . . . . . . 34

2.7.2 O teste de Shimodaira-Hasegawa . . . . . . . . . . 36

2.7.3 Inferência Bayesiana . . . . . . . . . . . . . 37

2.8 Considerações finais . . . . . . . . . . . . . . . . . . . 38 
3 Algoritmos evolutivos aplicados à filogenia $\quad 41$

3.1 Introdução . . . . . . . . . . . . . . . . . . . . . . . . 41

3.2 Computação evolutiva . . . . . . . . . . . . . . . . . . . 42

3.3 Algoritmos genéticos . . . . . . . . . . . . . . . . 44

3.3.1 Representação das soluções . . . . . . . . . . . . . . . 46

3.3.2 Definição da população inicial . . . . . . . . . . . . . . . . 47

3.3 .3 Operador de seleção . . . . . . . . . . . . . . . . 47

3.3 .4 Operador de recombinação . . . . . . . . . . . . . . . . . 49

3.3.5 Operador de mutação . . . . . . . . . . . . . . . . . . 50

3.3 .6 Exemplo do uso de um AG . . . . . . . . . . . . . 51

3.3.7 Diferenças entre os AGs e as técnicas de otimização tradicionais . . 53

3.4 Algoritmos evolutivos aplicados a filogenia . . . . . . . . . . . . . 55

3.4.1 Aplicação de AEs com o critério de máxima verossimilhança . . . . 55

3.4 .2 Aplicação de AEs com o critério de máxima parcimônia . . . . . . . 60

3.5 Considerações finais . . . . . . . . . . . . . . . . . . . . 61

4 AEs para otimização multi-objetivo $\quad 63$

4.1 Introdução . . . . . . . . . . . . . . . . . 63

4.2 Otimização multi-objetivo . . . . . . . . . . . . . . 64

4.2 .1 Formulação . . . . . . . . . . . . . . . . . . . . 64

4.2 .2 Soluções Pareto-ótimas . . . . . . . . . . . . . . . 65

4.2 .3 Metas em otimização multi-objetivo . . . . . . . . . . . . . 66

4.2.4 Diferenças com a otimização de objetivos simples . . . . . . . . 66

4.3 Técnicas tradicionais para MOOP . . . . . . . . . . . . . 67

4.3.1 Somatório de pesos . . . . . . . . . . . . . . . . 67

4.3.2 Método de restrições $\varepsilon \ldots \ldots \ldots \ldots$. . . . . . . . . 68

4.3.3 Programação por metas . . . . . . . . . . . . . . 69

4.3.4 Vantagens e desvantagens das técnicas tradicionais . . . . . . . 71

4.4 AEs para problemas de otimização multi-objetivo . . . . . . . . . . . . 71

4.4 .1 Algoritmo NSGA-II . . . . . . . . . . . . . . . . 73

4.5 Abordagens multi-objetivo aplicados em filogenia . . . . . . . . . 76

4.6 Considerações finais . . . . . . . . . . . . . . . . . . . 78

5 MOEA para o problema de filogenia $\quad 79$

5.1 Introdução . . . . . . . . . . . . . . . . . . . . . . 79

5.2 PhyloMOEA . . . . . . . . . . . . . . . . . 79

5.2.1 Representação de soluções . . . . . . . . . . . . . . . 80

5.2 .2 Funções de aptidão . . . . . . . . . . . . . . . . . 81

5.2 .3 Geração de soluções iniciais . . . . . . . . . . . . . . 86

5.2 .4 Operadores de recombinação e mutação . . . . . . . . . . . . 86 
5.2.5 Otimização dos comprimentos dos ramos . . . . . . . . . . 87

5.3 Considerações finais . . . . . . . . . . . . . . . . . . 90 90

6 Experimentos e resultados $\quad 91$

6.1 Introdução . . . . . . . . . . . . . . . . . . . . . . . . . 91

6.2 Conjuntos de seqüências . . . . . . . . . . . . . . . . . . 91

6.3 Condições iniciais . . . . . . . . . . . . . . . . . . . . 92

6.4 Resultados das execuções do PhyloMOEA . . . . . . . . . . . . . . 94

6.4.1 Testes de árvores alternativas e clados . . . . . . . . . . . 95

6.5 Incorporação da variação de taxas entre sítios . . . . . . . . . . . . . . 101

6.5.1 Resultados das execuções do PhyloMOEA utilizando ASRV . . . . 104

6.5.2 Testes de árvores alternativas para as soluções do PhyloMOEA considerando ASRV . . . . . . . . . . . . . . . . 105

6.6 Considerações finais . . . . . . . . . . . . . . . . . 109

7 Conclusões e trabalhos futuros $\quad 113$

$\begin{array}{lr}\text { Referências Bibliográficas } & 119\end{array}$ 


\section{Lista de Figuras}

2.1 Exemplos de seqüências de DNA e proteínas. . . . . . . . . . . . . . 9

2.2 Exemplos de grafos. . . . . . . . . . . . . . . . . 10

2.3 Exemplos de árvores com raiz. . . . . . . . . . . . . . . . . 10

2.4 Uma árvore filogenética para um grupo de primatas. . . . . . . . . . . . . 11

2.5 As 7 possíveis árvores geradas da árvore sem raiz de 5 seqüências. . . . . . 12

2.6 Aplicação do algoritmo de Fitch para um caracter. . . . . . . . . . . 17

2.7 Exemplo do método stepwise addition. . . . . . . . . . . . . . . . . . 19

2.8 Exemplo da aplicação do método NNI. . . . . . . . . . . . . . 20

2.9 Exemplo da aplicação do método SPR . . . . . . . . . . . . 20

2.10 Exemplo do método TBR. . . . . . . . . . . . . . . . . . 21

2.11 Árvore para o exemplo do cálculo da verossimilhança. . . . . . . . . . . . 28

2.12 Diagrama da análise de bootstrap. . . . . . . . . . . . . 35

3.1 Operador de Recombinação de um ponto. . . . . . . . . . . . . . . . . 49

3.2 Superfície suavizada da função $f(x, y)$ (Haupt e Haupt, 1998). . . . . . . . 51

3.3 Indivíduos distribuídos sobre a superfície da função $f(x, y) \ldots \ldots$. . . . 53

3.4 Gráfico da aptidão calculada em relação as gerações. . . . . . . . . . . . 54

3.5 Operador de recombinação implementado no GAML. . . . . . . . . . . 56

3.6 Exemplo do consenso por poda para duas árvores. . . . . . . . . . . 58

3.7 Operador de recombinação do METAPIGA. . . . . . . . . . . . . . 58

3.8 Algoritmo para otimização de comprimentos de ramos de GARLI . . . . . 60

4.1 Exemplo do preço-desempenho . . . . . . . . . . . . . . 65

4.2 Diferentes distribuições de soluções na fronteira de Pareto. . . . . . . . . . 66

4.3 Método de restrições $\varepsilon \ldots \ldots \ldots \ldots$. . . . . . . . . . . . 69

4.4 Método da programação de metas lexicográficas. . . . . . . . . . . . . 70

4.5 Ordenação por dominância. . . . . . . . . . . . . . . . 75 
4.6 Esquema do modelo NSGA-II. . . . . . . . . . . . . . . . 77

5.1 Ilustração do funcionamento do PhyloMOEA. . . . . . . . . . . . . . . 80

5.2 Representação interna empregada pelo PhyloMOEA para uma árvore sem raiz. ............................. 81

5.3 Algoritmo de Fitch para árvore sem raiz. . . . . . . . . . . . . . . 82

5.4 Cálculo de verossimilhança em árvores com raiz e sem raiz. . . . . . . . . . 83

5.5 Operador de recombinação do PhyloMOEA. . . . . . . . . . . . . 87

5.6 Otimização de dois comprimentos de ramo. . . . . . . . . . . . 88

6.1 Soluções Pareto-ótimas do banco $r b c L \_55 \ldots \ldots$. . . . . . . . . . . 95

6.2 Soluções Pareto-ótimas do banco $m t D N A \_186 \ldots$. . . . . . . . . . . . . 95

6.3 Soluções Pareto-ótimas do banco RDPII_218. . . . . . . . . . . . 96

6.4 Soluções Pareto-ótimas do banco ZILLA_500. . . . . . . . . . . . . . . 96

6.5 Grau de suporte do PhyloMOEA vs. Probabilidade Posterior do Mr.Bayes

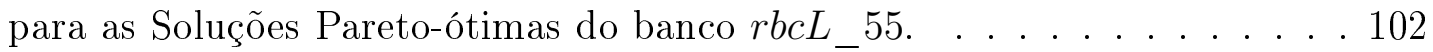

6.6 Grau de suporte do PhyloMOEA vs. Probabilidade Posterior do Mr.Bayes para as Soluções Pareto-ótimas do banco mtDNA_186. . . . . . . . . . . 102

6.7 Grau de suporte do PhyloMOEA vs. Probabilidade Posterior do Mr.Bayes para as Soluções Pareto-ótimas do banco RDPII_218. . . . . . . . . . . 102

6.8 Grau de suporte do PhyloMOEA vs. Probabilidade Posterior do Mr.Bayes para as Soluções Pareto-ótimas do banco ZILLA_500. . . . . . . . . . . 102

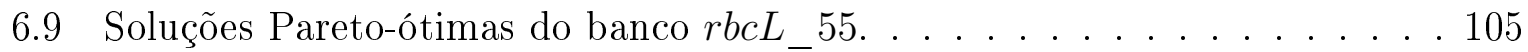

6.10 Soluções Pareto-ótimas do banco mtDNA_186. . . . . . . . . . . . . 105

6.11 Soluções Pareto-ótimas do banco RDPII_218. . . . . . . . . . . . . . 105

6.12 Soluções Pareto-ótimas do banco ZILLA_500. . . . . . . . . . . . . 105

6.13 Grau de suporte do PhyloMOEA vs. Probabilidade Posterior do Mr.Bayes para as Soluções Pareto-ótimas do banco $r b c L \_55 . \quad$. . . . . . . . . . . 110

6.14 Grau de suporte do PhyloMOEA vs. Probabilidade Posterior do Mr.Bayes para as Soluções Pareto-ótimas do banco $m t D N A \_186 \ldots$. . . . . . . . . 110

6.15 Grau de suporte do PhyloMOEA vs. Probabilidade Posterior do Mr.Bayes para as Soluções Pareto-ótimas do banco RDPII_218. . . . . . . . . . . 110

6.16 Grau de suporte do PhyloMOEA vs. Probabilidade Posterior do Mr.Bayes para as Soluções Pareto-ótimas do banco ZILLA_500. . . . . . . . . . . 110 


\section{Lista de Tabelas}

2.1 Número de árvores possíveis sem raiz e com raiz para 2 a 10 espécies. . . . 13

2.2 Principais métodos para construção de árvores filogenéticas. . . . . . . . . 15

3.1 Tabela de conversão de parâmetros contínuos para binário (Haupt e Haupt,

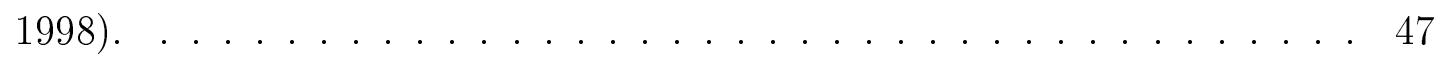

3.2 População inicial do AG. . . . . . . . . . . . . . . . . . . 52

3.3 Segunda geração do AG. . . . . . . . . . . . . . . . . . . . . 52

3.4 Décima geração do AG. . . . . . . . . . . . . . . . . . 53

4.1 Diferentes modelos de MOEAs. . . . . . . . . . . . . . 73

6.1 Resultados de máxima parcimônia e máxima verossimilhança obtidos pelo NONA e RAxML-V. . . . . . . . . . . . . . . . . 93

6.2 Parâmetros do PhyloMOEA para os experimentos. . . . . . . . . . . 93

6.3 Resumo dos resultados das execuções do PhyloMOEA. . . . . . . . . . . . 94

6.4 Resumo do número de soluções encontradas nas execuções do PhyloMOEA. 95

6.5 Resultados do teste SH para as Soluções Pareto-ótimas. . . . . . . . . . . . . 97

6.6 Resultados do teste SH para as Soluções Finais. . . . . . . . . . . . 97

6.7 Comparação dos resultados do PhyloMOEA e Mr.Bayes para as Soluções

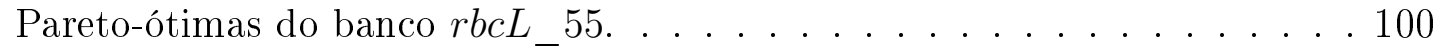

6.8 Comparação dos resultados do PhyloMOEA e Mr.Bayes para as Soluções

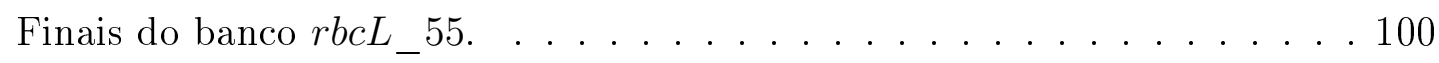

6.9 Comparação dos resultados do PhyloMOEA e Mr.Bayes para as Soluções Pareto-ótimas do banco mtDNA_186. . . . . . . . . . . . 100

6.10 Comparação dos resultados do PhyloMOEA e Mr.Bayes para as Soluções Finais do banco $m t D N A_{-} 186$. . . . . . . . . . . . . . 100

6.11 Comparação dos resultados do PhyloMOEA e Mr.Bayes para as Soluções Pareto-ótimas do banco RDPII_218. . . . . . . . . . . . . . 101 
6.12 Comparação dos resultados do PhyloMOEA e Mr.Bayes para as Soluções Finais do banco RDPII_218. . . . . . . . . . . . . . . . 101

6.13 Comparação dos resultados do PhyloMOEA e Mr.Bayes para as Soluções Pareto-ótimas do banco ZILLA_500. . . . . . . . . . . . . . . 101

6.14 Comparação dos resultados do PhyloMOEA e Mr.Bayes para as Soluções Finais do banco ZILLA_500. . . . . . . . . . . . . . . 101

6.15 Resultados de máxima parcimônia e máxima verossimilhança obtidos pelo NONA e RAxML-V+PHYML (considerando o ASRV). . . . . . . . . . . 103

6.16 Parâmetros do modelo HKY85 $+\Gamma$ para os experimentos. . . . . . . . . . . 103

6.17 Resumo dos resultados das execuções do PhyloMOEA considerando ASRV. 104

6.18 Resumo do número de soluções encontradas nas execuções do PhyloMOEA considerando ASRV. . . . . . . . . . . . . . . . . . . . 104

6.19 Resultados do teste SH para as Soluções Pareto-ótimas fornecidas pelo PhyloMOEA considerando ASRV . . . . . . . . . . . . . 106

6.20 Resultados do teste SH para as Soluções Finais fornecidas pelo PhyloMOEA considerando ASRV. . . . . . . . . . . . . . . 106

6.21 Comparação dos resultados (considerando ASRV) do PhyloMOEA e Mr.Bayes para as Soluções Pareto-ótimas do banco $r b c L_{-} 55$. . . . . . . . . . . 107

6.22 Comparação dos resultados (considerando ASRV) do PhyloMOEA e Mr.Bayes para as Soluções Finais do banco $r b c L_{-} 55 . \ldots$. . . . . . . . . . . . 108

6.23 Comparação dos resultados (considerando ASRV) do PhyloMOEA e Mr.Bayes para as Soluções Pareto-ótimas do banco $m t D N A_{-} 186$. . . . . . . . . . 108

6.24 Comparação dos resultados (considerando ASRV) do PhyloMOEA e Mr.Bayes

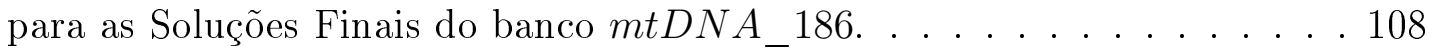

6.25 Comparação dos resultados (considerando ASRV) do PhyloMOEA e Mr.Bayes para as Soluções Pareto-ótimas do banco RDPII_218. . . . . . . . . . 108

6.26 Comparação dos resultados (considerando ASRV) do PhyloMOEA e Mr.Bayes para as Soluções Finais do banco RDPII_218. . . . . . . . . . . . . . . 109

6.27 Comparação dos resultados (considerando ASRV) do PhyloMOEA e Mr.Bayes para as Soluções Pareto-ótimas do banco ZILLA_500. . . . . . . . . . . 109

6.28 Comparação dos resultados (considerando ASRV) do PhyloMOEA e Mr.Bayes para as Soluções Finais do banco ZILLA_500. . . . . . . . . . . . 109 


\section{Lista de Abreviaturas}

$\begin{array}{ll}\text { AE } & \text { Algoritmo Evolutivo } \\ \text { AG } & \text { Algoritmo Genético } \\ \text { ASRV } & \text { (do inglês Among Site Rate Variation) } \\ \text { DNA } & \text { Acido dexoxiribonucleico } \\ \text { GTR } & \begin{array}{l}\text { Modelo de substituição geral reversível no } \\ \text { tempo (do inglês General Time-Reversible } \\ \\ \text { Model) }\end{array}\end{array}$

HYK85 Modelo de substituição de DNA (Hasegawa et al., 1985)

MCMC Método de Monte Carlo baseado cadeias de Markov

MOEA Algoritmo evolutivo multi-objetivo (do inglês Multi-Objective Evolutionary Algorith

MOOP Problema de otimização multi-objetivo (do inglês Multi-objective Optimization Problem)

NJ Método Neighboor Joining

NNI Troca dos vizinhos mais próximos (do inglês Nearest Neighboor Interchange)

NSGA-II Elitist Non-Dominated Sorting Genetic Algorithm II 
SPR Poda e inserção de subárvore (do inglês Subtree Prunning and Regrafting)

TBR Bisseção e reconexão de árvore (do inglês Tree Bisection and Reconnection) 


\section{Lista de Símbolos}

\begin{tabular}{|c|c|}
\hline$G(V, E)$ & $\begin{array}{l}\text { Grafo } G \text { descrito pelo conjunto de nós } V \text { e o } \\
\text { conjunto de ramos } E\end{array}$ \\
\hline $\mathcal{D}$ & $\begin{array}{l}\text { Conjunto de seqüências (DNA o proteinas) de } \\
n \text { espécies }\end{array}$ \\
\hline$N_{s i t}$ & $\begin{array}{l}\text { Número de sítios de cada seqüências do con- } \\
\text { junto de seqüências } \mathcal{D}\end{array}$ \\
\hline $\operatorname{Par}(\tau)$ & Valor de parcimônia para uma árvore $\tau$ \\
\hline $\operatorname{Par}_{j}$ & Valor de parcimônia para o sítio $j$ \\
\hline $\mathcal{C}_{v_{j}, u_{j}}$ & $\begin{array}{l}\text { Custo de mudar do estado } v_{j} \text { para o estado } u_{j} \\
\text { no sítio } j\end{array}$ \\
\hline Q & $\begin{array}{l}\text { Matriz de taxas instantânea para um modelo } \\
\text { de substituição de DNA }\end{array}$ \\
\hline$\pi_{x}$ & $\begin{array}{l}\text { Freqüência do estado } x \text { no conjunto de da- } \\
\text { dos } \mathcal{D}\end{array}$ \\
\hline $\mathbf{P}_{x, y}(t)$ & $\begin{array}{l}\text { Probabilidade de mudar do estado } x \text { para o } \\
\text { estado } y \text { no tempo } t\end{array}$ \\
\hline$L(\theta)$ & Verossimilhança do modelo $\theta$ \\
\hline$\theta=\{\tau, \mathcal{B}, \mathcal{M}\}$ & $\begin{array}{l}\text { Modelo evolutivo, onde onde } \tau \text { é uma topolo- } \\
\text { gia da árvore, } \mathcal{B} \text { é o conjunto de comprimento } \\
\text { de ramos de } \tau \text { e } \mathcal{M} \text { é o modelo de substituição } \\
\text { de seqüências. }\end{array}$ \\
\hline$L_{j}$ & Verossimilhança no sítio $j$ \\
\hline$L E_{j}$ & Verossimilhança escalonada no sítio $j$ \\
\hline$L_{j}^{r}\left(r_{j}\right)$ & $\begin{array}{l}\text { Verossimilhança condicional no sítio } j \text { da su- } \\
\text { bárvore cuja raiz é o nó } r\end{array}$ \\
\hline
\end{tabular}




$\begin{array}{ll}L E_{j}^{r}\left(r_{j}\right) & \text { Verossimilhança condicional escalonada no sí- } \\ & \text { tio } j \text { da subárvore cuja raiz é o nó } r \\ p\left(\tau_{i}\right) & \text { O valor } p \text { para uma topologia } \tau_{i} \text { determinado } \\ & \text { pelo teste SH } \\ \mathcal{P}\left(\tau_{i}, \mid \mathcal{D}\right) & \text { Probabilidade posterior de } \tau_{i} \text { dado } \mathcal{D} \\ P_{j} & \text { População do AG na geração } j \\ \mathbf{x}=\left(x_{1}, \ldots, x_{N_{v a r}}\right) & \text { Vetor de } N_{\text {var }} \text { variáveis de decisão } \\ \mathbf{f}(\mathbf{x})=\left[f_{1}(\mathbf{x}), \ldots, f_{N_{o b j}}(\mathbf{x})\right] & \text { Vetor funções objetivo } \\ S_{f a c t} & \text { Espaço de busca de soluções fatíveis } \\ \preceq & \text { Operador de dominância de Pareto }\end{array}$




\section{centruo

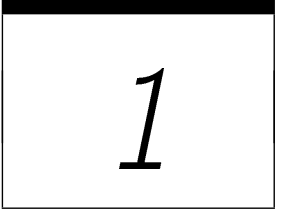 \\ Introdução}

A biologia molecular é uma ciência que apresentou avanços muito significativos nas últimas décadas. Os biólogos freqüentemente trabalham com uma grande quantidade de informação gerada a partir de experimentos em laboratório. Dada a necessidade de manipular essa informação, surgiu a bioinformática, que aplica técnicas computacionais, matemáticas e estatísticas para tratar os problemas da biologia molecular.

Um dos principais problemas nesta área é a inferência filogenética (Setubal e Meidanis, 1997). Esse problema consiste em determinar, empregando um conjunto de dados moleculares ou morfológicos, as relações evolutivas de um conjunto de espécies. Tais relações evolutivas são apresentadas usualmente em uma forma de árvore, conhecida como árvore filogenética.

Assim, o objetivo principal da inferência filogenética é determinar a árvore que reflete satisfatoriamente a história evolutiva das espécies consideradas (Felsenstein, 2004). Este problema é relevante tanto do ponto de vista biológico quanto do ponto de vista computacional. Dado que não se possui informações suficientes a respeito as espécies extintas, deve-se considerar cada árvore filogenética apenas como uma hipótese possível. Encontrar a melhor árvore filogenética (ou árvore verdadeira) é um problema muito difícil devido ao número de árvores a serem avaliados crescer muito rapidamente conforme ao número de espécies estudadas aumenta (Felsenstein, 2004).

Nesse contexto, uma série de métodos de inferência filogenética têm sido propostos na literatura (Felsenstein, 2004; Swofford et al., 1996). Alguns métodos transformam a informação molecular em matrizes de distância para, finalmente, empregar algum algoritmo de agrupamento que resulta em uma árvore. Outros métodos definem um critério 
de otimalidade que permita avaliar cada árvore possível para encontrar a solução ótima conforme ao critério definido. Dois dos principais métodos de reconstrução filogenética que empregam critério de otimalidade são a máxima parcimônia (Fitch, 1972) e a máxima verossimilhança (Felsenstein, 1981a).

O método de máxima parcimônia avalia cada árvore conforme ao número de mudanças de estado requeridos pela sua topologia (Swofford et al., 1996). Dessa forma, procura-se pela árvore (denominada como árvore de máxima parcimônia) que minimize o número total de tais mudanças. Embora a parcimônia seja um critério simples e muito utilizado pelos pesquisadores, há muita polêmica na comunidade em relação a sua validade.

A máxima verossimilhança procura a árvore que maximize a probabilidade de os dados moleculares adequarem-se a um determinado modelo de evolução. Tal modelo possui, basicamente, uma topologia de árvore, comprimentos dos ramos da árvore e parâmetros do modelo de substituição de seqüências escolhido. Uma dos maiores problemas deste método é o grande número de parâmetros a serem estimados e o tempo computacional necessário para otimizar a verossimilhança de apenas uma topologia (Felsenstein, 2004).

Várias pesquisas (Gogarten e Lewis, 2002; Huelsenbeck, 1995; Katoh et al., 2001; Russo et al., 1996; Saitou e Imanishi, 1989; Sourdis e Nei, 1988; Tateno et al., 1994; Zwickl, 2006) mostram que, a escolha do método de inferência empregado, influencia na árvore filogenética recuperada. Em outras palavras, a aplicação de diferentes métodos de reconstrução leva a recuperação de árvores que possuem partes conflitantes entre sim. Como os resultados da inferência filogenética são muito variáveis e dependentes das condições do experimento, não existe uma consenso a respeito de qual é o melhor método a ser empregado.

Uma dificuldade inerente aos métodos de otimalidade é procurar pela árvore ótima no espaço de busca que cresce rapidamente. Os métodos que garantem a solução ótima podem ser aplicados apenas para árvores com um número de espécies reduzido. Para conjuntos de dados maiores, apenas métodos de busca heurística podem ser utilizados.

Os métodos heurísticos para busca da melhor árvore começam, basicamente, por determinar uma árvore inicial que represente uma boa aproximação a solução ótima (Swofford et al., 1996). Após isso, são aplicadas várias modificações topológicas para melhorar a solução inicial. Tais passos são repetidos iterativamente até que não seja possível atingir uma melhor solução. Este procedimento geral é implementado na maioria dos principais programas de inferência filogenética como PAUP* (Swofford, 2000), PHYLIP (Felsenstein, 2000b), RAxML (Stamatakis, 2005), NONA (Goloboff, 1999b), entre outros.

Um outro grupo de heurísticas aplicadas em filogenia incluem os algoritmos evolutivos (AEs). Os AEs são técnicas de busca e otimização que emulam o comportamento dos princípios de evolução, genética e seleção natural. Uma série de estudos envolvendo aplicações dos AEs em problemas de reconstrução filogenética têm sido desenvolvidos, 
mostrando resultados relevantes (Gogarten e Lewis, 2002; Katoh et al., 2001; Lemmon e Milinkovitch, 2002a; Lewis, 1998; Matsuda, 1996; Zwickl, 2006). Em tais estudos, mostrase os benefícios de aplicar AEs empregando um determinado critério de otimalidade (como parcimônia, verossimilhança ou distância mínima). Os resultados mostraram um melhor desempenho tanto em tempo de computação quanto na qualidade das soluções encontradas pelos AEs em comparação com as soluções encontradas por programas tradicionais como PHYLIP e PAUP*. Além disso, esses trabalhos formularam novas formas de representação e modificação topológica de árvores (Gogarten e Lewis, 2002; Lemmon e Milinkovitch, 2002a; Matsuda, 1996) e procedimentos mais eficientes para a otimização de parâmetros envolvidos no problema (Lewis, 1998; Zwickl, 2006).

Os AEs são também aplicados em problemas de otimização que possuem várias funções objetivo (Coello et al., 2002; Deb, 2001). Em tais problemas, em geral, os objetivos a serem otimizados são conflitantes entre si, ou seja, se uma solução é melhor para um objetivo, é piorado outro objetivo. Uma exemplo típico de objetivos conflitantes é a relação custo/desempenho: enquanto é necessário diminuir custos, procura-se também aumentar o desempenho em determinados processos. Porém, a diminuição de custos afeta negativamente no desempenho enquanto o ganho de desempenho implica em maiores custos. Isso significa que, para tais problemas, não exista apenas uma solução ótima, mais um grupo de soluções que representam um compromisso para os objetivos do problema.

Recentemente, no trabalho de Handl et al. (2006), são discutidas as possíveis aplicações de abordagens multi-objetivo para problemas de bioinformática, sendo que vários desses problemas são de natureza multi-objetivo. Assim, uma abordagem multi-objetivo do problema de filogenia é uma contribuição relavante, pois as árvores encontradas resultariam consistentes para os critérios considerados.

A principal motivação para a elaboração da presente tese é a formulação da inferência filogenética como problema de otimização multi-objetivo. Esta proposta baseia-se no fato de que diversos métodos de inferência filogenética produzem árvores significativamente diferentes a partir dos mesmos dados. Buscando lidar de forma sistemática com essas diferenças, propõe-se a formulação do problema de filogenia considerando vários critérios de mais de um método de inferência para serem otimizados simultaneamente. A solução de tal problema seria um conjunto de árvores filogenética que representam um consenso entre os critérios de otimalidade.

Os critérios considerados neste trabalho são os de máxima parcimônia e máxima verossimilhança. Ambos os critérios são baseados em princípios muito diferentes. A parcimônia é um critério simples, empírico e possui as suas origens em idéias filosóficas (princípio de parcimônia). Por outro lado, a verossimilhança é um critério complexo e com bases estatísticas muito sólidas.

Dentre as técnicas existentes na literatura para resolver problemas multi-objetivo, destacam-se os AEs (Coello et al., 2002; Deb, 2001). O AE multi-objetivo desenvol- 
vido nesta pesquisa, denominado PhyloMOEA, permite resolver o problema de inferência multi-objetivo conforme proposto. O PhyloMOEA determina o conjunto de árvores correspondente às soluções Pareto-ótimas. Tais árvores representam um consenso entre os critérios de parcimônia e verossimilhança.

Deve-se notar que, tanto os principais programas de inferência filogenética quanto as abordagens de AEs pesquisadas na literatura empregam apenas um critério para avaliar as árvores. Nesse sentido, a abordagem apresentada nesta tese representa uma contribuição na literatura da área.

O PhyloMOEA foi testado com 4 bancos de seqüências de DNA que são comummente empregados na literatura para medir o desempenho de diversos métodos de inferência filogenética. É importante destacar que, os resultados fornecidos pelo PhyloMOEA não são diretamente comparáveis a outros programas, uma vez que esses consideram apenas um critério (parcimônia ou verossimilhança). Assim, para avaliar o conjunto de soluções fornecidas pelo PhyloMOEA, foram utilizados o teste de Shimodaira e Hasegawa (1999) (SH) e o método de inferência Bayesiana (Huelsenbeck e Ronquist, 2001).

O teste SH serve para determinar, a partir de um conjunto soluções, aquelas árvores que são estatisticamente significativas. Nos testes, verificou-se que, parte das soluções fornecidas pelo PhyloMOEA são significativas tanto para os critérios de parcimônia quanto para o critério de verossimilhança, mostrando que existe uma diversidade de filogenias que são consistentes com mais de um critério e que tais árvores podem ser obtidas simultaneamente por um AE multi-objetivo.

Por outro lado, o método inferência Bayesiana permite calcular, entre outras coisas, as probabilidades tanto das árvores inferidas quanto das componentes (clados) de cada árvore. Assim, foi possível determinar se a probabilidade de cada clado é consistente com o grau de suporte obtida a partir do conjunto Pareto-ótimo fornecido pelo PhyloMOEA. Os resultados mostraram que o PhyloMOEA foi consistente com a inferência Bayesiana para uma parte significativa do clados.

Uma outra contribuição importante deste trabalho é a definição de uma metodologia de avaliação de filogenias com mais de um critério de otimalidade combinando o teste $\mathrm{SH}$ com a inferência Bayesiana. Em resumo, pode-se dizer que a proposta descrita no decorrer da presente tese abre uma nova linha de pesquisa que amplia o espectro da aplicação de abordagens multi-objetivo, investiga métodos de reconstrução filogenética como AEs, técnicas de análise de filogenias por múltiplos critérios, bem como a relevância do PhyloMOEA para diferentes bases de dados da biologia molecular.

Esta tese está organizada em sete Capítulos. O Capítulo 2 apresenta os principais conceitos da área de inferência filogenética, considerando principalmente os métodos de máxima parcimônia e máxima verossimilhança. O Capítulo 3 introduz os AEs, destacando os algoritmos genéticos (AGs) e a aplicação de AEs no problema de filogenia. O 
Capítulo 4 detalha noções básicas dos problemas de otimização multi-objetivo e a aplicação dos AEs em tais problemas. O Capítulo 5 apresenta detalhadamente o PhyloMOEA, o modelo proposto de AE multi-objetivo para o problema de reconstrução filogenética. $\mathrm{O}$ Capítulo 6 mostra os resultados da aplicação do modelo proposto em bancos de seqüências de teste. Finalmente, o Capítulo 7 apresenta as principais conclusões trabalho e sugestões de pesquisas futuras. 


\section{CAPÍTULO \\ 2 \\ Reconstrução filogenética}

\subsection{Introdução}

A Filogenia é uma área de pesquisa da biologia que estuda as relações evolutivas entre os organismos (espécies). Segundo Graur e Li (2000), os estudos filogenéticos apontam a três objetivos:

- A correta reconstrução das semelhanças genealógicas entre as entidades biológicas;

- A estimação do período de divergência entre organismos, ou seja, a determinação do tempo de formação dessas espécies após compartilharem um antepassado comum;

- O detalhamento da seqüência de eventos entre as diferentes lineagens evolutivas.

Para explicar os mecanismos de evolução das espécies, foram propostas várias teorias. Dentre elas, destacam-se as teorias de Lamarck, Darwin e a Teoria Sintética da Evolução (ou Neodarwinismo).

Em 1.809, Joseph Lamarck publicou o seu livro "Filosofia Zoológica". Nele, postulou que os padrões de semelhanças entre os organismos são devidos a modificações evolutivas (Ayala, 1979). Essas modificações respondem à necessidade dos organismos adaptarem-se às novas condições do meio em que vivem. Assim, uma espécie adquiria características novas, as quais seriam herdadas por os seus descendentes. A teoria de Lamarck sugere que as espécies compartilham relações de ancestralidade. Contudo, esta teoria foi muito ousada para o seu tempo e terminou sendo esquecida. 
O inglês Charles Darwin retomou o interesse pela evolução como conseqüência das suas viagens ao redor do mundo a bordo do navio H.M.S. Beagle. No decorrer da sua viagem, Darwin coletou vários exemplares de animais, plantas e fósseis e fez observações sobre as diferenças encontradas entre indivíduos da mesma espécie. A comparação de fósseis de diferentes camadas geológicas revelou a Darwin que as espécies estavam modificando-se ao longo do tempo e que algumas características de espécies extintas são conservadas nas atuais. Além disso, Darwin observou que os fósseis de camadas geológicas mais recentes apresentam uma maior semelhança com as espécies vivas.

Uma outra questão de interesse para Darwin estava relacionada com o crescimento populacional das espécies. Por um lado, a grande capacidade de reprodução garantia um aumento de número de indivíduos, segundo uma progressão geométrica. Não obstante, os meios de subsistência seguiam apenas uma progressão aritmética. Na prática, o aumento de tamanho da população era menor que o predito teoricamente. Darwin concluiu então que deveria existir um método de seleção de indivíduos. Este método postula que, os indivíduos com características favoráveis teriam uma maior descendência em detrimento de indivíduos com características menos favoráveis. Assim, com o tempo, essas características seriam cada vez mais diferenciadas, constituindo novas espécies. Como produto das suas pesquisas, Darwin publicou, em 1.859, um dos mais influentes livros da história da ciência: "A Origem das Espécies", no qual se estabelece que a seleção natural é o mecanismo que determina quais espécies sobrevivem e quais são extintas (Futuyma, 1992).

A seleção natural ainda não explica a variabilidade dentro dos indivíduos da mesma espécie. Esta questão foi abordada por Mendel, que afirmou que as diferenças nas características físicas dos organismos, como cor, tamanho, forma eram devidas a fatores hereditários que Mendel denominou genes. Os resultados de Mendel foram publicados em 1.867, mas só após 1.940 uma teoria evolucionista mais consistente foi desenvolvida.

A Teoria Sintética da Evolução ou Neodarwinismo (Ridley, 1996) baseia-se nos mecanismos de seleção natural, mutação e recombinação gênica. Esta teoria postula que as variações entre indivíduos da mesma espécie é devida à recombinação de informações genéticas dos seus progenitores. A recombinação nunca ocorre da mesma forma em descendentes distintos. Além disso, no processo de cópia de informações genéticas podem acontecer mutações ou erros, produzindo um aumento da variabilidade genética. Essas mutações são geralmente insignificantes e não produzem mudanças perceptíveis. Caso as espécies já estejam adaptadas o suficiente ao seu ambiente, algumas mutações podem ser indesejáveis e, por isso, o mecanismo de seleção natural as elimina.

As teorias descritas anteriormente, permitem reconstruir a história evolutiva dos organismos vivos mediante relações ancestral/descendente. Os estudos filogenéticos clássicos estão baseados, principalmente, em características físicas (morfológicas), como: tamanho, cor, número de extremidades, etc. Por outro lado, os estudos atuais utilizam informação 
proveniente do material genético (fundamentalmente, seqüências de DNA e proteínas). Desta forma, as relações entre as espécies são deduzidas a partir de blocos bem conservados no alinhamento das seqüências provenientes das espécies estudadas (Sung, 2002).

As relações evolutivas entre um grupo de espécies é o foco de atenção da área de filogenia. Este problema é interessante tanto do ponto de vista biológico como computacional. O escopo do presente Capítulo é apresentar os conceitos básicos desta área de pesquisa que serão empregados no restante do presente trabalho.

Este Capítulo está organizado em 8 Seções. A Seção 2.2 introduz conceitos úteis sobre grafos e seqüências, que serão extensivamente empregados no decorrer do trabalho. A Seção 2.3 apresenta a área de reconstrução filogenética. As Seções 2.4 e 2.5 descrevem os métodos de reconstrução filogenética de máxima parcimônia e máxima verossimilhança, respectivamente. A Seção 2.6 apresenta uma revisão bibliográfica dos principais estudos que comparam os diversos métodos para filogenia. A Seção 2.7 descreve os principais testes de confidência para árvores filogenéticas. Finalmente, a Seção 2.7 revisa os principais pontos apresentados neste Capítulo mostrando como eles motivam a pesquisa proposta.

\subsection{Seqüências e grafos}

Existe uma grande quantidade de dados gerados pelos estudos de biologia molecular. Grande parte desses dados são apresentados usualmente como seqüências de diversos tipos. Uma seqüência s é uma sucessão $s_{1} s_{2} s_{3} s_{4} \ldots s_{n}$ de caracteres pertencentes a um conjunto finito denominado alfabeto (Felsenstein, 2004; Setubal e Meidanis, 1997). Por exemplo, as seqüências de DNA estão compostas de uma sucessão de nucleotídeos. Existem quatro tipos de nucleotídeos: adenina $(\mathrm{A})$ citocina $(\mathrm{C})$, timina $(\mathrm{T})$ e guanina $(\mathrm{G})$. Os nucleotídeos de tipo A e G são denominados purinas; enquanto os dos tipos C e T são denominados pirimidinas. Cada posição $s_{i}$ de uma seqüência de DNA pode ter quatro estados definidos no alfabeto: $\{A, C, T, G\}$. As seqüências proteicas consistem de uma sucessão de aminoácidos, os quais podem assumir 20 estados diferentes (Felsenstein, 2004; Setubal e Meidanis, 1997) . A Figura 2.1 mostra um exemplo de cada tipo de seqüência.

Seqüência de DNA : TGCAGGGAC

Seqüência proteica : ARRHASTKL

Figura 2.1: Exemplos de seqüências de DNA e proteínas.

Um grafo (Setubal e Meidanis, 1997), denotado por $G(V, E)$, é descrito por um conjunto de nós (vértices) $V$ e um conjunto ramos (arestas) $E$, as quais unem pares de nós. A Figura 2.2 mostra exemplos de grafos.

O grau de um nó é definido pelo número de arestas que se conectam a tal nó. Por exemplo, na Figura 2.2(a) o grau do nó a é 1; enquanto o grau do nó e é 3. Um caminho é 


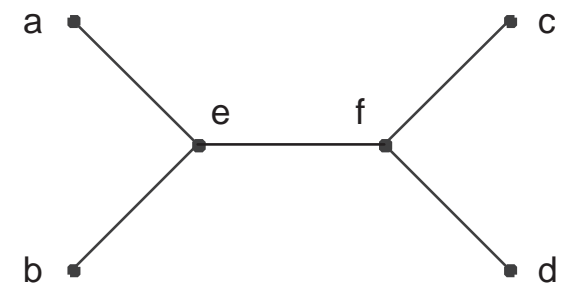

$V=\{a, b, c, d, e, f\}$

$E=\{(e, a),(e, b),(e, f),(f, c), f, d)\}$

(a)

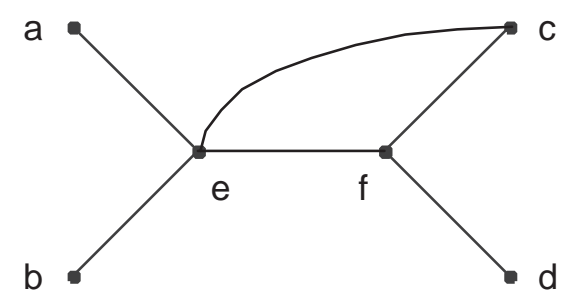

$V=\{a, b, c, d, e, f\}$

$E=\{(e, a),(e, b),(e, c),(e, f),(f, c), f, d)\}$

(b)

Figura 2.2: Exemplos de grafos.

uma sucessão de nós $\left(v_{1}, v_{2}, \ldots, v_{k}\right)$ tal que $\left(v_{i}, v_{i+1}\right) \in E$ para $1 \leq i<k$. Por exemplo, no grafo da Figura 2.2(a), $(a, e, f, c)$ é o caminho entre os nós $a$ e $c$. Se existe no máximo um caminho entre cada par de nós, o grafo é dito acíclico. Assim, o grafo da Figura 2.2(a) é acíclico; enquanto o da Figura 2.2(b) é cíclico dado que $(e, c)$ e $(e, f, c)$ são dois caminhos possíveis entre $e$ e $c$. Caso exista no mínimo um caminho entre cada par de nós, tem-se um grafo conexo (ambos os grafos mostrados na Figura 2.2 são conexos).

Uma árvore ${ }^{1}$ é um grafo $G(V, E)$ acíclico e conexo. Algumas árvores podem ter um nó especial denominado raiz que é usualmente desenhado no topo da árvore. Exemplos de árvores com raiz são mostrados na Figura 2.3. Os nós de uma árvore podem ser classificados como nós externos (ou folhas), se o grau de tais nós é 1; e como nós internos, caso contrário. Na árvore da Figura 2.2(a), os nós $\{a, b, c, d\}$ são externos, enquanto os $\{e, f\}$ são internos. De forma similar, os ramos podem ser externos, se um dos nós conectados é uma folha; ou internos, se ambos os nós que o ramo conecta são internos. Cada ramo da árvore divide o conjunto de espécies em duas partições. Por exemplo, na Figura 2.2(a), o ramo $(e, f)$ particiona as espécies nos subconjuntos $\{a, b\}$ e $\{c, d\}$.

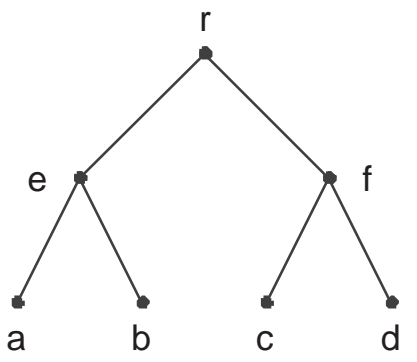

(a)

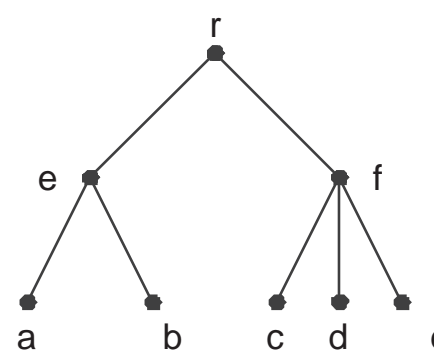

(b)

Figura 2.3: Exemplos de árvores com raiz.

\footnotetext{
${ }^{1}$ Neste texto emprega-se também o termo topologia para referir-se a uma árvore.
} 
A presença do nó raiz define relações ancestral/descendente entre os nós da árvore. Um nó $u$ é dito ancestral do nó $v$, se $u$ está no caminho entre a raiz e $u$. Por exemplo, na Figura 2.3(a), o nó e é ancestral de $a$, pois o nó e está no caminho $(r, e, a)$. Deve-se observar que o nó raiz é ancestral dos demais nós da árvore. Um clado é um grupo de nós representando espécies com um ancestral comum. Por exemplo, na Figura 2.3(a), a subárvore enraizada em $f$ define um clado, onde $f$ é o ancestral e $c$ e $d$ são as espécies descendentes.

Uma árvore é dita binária quando o grau dos nós é no máximo 3. Se o grau dos nós é 1 nas folhas, 2 para a raiz (se houver) e 3 para os demais nós internos, a árvore é estritamente binária. A Figuras 2.2(a) e 2.3(a) mostram árvores estritamente binárias não enraizadas e enraizadas respectivamente. As árvores estritamente binárias são a forma mais utilizada de representar soluções ao problema de filogenia. As próximas Seções descrevem este problema e os principais aspectos considerados na construção de soluções para filogenia.

\subsection{Reconstrução filogenética}

Uma filogenia é comummente representada por uma árvore de grafo denominada árvore filogenética, que reflete as relações genéticas entre um conjunto de espécies. Usualmente, as árvores filogenéticas são árvores estritamente binárias.

Em uma árvore filogenética, as folhas representam espécies. Todas as folhas são rotuladas, seja com o nome de uma espécie ou com caracteres provenientes da sua seqüência. A Figura 2.4 ilustra uma árvore filogenética mostrando a relação entre os humanos e os primatas. As folhas representam as espécies atuais e os nós internos, os ancestrais hipotéticos ou espécies extintas.

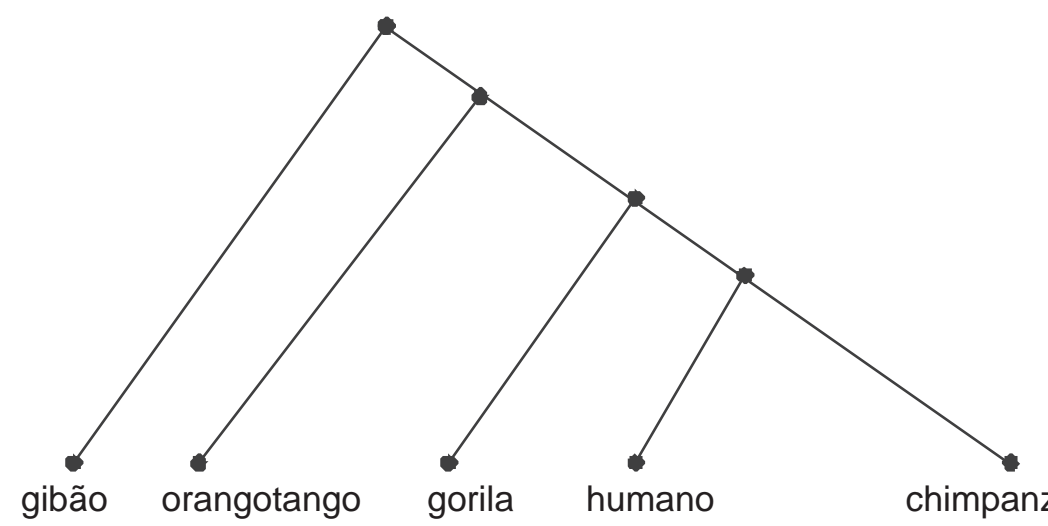

Figura 2.4: Uma árvore filogenética para um grupo de primatas (Page e Holmes, 1998).

Um dos principais problemas associados à construção de uma árvore filogenética é que geralmente não se possui informação suficiente sobre as espécies ancestrais extintas. 
Em geral, constrói-se uma árvore filogenética apenas a partir dos dados das espécies atualmente existentes. Desta forma, as árvores construídas são sempre hipotéticas.

É importante salientar que as árvores filogenéticas podem ter ou não raiz. A raiz da árvore indica o ancestral comum da qual todas as demais espécies descendem e, portanto, implica uma direção de tempo de evolução. Quanto mais próxima uma espécie da raiz, mais antiga esta é. Desta forma, as árvores com raiz mostram relações ancestral/descendente das espécies. Por exemplo, a árvore da Figura 2.4 indica que o ser humano e o chimpanzé tiveram um antepassado comum exclusivo deles.

Em contrapartida, as árvores sem raiz não indicam relações de ancestralidade. Não obstante, é possível inserir uma raiz nessas árvores por meio de uma espécie, chamada de outgroup, que é distante das espécies de interesse (Swofford et al., 1996). Dependendo do lugar onde a raiz é inserida, são geradas diferentes árvores enraizadas, conforme ilustrado na Figura 2.5. Observe que uma raiz e duas arestas adjacentes devem substituir uma das arestas da árvore sem raiz. Para a árvore da Figura 2.5, há 7 passibilidades de inserção de raiz.
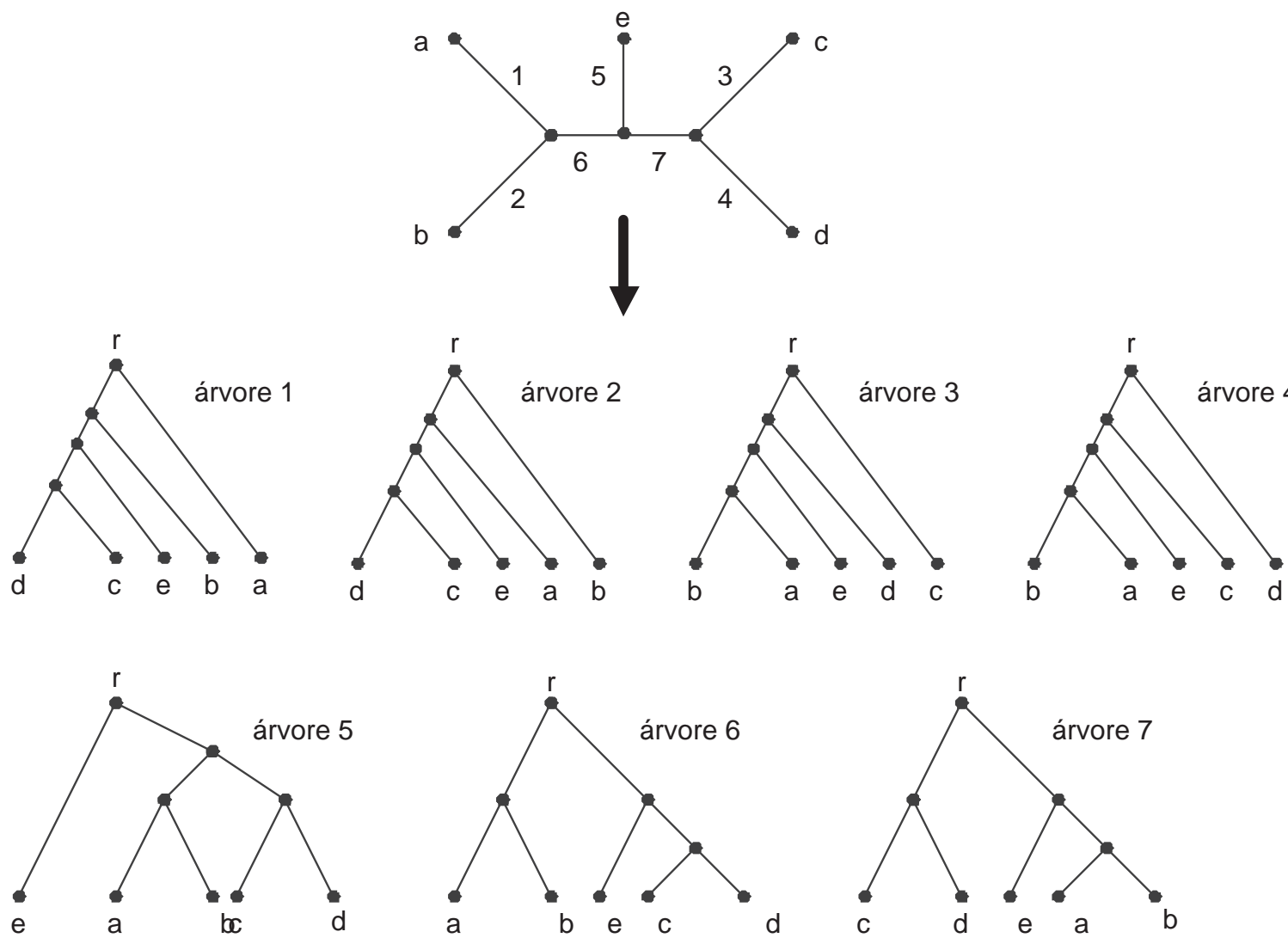

Figura 2.5: As 7 possíveis árvores geradas da árvore sem raiz de 5 seqüências. A árvore $i(i=1, \ldots, 7)$ resulta da inserção da raiz no lugar do ramo $i$ (Page e Holmes, 1998). 
O número de árvores filogenéticas possíveis cresce com número de folhas representando as espécies. O total de árvores com $n \geq 3$ folhas é dado por (Felsenstein, 2004):

$$
\prod_{i=3}^{n}(2 i-5)=1 \times 3 \times 5 \times \ldots \times(2 n-5) .
$$

A Equação 2.1 pode ser explicada intuitivamente da seguinte forma:

- Para $n=3$, existe apenas uma possível árvore sem raiz com 3 ramos internos. Uma árvore (estritamente binária) sem raiz de $n$ folhas possui $2 n-3$ ramos;

- Todas as árvores sem raiz, para $n=4$, podem ser obtidas inserindo a quarta folha em cada ramo da árvore de 3 folhas. Assim, para $n=4$, temos 3 árvores sem raiz possíveis;

- Em geral, para saber o número total de árvores sem raiz de $n$ espécies, basta inserir a folha $n$ em cada um dos $2(n-1)-3=2 n-5$ ramos das árvores de $n-1$ folhas. Desta forma, é obtida a Equação 2.1.

Para obter o número total de árvores com raiz de $n$ folhas basta inserir a raiz em cada um dos $2 n-3$ ramos das árvores sem raiz. Esse número é dado por:

$$
(2 n-3) \times \prod_{i=3}^{n}(2 i-5) .
$$

A Equação 2.2 também implica que o número de árvores sem raiz de $n$ folhas é igual ao número de árvores com raiz para $n-1$ folhas.

Tabela 2.1: Número de árvores possíveis sem raiz e com raiz para 2 a 10 espécies (Page e Holmes, 1998).

\begin{tabular}{|r|r|r|}
\hline$n$ & $\begin{array}{r}\text { Número de árvores } \\
\text { sem raiz }\end{array}$ & $\begin{array}{r}\text { Número de árvore } \\
\text { com raiz }\end{array}$ \\
\hline 2 & 1 & 1 \\
\hline 3 & 1 & 3 \\
\hline 4 & 3 & 15 \\
\hline 5 & 15 & 105 \\
\hline 6 & 105 & 945 \\
\hline 7 & 945 & 10.395 \\
\hline 8 & 10.395 & 135.135 \\
\hline 9 & 135.135 & 2.027 .025 \\
\hline 10 & 2.027 .025 & 34.459 .425 \\
\hline
\end{tabular}

A Tabela 2.1 mostra o número total de árvores com raiz e sem raiz para $n$ variando de 2 até 10 . O número de árvores cresce muito rapidamente com o número de espécies. 
Devido às árvores filogenéticas representarem hipóteses da história evolutiva das espécies, a inferência da árvore que se adequa melhor aos dados obtidos é uma tarefa complicada. O grande número de árvores possíveis a serem analisadas complica mais ainda este objetivo. Existem vários métodos para a inferência de árvores filogenéticas, os quais são classificados de diversas formas na literatura pesquisada (Morrison, 1996; Page e Holmes, 1998; Setubal e Meidanis, 1997; Swofford et al., 1996). Neste trabalho foi adotada a classificação elaborada por Swofford et al. (1996). Segundo essa classificação, os métodos de reconstrução filogenética podem ser divididos em duas classes: os métodos algorítmicos e os métodos baseados em critérios de otimalidade:

- Métodos de agrupamento ou algorítmicos: esses métodos formam uma série de agrupamentos sucessivos das espécies até chegar a uma árvore. Nesta categoria estão incluídos os métodos que utilizam agrupamentos por pares tais como o UPGMA (Michener e Sokal, 1957) e o Neighbor Joining (NJ) (Saitou e Nei, 1987). Tais algoritmos fornecem respostas rápidas dado que não requerem a avaliação de grandes quantidades de possíveis soluções. Em geral, esses métodos produzem apenas uma árvore como resposta;

- Métodos de busca ou de critério de otimalidade: esses métodos avaliam as possíveis árvores segundo algum critério de otimalidade (descrito por uma função objetivo) que reflita a relação entre os dados e a árvore produzida. Portanto, o critério de otimalidade é utilizado como uma métrica da qualidade para qualquer árvore, permitindo comparar diferentes soluções alternativas. Os métodos baseados em critério de otimalidade devem resolver dois tipos de problemas:

- Dada uma árvore e um conjunto de dados (espécies), avaliá-los segundo o critério de otimalidade considerado;

- Encontrar a árvore, dentro de todas as árvores possíveis, que possui a melhor avaliação.

A utilização de critérios de otimalidade implica na procura de soluções ótimas dentro de um espaço de busca que cresce rapidamente com o aumento do conjunto de dados. Desta forma, tal procura é custosa computacionalmente e, portanto, são freqüentemente utilizadas uma série de heurísticas para se obter uma solução razoável. Deve-se salientar que o uso de heurísticas não garante que se encontre a solução ótima.

A Tabela 2.3, baseada no trabalho de Morrison (1996), especifica os principais métodos de reconstrução filogenética. A máxima parcimônia (Fitch, 1981) e máxima verossimilhança (Felsenstein, 1981a) são dois do métodos mais empregados em inferência filogenética. Esses critérios são de maior interesse para o presente trabalho e serão apresentados nas seções seguintes. 
Tabela 2.2: Principais métodos para construção de árvores filogenéticas. Tabela baseada em (Morrison, 1996).

\begin{tabular}{|l|l|l|}
\hline Método & Referências & Tipo \\
\hline UPGMA & (Michener e Sokal, 1957) & agrupamento \\
\hline Neighbor-joining (NJ) & (Saitou e Nei, 1987) & agrupamento \\
\hline Neighborliness & (Fitch, 1981; Sattath e Tversky, 1977) & agrupamento \\
\hline Evolução Mínima & (Edwards e Cavalli-Sforza, 1964) & otimalidade \\
\hline Parcimônia de Wagner & (Farris, 1970) & otimalidade \\
\hline Mínimos Quadrados & (Fitch e Margoliash, 1967) & otimalidade \\
\hline Máxima Parcimônia & (Farris, 1972; Fitch, 1972) & otimalidade \\
\hline Parcimônia Ponderada & (Farris, 1969; Sankoff, 1975) & otimalidade \\
\hline Compatibilidade & (Quesne, 1969, 1982) & otimalidade \\
\hline Máxima Verossimilhança & (Felsenstein, 1973a,b, 1981a,b) & otimalidade \\
\hline Invariantes & (Cavender e Felsenstein, 1987; Lake, 1987) & otimalidade \\
\hline Análise Espectral & (Hendy e Penny, 1993; Penny et al., 1987) & otimalidade \\
\hline Inferência Bayesiana & $\begin{array}{l}\text { (Mau e Newton, 1997; Rannala e Yang, 1996) } \\
\text { (Larget e Simon, 1999; Li et al., 2000) }\end{array}$ & otimalidade \\
\hline
\end{tabular}

\subsection{Máxima parcimônia}

A máxima parcimônia (Farris, 1972; Fitch, 1972) é um dos métodos mais empregados na reconstrução filogenética, embora tenha sido preterida mais recentemente por métodos mais robustos (Swofford e Sullivan, 2003) como a máxima verossimilhança (Felsenstein, 1981a) ou a inferência Bayesiana (Huelsenbeck et al., 2001). O objetivo da máxima parcimônia é procurar a árvore (ou árvores) cujo número total de mudanças evolutivas seja mínima. Tais mudanças referem-se as diferenças entre os estados dos nós conectados em cada ramo. A justificativa do método de máxima parcimônia possuem bases filosóficas: se existem várias hipóteses que forneçam explicações igualmente válidas para algum fenômeno, deve-se escolher a mais simples delas. Este princípio é conhecido como a navalha de Occam (Felsenstein, 2004). Assim, na reconstrução filogenética, a parcimônia estabelece uma correspondência entre o número de mudanças evolutivas e a complexidade das hipóteses. Tal relação é muito polêmica, e vários pesquisadores defensores de métodos estatísticos (de Queiroz e Poe, 2001; Swofford e Sullivan, 2003; Tuffley e Steel, 1997) expressam que a conexão entre mudanças evolutivas e complexidade da hipótese é muito fraca.

Seja $\mathcal{D}$ um conjunto de seqüências de $n$ espécies e $N_{\text {sit }}$ sítios (caracteres) para cada seqüência. A contagem do número de mudanças de estado para uma árvore $\tau$ é dada pela seguinte expressão:

$$
\operatorname{Par}(\tau)=\sum_{j=1}^{N_{s i t}} \operatorname{Par}_{j}
$$


onde $\mathrm{Par}_{j}$ representa o valor de parcimônia para o sítio $j$. Tal valor é calculado pela soma das diferenças dos estados entre cada par de nós conetados nos ramos de $\tau$. Assim, $\mathrm{Par}_{j}$ pode ser calculado por:

$$
\operatorname{Par}_{j}=\sum_{(v, u) \in E} \mathcal{C}_{v_{j}, u_{j}}
$$

onde $E$ é o conjunto de $\operatorname{ramos}(v, u)$ de $\tau, v_{j}$ e $u_{j}$ são os estados no sítio $j$ para as seqüências correspondentes aos nós $v$ e $u$, respectivamente. $\mathcal{C}_{v_{j}, u_{j}}$ é o custo de mudar do estado $v_{j}$ para o estado $u_{j}$ no sítio $j$. Pode-se observar das Equações 2.3 e 2.4 que o valor de parcimônia $\operatorname{Par}(\tau)$ é calculado para cada sítio separadamente, dependendo unicamente da topologia da árvore e dos estados dos nós.

Existem uma série de variantes do critério de parcimônia (Felsenstein, 2004; Swofford et al., 1996), sendo uma das mais simples e utilizadas a parcimônia de Fitch (Fitch, 1972; Hartigan, 1973). Em tal critério, emprega-se um custo unitário para cada troca de estado, ou seja; $\mathcal{C}_{x, y}=1$, se $x \neq y$ e $\mathcal{C}_{x, y}=0$, caso contrário. Os estados dos nós folhas, correspondentes às espécies, são determinados pelas seqüências contidas em $\mathcal{D}$. Porém, para calcular o valor de parcimônia de uma árvore, é preciso obter os estados dos nós internos de forma que $\operatorname{Par}(\tau)$ seja minimizada. O problema da determinação dos estados internos é conhecido como pequeno problema de parcimônia. No caso da parcimônia de Fitch, esse problema é resolvido de forma eficiente empregando o algoritmo proposto pelo mesmo autor.

O algoritmo de Fitch começa determinando um conjunto $\mathcal{S}_{k}$ de estados para cada nó interno $k$ da árvore. Tal procedimento é realizado mediante um percurso pós-ordem. Assim, dado um nó interno $v$ e seus descendentes $u$ e $w, \mathcal{S}_{v}$ é calculado pela seguinte expressão:

$$
\mathcal{S}_{v}=\left\{\begin{array}{l}
\mathcal{S}_{u} \cap \mathcal{S}_{w}, \text { se } \mathcal{S}_{u} \cap \mathcal{S}_{w} \neq \emptyset \\
\mathcal{S}_{u} \cup \mathcal{S}_{w}, \text { caso contrário }
\end{array}\right.
$$

Caso os nós $u$ e $w$ estejam nas folhas das árvores, $\mathcal{S}_{u}=\left\{u_{j}\right\}$ e $\mathcal{S}_{w}=\left\{w_{j}\right\}$, ou seja, estão determinados pelo conjunto de dados $\mathcal{D}$. Cada vez que $\mathcal{S}_{u} \cap S_{w} \neq \emptyset$, o valor de $\operatorname{Par}_{j}$ é incrementado em uma unidade. Uma vez determinados os conjuntos $\mathcal{S}_{k}$ para os nós internos da árvore, um segundo percurso na árvore, desta vez em pré-ordem, é realizado para determinar os estados de cada nó interno. Para a raiz da árvore, pode-se atribuir qualquer estado do seu conjunto $\mathcal{S}_{r}$. Para os demais nós internos $u$ com seu correspondente antecessor $v$, o estado $u_{j}$ é determinado pela seguinte expressão:

$$
u_{j}=\left\{\begin{array}{l}
v_{j}, \text { se } v_{j} \in \mathcal{S}_{u} \\
x, \text { tal que } x \in \mathcal{S}_{u}, \text { caso contrário. }
\end{array}\right.
$$


Assim, mediante o percurso pré-ordem, uma das possíveis atribuições de estados que minimizam $\operatorname{Par}_{j}$ é determinada. Dado que o cálculo de $\mathrm{Par}_{j}$ é independente para diferentes sítios $j$, repete-se o algoritmo de Fitch em cada posição obtendo finalmente o valor mínimo para $\operatorname{Par}(\tau)$. A Figura 2.6 mostra um exemplo do algoritmo de Fitch: os conjuntos junto aos nós internos na árvore da esquerda mostram os valores $S_{k}$ obtidos no percurso pós-ordem; enquanto as duas árvores da direita mostram duas possíveis atribuições dos estados internos que minimizam $\mathrm{Par}_{j}$. Cada linha que corta um ramo de cada árvore indica uma diferença entre os estados dos nós conetados a tais ramos. A descrição detalhada do algoritmo de Fitch é mostrado no Algoritmo 1.
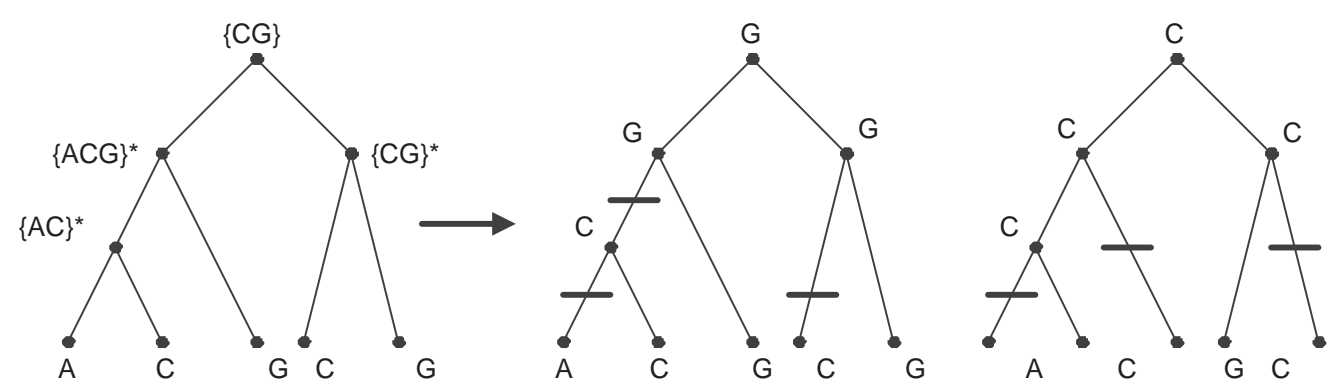

Figura 2.6: Aplicação do algoritmo de Fitch para um caracter.

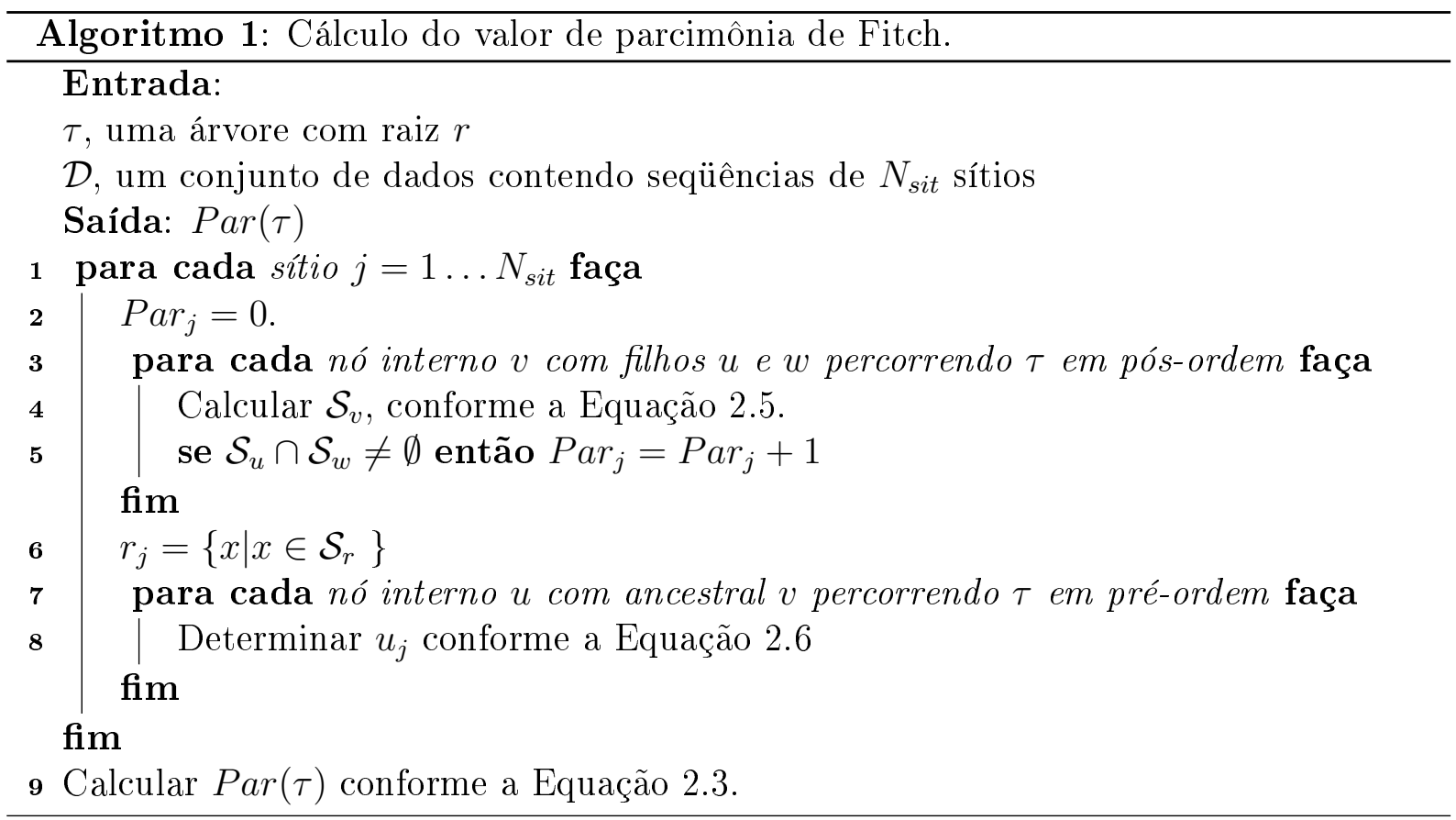

Além do critério de parcimônia de Fitch, há outras formas de parcimônia como a de Wagner, Dollo, Camin-Sokal, entre outras (Felsenstein, 2004; Swofford et al., 1996). Tais variantes diferenciam-se basicamente em como os custos das mudanças de estados são quantificadas e a forma em que tais mudanças são consideradas (Swofford et al., 1996). As diversas formas de parcimônia podem ser sintetizadas no modelo de parcimônia 
generalizada. Neste modelo, o pequeno problema de parcimônia é resolvido empregando uma abordagem de programação dinâmica, proposta por Sankoff (Sankoff, 1985).

O pequeno problema de parcimônia permite determinar o valor mínimo de $\operatorname{Pars}(\tau)$ para uma determinada topologia $\tau$. Porém, encontrar a árvore (ou árvores) $\tau^{*}$ tal que $\operatorname{Pars}\left(\tau^{*}\right)$ seja mínima no espaço de árvores é uma tarefa muito complexa. Tal problema é conhecido como o grande problema de parcimônia, o qual é NP-difícil (Felsenstein, 2004). Para resolvê-lo, podem ser usadas técnicas exatas para um número moderado de espécies ou técnicas heurísticas nos demais casos. Tais abordagens são tratadas na Seção 2.4.1.

\subsubsection{Estratégias de busca da árvore ótima}

Encontrar a melhor árvore que otimize um determinado critério é um problema bastante complexo devido ao grande tamanho do espaço de busca de possíveis árvores. Existem duas formas de enfrentar tal problema: usando busca exata ou busca heurística.

As técnicas de busca exata, no pior caso, procuram a solução ótima em todo o espaço de busca. Um exemplo desse tipo de busca é a busca exaustiva, onde as espécies são adicionadas uma a uma explorando todas as topologias possíveis. Assim, a i-ésima espécie é adicionada em todas as árvores contendo $i-1$ espécies. Tal procedimento é repetido até que todas as espécies sejam consideradas e, finalmente, a árvore com a melhor topologia é a solução ótima. Uma outra técnica, conhecida como branch and bound (Hendy e Penny, 1982) avalia implicitamente todas as topologias do espaço de busca, descartando regiões cuja exploração não levem a árvore ótima. Uma vantagem dos métodos exatos é que fornecem a topologia ótima, embora essas abordagens sejam adequadas apenas para conjuntos de dados com poucas espécies. Para outros conjuntos, tais técnicas requerem de muito tempo computacional, sendo inviáveis em termos práticos (Swofford e Sullivan, 2003).

As técnicas de busca heurística, que são de maior interesse no presente trabalho, começam com uma árvore inicial não ótima, sobre a qual são aplicadas várias formas de troca de ramos de forma iterativa buscando melhorar tal solução. A construção da árvore inicial pode empregar os seguintes métodos (Nei e Kumar, 2000; Swofford, 2000):

- Adição por passos (stepwise addition): começa com uma árvore de 3 espécies. As demais espécies são adicionadas iterativamente. A posição onde a nova folha será inserida é escolhida analisando todos os ramos onde esta pode ser inserida. Assim, escolhe-se a melhor posição de inserção conforme algum critério de otimalidade. Esse processo é repetido até que todas as espécies estejam adicionadas na árvore. A Figura 2.7 mostra uma aplicação deste método;

- Decomposição de estrela (star decomposition): essa técnica começa com uma topologia de estrela, onde todas as espécies estão unidas a um nó interno. Posteriormente, 
duas espécies são agrupadas e separadas da estrela mediante a criação de um novo nó interno. A seleção de tais espécies pode ser realizada aleatoriamente ou analisando todas as alternativas possíveis. Tal processo é repetido iterativamente até que seja formada uma árvore.

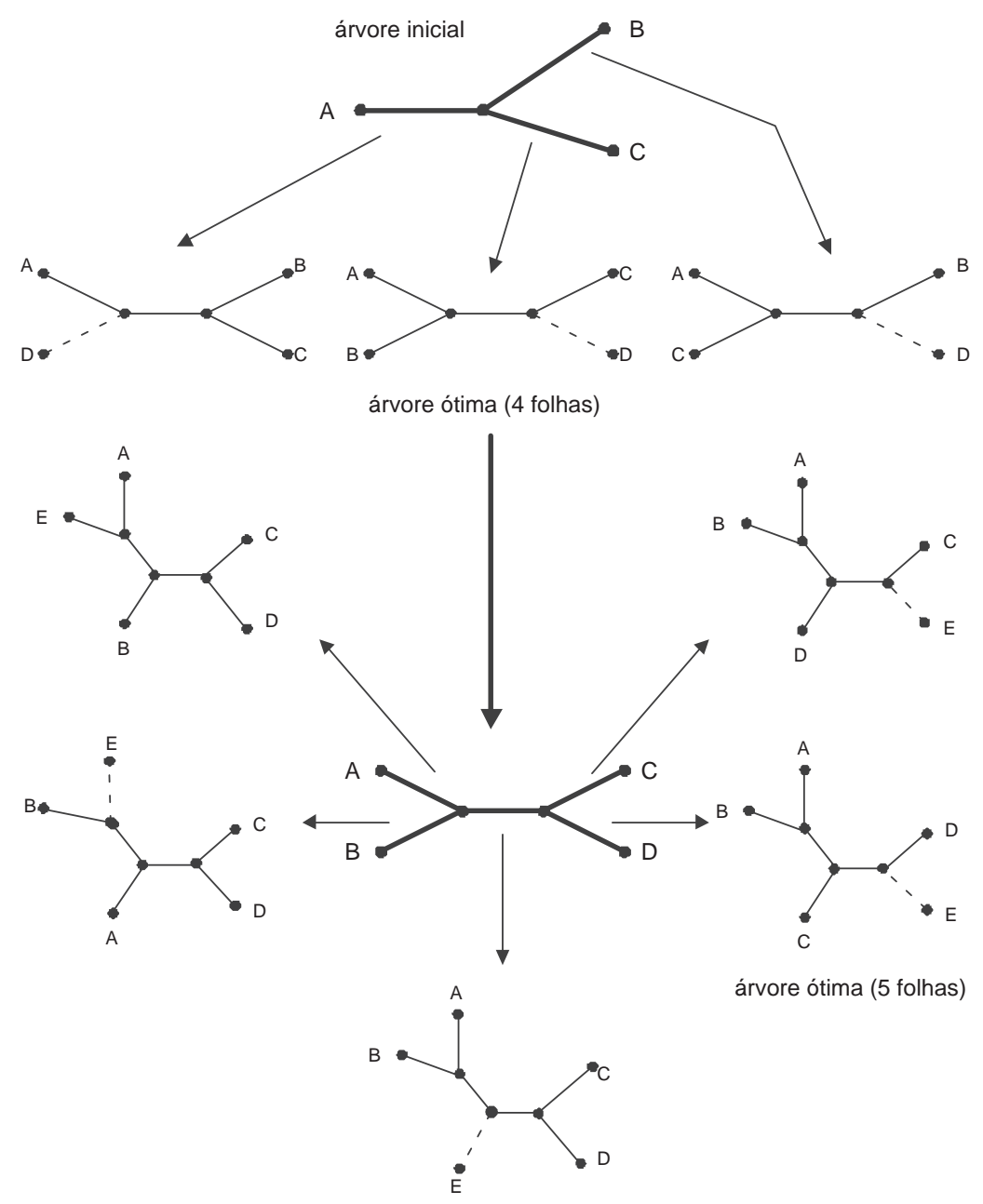

Figura 2.7: Exemplo do método stepwise addition (Gogarten e Lewis, 2002).

Os métodos de adição por passos e decomposição por estrela raramente levam à árvore ótima. Outras modificações de árvore podem ser aplicadas para melhorar as soluções fornecidas por tais métodos. Swofford et al. (1996) descrevem três formas usuais de modificação topológica:

- Troca dos vizinhos mais próximos (NNI, do inglês Nearest Neighboor Interchange): essa técnica trabalha com os ramos interiores da árvore. Cada ramo define 4 subárvores vizinhas conectadas aos seus extremos. Cada um dos extremos possui um par de subárvores. O NNI troca subárvores vizinhos de pares diferentes modificando a árvore inicial. Todas as operações NNI são efetuadas nos ramos da árvores original e, finalmente, a melhor solução é retornada. O NNI provoca pequenas modificações 
topológicas, sendo adequado para uma busca na vizinhança da árvore inicial (Swofford e Sullivan, 2003). A Figura 2.8 mostra essa operação;

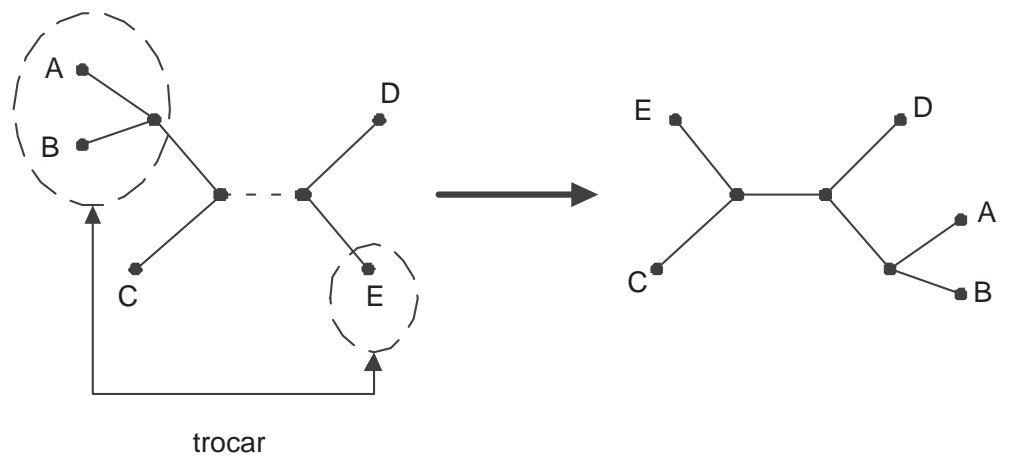

Figura 2.8: Exemplo do método NNI (Gogarten e Lewis, 2002).

- Poda e inserção de subárvore (SPR, do inglês Subtree Prunning and Regrafting): esta operação separa uma subárvore da solução inicial e, posteriormente, é reinserida em todas as posições possíveis. Tal processo é repetido para todas as subárvores da solução inicial, retornando a melhor solução encontrada. O SPR realiza uma busca mais abrangente que o NNI, permitindo avaliar um maior número de árvores (Swofford e Sullivan, 2003). A Figura 2.9 mostra um exemplo do SPR;
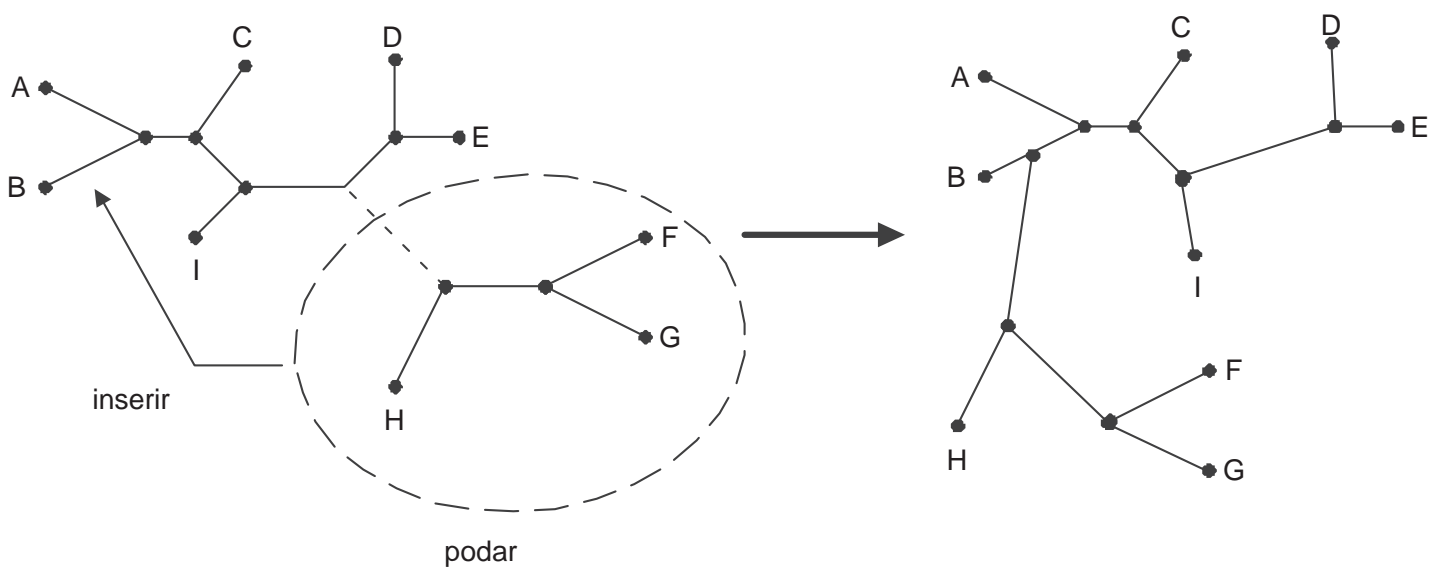

Figura 2.9: Exemplo do método SPR (Gogarten e Lewis, 2002).

- Bisseção e reconexão de árvore (TBR, do inglês Tree Bisection and Reconnection): essa técnica elimina um ramo interno da árvore original, separando-a em duas subárvores. Seguidamente, tais subárvores são reconectadas, criando um novo ramo que conecta as duas subárvores. Todas as subárvores e todas as reconexões possíveis são examinadas, retornado a melhor árvore encontrada. O TBR permite explorar um maior número de soluções que o SPR (Swofford e Sullivan, 2003). A Figura 2.10 mostra o emprego do TBR. 


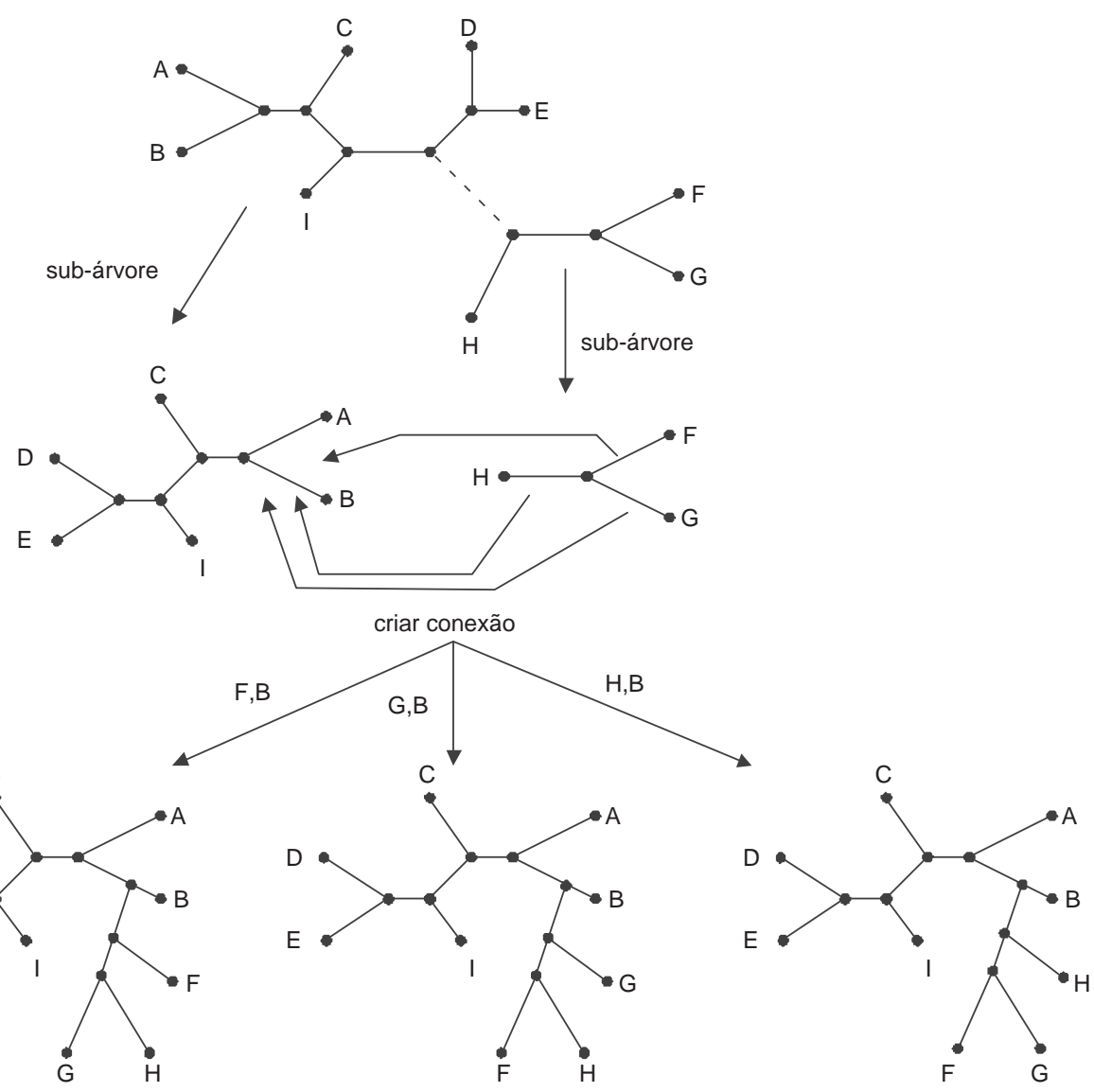

Figura 2.10: Exemplo do método TBR (Gogarten e Lewis, 2002).

As modificações topológicas descritas anteriormente são aplicadas em forma iterativa. Isto é, após a construção da árvore inicial, modificações topológicas são realizadas nesta árvore. Caso seja encontrada uma melhor solução, esta é usada como novo ponto de partida para as próximas modificações. Este processo é repetido iterativamente até que não seja possível encontrar melhores soluções.

A estratégia de obter uma árvore por busca heurística (frequentemente usa-se a adição por passos) e, em seguida, aplicar NNI, SPR ou TBR é implementada na maioria dos programas de inferência filogenética, tais como PHYLIP (Felsenstein, 2000b), PAUP* (Swofford, 2000) e PAML (Yang, 1997). Porém, tal estratégia usualmente leva a regiões de ótimo locais (Swofford et al., 1996; Swofford e Sullivan, 2003). Uma forma de obter melhores resultados é aplicar o mesmo procedimento em diversas pontos de partida (árvores iniciais). Estas topologias são geradas por meio de várias aplicações da adição por passos, com as espécies sendo adicionadas em ordem diferente em cada aplicação. Porém, os autores (Goloboff e Farris, 2001; Swofford e Sullivan, 2003) concordam em que tal abordagem é efetiva em conjuntos de dados de até 100 espécies.

Deve-se observar que os métodos heurísticos de busca topológica descritos nesta seção são independentes do critério de otimalidade, podendo ser empregados em buscas de 
árvore de máxima parcimônia, máxima verossimilhança, entre outras. As heurísticas especificamente desenvolvidas para a busca de árvore de máxima parcimônia são brevemente explicadas na Seção 2.4.2.

\subsubsection{Heurísticas para busca da árvore de máxima parcimônia}

O programa DNAPARS, incluído no PHYLIP (Felsenstein, 2000b), calcula a topologia inicial empregando o método de adição por passos. Após a inserção de uma espécie e antes de adicionar uma outra, o DNAPARS aplica sistematicamente todos as modificações topológicas de tipo NNI, e um nova topologia é aceita desde que o seu valor de parcimônia seja menor que a melhor solução encontrada até momento. Uma vez que todas as espécies foram adicionadas, o DNAPARS fornece uma opção para fazer modificações topológicas adicionais empregando SPR. Felsenstein (2000b) recomenta rodar o DNAPARS várias vezes modificando a ordem com que as espécies são acrescentadas na árvore, dado que assim é possível obter diferentes resultados em cada execução e, possivelmente, escapar de ótimos locais.

O programa PAUP*, um dos programas mais empregados na inferência filogenética, emprega heurísticas muito similares ao DNAPARS, com a ventagem de oferecer ao usuário mais opções com relação a procedimentos de busca (Swofford, 2000). A topologia inicial pode ser obtida usando tanto adição de espécies quanto empregando um método de distância como NJ (Saitou e Imanishi, 1989). As modificações topológicas podem ser do tipo SPR, TBR ou NNI, além de possibilitar a restrição da forma em que tais operações são aplicadas. É possível efetuar várias réplicas da busca, podendo inclusive calcular graus de suporte a cada ramo mediante técnicas de amostragem de dados como o bootstrap (Felsenstein, 1985) (ver Seção 2.7).

Nixon (1999) propôs o método chamado de Parcimônia Ratchet para a análise de grandes conjuntos de seqüências. O Ratchet começa com uma árvore inicial que pode ou não ser submetida a operações de modificação topológica. Um subconjunto de sítios é escolhido, modificando os pesos de cada sítio (por exemplo, adicionando 1 para os pesos dos sítios escolhidos). A seguir, modificações topológicas de tipo TBR são aplicadas aos dados considerando os novos pesos. As melhores árvores nessa busca são mantidas e, posteriormente, aplica-se uma busca com o operador TBR em tais árvores, mas considerando os dados originais (todos os sítios com os mesmos pesos). Na próxima iteração, um outro grupo de sítios é escolhido e todo o processo é repetido. O método Ratchet foi implementado nos programas PAUP* (Swofford, 2000) e NONA (Goloboff, 1999b) mostrando que o tempo para encontrar as árvores ótimas é consideravelmente reduzido.

Os trabalhos de Goloboff (1993, 1996, 1999a), Ronquist (1998) e Gladstein (1997) descrevem várias estratégias para melhorar o desempenho da busca da árvore de máxima parcimônia. Em tais trabalhos são descritos métodos que permitem calcular o valor de 
parcimônia da árvore, após modificações topológicas serem aplicadas, sem necessidade de aplicar o algoritmo de Fitch (Fitch, 1972). São propostas também vários procedimentos para determinar os estados dos nós internos a priori sem a necessidade examinar novamente os nós afetados pela aplicação das operações SPR ou TBR (Goloboff, 1993, 1996). Além disso, é apresentado um método que permite detectar árvores subótimas que são produto de modificações SPR e TBR antes de tais alterações serem realizadas. Com isso, consegue-se uma redução no tempo de execução significativa, uma vez que as mudanças subótimas não são efetuadas.

Goloboff também fez importantes contribuições nas heurísticas para busca da melhor topologia de máxima parcimônia (Goloboff, 1999a). O autor critica o emprego da técnica de adição por passos e modificações topológicas TBR (ver Seção 2.4.1), afirmando que são ineficientes para encontrar a melhor solução quando o conjunto de dados tem mais de 100 espécies. Assim, ele propôs três novas abordagens de busca topológica:

1. Fusão de árvore (TF, do inglês Tree-Fusing): esta estratégia combina subárvores de duas árvores distintas, desde que ambas as subárvores possuam as mesmas espécies. Tal método produz melhores árvores se as subárvores combinadas possuam valores de parcimônia ótimos ou quase-ótimos;

2. Buscas Setoriais Aleatórias (RSS, do inglês Random Sectorial Searches): neste método escolhe-se um setor da árvore (subárvore contendo um número determinado de espécies) o qual é analisado separadamente usando o método de adição por passos e TBR. Se um melhor valor de parcimônia para uma subárvore é encontrado, essa nova configuração do setor é adicionada na árvore. As operações TBR são realizadas desde que o número de novas configurações de setores encontradas sobrepasse um determinado valor. A principal vantagem de tal método é que diversos setores da árvores podem ser analisados bem mais rapidamente do que a árvore inteira;

3. Tree-Drifting (DFT): esta estratégia possibilita que modificações topológicas que resultem em árvore subótimas sejam incorporadas ocasionalmente visando explorar novas regiões do espaço de busca. A probabilidade de que uma solução subótima seja aceita depende da métrica RFD (do inglês Relative Fit Difference) (Goloboff e Farris, 2001) entre a árvore original e a árvore modificada.

Todas as heurísticas apresentadas por Goloboff foram implementadas nos programas NONA (Goloboff, 1999b) e TNT (Goloboff et al., 2004). Os experimentos mostraram que os novos métodos de busca topológica propostos foram significativamente mais rápidos e produziram árvores melhores que o método de adição por passos com arranjos TBR. 


\subsection{Máxima verossimilhança}

A máxima verossimilhança é um dos estimadores mais empregados na inferência estatística (Bryant et al., 2005). O conceito de verossimilhança lida com situações em que hipóteses ou modelos referentes a um conjunto de dados são avaliados. Na inferência filogenética, tais hipóteses incluem usualmente parâmetros como topologia de árvore, comprimento de ramos e um modelo de substituição de seqüências. Tais modelos são apresentados a seguir.

\subsubsection{Modelos de substituição de seqüências de DNA}

Uma tarefa fundamental na análise filogenética é a determinação de distância entre um par de seqüências. Tais valores são importantes tanto para a aplicação dos métodos de agrupamento como UPGMA (Michener e Sokal, 1957) ou NJ (Saitou e Nei, 1987) quanto de métodos probabilísticos (como máxima verossimilhança e inferência Bayesiana). A distância entre duas seqüências é determinada pelo número esperado de substituições por sítio. As substituições de nucleotídeos e aminoácidos são geralmente consideradas processos estocásticos. Para calcular tal distância é preciso definir um modelo de substituição que descreva esses processos (Strimmer e von Haeseler, 2003). Nesta subseção são apresentados os modelos de substituição de DNA, enfatizando apenas o cálculo das probabilidades de transição de estados. Tais probabilidades são empregadas no cálculo da verossimilhança de uma árvore filogenética (ver Seção 2.5.2).

Os modelos de substituição de DNA podem ser representados por uma matriz de taxas instantânea $\mathbf{Q}$, onde $\mathbf{Q}_{i, j}$ representa a taxa de mudança do estado $i$ para o estado $j$ durante um intervalo de tempo infinitesimal. A forma mais usual de expressar essa matriz é a seguinte:

$$
\mathbf{Q}=\left[\begin{array}{cccc}
-\sum_{j=2}^{4} \mathbf{Q}_{1, j} & a \pi_{C} & b \pi_{G} & c \pi_{T} \\
g \pi_{A} & -\sum_{j=1, j \neq 2}^{4} \mathbf{Q}_{2, j} & d \pi_{G} & e \pi_{T} \\
h \pi_{A} & i \pi_{C} & -\sum_{j=1, j \neq 3}^{4} \mathbf{Q}_{3, j} & f \pi_{T} \\
j \pi_{A} & k \pi_{C} & l \pi_{G} & -\sum_{j=1}^{3} \mathbf{Q}_{4, j}
\end{array}\right]
$$

A ordem das colunas e filas de $\mathbf{Q}$ seguem a ordem dos nucleotídeos $A, C, G$ e $T$ de tal forma que $\mathbf{Q}_{1,2}=\mathbf{Q}_{A, C}$ representa a taxa instantânea de mudança de $A$ para $C$. Os parâmetros $a, b, c, d, e, f, g, h, i, j, k$ e $l$ são taxas relativas de mudança para cada par de 
nucleotídios. Então, a representa a taxa relativa de mudança de $A$ para $C, b$ é a taxa relativa de mudança de $A$ para $G$ e assim sucessivamente. Os parâmetros $\pi_{A}, \pi_{C}, \pi_{G}$ e $\pi_{T}$ correspondem as estimativas das freqüências dos nucleotídeos no conjunto de dados $D$. Os elementos não diagonais da matriz representam o fluxo de saída a partir do nucleotídeo $x$; enquanto os elementos diagonais de $\mathrm{Q}$ fazem com que a somatória dos elementos em cada linha (o fluxo total de saída a partir do nucleotídeo $i$ ) seja zero.

Os modelos descritos pela matriz $\mathbf{Q}$ correspondem à classe de processos de Markov contínuos no tempo, os quais possuem as seguintes características (Strimmer e von Haeseler, 2003):

- Para todos os sítios das sequências, a taxa de mudança do estado $x$ para o estado $y$ é independente do estado anterior (propriedade dos processos Markov);

- As taxas de substituição não mudam no tempo (propriedade de homogeneidade);

- As freqüências dos estados $A, C, G$ e $T\left(\pi_{A}, \pi_{C}, \pi_{G}\right.$ e $\pi_{T}$, respectivamente) estão em equilíbrio.

Uma outra propriedade muito importante de vários modelos de substituição de DNA é que são reversíveis no tempo. Em outras palavras, para um ramo na árvore, a probabilidade de que o estado de um extremo do ramo seja $x$ e o outro extremo tenha estado $y$ é a mesma probabilidade de o estado de um extremo de ramo ser $y$ e terminar com estado $x$ no outro extremo (Felsenstein, 2004). Tal propriedade é expressada como:

$$
\pi_{x} \mathbf{P}_{x, y}(t)=\pi_{y} \mathbf{P}_{y, x}(t),
$$

onde $\mathbf{P}_{x, y}(t)$ é a probabilidade de mudar do estado $x$ para o estado $y$ no tempo $t$. O valor $t$ representa o comprimento do ramo da árvore.

É possível mostrar que a Equação 2.8 implica que $\pi_{x} \mathbf{Q}_{x, y}=\pi_{y} \mathbf{Q}_{y, x}$ (Bryant et al., 2005). Isso significa que a taxa de mudança de $i$ para $j$ é igual a taxa de mudança de $j$ para $i$ (Bryant et al., 2005; Strimmer e von Haeseler, 2003). Assim, tem-se que $a=g$, $b=h, c=j, d=i, e=k$ e $f=l$. Tais restrições permitem obter a matriz $\mathbf{Q}$ para o modelo geral reversível no tempo (GTR, do inglês General Time-Reversible Model):

$$
\mathbf{Q}=\left[\begin{array}{cccc}
-\sum_{j=2}^{4} \mathbf{Q}_{1, j} & a \pi_{C} & b \pi_{G} & c \pi_{T} \\
a \pi_{A} & -\sum_{j=1, j \neq 2}^{4} \mathbf{Q}_{2, j} & d \pi_{G} & e \pi_{T} \\
b \pi_{A} & d \pi_{C} & -\sum_{j=1, j \neq 3}^{4} \mathbf{Q}_{3, j} & f \pi_{T} \\
c \pi_{A} & e \pi_{C} & f \pi_{G} & -\sum_{j=1}^{3} \mathbf{Q}_{4, j}
\end{array}\right]
$$


Vários dos modelos de substituição de DNA mais conhecidos na literatura aplicam restrições adicionais na matriz Q. O modelo mais simples, conhecido como modelo de Jukes e Cantor (1969) (JC69) assume a igualdade das freqüências de nucleotídeos $\left(\pi_{A}=\right.$ $\left.\pi_{C}=\pi_{G}=\pi_{T}=0,25\right)$ e que todas as mudanças de estado acontecem com mesma taxa relativa $(a=b=c=d=e=f=1$ ) (Strimmer e von Haeseler, 2003). O modelo proposto por Felsenstein (1981a) (F81) permite diferentes freqüências de nucleotídeos com taxas relativas constantes $(a=b=c=d=e=f=1)$. O modelo devido a Hasegawa et al. (1985) (HKY85) permite diferenciar as taxas de mudança de transição (mudança de purina para purina ou pirimidina para pirimidina) e transversão (mudança de purina para pirimidina e viceversa) mediante o parâmetro $\kappa(b=e=\kappa$ e $a=c=d=f=1)$. Outros modelos são também casos particulares do modelo GTR (Strimmer e von Haeseler, 2003; Swofford et al., 1996).

Uma vez obtida a matriz $\mathbf{Q}$, a matriz de probabilidades de transição de estados para um comprimento de ramo $t$, denotada como $\mathbf{P}(t)$ é calculada como:

$$
\mathbf{P}(t)=e^{\mathbf{Q} t}
$$

A matriz $\mathbf{P}$ pode ser obtida mediante a descomposição da $\mathbf{Q}$ em seus autovalores e autovetores(Swofford et al., 1996) como mostrado pela seguinte expressão:

$$
\mathrm{Q}=\mathrm{ADA}^{-1}
$$

onde $\mathbf{D}$ é a matriz diagonal cujos elementos são os autovalores de $\mathbf{Q}$ e $\mathbf{A}$ é a matriz cujas colunas são os autovetores direitos de $\mathbf{Q}$. A matriz $\mathbf{Q}$ pode ser expressada como:

$$
\mathrm{Q}=\Pi \mathrm{B}
$$

onde $\Pi$ e B são duas matrizes simétricas. A matriz $\Pi$ é uma matriz diagonal cujos elementos correspondem às freqüências $\pi_{A}, \pi_{C}, \pi_{G}$ e $\pi_{T}$. É mostrado que, determinando os autovetores da matriz simétrica $\Pi^{1 / 2} \mathbf{B} \Pi^{1 / 2}$, é possível expressar $\mathbf{Q}$ como:

$$
\mathbf{Q}=\left(\boldsymbol{\Pi}^{1 / 2} \mathbf{U}\right) \mathbf{D}\left(\boldsymbol{\Pi}^{1 / 2} \mathbf{U}\right)^{-1}
$$

onde a matriz $\mathbf{U}$ contém os autovetores direitos de $\boldsymbol{\Pi}^{1 / 2} \mathbf{B} \boldsymbol{\Pi}^{1 / 2}$. Os autovalores de $\mathbf{Q}$ estão nos elementos diagonais da matriz $\mathbf{D}$ e os respectivos autovetores estão em $\Pi^{1 / 2} \mathbf{U}$. Dessa forma, a matriz $\mathbf{P}(t)$ é obtida substituindo na Equação 2.11, os elementos diagonais $d_{i, i}$ da matriz $\mathbf{D}$ por $e^{d_{i, i} t}$. 


\subsubsection{Cálculo de verossimilhança para uma árvore}

A verossimilhança fornece a probabilidade $\mathcal{P}(\mathcal{D} \mid \theta)$ de o conjunto de dados $\mathcal{D}$ ajustar-se ao modelo $\theta=\{\tau, \mathcal{B}, \mathcal{M}\}$, onde $\tau$ é uma topologia da árvore, $\mathcal{B}$ é o conjunto de comprimento de ramos de $\tau$ e $\mathcal{M}$ é o modelo de substituição de seqüências. O objetivo do critério de máxima verossimilhança é encontrar os parâmetros do modelo $\theta$, tal que a função de verossimilhança definida como $L(\theta)=\mathcal{P}(\mathcal{D} \mid \theta)$ seja maximizada.

A estimação da verossimilhança é ilustrada empregando um exemplo. Seja $\mathcal{D}$ um conjunto de dados correspondentes às seqüências de três espécies $(u, w$ e $s)$. Cada seqüência possui $N_{s i t}$ sítios (colunas) tal que $u_{j}, w_{j}, s_{j}$ representam os estados da espécies $u, w$ e $s$ no sítio $j$, respectivamente. Tais estados estão definidos em um alfabeto de caracteres de DNA $\Omega=\{A, G, C, T\}$. A Figura 2.11 mostra uma árvore com as três espécies atuais $(u, w$ e $s)$, duas espécies ancestrais $(v$ e $r)$ e os respectivos comprimentos de ramo. Além disso, supõe-se a existência de um modelo de substituição de seqüências que possibilite o cálculo das probabilidades de transição de estados. O cálculo da verossimilhança precisa de duas premissas (Felsenstein, 2004):

- Os sítios das seqüências evoluem de forma idêntica e independente;

- A ramificação da árvore é um processo de Markov, ou seja, a probabilidade de um nó possuir um determinado estado é função apenas do estado anterior.

A primeira suposição permite que a verosimilhança seja descomposta num produto conforme a seguinte equação:

$$
L=\prod_{j=1}^{N_{s i t}} \mathcal{P}\left(\mathcal{D}^{(j)} \mid \theta\right),
$$

onde $\mathcal{P}\left(\mathcal{D}^{(j)} \mid \theta\right)$ representa a verossimilhança no sítio $j$ que será denotada de agora em diante por $L_{j}$. Essa quantidade é igual a soma das probabilidades de cada cenário possível levando em conta todos os possíveis estados dos nós internos (que são desconhecidos). A independência da ramificação da árvore permite que $L_{j}$ seja expressada como:

$$
L_{j}=\sum_{r_{j} \in \Omega} \sum_{v_{j} \in \Omega} \pi_{r_{j}} \mathbf{P}_{r_{j}, s_{j}}\left(t_{r s}\right) \mathbf{P}_{r_{j}, v_{j}}\left(t_{r v}\right) \mathbf{P}_{v_{j}, u_{j}}\left(t_{v u}\right) \mathbf{P}_{v_{j}, w_{j}}\left(t_{v w}\right)
$$

onde $r_{j}, v_{j}$ representam os possíveis estados para os nós internos $r$ e $v, t_{i j}$ é o comprimento do ramo que conecta os nós $i$ e $j, \pi_{r_{j}}$ é a freqüência do nucleótido correspondente ao estado $r_{j}$ no conjunto de seqüências $\mathcal{D}$, e $\mathbf{P}_{x, y}(t)$ é a probabilidade da mudança do estado $x$ para o estado $y$ após um tempo $t$. As últimas duas quantidades são fornecidas pelo modelo de substituição $\mathcal{M}$. 


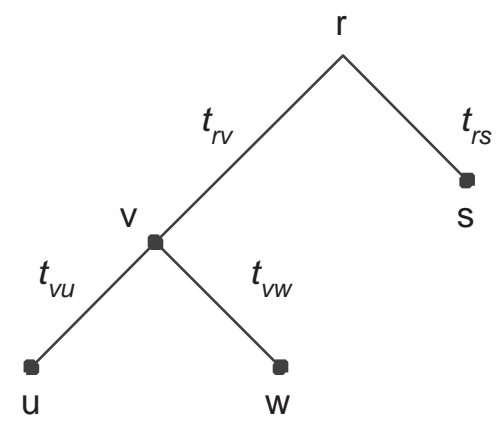

Figura 2.11: Árvore para o exemplo do cálculo da verossimilhança.

O cálculo da verossimilhança pode ser efetuado recursivamente empregando as verossimilhanças condicionais de subárvores. A verossimilhança condicional da subárvore cuja raiz é o nó $r$, denotada como, $L_{j}^{r}\left(r_{j}\right)$, é a probabilidade dos eventos observados a partir da tal subárvore, dado que o estado do nó $r$ no sítio $j$ seja $r_{j}$. Assim, se o nó $r$ tem descendentes $v$ e $s$, temos que:

$$
L_{j}^{r}\left(r_{j}\right)=\left[\sum_{v_{j} \in \Omega} \mathbf{P}_{r_{j}, v_{j}}\left(t_{r v}\right) L_{j}^{v}\left(v_{j}\right)\right] \times\left[\sum_{s_{j} \in \Omega} \mathbf{P}_{r_{j}, s_{j}}\left(t_{r s}\right) L_{j}^{s}\left(s_{j}\right)\right],
$$

e para as folhas $a$, onde o estado $a_{j}$ é fornecido por $\mathcal{D}$, temos que:

$$
L_{j}^{a}(x)= \begin{cases}1, & \text { se } a_{j}=x, \\ 0, & \text { caso contrário. }\end{cases}
$$

Para o exemplo relativo à árvore mostrada na Figura 2.11, tem-se pela Equação 2.17 que $L_{j}^{v}\left(v_{j}\right)=\mathbf{P}_{v_{j}, u_{j}}\left(t_{v u}\right) \mathbf{P}_{v_{j}, w_{j}}\left(t_{v w}\right)$ e $L_{j}^{s}\left(s_{j}\right)=\mathbf{P}_{r_{j}, s_{j}}\left(t_{r s}\right)$. Assim, substituindo os termos nas Equações 2.16 e 2.15 temos que:

$$
L_{j}=\sum_{r_{j} \in \Omega} \pi_{r_{j}} L_{j}^{r}\left(r_{j}\right)
$$

Para calcular a verossimilhança total conforme a Equação 2.14 é necessário fazer o produto dos valores $L_{j}$ para todos os sítios. Dado que tais valores são números muito pequenos podem ocorrer erros de precisão numérica. Uma forma mais conveniente de tratar tais números é calculando os seus logaritmos naturais. Assim, aplicando logaritmo natural a ambos lados da Equação 2.14, tem-se que:

$$
\ln L=\sum_{j=1}^{N_{s i t}} \ln L_{j}
$$

As Equações 2.18 e 2.16 definem uma forma recursiva de calcular a verossimilhança para árvores filogenéticas, no qual as verossimilhanças condicionais de cada subárvore em- 
pregando um percurso pós-ordem. Tal procedimento foi proposto por Felsenstein (1981a), e é apresentado no Algoritmo 2.

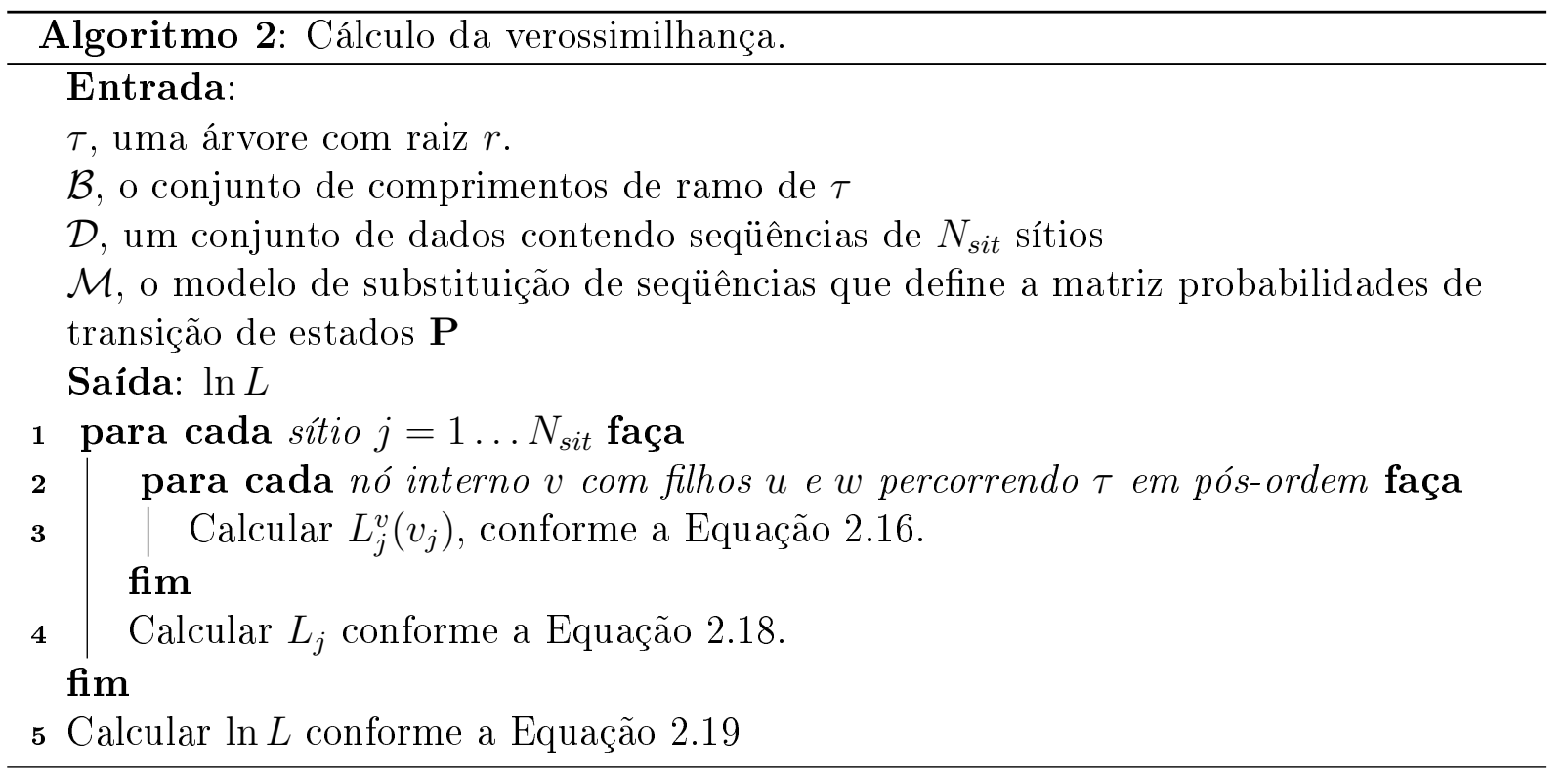

O modelo de substituição $\mathcal{M}$ emprega tacitamente a suposição de que os sítios dos dados $\mathcal{D}$ evoluem a uma taxa constante. Porém, em bancos de seqüências reais, os sítios evoluem com taxas diferentes. Quando a variação das taxas entre sítios (denotada como ASRV, do inglês among-site rate variation) é incorporada no modelo, os resultados da análise de verossimilhança podem ser sensivelmente melhorados (Yang, 2000). Basicamente, existem duas formas de incorporar o ASRV (Stamatakis, 2006a; Zwickl, 2006): taxas de heterogeneidade específicas por sítios e taxas de heterogeneidade Gama.

No modelo de taxas específicas por sítio, incorpora-se ao modelo $\mathcal{M}$ um vetor $\mathbf{W}=$ $\left[\omega_{1}, \omega_{2}, \ldots, \omega_{N_{s i t}}\right]^{T}$, onde $\omega_{j}$ corresponde a taxa de evolução correspondente ao sítio $j$. A verossimilhança $L$ é calculada da mesma forma descrita anteriormente, mas multiplica-se cada comprimento de ramo $t_{i j}$ por $\omega_{j}$ na obtenção das verossimilhanças condicionais da Equação 2.16. Uma vantagem dessa abordagem é que o tempo de cálculo da verossimilhança não é acrescentado significativamente (Stamatakis, 2006a). Porém, os valores de $\omega_{j}$ devem ser fornecidos a priori, o que aumenta consideravelmente o número de parâmetros a serem estimados.

No modelo de taxa de heterogeneidade Gama, $\omega_{j}$ é uma variável aleatória obtida de uma distribuição contínua Gama $(\Gamma)$ (Yang, 1993). Assim, a verossimilhança para um sítio $j$ é calculada por:

$$
L_{j}=\int_{0}^{\infty} \mathcal{P}\left(\mathcal{D}^{(j)} \mid \theta, \omega_{j}=x\right) f(x) d x
$$

onde $f$ é a função de densidade de probabilidade com distribuição $\Gamma$, e $\mathcal{P}\left(\mathcal{D}^{(j)} \mid \theta, \omega_{j}=x\right)$ é a verossimilhança do sítio $j$ condicionado a que o taxa de tal sítio seja $x$. Na prática, o 
cálculo da integral da Equação 2.20 é muito custosa computacionalmente. Devido a isso, emprega-se uma distribuição discreta $\Gamma$ que aproxima tal valor (Yang, 1994):

$$
L_{j}=\int_{0}^{\infty} \mathcal{P}\left(\mathcal{D}^{(j)} \mid \theta, \omega_{j}=x\right) f(x) d x \approx \sum_{k=1}^{N_{c a t}} \rho_{k} \mathcal{P}\left(\mathcal{D}^{(j)} \mid \theta, \omega_{j}=x_{k}\right),
$$

onde a distribuição $\Gamma$ para as taxas dos sítios é discretizada em $k=1 \ldots N_{\text {cat }}$ categorias, $x_{k}$ corresponde a taxa de evolução da categoria $k$ e $\rho_{k}$ é a probabilidade da categoria $k$. A Equação 2.21 pode ser escrita também da seguinte maneira:

$$
L_{j}=\sum_{k=1}^{N_{c a t}} \sum_{r_{j} \in \Omega} \rho_{k} \pi_{r_{j}} L_{j}^{r}\left(r_{j}, x_{k}\right),
$$

onde $L_{j}^{r}\left(r_{j}, \omega_{j}=x_{k}\right)$ é obtida da mesma forma que $L_{j}^{r}\left(r_{j}\right)$ na Equação 2.16, multiplicando por $x_{i}$ os comprimentos de ramo $t_{r v}$ e $t_{r s}$. Dessa forma, é possível adaptar o Algoritmo 2 para incorporar a heterogeneidade da taxa de substituição entre os sítios.

A vantagem do modelo de taxa de heterogeneidade Gama é que os valores $\omega_{j}$ são obtidos a partir da distribuição $\Gamma$. Tal distribuição possui dois parâmetros que são $\alpha$, parâmetro de forma e $\beta$, parâmetro de escala. Na prática, emprega-se apenas o parâmetro $\alpha$, sendo $\beta$ fixado em $1 / \alpha$. Contudo, o cálculo da verossimilhança torna-se mais lento pois o cálculo da Equação 2.22 é realizado para as $N_{\text {cat }}$ categorias empregadas.

\subsubsection{Heurísticas para busca da árvore de máxima verossimilhança}

Nesta seção é apresentado um resumo das principais heurísticas empregadas na busca da árvore de máxima verossimilhança nos principais programas de inferência filogenética. As principais diferenças nas estratégias adotadas por tais programas são:

- A forma como uma topologia inicial é gerada;

- A maneira como as modificações topológicas da árvore inicial são aplicadas;

- As técnicas de otimização de comprimentos de ramo e parâmetros do modelo evolutivo empregado.

O programa DNAML, incluído no PHYLIP (Felsenstein, 2000b), para a determinação de filogenias por máxima verossimilhança incorpora heurísticas de busca topológica similares ao DNAPARS, visto na Seção 2.4.2. A otimização de todos os comprimentos de ramo é efetuada a cada modificação topológica da árvores, embora na versão mais recente (3.67) essa abordagem tenha sido substituída pela otimização dos ramos somente na vizinhança onde as mudanças aconteceram. 
As heurísticas de busca topológica para máxima verossimilhança implementadas no PAUP* (Swofford, 2000) são as mesmas que nas aplicadas na busca da árvore de máxima parcimônia. No PAUP* (Swofford, 2000), a determinação de comprimento de ramos iniciais e de parâmetros do modelo é baseada em reconstruções de máxima parcimônia (Rogers e Swofford, 1998). Uma outra característica importante, é que na otimização de parâmetros de modelo evolutivo pode ser limitada às árvores cujas verossimilhanças não sejam menores que a da melhor árvore encontrada. Assim, reduz-se o número de otimizações realizadas tornando o tempo de busca significativamente menor.

O software PHYML (Guindon e Gascuel, 2003) emprega uma abordagem heurística que diminui notavelmente o tempo de execução, fornecendo árvores compráveis às obtidas mediante programas como PAUP* e fastDNAml (Olsen et al., 1994). Tal ganho de desempenho é devido a um procedimento pelo qual, as modificações topológicas e a otimização dos comprimentos de ramos e parâmetros estão fortemente relacionadas. A topologia inicial é obtida mediante um método de distâncias conhecido como BIONJ (Gascuel, 1997). Os parâmetros do modelo de substituição de seqüências são inicialmente estimados pelo métodos de seção áurea (Press et al., 1992). A seguir, são examinadas todas as modificações topológicas do tipo NNI, sendo apenas otimizado o comprimento do ramo envolvido em tal operação. Dessa forma, todas as mudanças possíveis são independentemente calculadas com um menor custo computacional. Aplica-se uma proporção das modificações que mais aumentaram a verossimilhança das árvores e, finalmente, recalculam-se os parâmetros do modelo de substituição de seqüências. A nova topologia obtida é o novo ponto de partida para uma nova iteração do algoritmo, que continua até que não haja mais modificações a serem aplicadas. Finalmente, os comprimentos de ramos e parâmetros do modelo são reotimizados. Tal procedimento emprega o método de otimização de Brent (1973), o qual não precisa do cálculo de derivadas. Extensões para o PHYML, que utilizam as modificações topológicas SPR ao invés da NNI original têm sido propostas na literatura (Hordijk e Gascuel, 2005), embora ainda não tenham sido acrescentadas ao programa.

A série de programas RAxML (Stamatakis, 2005, 2006b; Stamatakis et al., 2005a,b, 2002b; Stamatakis e Meier, 2004) (cujas versões iniciais foram fortemente baseadas no fastDNAml) implementam heurísticas que aceleram o cálculo da verossimilhança (Stamatakis et al., 2002a) e a obtenção da topologia de máxima verossimilhança. No RAxML, a topologia da árvore é obtida mediante um algoritmo de adição por passos empregando o critério de máxima parcimônia. Os parâmetros e comprimentos de ramos são também otimizados neste etapa inicial. Posteriormente, são aplicadas modificações do tipo SPR, onde uma subárvore é removida e logo reinserida em uma outra posição da árvore. O RAxML aplica tais movimentações de forma que a distância da onde árvore é removida e inserida não sobrepassa um certo limite. Além disso, apenas os comprimentos de ramo que são afetados pela reinserção da árvore são otimizados. As 20 melhores topologias 
resultantes das modificações topológicas são posteriormente otimizadas e a melhor delas é a nova topologia inicial para uma nova iteração do algoritmo. As novas versões do programa permitem inferências de grandes conjuntos de dados (mais de 10.000 espécies), o que é possível devido a vários fatores:

- Uma implementação eficiente para armazenar topologias grandes;

- A reutilização de cálculos prévios na verossimilhança;

- Melhorias no desempenho dos cálculos que incorporam heterogeneidade de taxas dos sítios (Stamatakis, 2006a);

- Emprego de recursos de computação paralela (Blagojevic et al., 2007; Stamatakis, 2006b).

Outras referências da aplicação de busca heurística para determinar a árvore de máxima verossimilhança, podem ser consultadas em (Adachi e Hasegawa, 1996; Hordijk e Gascuel, 2005; Jobb, 2007; Larget e Simon, 1998; Pond e Muse, 2004; Pupko e Graur, 2002; Stamatakis, 2005; Strimmer e von Haesler, 1996; Vinh e von Haeseler, 2004; Yang, 1997).

\subsection{Comparação de métodos de inferência filogenética}

Na literatura, existem uma série de trabalhos que comparam o desempenho dos diversos métodos de reconstrução filogenética. Para que tais estudos sejam possíveis é necessário que a árvore verdadeira de um conjunto de dados seja conhecida ou bem estabelecida $a$ priori. Segundo Yang (2006), esses estudos têm sido realizados de 3 formas:

- Gerando evolução de espécies diretamente no laboratório;

- Utilizando filogenias fortemente aceitas pelos pesquisadores e;

- Empregando simulação.

Um exemplo do primeiro tipo de estudo é o trabalho Hillis et al. (1992 apud Yang, 2006). Foram evoluídos bacteriófagos T7 no laboratório, assim, tanto a filogenia como os estados de todas as espécies (incluindo as ancestrais) são conhecidas a priori. Todos os métodos testados conseguiram encontrar a árvore filogenética correta e ainda, o método de parcimônia recuperou os estados ancestrais com grande precisão.

O trabalho de Russo et al. (1996) investigou a eficiência de diferentes métodos de reconstrução filogenética. Tais métodos foram aplicados em 13 bancos de genes (aminoácidos e nucleotídeos) pertencentes a 11 espécies de vertebrados cuja filogenia foi estabelecida a priori. Os métodos comparados foram: Neighboor Joining (NJ) (Saitou e 
Nei, 1987), evolução mínima (Rzhetsky e Nei, 1992), máxima parcimônia (Fitch, 1972) e máxima verossimilhança (Felsenstein, 1981a). Os bancos usados apresentaram variadas características como o tamanho do banco, distância entre seqüências e sítios informativos. Os experimentos foram realizados com várias tipos de distâncias e, para o método de parcimônia, testou-se as variantes de parcimônia simples (Fitch, 1972) e com pesos (Sankoff, 1975). Os desempenhos das técnicas foram determinados utilizando uma medida de distância topológica (Rzhetsky e Nei, 1992) em relação à árvore correta. Os resultados mostraram que todos os métodos foram capazes de obter a árvore verdadeira para alguns bancos; enquanto que para outros bancos, nenhum método foi capaz de atingir a árvore correta. Repetiu-se os experimentos usando a concatenação de todos os bancos como entrada para uma nova avaliação. Nesse casso, todos os métodos encontraram a árvore verdadeira. Duas conclusões significativas são destacadas pelos autores: os métodos mais simples como NJ (Saitou e Nei, 1987) produziram resultados comparáveis a outros métodos mais complexos, e a escolha dos dados adequados ou de grandes bancos de dados produzem melhores resultados independentemente do método de inferência usado.

A importância da simulação de dados para avaliar diversos métodos de reconstrução filogenética foi destacado no trabalho de Huelsenbeck (1995). O autor empregou uma árvore de 4 espécies e simulou um conjunto de 1.296 árvores, todas com a mesma topologia e diferentes combinações de comprimentos de ramos. Tais combinações possuem uma amostragem representativa das diferentes condições em que os métodos são testados. Para comparar o desempenho dos métodos avaliados (UPGMA (Michener e Sokal, 1957), invariantes (Lake, 1987), parcimônia (Fitch, 1972), NJ (Saitou e Nei, 1987), mínimos quadrados (Cavalli-Sforza e Edwards, 1967) e máxima verossimilhança (Felsenstein, 1981a) foram utilizados 3 critérios: consistência, robustez e eficiência. A consistência de um método mostra a capacidade de estimar a árvore correta quando há dados suficientes. A eficiência é a rapidez com que o método converge para a árvore correta. A robustez do método é a capacidade de achar a árvore correta se os requisitos do método não são satisfeitos. Os resultados mostraram que o método de máxima verossimilhança obteve um comportamento levemente melhor em relação aos outros; enquanto os métodos de UPGMA e invariantes mostraram dificuldade para encontrar a árvore correta. Porém, o autor destaca que todos os outros métodos tiveram desempenho satisfatório na maioria dos experimentos. O emprego de pesos no caso dos métodos de parcimônia e mínimos quadrados melhorou significativamente o desempenho de tais métodos. Segundo Huelsenbeck, a conclusão mais importante de seu trabalho é que, se os requisitos de um método são satisfeitos, tal método apresenta o ser melhor desempenho.

Existem outros trabalhos na literatura (Jin e Nei, 1990; Kuhner e Felsenstein, 1994; Nei et al., 1994; Saitou e Imanishi, 1989; Sourdis e Nei, 1988; Tateno et al., 1994) comparando diversos métodos de reconstrução filogenética. Yang (2006) sintetiza algumas conclusões relevantes dos trabalhos nessa área: 
- Os métodos de máxima parcimônia e verossimilhança empregados com modelos simples, são propensos ao problema de atração de ramos longos. Porém, se a máxima verossimilhança é baseada em modelos mais complexos, a inferência é mais robusta;

- O método de máxima verossimilhança é, na maioria dos casos, mais eficiente que métodos de parcimônia para recuperar a árvore filogenética;

- O nível de divergência entre as seqüências contidas nos dados tem uma influência determinante no desempenho dos métodos de reconstrução. Conjuntos de dados com pouca divergência possuem informação insuficiente para ajudar na inferência da árvore correta. Por outro lado, dados muitos divergentes contém muito ruído. O nível de informação relevante para a reconstrução filogenética é melhor em níveis médios de divergência (Goldman, 1998; Yang, 2006);

- A topologia da árvore e os comprimentos de ramos possuem um efeito significativo no desempenho dos métodos. Árvores com ramos internos curtos e ramos externos compridos distribuídos em diferentes partes da árvore são difíceis de reconstruir. Nesses casos, tanto os métodos de parcimônia, verossimilhança e distâncias têm problemas em inferir a solução correta. Árvores com ramos internos mais compridos que os ramos externos são mais fáceis de inferir. Nesse caso, todos os métodos de reconstrução filogenética conseguem um desempenho satisfatório.

Embora as afirmações destacadas acima sejam geralmente aceitas, na literatura da área não existe um consenso sobre o desempenho dos diferentes métodos de reconstrução filogenética. Além disso, conforme apontado por Rokas et al. (2003), existem várias outras fontes de incongruência na análise filogenética que podem influenciar significativamente nos resultados.

\subsection{Avaliação de clados e árvores alternativas}

Uma vez obtida a árvore filogenética empregando algum método de reconstrução, é desejável utilizar alguma medida de confiabilidade no resultado obtido. Nesta seção são revisadas brevemente técnicas para avaliação dos componentes (clados) de uma determinada árvore bem como os principais testes estatísticos disponíveis para avaliar um conjunto de árvores alternativas.

\subsubsection{Análise de bootstrap}

O bootstrap é uma técnica de reamostragem estatística empregada freqüentemente na avaliação de clados de uma árvore inferida. Felsenstein foi o primeiro a sugerir tal técnica 
no método de máxima verossimilhança (Felsenstein, 1985). Contudo, o bootstrap pode ser empregado com outros métodos de reconstrução filogenética como a máxima parcimônia, ou métodos de agrupamento (Yang, 2006).

O método de bootstrap consiste em gerar um determinado número de bancos de dados a partir de uma amostragem dos sítios dos dados originais. Os conjuntos de seqüências gerados pelo bootstrap (chamados também de réplicas) possuem o mesmo número de sítios que as seqüências originais. Em cada réplica, cada sítio é escolhido aleatoriamente a partir dos dados originais. Assim, um conjunto gerado poder ter várias cópias do $j$ ésimo sítio e não possuir cópias do $i$-ésimo. Após isso, cada réplica gerada é empregada como entrada para o método de reconstrução filogenética considerado e uma árvores é inferida por cada réplica. Finalmente, calcula-se a proporção de cada clado da árvore inicial (inferida a partir dos dados originais) presente nas árvores das réplicas. Tal valor mede a probabilidade de um clado ser recuperado em no conjunto de replicas.

Uma outra forma de processar as árvores inferidas a partir das réplicas é calculando uma árvore de consenso (Swofford e Sullivan, 2003), A proporção de cada clado de dita árvore é conhecida como grau de suporte ou proporção de bootstrap. A Figura 2.12 mostra um diagrama da aplicação do bootstrap.

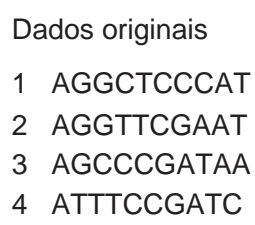

Réplica 1

1 AAAGCGGCAC

2 AAAGTGGAAC

3 AAACCGGTAG

4 AAATTTTATC

Réplica 2

1 GGGTTTTTCT

2 GGGTTTTTGT

3 GGCCCAAAAA

4 TTTCCCCCGC

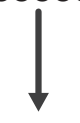

Réplica $N_{\text {rep }}$

1 AGGTTCCAAT

2 AGGTTCCAAT

3 AGGCCGGTAA

4 ATTCCCCGTC
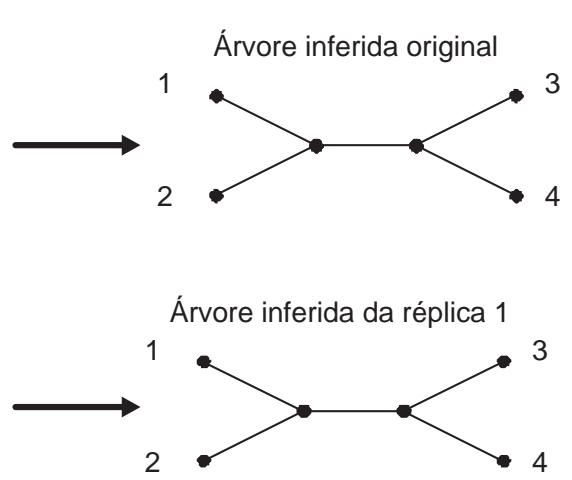

Árvore inferida da réplica 2

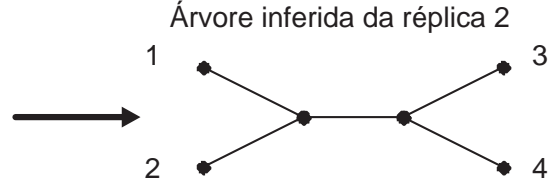

Árvore inferida da réplica $N_{\text {rep }}$

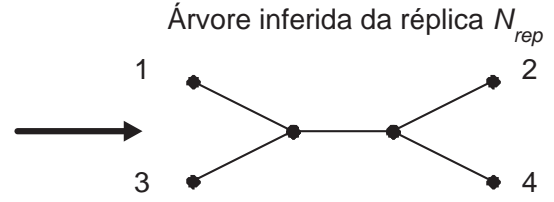

Valores de bootstrap na árvore original
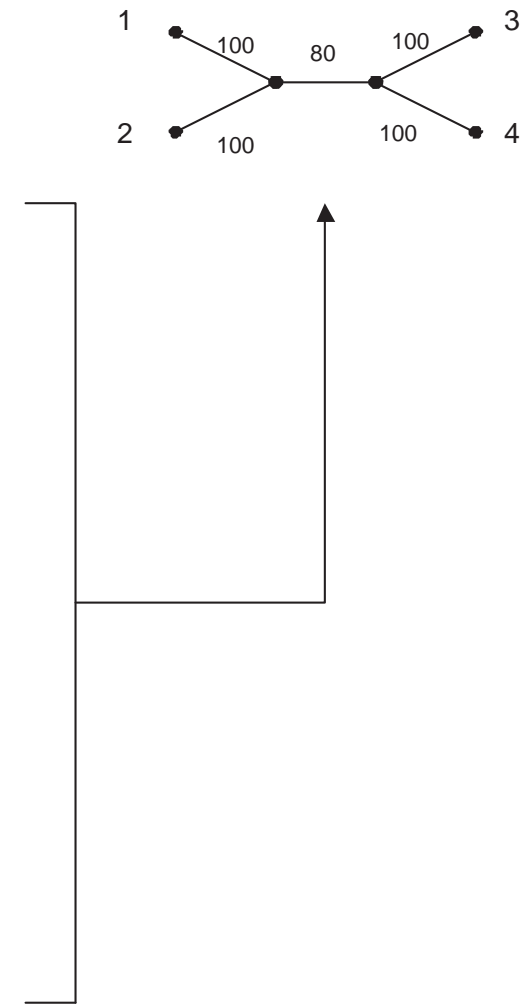

Figura 2.12: Diagrama da análise de bootstrap (Van de Peer, 2003). 
Embora o bootstrap seja uma técnica simples e efetiva que mede a repetibilidade dos clados da árvore inferida, os graus de suporte calculados podem ser propensos a erros se o método de inferência não for empregado corretamente (Van de Peer, 2003). Um outro inconveniente é o tempo necessário para realizar a análise de bootstrap. Dado que um grande número de réplicas é recomendado (entre 200 e 2.000), o tempo requerido de inferência de cada réplica pode ser inviável em termos práticos. Uma forma de resolver esse problema é empregar o método de RELL (do inglês Resampling Estimated Log Likelihoods) (Kishino e Hasegawa, 1989), que é uma aproximação do bootstrap descrito nesta seção. Tipicamente, os graus de suporte maiores que 70 ou $75 \%$ fornecem uma confiabilidade adequada aos clados inferidos (Van de Peer, 2003).

\subsubsection{O teste de Shimodaira-Hasegawa}

Um estudo filogenético pode resultar em várias árvores (por exemplo produzidas por um análise de bootstrap), possibilitando a realização de análises estatísticas. Os testes de Templeton (1983) e Kishino e Hasegawa (1989) têm sido aplicados para comparar topologias alternativas inferidas com os critérios de parcimônia e verossimilhança respectivamente. Porém, Shimodaira e Hasegawa (1999), bem como Goldman et al. (2000) apontam que a aplicação de tais testes é incorreta estatisticamente. Além disso, tem-se observado que tais testes rejeitam muitas topologias válidas (Felsenstein, 2004). Assim, Shimodaira e Hasegawa (1999) desenvolveram o teste SH para comparar várias topologias de acordo com ao critério de máxima verossimilhança. Tal teste tem como objetivo determinar quais topologias pertencem ao conjunto de confiança, isto é, as topologias que não podem ser rejeitadas.

Inicialmente, tem-se um conjunto $\mathcal{T}$ de $N_{\text {arv }}$ árvores tal que $\tau_{i}$ é a $i$-ésima árvore. A verossimilhança de $\tau_{i}$ é denotada por $\ln L\left(\tau_{i}\right)$. A partir do conjunto de dados iniciais, gera-se um conjunto de $N_{\text {rep }}$ réplicas dos dados por bootstrap. Apos isso, calcula-se o valor $\ln L_{j}\left(\tau_{i}\right)$, que representa a verossimilhança da $i$-ésima árvore na $j$-ésima replica dos dados. Para a $i$-ésima árvore e $j$-ésima replica, obtem-se $\mathcal{R}_{i, j}$, que representa a diferença entre a verossimilhança de $\tau_{i}$ e a média das tais valores em todas as replicas:

$$
\mathcal{R}_{i, j}=\ln L_{j}\left(\tau_{i}\right)-\frac{1}{N_{\text {rep }}} \sum_{k=1}^{N_{\text {rep }}} \ln L_{k}\left(\tau_{i}\right)
$$

A seguir, calcula-se o valor $\mathcal{O}_{i, j}$ que representa a diferença entre o máximo $\mathcal{R} k, j$ para a replica $j$ e o valor de $\mathcal{R}_{i, j}$, isto é:

$$
\mathcal{O}_{i, j}=\max _{k=1 \ldots N_{\text {arv }}}\left(\mathcal{R}_{k, j}\right)-\mathcal{R}_{i, j}
$$


O valor $p$ para uma topologia $\tau_{i}$ é determinado pela proporção de valores $\mathcal{O}_{i, j}$, que são menores que a diferença entre a verossimilhança da melhor árvore (denotada por $\tau *$ ) e a verossimilhança de $\tau_{i}$. A expressão para $p$ é dada por:

$$
p\left(\tau_{i}\right)=\mid\left\{\mathcal{O}_{i, j}, j=1 \ldots N_{\text {rep }} \text { tal que } \mathcal{O}_{i, j}<\ln L(\tau *)-\ln L\left(\tau_{i}\right)\right\} \mid
$$

$\mathrm{O}$ valor $p$ para cada solução indica a probabilidade da árvore correspondente não ser significativamente pior que a melhor árvore do conjunto. Se tal valor encontra-se abaixo de um determinado limite (usualmente 0,05), a solução analisada pode ser rejeitada. O teste $\mathrm{SH}$ é amplamente empregado em pesquisa filogenética além de estar implementado nos principais programas de inferência tais como PHYLIP (Felsenstein, 2000b), PAUP* (Swofford, 2000) ou PAML (Yang, 1997). Uma desvantagem do teste SH é que pode ser muito conservador. Por outro lado, existem outros testes que podem diminuir este efeito (Shimodaira, 2002; Yang, 2006).

\subsubsection{Inferência Bayesiana}

A inferência Bayesiana é um método estatístico de recente aplicação na inferência filogenética (Larget e Simon, 1999; Li et al., 2000; Mau e Newton, 1997; Rannala e Yang, 1996). O objetivo principal desse método é calcular a probabilidade condicional (ou probabilidade a posteriori) das diferentes árvores e parâmetros do modelo evolutivo em função de um conjunto de dados. Seja $\mathcal{D}$ um conjunto de dados, $\tau_{i}$ a i-ésima topologia do conjunto total de $N T$ topologias possíveis para $n$ espécies, e $\varphi=\{\mathcal{B}, \mathcal{M}\}$ um modelo onde é $\mathcal{B}$ o conjunto de os comprimento de ramos de $\tau_{i}$, e $\mathcal{M}$ os parâmetros do modelo de substituição de sequências. A probabilidade posterior de $\tau_{i}$ dado $\mathcal{D}$ é expressada por:

$$
\mathcal{P}\left(\tau_{i} \mid \mathcal{D}\right)=\frac{\mathcal{P}\left(\mathcal{D} \mid \tau_{i}, \varphi\right) \mathcal{P}\left(\tau_{i}, \varphi\right)}{\sum_{j=0}^{N T} \int \mathcal{P}\left(\mathcal{D} \mid \tau_{j}, \varphi\right) \mathcal{P}\left(\tau_{j}, \varphi\right) d \varphi}
$$

onde $\mathcal{P}\left(\mathcal{D} \mid \tau_{i}, \varphi\right)=\mathcal{P}\left(\mathcal{D} \mid \theta=\left\{\tau_{i}, \varphi\right\}\right)$ é a verossimilhança da árvore $\tau_{i}$ com os comprimentos de ramos $\mathcal{B}$ e parâmetros do modelo de substituição contidos em $\mathcal{M}$ (ver Seção 2.5.2), e $\mathcal{P}\left(D \mid \tau_{j}, \varphi\right)$ é o produto das probabilidades a priori da topologia $\tau_{j}$ e os parâmetros em $\varphi$. A escolha da distribuição de tais probabilidades é subjetiva (Felsenstein, 2004; Guindon, 2003; Yang, 2006). O cálculo do denominador da Equação 2.26 implica a somatória, para todas as topologias existentes, da integral sobre todos os valores possíveis dos parâmetros em $\varphi$. Na prática, a determinação de tal valor diretamente é possível somente em pequenos conjuntos de dados. Para resolver este problema emprega-se o método de Monte Carlo baseado cadeias de Markov (MCMC) (Yang, 2006). Um esquema do método MCMC é mostrado no Algoritmo 3. 


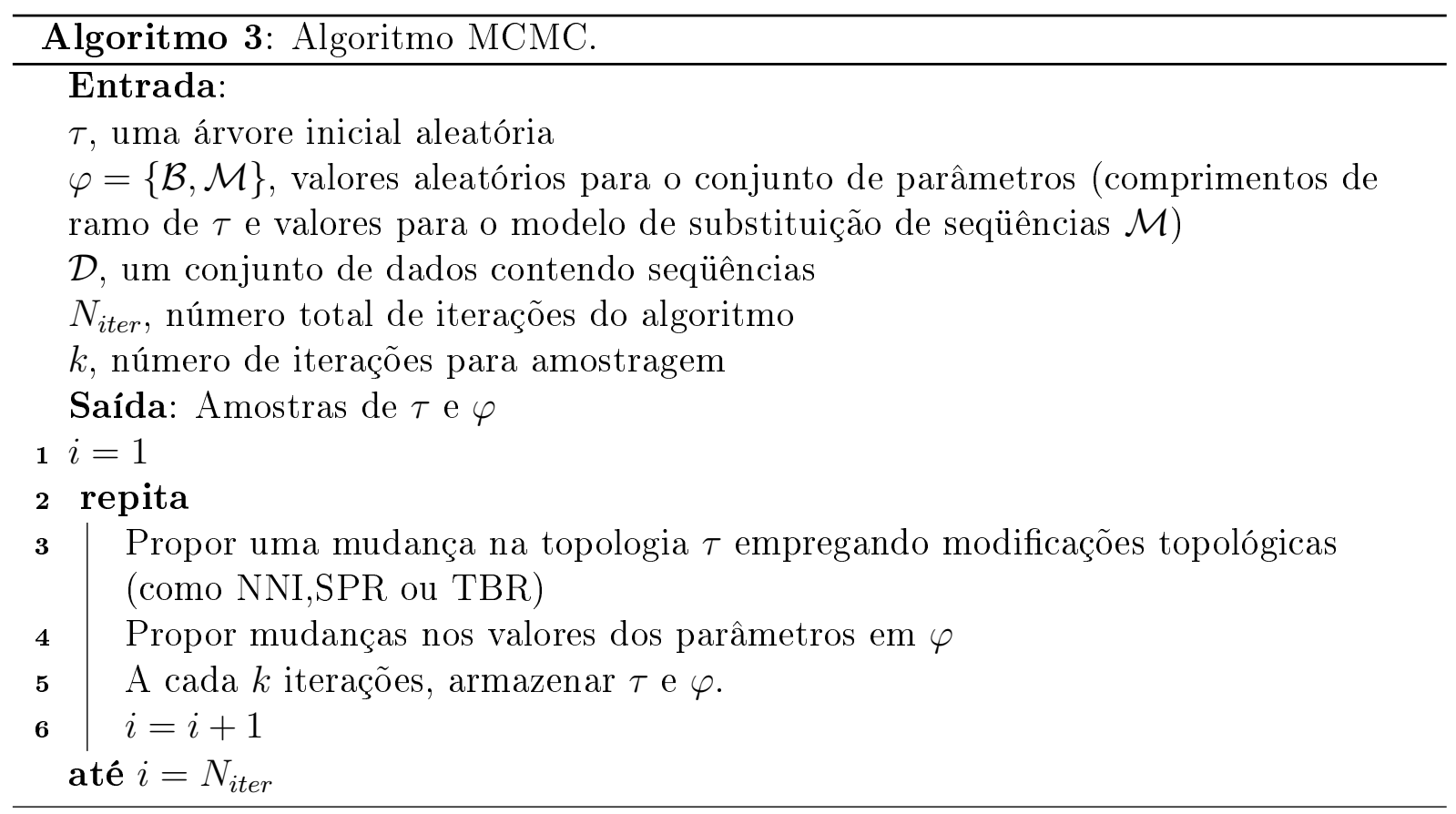

A idéia fundamental do algoritmo MCMC é realizar uma amostragem percorrendo os espaços de topologias $\tau_{j}$ e valores $\varphi$ para aproximar a probabilidade a posteriori de tais parâmetros. A topologia com maior probabilidade é aquela que foi visitada mas vezes durante as iterações do MCMC. As probabilidades para as outras topologias também podem ser calculadas da amostragem realizada. Se o número de espécies analisadas for muito alto e os dados não fornecem informações suficientes, é possível que as probabilidades das árvores apresentem valores muito baixos (Yang, 2006). Uma forma de sumarizar os resultados é usar as árvores de amostra para calcular uma árvore de consenso. Para cada clado na árvore de consenso, calcula-se a proporção de árvores da amostra que contém tal clado. Esse valor é denominado probabilidade posterior do clado. Embora esta forma de sumarizar os resultados seja questionada por alguns autores, esta é implementada nos programas de inferência bayesiana como Mr.Bayes (Ronquist et al., 2005) e BAMBE (Larget e Simon, 1998).

\subsection{Considerações finais}

Neste capítulo apresentou-se os principais conceitos da área de inferência filogenética. A reconstrução da árvore filogenética que melhor explique as relações evolutivas entre as espécies analisadas é um problema bastante complexo, devido ao grande espaço de busca e a falta de informação sobre espécies ancestrais extintas. Uma série de métodos que buscam reconstruir a melhor árvore têm sido propostos na literatura. A máxima parcimônia e a máxima verossimilhança são dois dos métodos de reconstrução filogenética mais empregados pelos pesquisadores. Tais métodos definem critérios de otimalidade diferentes. Os 
algoritmos de Fitch (Fitch, 1972) e Felsenstein (Felsenstein, 1981a) otimizam os critérios de parcimônia e verossimilhança para uma determinada árvore.

Contudo, a busca pela árvore ótima no espaço de busca é uma tarefa complexa. Assim, no decorrer deste Capítulo foram descritas várias estratégias heurísticas descritas na literatura. As heurísticas apresentadas são tanto gerais (podendo ser aplicadas com quaisquer dos critérios de otimalidade), quanto específicas para os critérios de parcimônia e de verossimilhança. Uma das heurísticas utilizadas neste problema são os Algoritmos Evolutivos, que serão revisados no Capítulo 3.

Embora existam várias formas de recuperar a filogenia de um conjunto de espécies, a aplicação de diferentes métodos podem produzir resultados distintos. Os estudos comparativos de tais métodos mostram que os resultados são muito variáveis e dependentes das condições do experimento. A verificação de que a aplicação de diversos métodos resulta em soluções conflitantes motiva a investigação de uma abordagem multi-objetivo do problema da inferência filogenética. Em tal formulação, é possível obter um conjunto de soluções que representem um equilíbrio entre os critérios empregados como objetivos. A aplicação dos AEs para problemas multi-objetivo e a modelagem multi-objetivo do problema de reconstrução filogenética são explorados nos Capítulos 4 e 5, respectivamente. O conjunto de soluções obtidas pode ser avaliado estatisticamente mediante os testes descritos neste capítulo. Esses testes são utilizados na parte experimental desta pesquisa (Capítulo 6). 


\section{CAPÍTULO \\ 3 \\ Algoritmos evolutivos aplicados à \\ filogenia}

\subsection{Introdução}

A Computação Evolutiva é uma área de pesquisa que tem evoluído significativamente nas últimas décadas. Embora as primeiras pesquisas nessa área são da década de 1.930, é a partir da década de 1.960 que os trabalhos diversificaram-se devido, entre outras coisas, ao maior acesso a computadores (De Jong, 2006). Assim, vários tipos de Algoritmos Evolutivos (AEs) que imitam mecanismos de evolução existentes na natureza foram propostos. A aplicação de tais abordagens tem-se destacado principalmente na resolução de problemas de otimização computacionalmente complexos (Deb, 2001). O problema de reconstrução filogenética pode ser visto como um problema de otimização, no qual se deve determinar a árvore ótima segundo algum critério.

A determinação de filogenias é um problema complicado dado que o número possível de árvores filogenética cresce muito rapidamente com o número de espécies analisadas (ver Capítulo 2). Assim, o emprego dos AEs surge como uma alternativa viável para este tipo de problema. Além disso, diversos trabalhos na literatura têm mostrado resultados relevantes de AEs aplicados à filogenia (Katoh et al., 2001; Lemmon e Milinkovitch, 2002a; Lewis, 1998; Zwickl, 2006).

Este capítulo está organizado conforme segue. A Seção 3.2 apresenta os principais conceitos da Computação Evolutiva. A Seção 3.3 mostra mais detalhadamente os Algoritmos 
Genéticos (AGs), um dos AEs mais utilizados. A Seção 3.4 contém uma revisão da literatura sobre o emprego de AGs no problemas de reconstrução filogenética, considerando trabalhos que empregam como função objetivo os critérios de parcimônia e verossimilhança. Finalmente, na Seção 3.5, apresenta-se as considerações finais deste capítulo.

\subsection{Computação evolutiva}

A Computação Evolutiva abrange um conjunto de algoritmos (AEs) baseados na simulação dos princípios de evolução e seleção natural (Deb, 2001). Cientistas da área de biologia interessaram-se pelos AEs para diversas aplicações como o teste de processos evolutivos e a simulação de modelos de evolução natural. Cientistas de computação e engenheiros estudam o potencial de tais algoritmos para resolver uma série de problemas complexos, principalmente na área de otimização, aprendizado de máquina, e vida artificial (De Jong, 2006).

Uma vez que os AEs são fortemente inspirados em processos evolutivos que ocorrem na natureza, é preciso explorar as bases de tais processos. De Jong (2006) identifica os principais componentes dos sistemas evolutivos darwinianos:

- Uma ou mais populações de indivíduos concorrendo por recursos limitados;

- A noção de mudanças dinâmicas nas populações devido ao nascimento e morte dos indivíduos;

- O conceito de aptidão, que reflete a habilidade do indivíduo para sobreviver e reproduzir-se;

- A variação na hereditariedade, ou seja, os novos indivíduos possuem muitas das características de os seus pais, embora não sejam idênticos.

Os processos evolutivos descritos acima são de natureza iterativa. Dadas as condições iniciais, o processo segue uma trajetória no tempo em um espaço de estados evolutivos. A idéia de embutir processos evolutivos em algoritmos para resolução de problemas foi explorado paralelamente por vários pesquisadores produzindo vários tipos de AEs. De Jong (2006) classifica as principais tipos de AEs em Estratégias Evolutivas, Programação Evolutiva e Algoritmos Genéticos.

As Estratégias Evolutivas (EEs) foram propostas por Rechenberg e Schwefel (Rechenberg, 1965; Schwefel, 1968 apud Deb, 2001) na Universidade Técnica de Berlim. O foco principal das EEs é a resolução de problemas de otimização de funções cujos parâmetros são números reais. Em tais problemas os indivíduos, os quais representam uma solução para tal problema, são armazenados como um vetor de números reais (chamados genes). 
A proposta inicial foi um modelo denominado $(1+\lambda)$-EE, onde uma solução pai produz $\lambda$ descendentes e a melhor das $(1+\lambda)$ soluções é escolhida para ser o pai do novo conjunto de soluções. Os descendentes são obtidos por mutação dos genes do pai. A mutação em geral utiliza uma perturbação Gaussiana $G(0, \sigma)$ de média nula e desvio padrão $\sigma$. Os estudos preliminares indicaram que o desempenho das EEs dependem da escolha da $G(0, \sigma)$. Assim, a representação dos indivíduos foi estendida para incorporar um valor $\sigma$ para cada parâmetro do problema. Esta é uma característica fundamental das EEs, que permite o auto-ajuste de seus parâmetros.

Uma série de inconvenientes da proposta original como escalabilidade para problemas de alta dimensão e de superfícies multimodais, gerenciamento de interação entre os parâmetros foram identificados. Assim, surgiram duas extensões do modelo $(1+\lambda)$-EE: a $(\mu+\lambda)$-EE e a $(\mu, \lambda)$-EE. Na primeira, $\mu$ indivíduos reproduzem-se gerando $\lambda$ descendentes, obtendo uma população (conjunto de soluções) temporária de $(\mu+\lambda)$ indivíduos, dos quais são escolhidos os $\mu$ melhores indivíduos da próxima geração. Na $(\mu, \lambda)$-EE, $\mu$ indivíduos reproduzem-se produzindo $\lambda$ descendentes, com $\mu<\lambda$, sendo que a nova população de $\mu$ indivíduos é selecionada dos $\lambda$ descendentes. Esta última abordagem é dita geracional, pois o período de vida de cada indivíduo é de uma geração.

Fogel (1962); Fogel et al. (1966), na Universidade de Califórnia, iniciou os estudos de métodos de Programação Evolutiva (PE) os quais foram aplicados a problemas de Inteligência Computacional (Rich e Knight, 1991; Russell e Norvig, 1995). Em tal aplicação, agentes inteligentes foram representados como máquinas de estado finito, as quais evoluíram em melhores máquinas no decorrer da execução do algoritmo. A abordagem de PE é focada nos modelos de populações fixas de $N$ indivíduos pais, cada um dos quais gera um indivíduo descendente. A nova geração de $N$ pais é determinada combinando pais e descendentes em uma população de tamanho $2 N$, classificando tais indivíduos pelo valor de aptidão e, posteriormente, permitindo a sobrevivência de apenas $N$ deles. Os indivíduos são submetidos a diferentes tipos de mutação que simplesmente alteram aspectos da solução de acordo com uma distribuição estatística que pondera variações menores ou maiores conforme a proximidade dos indivíduos do ótimo global.

Os Algoritmos Genéticos (AGs) foram introduzidos por Holland (1975), na Universidade de Michigan. Holland enfatizou na necessidade de sistemas auto-adaptativos no tempo em função da realimentação obtida pela interação com o ambiente onde operam (De Jong, 2006). Os estudos inicias de AGs propuseram modelos geracionais, nos quais, uma população de $N$ pais produz uma nova população de $N$ descendentes que substituem incondicionalmente os pais. Diferentemente das EEs e PEs, o desenvolvimento dos AGs teve como objetivo ser independente do problema tratado. Assim, as soluções do problema (os indivíduos da população) são codificados em cadeias de caracteres binários de comprimento fixo. A reprodução dos indivíduos é realizada por operadores genéticos de mutação e recombinação sobre tais cadeias. A codificação (decodificação) dos parâmetros 
do problema para (a partir) de cadeias de bits é dependente do problema analisado. Uma outra característica importante dos AGs é que os pais são selecionados estocasticamente conforme ao seu valor de aptidão. Desta forma, os indivíduos com maior aptidão contribuem significativamente na geração dos descendentes. Os AGs foram aplicados a um grande número de problemas de otimização (De Jong, 2006; Deb, 2001). Tais aplicações evidenciaram vários problemas na proposta original de AGs. Com o decorrer das pesquisas, mudanças significativas referentes aos mecanismos de seleção, elitismo e representação de indivíduos foram realizadas.

Embora EEs, PEs, e AGs tenham sido desenvolvidas separadamente, compartilham muitos conceitos e idéias comuns. O surgimento de uma visão geral e abrangente envolvendo essas técnicas foi produto das principais conferências e encontros entre os pesquisadores de tais abordagens. O termo de Computação Evolutiva foi amplamente aceito para unificar as diversas tendências. Na próxima seção, os principais conceitos dos AEs são explicados com base nos AGs, os quais são de maior interesse no presente trabalho.

\subsection{Algoritmos genéticos}

Os AGs podem ser vistos como técnicas de busca ou otimização inspirados nos mecanismos de evolução, seleção natural e nos princípios de genética. Eles têm sido empregados satisfatoriamente a uma grande variedade de problemas de diversas áreas como: engenharia, otimização, inteligência computacional, bioinformática, entre outras (De Jong, 2006; Deb, 2001; Goldberg, 1989).

Considerando um problema de otimização qualquer, os AGs inicializam a busca pela melhor solução a partir de um conjunto inicial de soluções aleatórias, chamado de população inicial. Em princípio, é desejável que as soluções aleatórias de tal população estejam bem distribuídas no espaço de busca. Cada uma dessas soluções (indivíduo) é representada em uma estrutura de dados chamada cromossomo. Em geral, os cromossomos são cadeias de caracteres binários. A representação interna deve ser capaz de codificar qualquer solução fatível do problema considerado.

A avaliação dos indivíduos de uma população é realizada empregando a função objetivo do problema. Com base em tal valor, é calculada a aptidão dos indivíduos, que indica quais indivíduos dentro da população são os mais aptos (as melhores soluções para o problema). Esses indivíduos são fortes candidatos para se reproduzirem e transferirem as suas características para novos indivíduos, os quais poderão formar uma nova população (também chamada de geração).

O operador de seleção para reprodução utiliza a aptidão dos indivíduos para escolher as melhores soluções encontradas para o problema. Tais indivíduos recebem um maior número de cópias dentro de uma lista de reprodução (conjunto de indivíduos que irão se 
reproduzir, pais); enquanto os piores indivíduos dificilmente reproduzem-se. Repetidamente, uma nova população é gerada utilizando os operadores genéticos de recombinação e mutação. Esses operadores são empregados segundo determinadas freqüências que devem ser fornecidas como parâmetros da execução do AG. O funcionamento de ambos os operadores depende fortemente da representação interna das soluções.

Empregando os operadores de seleção, recombinação e mutação, o AG gera uma nova população buscando melhorar a aptidão dos indivíduos de tal população em relação à população anterior. Novas gerações são produzidas até que um critério de parada seja atingido, fornecendo soluções do problema na população final. O funcionamento de um AG é apresentado no Algoritmo 4.

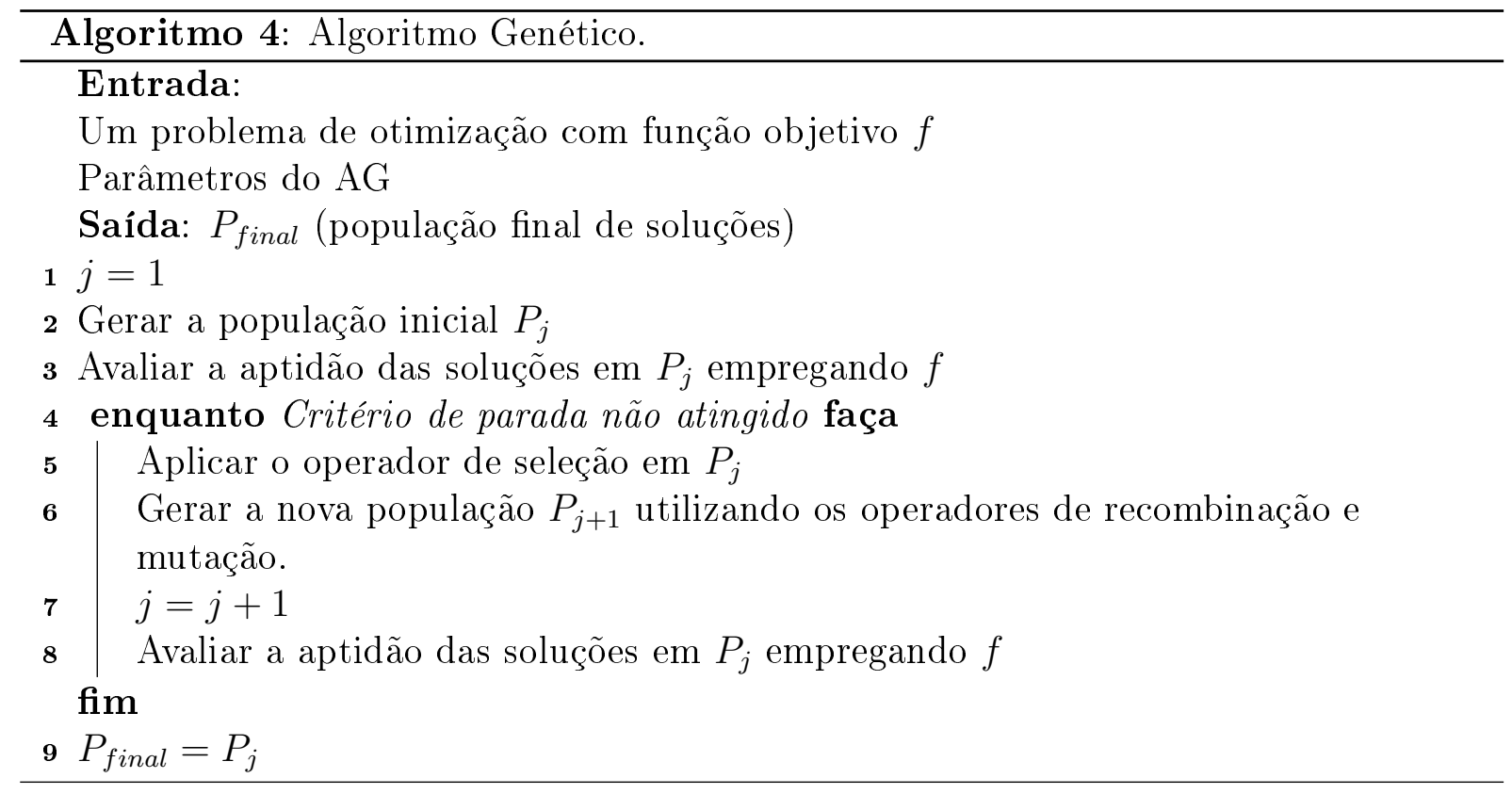

No desenvolvimento de um AG para um problema particular deve-se especificar os seguintes componentes:

- Codificação para as soluções potenciais do problema;

- Procedimento para criar uma população inicial;

- Função de aptidão para classificar as soluções em termos de sua adaptação ao ambiente (sua capacidade de resolver o problema);

- Definição dos operadores genéticos com base na codificação utilizada;

- Determinação dos diversos parâmetros do AG, tamanho da população, probabilidades de aplicação dos operadores genéticos e outros.

As próximas Seções apresentam algumas características importantes dos principais componentes dos AGs. 


\subsubsection{Representação das soluções}

É importante que cada indivíduo da população seja capaz de representar completamente uma possível solução do problema tratado. Para isso, todas as variáveis da função objetivo devem estar representadas em cada indivíduo.

Os trabalhos iniciais em AGs propuseram cromossomos formados por cadeias de caracteres binários. A princípio, qualquer problema poderia ser tratado com operadores de recombinação e mutação baseados na representação binária. O cromossomo precisa ser decodificado antes de ser avaliado pela função de aptidão (Haupt e Haupt, 1998). A representação binária é do tipo genotípica, dado que existe um mapeamento entre a cadeia de caracteres (genótipo) e a decodificação de tal cadeia (fenótipo), que depende do problema a ser resolvido (De Jong, 2006). É possível empregar representação binária para codificar parâmetros como números inteiros, reais ou outra estrutura relevante ao problema.

Como exemplo, considere um vetor de variáveis contínuas no intervalo $[0 ; 1]$ que deve ser representado por cadeias binárias de tamanho 3. A Tabela 3.1 ilustra uma representação binária de valores contínuos. De acordo com esta tabela, as variáveis $[0,55 ; 0,11 ; 0,95 ; 0,63]$ serão representados pela cadeia 100000111 101. A Tabela 3.1 fornece a decodificação de valores binários para contínuos. Os números à esquerda e à direita representam os limites superior e inferior para cada trio binário. Por exemplo, para 111 os limites são [0,9375;1,000]. Assim, o mesmo indivíduo, 100000111101, é recuperado como $[0,500 ; 0,00 ; 0,875 ; 0,625],[0,625 ; 0,125 ; 1,00 ; 0,750]$ ou $[0,5625 ; 0,0625 ; 0,9375 ; 0,6875]$ quando se considera, respectivamente, os limites inferior, superior ou a média de ambos os limites. Nota-se que a conversão adiciona uma margem de erro a cada variável.

A grande motivação para o emprego da codificação binária está na Teoria de Esquemas (Holland, 1992), utilizada para justificar a eficiência dos AGs. Segundo Holland (1975), a representação binária maximiza o paralelismo implícito inerente ao AG. Contudo, em diversas aplicações práticas a codificação binária leva a um desempenho insatisfatório. Nos problemas de otimização com parâmetros reais, Michalewicz (1996) e Deb (2001) apresentam resultados de comparações do desempenho de AGs com codificação binária e com ponto flutuante. Os resultados apresentados revelam a superioridade da codificação em ponto flutuante. Assim, em problemas de otimização numérica com parâmetros reais, pode-se empregar diretamente o vetor de parâmetros numéricos ou reais da função para determinar os indivíduos. A representação que emprega diretamente as variáveis do problema no indivíduo é dita fenotípica. Neste tipo de representação não se tem a preocupação da decodificação de genótipo para fenótipo. Em contrapartida, empregar representações fenotípicas supõe o desenvolvimento de operadores de recombinação e mutação específicos ao problema tratado (De Jong, 2006).

A codificação é uma das etapas mais críticas na definição de um AG. A definição inadequada da codificação pode acarretar diversos problemas, entre esses um dos mais 
Tabela 3.1: Tabela de conversão de parâmetros contínuos para binário (Haupt e Haupt, 1998).

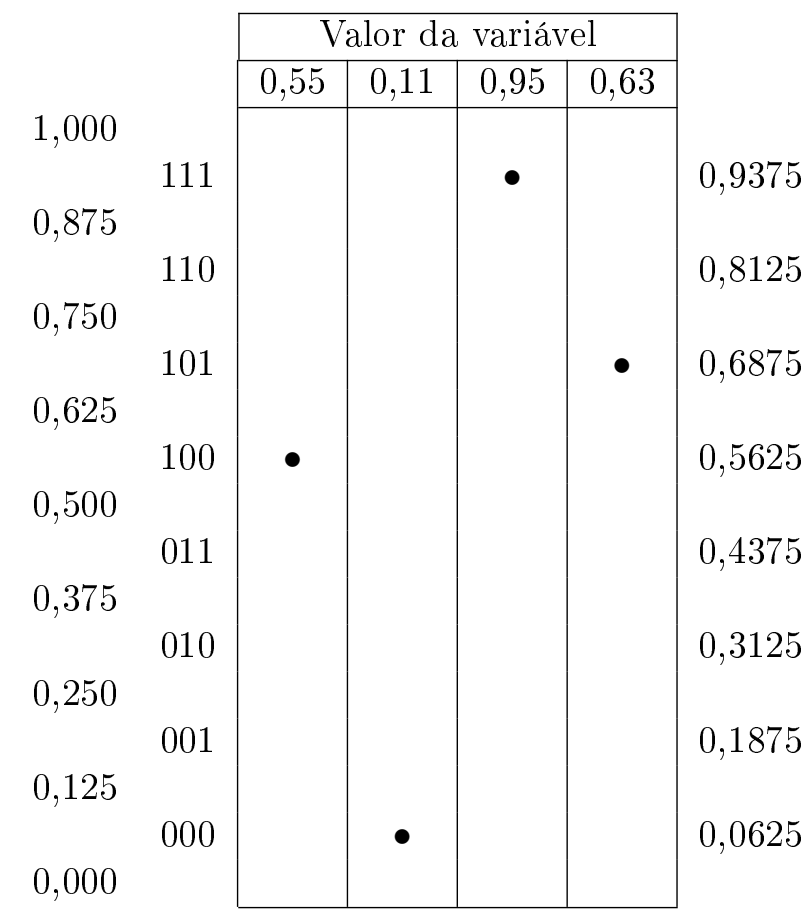

importantes é o problema de convergência prematura. Em uma série de problemas de otimização com restrição, a codificação adotada pode fazer com que indivíduos modificados pela recombinação ou mutação sejam inválidos. Nesses casos, cuidados especiais são necessários na definição da codificação e/ou dos operadores (Michalewicz, 1996).

\subsubsection{Definição da população inicial}

O método geralmente utilizado na criação da população é a inicialização aleatória dos indivíduos. Se algum conhecimento inicial a respeito do problema estiver disponível, pode ser utilizado na inicialização da população. Por exemplo, no caso de codificação binária, se é sabido que a solução final vai apresentar mais $0^{\prime}$ s do que 1 's, tal informação pode ser utilizada. Por outro lado, em problemas com restrições, deve-se tomar cuidado para não gerar indivíduos inválidos na etapa de inicialização.

\subsubsection{Operador de seleção}

No operador de seleção, os indivíduos são escolhidos para participar da produção dos descendentes da próxima geração. Indivíduos com melhor valor de aptidão têm a maior probabilidade de gerar um ou mais descendentes para a geração seguinte. Este operador é a versão artificial da seleção das espécies do Darwinismo, que estabelece que os seres mais 
aptos têm maio probabilidade de sobreviver, ou seja, os mais fortes e menos vulneráveis aos predadores e doenças.

O objetivo principal da seleção é copiar as melhores soluções e eliminar soluções de baixa aptidão, mantendo tamanho da população é constante (Deb, 2001). Isso é realizado utilizando os seguintes passos:

1. Identificar os melhores indivíduos na população;

2. Realizar múltiplas cópias das soluções com aptadão mais alta ou de informações dessas soluções;

3. Eliminar indivíduos de baixa aptidão da população.

Os melhores indivíduos são armazenados em uma lista de reprodução a ser empregada pelos operadores de recombinação e mutação. Existem várias abordagens possíveis para o operador de seleção, sendo as mais comuns são a seleção pelo torneio, seleção proporcional, e seleção por ranking.

Na seleção por torneio, duas ou mais soluções são escolhidas aleatoriamente e a melhor solução é copiada na lista de reprodução. Este processo é repetido até preencher tal lista. Deb (2001) mostrou que esta estratégia de seleção possui uma convergência igual ou melhor que outras abordagens, além de possuir uma complexidade computacional menor.

Na estratégia de seleção proporcional, o número de cópias de uma solução na lista de reprodução é proporcional ao seu valor de aptidão. Para calcular o número de cópias esperado, é necessário obter a probabilidade de cada solução:

$$
\operatorname{prob}_{i}=\frac{A p t_{i}}{\sum_{i=1}^{N_{\text {ind }}} A p t_{i}}
$$

sendo que $A p t_{i}$ é a aptidão da solução $i$ e $N_{\text {ind }}$ é o tamanho da população. O número de cópias do indivíduo $i$ na lista de reprodução $\operatorname{prob}_{i} \times N_{\text {ind }}$. Ou seja, as soluções com melhor valor de aptidão terão mais cópias na lista de reprodução. O escalonamento é um problema associado com esta estratégia. Quando existe uma solução com um valor de aptidão muito maior comparado com o resto da população, esta super-solução terá uma probabilidade de escolha perto de 1, e terá cópias muitas cópias. Caso todas as soluções possuam valores similares de aptidão, a probabilidade de serem escolhidas será a mesma, e cada uma será copiada na lista de reprodução. Isso é equivalente a não realizar operação de seleção.

A estratégia de seleção pelo ranking ordena as soluções da população conforme ao seu valor de aptidão, desde a pior solução (ranking 1 ) até a melhor (ranking $\left.N_{\text {rank }}\right)$. O número 
de copias de uma solução é proporcional ao seu valor de ranking. Esse procedimento minimiza o problema apontado na estratégia anterior.

A escolha da estratégia de seleção é importante devido à influência na diversidade dos indivíduos da população no decorrer do AG. Cada estratégia possui um certo grau de pressão de seleção, ou seja, a ênfase com que o operador de seleção escolhe os melhores indivíduos da população (Deb, 2001). Uma forma de aumentar a pressão de seleção é utilizando o elitismo, que consiste em é copiar diretamente um ou vários dos melhores indivíduos população atual para a população seguinte. Assim, as melhores soluções são sempre preservadas na geração seguinte. Contudo, se a pressão de seleção for muito forte, é provável que o AG convirja para uma região subótima do espaço de busca, dado que os indivíduos da população possuirão pouca diversidade (De Jong, 2006). Desta forma, pode-se dizer que o mecanismo de seleção determina o grau de refinamento das boas soluções, enquanto os operadores de recombinação e mutação influenciam na exploração do espaço de busca.

\subsubsection{Operador de recombinação}

No operador de recombinação, em geral, são criados dois novos indivíduos (filhos) empregando dois indivíduos (pais) escolhidos da lista de reprodução. A idéia intuitiva da recombinação é a troca de informação entre diferentes soluções pais. Comumente é atribuída uma probabilidade fixa de ocorrer recombinação aos indivíduos da população. Uma forma de recombinação muito empregada na representação binária é a recombinação de um ponto. Nesse operador, um ponto de corte na posição $j$ da cadeia de caracteres divide os pais em dois segmentos cada um. Os dois indivíduos descendentes são criados trocando as cadeias parciais dos pais. Assim, um descendente (filho 1) é formado pela combinação das subcadeias nas posições $1 \ldots j$ do pai 1 , e $j+1 \ldots n$ do pai 2 . O outro descendente (filho 2) é formado pela concatenação das subcadeias nas posições $1 \ldots j$ do pai 2 , e $j+1 \ldots n$ do pai 1 . A Figura 3.1 mostra um exemplo da recombinação de um ponto.

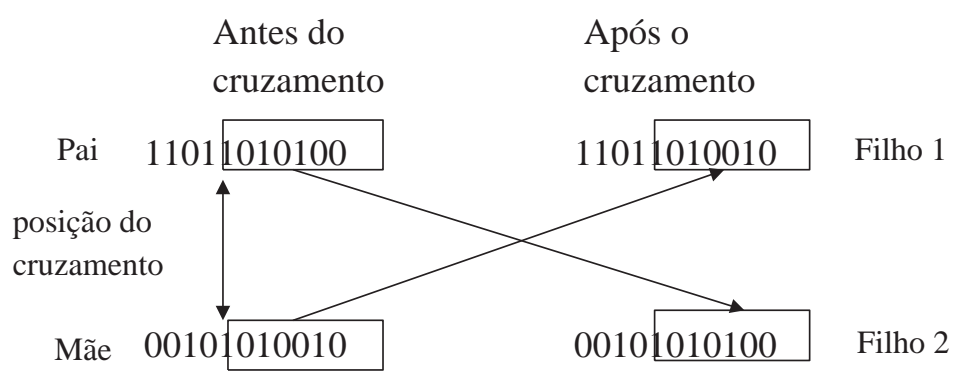

Figura 3.1: Operador de Recombinação de um ponto. 
Com a combinação das características dos pais é esperado que as soluções descendentes possuam um melhor valor aptidão que os seus ancestrais. O motivo de tal espectativa é que as soluções pais sejam escolhidas pela seleção, a qual enfatiza os melhores indivíduos. Soluções pais representam indivíduos que sobreviveram à seleção e, portanto, a sua aptidão é relativamente boa. Contudo, nem sempre são gerados descendentes superiores aos pais, pois o ponto de corte pode dividir o indivíduo de forma que os segmentos de boa aptidão sejam quebrados. Em tal caso, tais indivíduos tendem a ser eliminados na próxima operação de seleção (Deb, 2001).

Uma extensão simples da recombinação de um ponto é empregar dois ou mais pontos de corte. Para esta classe de operadores de recombinação a diversidade produzida pela geração de descendentes depende do número de pontos de corte e da semelhança das soluções pais. A diversidade na população introduzida pela recombinação diminui no decorrer das iterações dado que o operador de seleção faz com que os indivíduos da população sejam mais homogêneos, pois os melhores indivíduos produzem mais descendentes espalhando suas características pela população (De Jong, 2006). Outro tipo de recombinação muito comum é denominada uniforme (Sywerda, 1989). Em tal operador, o valor de qualquer posição do cromossomo de um dos descendentes pode ser obtido tanto de um pai quanto do outro (tal decisão é feita estocasticamente para cada posição). Conseqüentemente, a recombinação uniforme permite combinar características dos pais independentemente da sua posição no cromossomo.

No caso das representações fenotípicas, há uma série de operadores de recombinação específicos propostos na literatura (Deb, 2001). Por exemplo, no caso de número reais, têm sido propostos a recombinação aritmética, de mistura, simulação binária, fuzzy, entre outras (Deb, 2001). De acordo com Deb (2001), o desempenho de um determinado tipo de recombinação é fortemente dependente do tipo de problema. Assim, um tipo de operador que é particularmente eficiente para uma determinada classe de problemas pode ser ineficiente para outras.

\subsubsection{Operador de mutação}

A mutação é um operador que produz uma alteração aleatória em um gene de um indivíduo. A probabilidade de aplicação deste operador é denominada taxa de mutação. Usualmente, são atribuídos valores pequenos para este parâmetro. A idéia intuitiva do operador de mutação é criar uma variabilidade extra na população, mas sem destruir o progresso já obtido com a busca. Além disso, as alterações introduzidas pelos operador de mutação podem evitar a convergência prematura do AG, ou seja, que a população esteja estabilizada em regiões subótimas do espaço de busca.

Considerando a codificação binária, o operador de mutação geralmente inverte o valor de uma posição do cromossomo. Se a posição escolhida tem valor um, o seu valor passará a 
ser zero após a aplicação da mutação e viceversa. No caso das representações fenotípicas, como vetores de números reais, existe uma série de tipos de mutação propostos na literatura (Deb, 2001) tal como uniforme, não uniforme, ou Gaussiana (similar ao operador empregado nas EEs).

Enquanto o operador de recombinação explora as regiões trocando informações das soluções já encontradas; a mutação introduz continuamente mudanças que pode aumentar a diversidade entre os indivíduos, permitindo a exploração de novas regiões do espaço de busca. Tanto nos AGs como nos outros tipos de AEs, é importante que exista um equilíbrio entre a exploração de novas regiões e o refinamento de soluções em regiões mais exploradas do espaço de busca. Assim, o nível de refinamento pode ser controlado basicamente pelo operador de seleção; enquanto o grau de exploração pode se ajustado pela escolha dos mecanismos de recombinação e mutação (De Jong, 2006).

\subsubsection{Exemplo do uso de um AG}

Para exemplificar o funcionamento dos AGs, considere o problema de encontrar o máximo da função (Haupt e Haupt, 1998):

$$
f(x, y)=21,5+x \operatorname{sen}(4 \pi x)+y \operatorname{sen}(20 \pi y)
$$

Suponha que a solução que se busca tem coordenadas $x$ e $y$. Essas coordenadas representam o ponto de máximo da função. A superfície gerada por esta função possui vários picos e vales, caracterizando assim um problema com possibilidades de convergência para pontos de máximo local. A Figura 3.2 ilustra uma projeção suavizada desta superfície.

$f(x, y)=21.5+x^{*} \sin \left(4^{*} p^{*} x\right)+y^{*} \sin \left(20^{*} i^{*} y\right)$

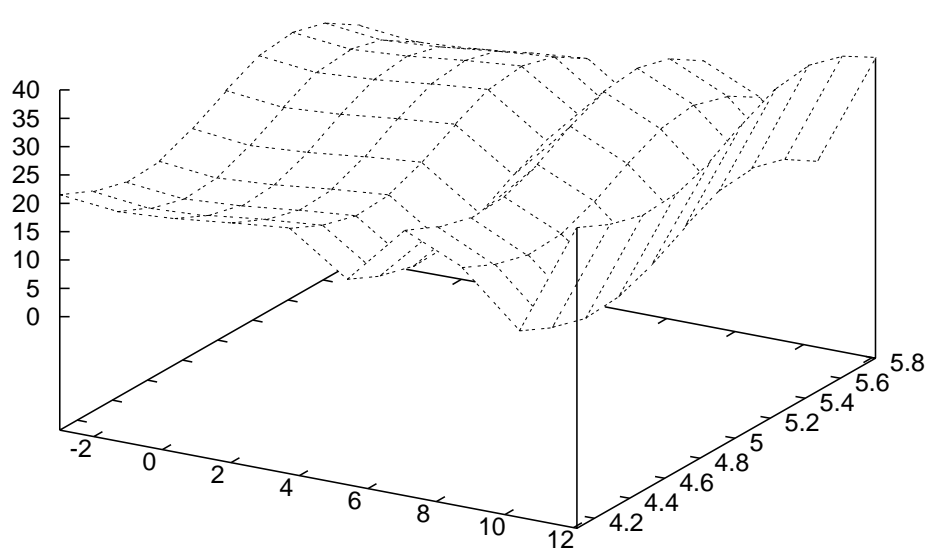

Figura 3.2: Superfície suavizada da função $f(x, y)$ (Haupt e Haupt, 1998). 
Tabela 3.2: População inicial do AG.

\begin{tabular}{|c|c|c|c|}
\hline Solução & $x$ & $y$ & Aptidão \\
\hline 1 & 8,55696 & 4,84176 & 29,51089 \\
\hline 2 & $-2,14217$ & 5,44308 & 25,88302 \\
\hline 3 & 1,96259 & 4,79317 & 18,61883 \\
\hline 4 & $-0,40211$ & 4,26638 & 17,46505 \\
\hline 5 & $-0,53782$ & 5,08256 & 17,22745 \\
\hline 6 & 10,91246 & 5,41764 & 16,63308 \\
\hline 7 & $-1,36431$ & 5,46409 & 15,91625 \\
\hline 8 & 3,44358 & 4,88583 & 15,80166 \\
\hline 9 & 1,88679 & 5,47073 & 14,35801 \\
\hline 10 & 6,35054 & 5,38383 & 10,87223 \\
\hline \multicolumn{3}{|c|}{ Aptidão média } & $\mathbf{1 8 , 2 2 8 6 5}$ \\
\hline
\end{tabular}

Tabela 3.3: Segunda geração do AG.

\begin{tabular}{|c|c|c|c|}
\hline Solução & $x$ & $y$ & Aptidão \\
\hline 1 & 8,55305 & 5,42428 & 32,20755 \\
\hline 2 & 8,55281 & 5,42428 & 32,18789 \\
\hline 3 & 1,00293 & 5,43068 & 26,62459 \\
\hline 4 & 8,55696 & 4,59307 & 25,17936 \\
\hline 5 & 8,55305 & 5,68915 & 23,20583 \\
\hline 6 & 8,55696 & 4,57343 & 22,56428 \\
\hline 7 & $-2,14217$ & 4,26627 & 19,95104 \\
\hline 8 & $-1,78296$ & 4,79338 & 18,84688 \\
\hline 9 & $-0,40211$ & 5,96177 & 18,30942 \\
\hline 10 & $-0,40211$ & 4,26607 & 17,50904 \\
\hline \multicolumn{3}{|c|}{ Aptidão média } & $\mathbf{2 3 , 6 5 8 5 9}$ \\
\hline \multicolumn{4}{|c}{}
\end{tabular}

O AG utilizado segue as características do AG simples definido por Goldberg (1989). Este algoritmo começa gerando uma população inicial aleatória. Os indivíduos são ordenados de acordo com o seu valor de aptidão calculado pela Equação 3.2. Alguns, entre os melhores, são selecionados para a recombinação. Os indivíduos da nova população também são ordenados. Após esta etapa, os operadores de seleção, recombinação e mutação são repetidos até a convergência do algoritmo. As Tabelas 3.2, 3.3 e 3.4 apresentam a população inicial e as populações referentes à segunda e à décima geração respectivamente.

A Figura 3.3 ilustra a distribuição dos indivíduos ao longo da superfície. As gerações 0 (Ger 0), 50 (Ger 50), 100 (Ger 100), 150 (Ger 150) e 200 (Ger 200) também são mostradas nesta figura. A Figura 3.4 apresenta um gráfico da função aptidão calculada em diferentes gerações, incluindo os valores de máximo e mínimo, além da média e desvio padrão. 
Tabela 3.4: Décima geração do AG.

\begin{tabular}{|c|c|c|c|}
\hline Solução & $x$ & $y$ & Aptidão \\
\hline 1 & 8,55305 & 5,42428 & 32,20755 \\
\hline 2 & 8,55305 & 5,42428 & 32,20755 \\
\hline 3 & 8,55305 & 5,42428 & 32,20755 \\
\hline 4 & 8,55305 & 5,42428 & 32,20755 \\
\hline 5 & 8,55305 & 5,42428 & 32,20755 \\
\hline 6 & 8,55305 & 5,42407 & 32,20368 \\
\hline 7 & 8,55305 & 5,42407 & 32,20368 \\
\hline 8 & 8,52355 & 5,42428 & 29,40521 \\
\hline 9 & 8,78899 & 5,42428 & 22,78260 \\
\hline 10 & 8,55305 & 4,57426 & 22,21939 \\
\hline \multicolumn{3}{|c|}{ Aptidão média } & $\mathbf{2 9 , 9 8 5 2 3}$ \\
\hline \multicolumn{4}{|c}{}
\end{tabular}

Gerações do Algoritmo Genético

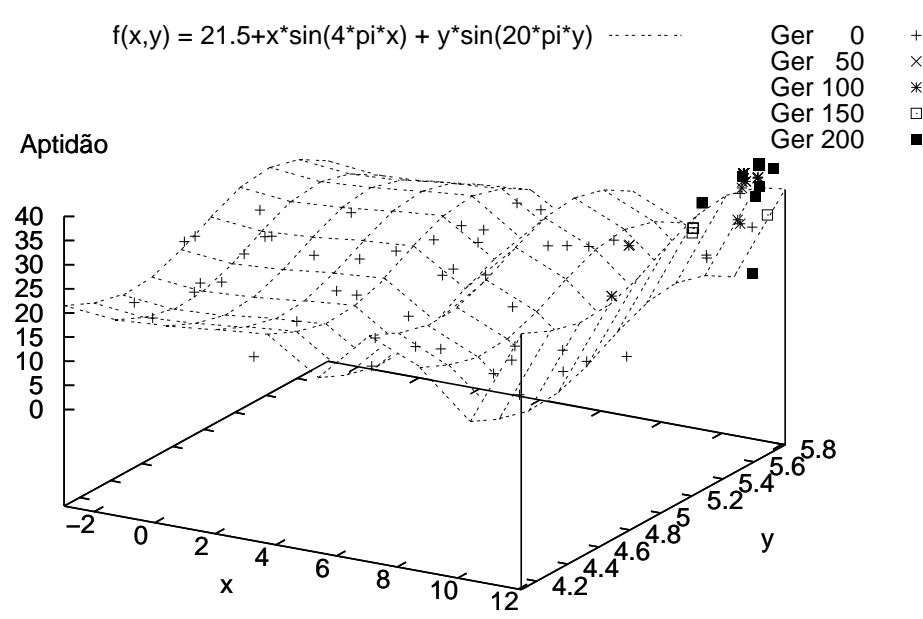

Figura 3.3: Indivíduos distribuídos sobre a superfície da função $f(x, y)$.

\subsubsection{Diferenças entre os AGs e as técnicas de otimização tradi- cionais}

As principais características do funcionamento dos AGs descritos nas seções anteriores mostram várias diferenças dos AGs em relação às técnicas de otimização tradicionais. Goldberg (1989) e Deb (2001) destacam as seguintes propriedades:

- O fato dos AGs poderem empregar representação binária que codifica os parâmetros de um problema determinado, permite a sua aplicação para um escopo de aplicações bastante amplo;

- Os operadores de seleção, recombinação e mutação permitem o aproveitamento das semelhanças entre cadeias binárias para uma busca efetiva no espaço das soluções; 


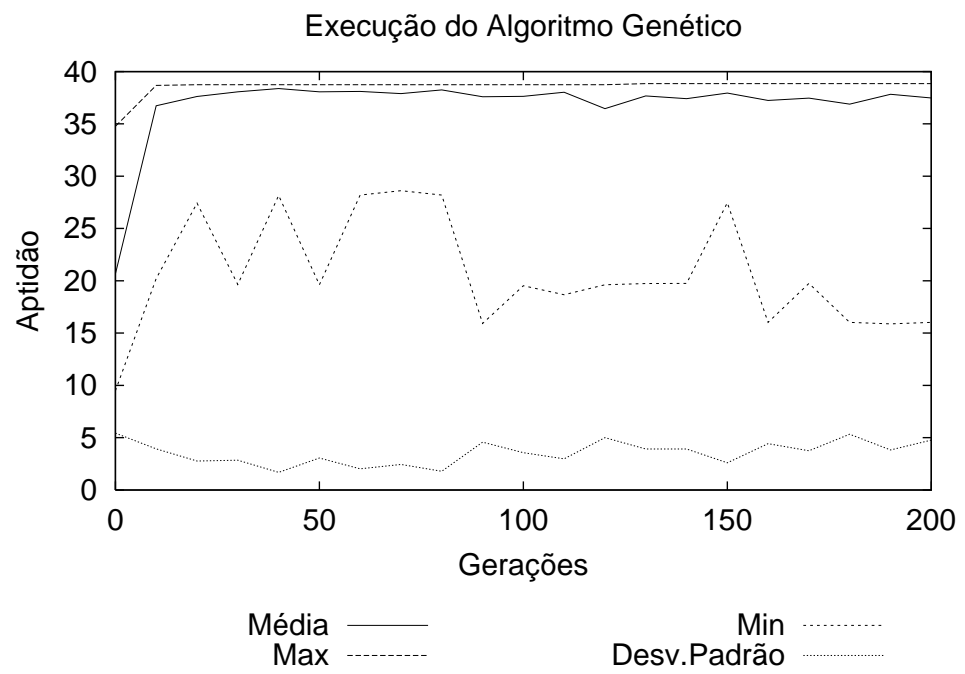

Figura 3.4: Gráfico da aptidão calculada em relação as gerações.

- Os AGs trabalham com uma população de soluções ao invés de uma única solução. Em cada iteração os AGs processam um conjunto de soluções, esta característica é denominada de paralelismo implícito. O processo de busca é, portanto, multidirecional, com a manutenção de soluções candidatas que representam a busca em várias partes do domínio e com troca de informações entre essas soluções;

- Os AGs não precisam de informação adicional (por exemplo, derivadas da função objetivo) a não ser o valor de aptidão das soluções. Isso torna possível a aplicação dos AGs a problemas nos quais não se têm informações a priori;

- Os AGs empregam regras probabilísticas para guiar sua busca. Por exemplo, o operador de seleção é baseado na aleatoriedade de duas soluções (seleção pelo torneio), ou na probabilidade de escolha (seleção proporcional) dessas soluções. O operador de mutação procura evitar que os AGs parem em ótimos locais, mudando a busca para outra região do espaço. Além disso, as soluções da população inicial são escolhidas aleatoriamente. Em contrapartida, uma técnica de otimização determinística não terá como escapar de ótimos locais, em caso de uma decisão ruim sobre a direção da busca.

A possibilidade de trabalhar com várias soluções simultaneamente, de não precisar de informações adicionais e poder evitar ótimos locais fazem dos AGs uma técnica promissora para ser empregada nos problemas de reconstrução filogenética. A Seção 3.4 aborda este tema. 


\subsection{Algoritmos evolutivos aplicados a filogenia}

A aplicação de AEs no problema de filogenia é relativamente recente. A maioria dos trabalhos de reconstrução filogenética utilizando AEs empregam o critério de máxima verossimilhança, embora existam trabalhos dedicados ao critério de parcimônia e distâncias. Nas próximas subseções, os principais trabalhos de AGs aplicados a filogenia são brevemente apresentados procurando destacar as principais contribuições de cada um.

\subsubsection{Aplicação de AEs com o critério de máxima verossimilhança}

Matsuda (1996) foi o primeiro a propor um AG para a reconstrução de árvores filogenéticas. O AG proposto avalia as soluções segundo o critério de máxima verossimilhança para seqüências de aminoácidos. O AG emprega um operador de recombinação que troca subárvores de duas soluções baseando-se no princípio de evolução mínima (Cavalli-Sforza e Edwards, 1967). Um dos problemas deste operador é que requer a otimização prévia dos comprimentos de ramos das árvores escolhidas para recombinação, o que resulta em lentidão no processo. Consequentemente, o AG não determina os comprimentos de ramos ótimos, senão que emprega tal informação para buscar a melhor topologia da árvore. Matsuda comparou os resultados do seu modelo contra as soluções obtidas a partir do programa PHYLIP (Felsenstein, 2000b) e algoritmos de agrupamento, obtendo resultados melhores ou comparáveis.

Em um trabalho posterior, Lewis (1998) desenvolveu o software GAML (do inglês Genetic Algorithm for Maximum Likelihood Phylogeny Inference). Diferentemente do trabalho de Matsuda (1996), o GAML emprega seqüências de nucleotídeos para o calculo da aptidão das soluções segundo o modelo de substituição HYK85 (Hasegawa et al., 1985). No GAML, as árvores inicias são geradas aleatoriamente, os comprimentos dos ramos são fixados em valores arbitrários, e o parâmetro $\kappa$ do modelo HKY85 é iniciado com um valor predeterminado Após a avaliação dos indivíduos pelo operador de seleção baseado em ranking, o operador de recombinação (mostrado na Figura 3.5) efetua uma troca de subárvores de duas soluções pais a fim de gerar duas novas soluções. O GAML possui dois operadores de mutação: um operador de mutação topológica que faz uma movimentação de tipo SPR na árvore e um operador de mutação de comprimentos de ramos, que vai alterando tais valores durante a execução do AG.

Nos experimentos, o GAML foi comparado com o software PAUP* (Swofford, 2000) (versão 3.1). O GAML foi capaz de fornecer resultados comparáveis ao PAUP* num tempo de execução muito menor. O GAML serviu de base para futuros desenvolvimentos do algoritmo (Brauer et al., 2002) e novas propostas de AEs (Mak e Lam, 2003; Zwickl, 2006). 
Pai 1

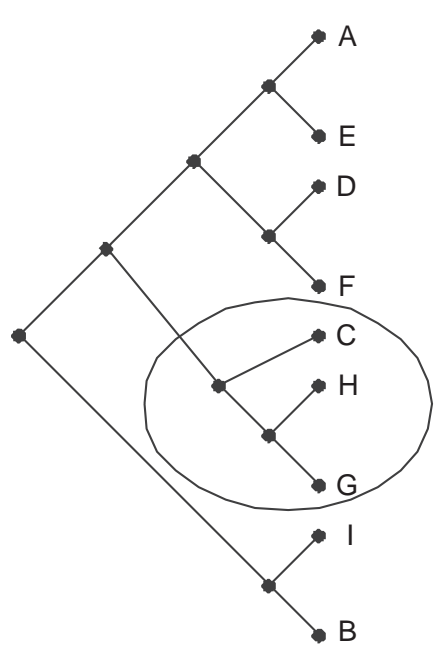

Pai 2

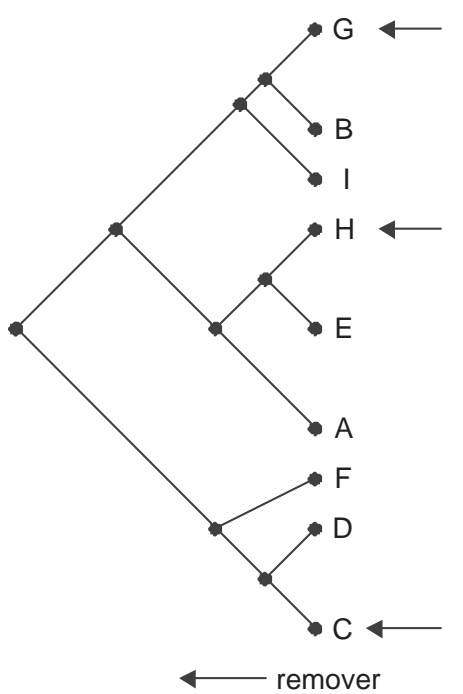

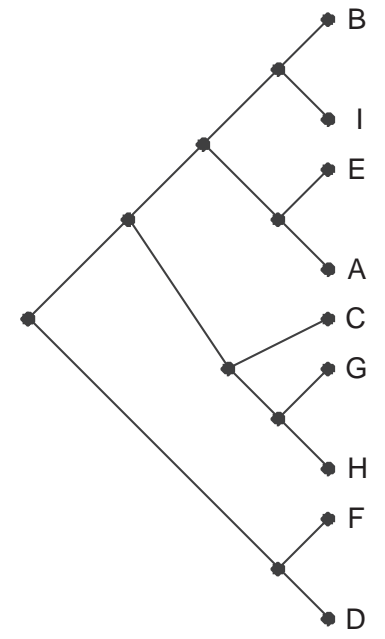

Figura 3.5: Operador de recombinação implementado no GAML (Lewis, 1998).

Katoh et al. (2001) desenvolveram o programa GA-mt, que é uma implementação paralela de um AE utilizando a biblioteca PVM (Geist et al., 1994). O GA-mt avalia a verossimilhança das soluções (considerando a heterogeneidade de taxas nos sítios) conforme ao modelo de substituição JTT (Jones et al., 1992) aplicado a seqüências de aminoácidos. O AG implementado nesse programa é da classe de algoritmos de estado estacionário (steady state): após a iteração inicial, cria-se apenas uma nova solução para nova geração, mantendo o restante de soluções da população anterior. A nova solução gerada entra na população se a sua aptidão for melhor que a aptidão de algum outro indivíduo. Assim, o GA-mt fornece um conjunto de soluções alternativas (não duplicadas). As árvores da população inicial são geradas pelos algoritmos de distância NJ (Saitou e Nei, 1987) ou WNJ (Bruno et al., 2000). O operador de recombinação no GA-mt é similar ao proposto no GAML; enquanto o operador de mutação faz uma modificação topológica do tipo TBR ou NNI. Segundo os autores, garantir a diversidade das soluções é um processo de alto custo computacional, razão pela qual tal processo é efeituado em paralelo. Nos experimentos, o GA-mt mostrou-se muito rápido em relação a heurísticas implementadas nos programas MOLPHY (Adachi e Hasegawa, 1996), fastDNAML (Olsen et al., 1994) e PHYLIP (Felsenstein, 2000b). Além disso, o GA-mt foi comparado com métodos de inferência baseados em distâncias como NJ (Saitou e Nei, 1987) e WNJ (Bruno et al., 2000), mostrando resultados mais consistentes quando se considerou o tamanho do conjunto de dados testado.

O trabalho de Lemmon e Milinkovitch (2002a,b) descreve o algoritmo METAPIGA, o qual introduz várias inovações em relação aos trabalhos anteriores. O METAPIGA é um AG que possui várias subpopulações (chamadas meta-populações) que ao invés de evoluir 
independentemente, colaboram na busca da árvore de máxima verossimilhança. As árvores das populações iniciais podem ser geradas por métodos aleatórios ou por amostragem de dados jacknife (Yang, 2006) usado conjuntamente com o método de agrupamento NJ (Saitou e Nei, 1987). METAPIGA também permite escolher entre várias abordagens para o método de seleção. Um outro elemento chave no algoritmo é o processo denominado poda por consenso (CP, do inglês consensus prunning), o qual identifica as regiões de consenso (partições) das árvores contidas nas subpopulações. As regiões de consenso são fixadas no decorrer as iterações tal que não podem ser modificadas pelos operadores de recombinação ou mutação. Desta forma, os operadores genéticos são guiados pelas comparações das melhores soluções entre as subpopulações. Uma conseqüência da utilização do CP, é que o número de regiões de consenso aumenta a medida que o algoritmo itera; enquanto o número de modificações permitidas diminui. Conseqüentemente, o espaço de busca é progressivamente reduzido levando a uma convergência rápida do algoritmo. A Figura 3.6 mostra como funciona a poda por consenso em duas árvores, bem como as operações permitidas nas regiões de consenso. O operador de recombinação do METAPIGA é baseado na troca de regiões de consenso entre duas soluções, como mostrado na Figura 3.7. O METAPIGA fornece várias formas mutação topológica (além das conhecidas NNI, SPR e TBR) e de comprimento de ramos. As taxas dos operadores de recombinação e mutação podem ser gerenciadas dinamicamente conforme a contribuição que cada operador faz para a melhora da aptidão das soluções. O critério de parada por defeito finaliza a execução do AG quando não existem mais modificações topológicas possíveis, embora seja permitido escolher outros critérios. Ao final da execução do METAPIGA, se realiza a otimização final dos comprimentos de ramos e dos parâmetros do modelo empregado. Nos experimentos, o METAPIGA foi comparado com os programas PAUP* (Swofford, 2000) e Mr.Bayes (Huelsenbeck e Ronquist, 2001) empregando conjuntos de dados de seqüências de nucleotídeos. Os resultados mostraram que o METAPIGA é bem mais rápido que as heurísticas convencionais, porém o ganho de desempenho depende do modelo substituição utilizado. Além disso, comparado a outras implementações, o METAPIGA fornece uma interface gráfica funcional e amigável para o usuário.

A tese de doutorado de Zwickl (2006) propõe o algoritmo denominado GARLI (Genetic Algorithm for Rapid Likelihood Inference). O GARLI foi projetado para melhorar o desempenho em relação a abordagens similares, permitindo analisar maiores bancos de seqüências em períodos de tempo menor. Tais objetivos são atingidos mediante uma série de inovações que permitem realizar a busca topológica e a otimização dos comprimentos de ramo de forma eficiente. Nessa última tarefa, reduz-se significativamente o número de operações numéricas requeridas. Na iteração inicial do GARLI, as soluções da população inicial podem ser geradas aleatoriamente ou especificadas pelo usuário. Posteriormente, são otimizados os parâmetros do modelo substituição GTR, o parâmetro $\alpha$ para a heterogeneidade dos sítios, a porcentagem de sítios invariantes e os comprimentos de ramos 

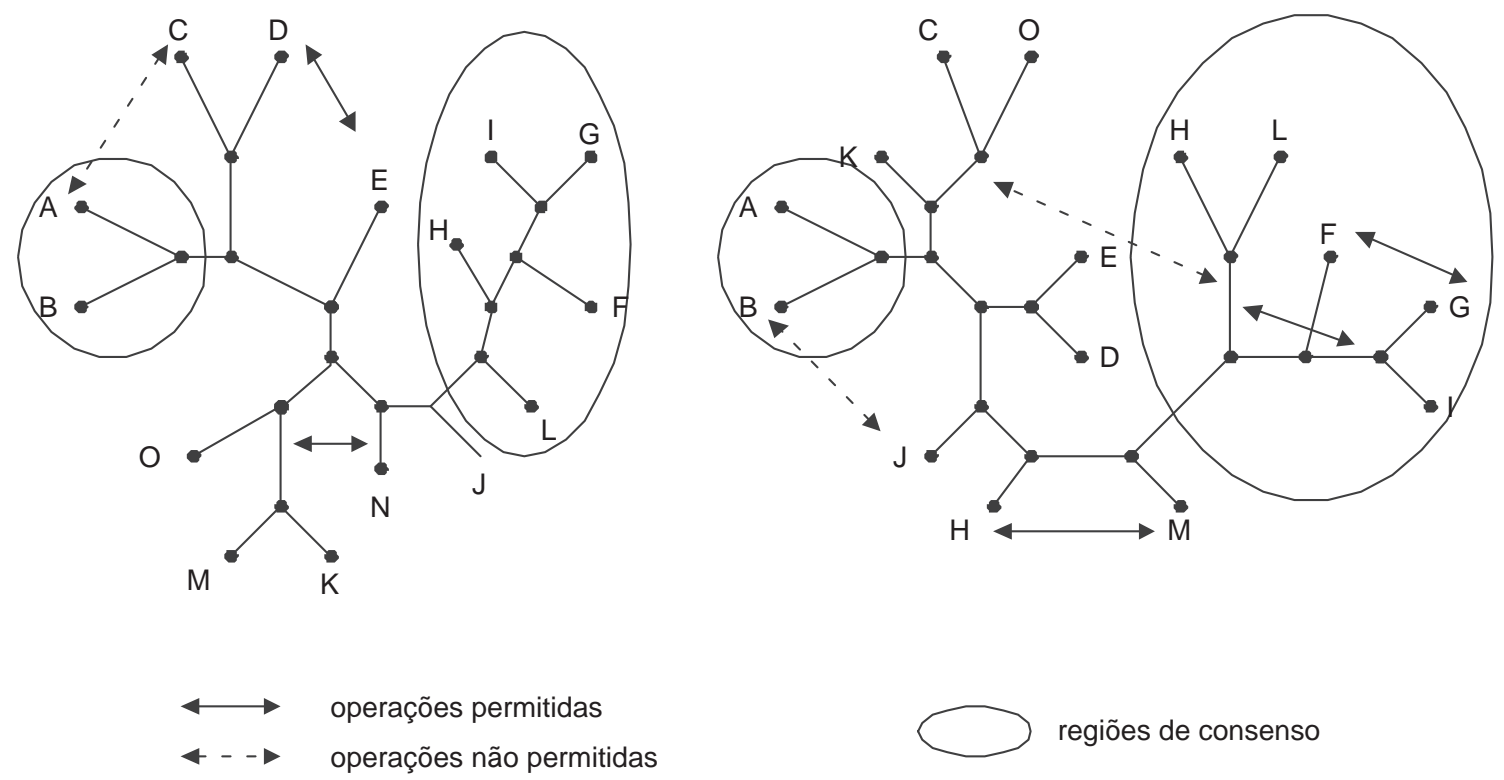

Figura 3.6: Exemplo do consenso por poda para duas árvores. As regiões de consenso definem as operações de troca de ramos e folhas que são permitidas (Lemmon e Milinkovitch, 2002a).

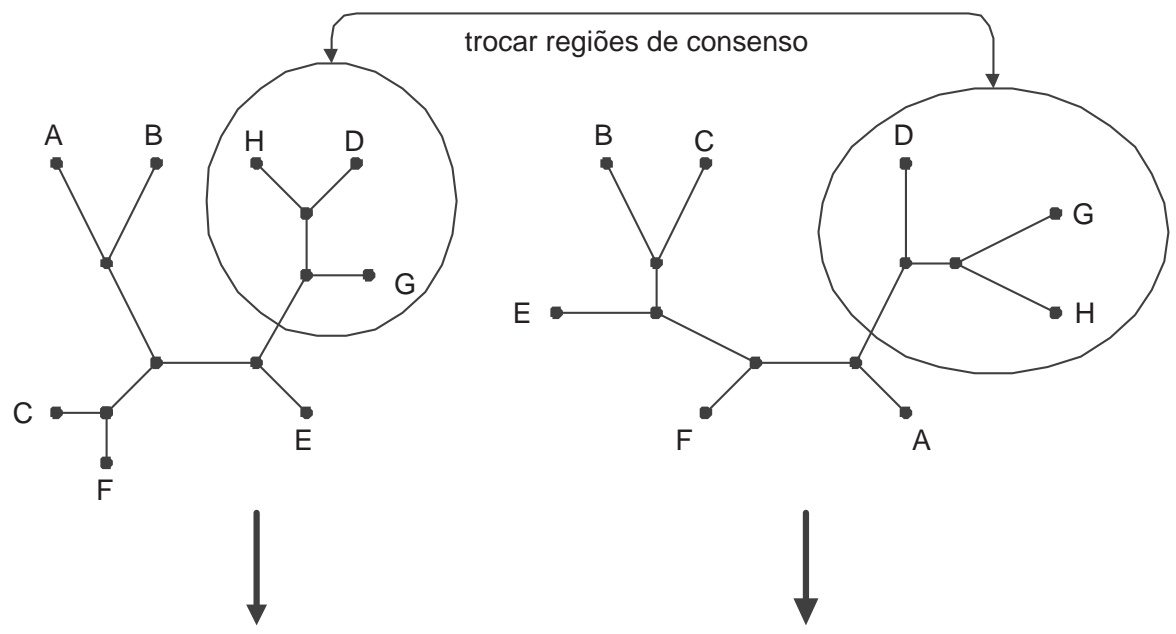

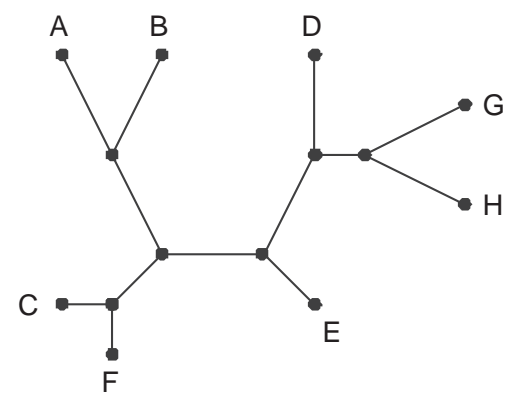

filho 1

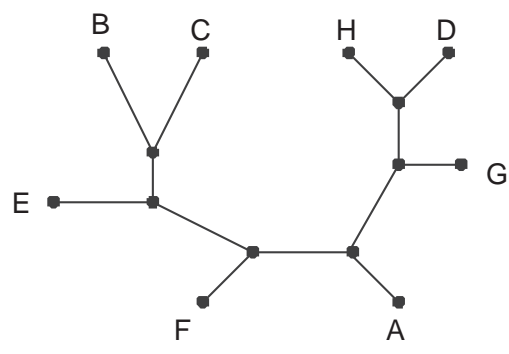

filho 2

Figura 3.7: Operador de recombinação do METAPIGA (Lemmon e Milinkovitch, 2002a). 
das topologias iniciais. O GARLI emprega um esquema de seleção baseado em ranking que permite controlar a pressão seletiva. A melhor solução é automaticamente escolhida e copiada diretamente para nova população (elitismo), enquanto os demais indivíduos são escolhidos aleatoriamente para serem processados pelos operadores de recombinação e mutação. Os tipos de mutação implementados são topológica, de parâmetros de modelo e de comprimentos de ramos. A mutação topológica realiza mudanças do tipo NNI e SPR, esta última pode ser controlada por um parâmetro que limita a distância entre os pontos de poda e reinserção da subárvore. A mutação do parâmetros do modelo de substituição e dos comprimentos de ramos multiplica tais valores por um número aleatório obtido de uma distribuição $\Gamma$ com média 1 e parâmetro $\alpha$ especificado. As taxas de aplicação dos operadores de mutação são modificadas dinâmicamente no decorrer das iterações. Assim, os operadores de mutação do modelo de substituição, que são caros computacionalmente, são efetuados apenas quando um ganho significativo de aptidão é esperado.

Uma das contribuições mais importantes do GARLI é o proposta de otimização dos comprimentos de ramos. Tal método é controlado por um parâmetro, denominado $\Delta_{b}$, que determina o ganho mínimo na verossimilhança após aplicar otimização para um ramo. Se o ganho não ultrapassar $\Delta_{b}$, então o ramo não é otimizado. Assim, o número de operações numéricas necessárias é consideravelmente reduzido. A otimização de comprimentos de ramos é realizada em cada modificação topológica do tipo SPR. Primeiramente, são otimizados os ramos diretamente afetados pelo operador SPR (ou seja, os ramos adjacentes ao ponto de poda e reinserção da árvore). Após isso, as otimizações são propagadas em ramos adjacentes aos anteriormente otimizados, de forma recursiva, desde que o ganho na verossimilhança seja maior que $\Delta_{b}$. Finalmente, todos os ramos que foram modificados no processo anterior são reotimizados. O parâmero $\Delta_{b}$ é diminuído progressivamente no decorrer das iterações do GARLI até que um certo valor mínimo é atingido. A Figura 3.8 mostra um exemplo do processo de otimização de comprimento de ramos adotado no GARLI. Após uma modificação topológica SPR, são otimizados os ramos indicados pelas linhas ponteadas (b1 da subárvore podada e b2, que é dividido em b1a e b2a após a reinserção). Posteriormente, os ramos adjacentes a b1,b2a, e b2b (indicados com setas) são otimizados recursivamente.

Existem 3 critérios de parada da execução do GARLI:

1. Se as modificações topológicas não encontram uma solução significativamente melhor durante um número especificado de iterações;

2. Se as melhoras atingidas forem menores que um certo valor;

3. Se o parâmetro $\Delta_{b}$ atingiu um valor mínimo.

Ao final da execução do GARLI, é feito um último ajuste dos comprimentos de ramos das soluções contidas na população final. Nos experimentos, comparou-se o desempe- 


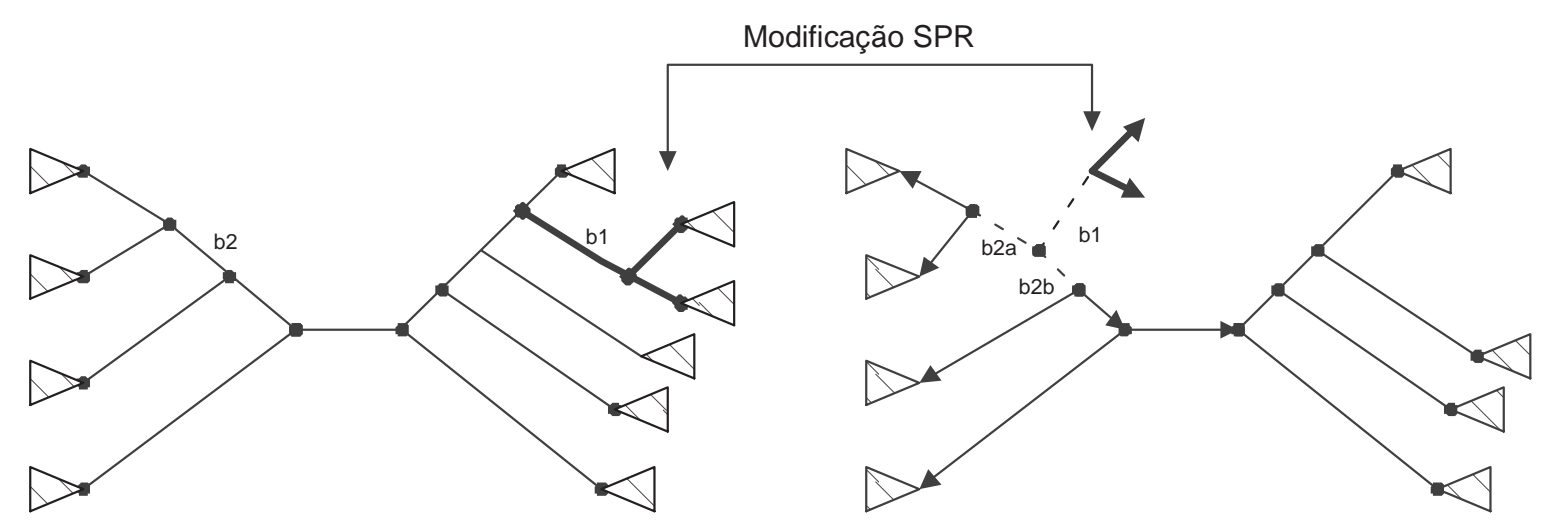

Figura 3.8: Algoritmo para otimização de comprimentos de ramos de GARLI (Zwickl, 2006).

nho do GARLI contra o PHYML (Guindon e Gascuel, 2003) e o RAxML (Stamatakis, 2005) (versão V) em vários bancos de nucleotídeos de diferentes graus de dificuldade. Os resultados mostraram que o GARLI produz resultados mais consistentes em bancos de seqüências maiores comparado aos concorrentes. O GARLI conta também com uma versão paralela do tipo mestre-escravo, chamada de P-GARLI. O funções do processo mestre são controlar a evolução do algoritmo, coletar as soluções dos processos escravos, determinar a migração de indivíduos e efetuar o operador de recombinação das soluções encontradas. Os processos escravos realizam o mesmo procedimento que a versão serial do algoritmo, comunicando-se com o mestre para enviar-lhe a melhor solução encontrada.

Existem ainda outros trabalhos que utilizam AEs para o critério de máxima verossimilhança. Mais informações pode ser encontrada na literatura pertinente (Prado, 2002; Skourikhine, 2000).

\subsubsection{Aplicação de AEs com o critério de máxima parcimônia}

O trabalho de Moilanen $(1999,2001)$ apresenta o programa PARSIGAL, que emprega AGs e o critério de máxima parcimônia na construção de árvores filogenéticas. O PARSIGAL é um algoritmo híbrido que combina o operador recombinação com estratégias de busca local. O operador de recombinação é baseado em troca de subárvores. No lugar do operador de mutação, é realizada uma busca de tipo NNI e TBR nas soluções encontradas pelo algoritmo. Assim, enquanto o AG define a região do espaço de busca que contém a solução ótima, o operador de busca local permite chegar a tal ótimo de forma rápida. Uma outra contribuição relevante desse trabalho é a proposta de uma abordagem eficiente para calcular o valor de parcimônia mediante operações lógicas de bits. De acordo com o autor, o desempenho do PARSIGAL foi comparável a de programas que empregam o critério de parcimônia como o NONA (Goloboff, 1999a,b) e o Hennig86 (Farris, 1988). 
O programa GAPhyl é descrito pela série de trabalhos de Congdon (2002); Congdon e Greenfest (2000); Congdon e Septor (2003). O AG proposto avalia as soluções segundo o critério de parcimônia de Wagner (Farris, 1970). O GAPhyl usa várias subpopulações que evoluem de forma independente. A cada certo número de iterações, um conjunto de soluções é trocado entre as várias subpopulações. O intervalo entre cada migração e o número de soluções a serem migradas são fornecidos como parâmetros do AG. Esse mecanismo evita a convergência prematura para soluções subótimas. Nos experimentos, o GAPhyl foi comparado como o PHYLIP (Felsenstein, 2000b) para seqüências de nucleotídeos. Porém, conforme aos autores do trabalho, os resultados obtidos não indicam os possíveis benefícios da aplicação do AG.

Existem ainda outros trabalhos relativos ao emprego de AEs no problema de filogenia, que utilizam critérios de otimalidade baseados em medidas de distância (Cotta e Moscato, 2002; Reijmers et al., 1999).

\subsection{Considerações finais}

Neste Capítulo foi introduzida a Computação Evolutiva como uma área de pesquisa que abrange um conjunto de algoritmos que tem por base simular ou reproduzir princípios da genética e evolução natural. Neste contexto, os AGs têm-se destacado como técnicas de busca e aprendizado de máquina que têm sido intensamente aplicadas a problemas de otimização. O funcionamento de um AG, os seus principais componentes, as formas de representar as soluções, os principais tipos de operadores de seleção, recombinação e mutação foram apresentados. Além disso, foram ressaltadas as principais características dos AGs que os diferenciam de técnicas de otimização tradicionais.

Como explicado no Capítulo 2, o problema de reconstrução filogenética pode ser visto como um problema de otimização, onde um determinado critério de otimalidade avalia as soluções no espaço de busca de topologias. Assim, o emprego de AEs surge como uma alternativa viável para tratar este problema devido a suas dificuldades inerentes. Uma revisão bibliográfica da aplicação dos AEs para encontrar as árvores de máxima verossimilhança e máxima parcimônia foi apresentada. Em tais trabalhos, a aplicação dos AEs está restringido ao emprego de um critério de otimalidade para avaliar as topologias. Contudo, problemas com vários objetivos são comuns em aplicações reais. O emprego de AEs pode ser estendido para tais problemas. O próximo Capítulo apresenta uma abordagem de AEs para problemas com vários objetivos a serem otimizados. 


\section{CAPÍtulo \\ 4 \\ Algoritmos evolutivos para otimização multi-objetivo}

\subsection{Introdução}

A otimização multi-objetivo aborda os problemas de otimização que possuem vários objetivos a serem simultaneamente atingidos. Para este tipo de problema, existe um conjunto de soluções que representa um compromisso entre os objetivos. Diversas técnicas de otimização tradicionais têm sido propostas na literatura (Coello et al., 2002; Deb, 2001). Embora essas técnicas garantam encontrar o conjunto de soluções ótimas, em geral, precisam de bastante conhecimento sobre o espaço de busca do problema. Devido a esta limitação uma série de técnicas heurísticas e estocásticas têm sido desenvolvidas dentre as quais têm-se destacado os AEs (Coello et al., 2002; Deb, 2001).

O restante deste Capítulo está organizado em 5 seções. A Seção 4.2 apresenta os principais conceitos teóricos sobre otimização multi-objetivo. A Seção 4.3 descreve as principais técnicas de otimização tradicional empregadas nos problemas de otimização multi-objetivo. A Seção 4.3 apresenta os AEs para otimização multi-objetivo destacando o algoritmo NSGA-II (Deb et al., 2000). A Seção 4.5 mostra uma revisão das principais abordagens multi-objetivo aplicados a filogenia. Finalmente, a Seção 4.6, sintetiza os principais pontos considerados neste Capítulo. 


\subsection{Otimização multi-objetivo}

Esta Seção introduz vários conceitos e propriedades dos problemas de otimização multiobjetivo (MOOPs, do inglês Multi-objective Optimization Problems) (Coello et al., 2002; Deb, 2001) envolvendo a modelagem formal de MOOPs, as características das soluções para esses problemas e as diferenças entre otimização simples de multi-objetivo.

\subsubsection{Formulação}

Um MOOP possui um conjunto de funções objetivo a serem otimizadas (maximizar ou minimizar). Além disso, possui restrições que devem de ser satisfeitas para que uma solução seja factível para o problema. O enunciado geral de um MOOP é o seguinte (Deb, 2001):

$$
\left.\begin{array}{cll}
\operatorname{maximizar} / \operatorname{minimizar} & f_{m}(\mathbf{x}), & m=1,2, \ldots, N_{\text {obj }} \\
\text { restrita a } & g_{j}(\mathbf{x}) \geq 0, & j=1,2, \ldots, N R_{\text {des }} ; \\
& h_{k}(\mathbf{x})=0, & k=1,2, \ldots, N R_{\text {igu }} ; \\
& x_{i}^{(\text {inf })} \leq x_{i} \leq x_{i}^{(\text {sup })}, & i=1,2, \ldots, N_{\text {var }}
\end{array}\right\}
$$

onde $\mathbf{x}$ é um vetor de $N_{v a r}$ variáveis de decisão $\mathbf{x}=\left(x_{1}, x_{2}, \ldots, x_{N_{v a r}}\right)^{T}$ também denominado de solução. Os valores $x_{i}^{(i n f)}$ e $x_{i}^{(\text {sup })}$ representam os limites inferior e superior, respectivamente, para a variável $x_{i}$. Esses limites definem o espaço de variáveis de decisão ou espaço de decisão $S_{\text {dec }}$. As $N R_{\text {des }}$ desigualdades $\left(g_{j}\right)$ e as $N R_{\text {igu }}$ igualdades $\left(h_{k}\right)$ são chamadas de funções de restrição. Uma solução x factível satisfaz as $N R_{i g u}+N R_{\text {des }}$ funções de restrição e os $2 N_{\text {var }}$ limites. Caso contrário, a solução não será factível. O conjunto de todas as soluções factíveis formam a região factível ou espaço de busca $S_{\text {fact }}$.

Cada função $f_{m}(\mathbf{x})$ pode ser maximizada ou minimizada. Porém, para trabalhar com os algoritmos de otimização, é necessário converter todas as funções para serem apenas maximização ou minimização. O vetor funções objetivo $\mathbf{f}(\mathbf{x})=\left(f_{1}(\mathbf{x}), f_{2}(\mathbf{x}), \ldots, f_{N_{o b j}}(\mathbf{x})\right.$ compõe um espaço multidimensional chamado espaço de objetivos $S_{o b j}$. Para cada solução $\mathbf{x}$ no espaço de decisão, existe um $\mathbf{f}(\mathbf{x})$ em $S_{o b j}$. Esta é uma diferença fundamental em relação à otimização de objetivos simples, cujo espaço de objetivos é unidimensional. O mapeamento ocorre então entre um vetor $\mathbf{x}$ (de dimensão $N_{\text {var }}$ ) e um vetor $\mathbf{f}(\mathbf{x}$ ) (de dimensão $\left.N_{o b j}\right)$. Por exemplo, se cada elemento de $\mathbf{x}$ e $\mathbf{f}(\mathbf{x})$ são números reais, então $\mathbf{f}(\mathbf{x})$ estaria mapeada como $\mathbf{f}(\mathbf{x}): \mathbb{R}^{N_{v a r}} \rightarrow \mathbb{R}^{N_{o b j}}$. 


\subsubsection{Soluções Pareto-ótimas}

Em um MOOP, emprega-se o conceito de dominância de Pareto para comparar duas soluções factíveis do problema. Dadas duas soluções $\mathbf{x}_{\mathbf{1}}$ e $\mathbf{x}_{\mathbf{2}}$, diz-se que $\mathbf{x}_{\mathbf{1}}$ domina a $\mathbf{x}_{\mathbf{2}}$ (denotado como $\mathbf{x}_{\mathbf{1}} \preceq \mathbf{x}_{\mathbf{2}}$ ) se as seguintes condições são satisfeitas:

1. A solução $\mathbf{x}_{1}$ é pelo menos igual a $\mathbf{x}_{2}$ em todas funções objetivo;

2. A solução $\mathbf{x}_{1}$ é superior a $\mathbf{x}_{2}$ em pelo menos uma função objetivo.

As funções objetivo empregadas nos MOOPs são em geral conflitantes entre sim. Uma função objetivo $f_{1}$ é conflitante com uma outra função $f_{2}$ quando não é possível melhorar o valor de $f_{1}$ sem piorar o valor da função $f_{2}$. Um exemplo prático de objetivos conflitantes são preço e desempenho na compra de equipamentos, por exemplo, de computadores. Os computadores de maior custo são usualmente os de melhor desempenho e vice-versa. Assim, em uma compra devem ser considerados vários modelos de computadores com diversos valores nos objetivos de preço e desempenho. Se ambos os objetivos possuem a mesma importância, não há como afirmar, por exemplo, que certa redução do preço compensa certa perda de desempenho. Assim, existe um conjunto de soluções que possuem vantagens em desempenho mas que não são melhores em custo e vice-versa. Ou seja, existe um conjunto de alternativas ótimas que são não dominadas entre sim nos objetivos custo e desempenho. Em um MOOP, o conjunto de soluções não dominadas é chamado de conjunto Pareto-ótimo, o qual representa as soluções ótimas do problema. A fronteira de Pareto é o conjunto de valores das funções objetivo das soluções do conjunto Paretoótimo. A Figura 4.1 mostra os valores de preço e desempenho (de 0 a 100) de vários alternativas para o exemplo de compra de computadores. Nessa Figura são mostradas a relação de dominância entre as soluções, o conjunto Pareto-ótimo e a fronteira do Pareto.

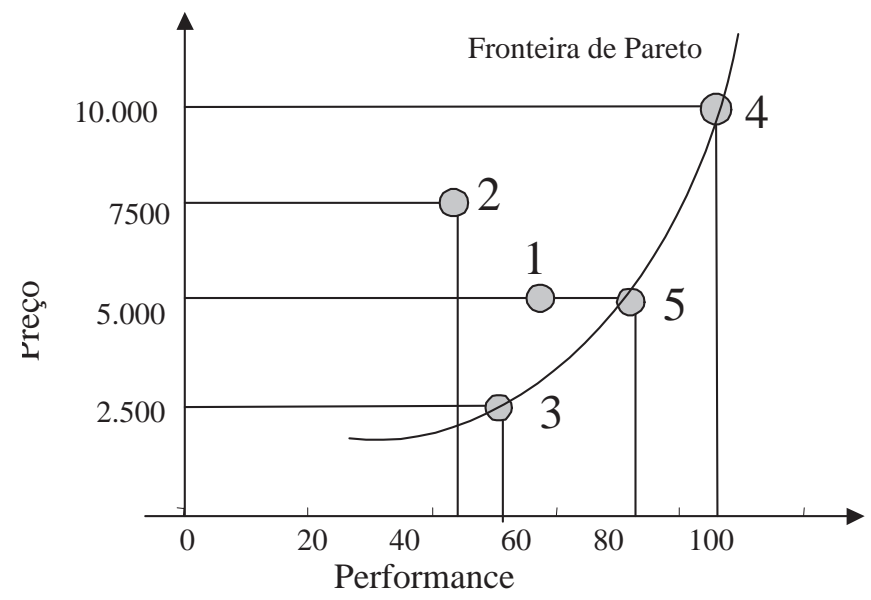

$$
\begin{aligned}
& \text { Relações de dominância } \\
& 3 \preceq 2,5 \preceq 1,5 \preceq 2 \\
& \text { Conjunto Pareto-ótimo }=\{3,4,5\}
\end{aligned}
$$

Figura 4.1: Exemplo que ilustra o preço e a desempenho de várias opções (1-5) de compra de computadores. 


\subsubsection{Metas em otimização multi-objetivo}

Se a informação adicional sobre importância relativa dos objetivos é desconhecida, todas as soluções Pareto-ótimas são igualmente importantes. Deb (2001) assinala duas importantes metas em otimização multi-objetivo:

1. Encontrar um conjunto de soluções que esteja o mais próximo possível da fronteira de Pareto;

2. Encontrar um conjunto de soluções com a maior diversidade possível.

A primeira meta é comum a qualquer processo de otimização. Soluções muito distantes da fronteira de Pareto não são desejáveis. Por outro lado, encontrar a maior diversidade dentro das soluções é uma meta específica para a otimização multi-objetivo. A Figura 4.2(a) mostra uma distribuição quase uniforme de soluções na fronteira de Pareto. A Figura 4.2(b) apresenta a fronteira com as soluções apenas em algumas regiões, isto é, com baixa diversidade. É necessário assegurar a maior cobertura possível da fronteira, buscando um conjunto de soluções "comprometidas" com os objetivos desejados. Como em MOOP trabalha-se com o espaço de decisões e o espaço de objetivos, é também desejável que as soluções estejam adequadamente distribuídas em ambos os espaços. Em geral, a diversidade em um desses espaços garante também a diversidade no outro. Para alguns problemas, entretanto, isso não acontece.

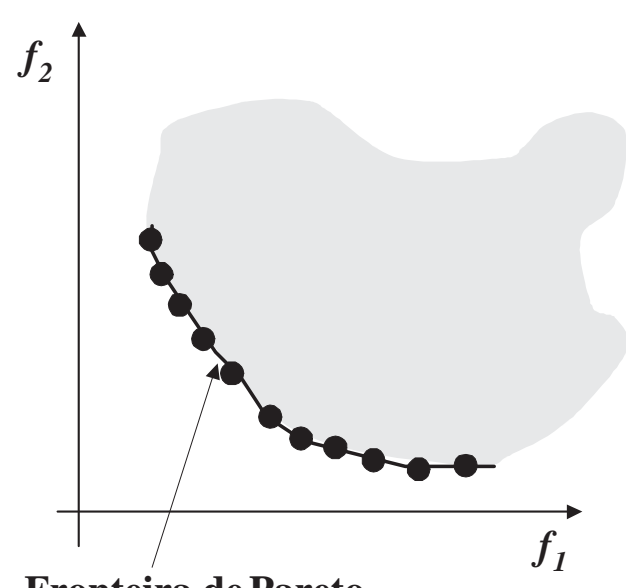

Fronteira dePareto

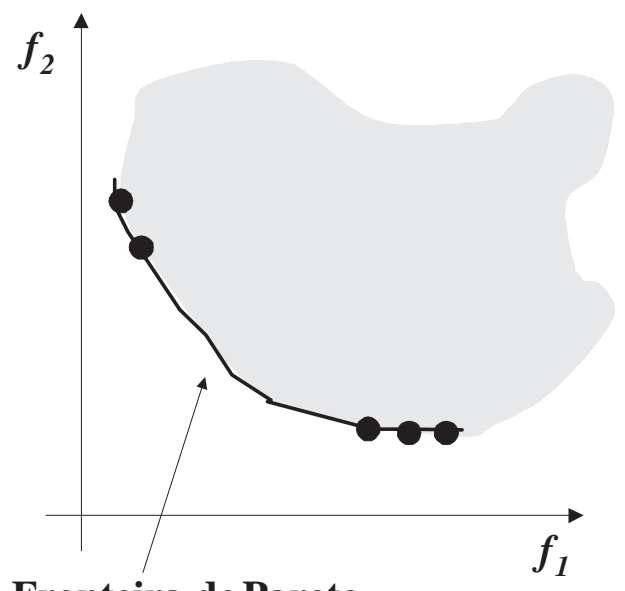

Fronteira dePareto

(a)

(b)

Figura 4.2: Diferentes distribuições de soluções na fronteira de Pareto.

\subsubsection{Diferenças com a otimização de objetivos simples}

Deb (2001) identifica três importantes aspectos que diferenciam a otimização multiobjetivo e a otimização de objetivo simples: 
1. Em problemas de otimização com um único objetivo, a meta é encontrar uma solução ótima global. Se a função objetivo desses problemas fosse multimodal, pode existir mais de um ótimo global. Neste caso, todos os ótimos são equivalentes. Por outro lado, em MOOP, determinar o conjunto de soluções da fronteira de Pareto é tão importante quanto preservar a diversidade neste conjunto. Um algoritmo eficiente para otimização multi-objetivo deve considerar ambos os aspectos;

2. Um MOOP trabalha com dois espaços (das variáveis e dos objetivos) ao invés de um. Problemas de objetivo simples trabalham unicamente no espaço de variáveis, pois procuram apenas uma solução no espaço de objetivos. Manter a diversidade em ambos espaços complica mais o problema, dado que a proximidade de duas soluções no espaço de variáveis não implica proximidade no espaço de objetivos.

3. Os métodos tradicionais de otimização multi-objetivo reduzem o conjunto de funções objetivo a uma função simples a qual pondera cada objetivo. Estes métodos podem também tratar cada objetivo separadamente, utilizando os demais objetivos como restrições. Portanto, um MOOP pode ser convertido por meio de algumas técnicas, em um problema de otimização simples.

\subsection{Técnicas tradicionais para MOOP}

Nesta Seção serão descritas as principais técnicas tradicionalmente utilizadas em MOOP: somatório de pesos (Seção 4.3.1), método de restrições $\epsilon$ (Seção 4.3.2) e programação por metas (Seção 4.3.3). A Seção 4.3.4 discute as vantagens e desvantagens de tais técnicas.

\subsubsection{Somatório de pesos}

O método de somatório dos pesos consiste em criar uma função objetivo somando cada objetivo multiplicado por um peso (Deb, 2001). Os pesos são fornecidos como parâmetros. A escolha dos pesos é um problema importante que depende da relevância de cada objetivo. É necessário realizar a normalização de cada função objetivo dado que os diferentes objetivos podem ter diferentes magnitudes. Por exemplo, o preço de um carro pode variar de $\mathrm{R} \$ 4.000$ a $\mathrm{R} \$ 30.000$; enquanto o conforto pode estar entre $0 \%$ e $100 \%$.

Uma vez que os objetivos estejam normalizados, pode-se formular uma função $F(\mathbf{x})$ que soma os objetivos normalizados e multiplicados por seus respectivos pesos. Assim, um MOOP pode ser formulado como segue: 


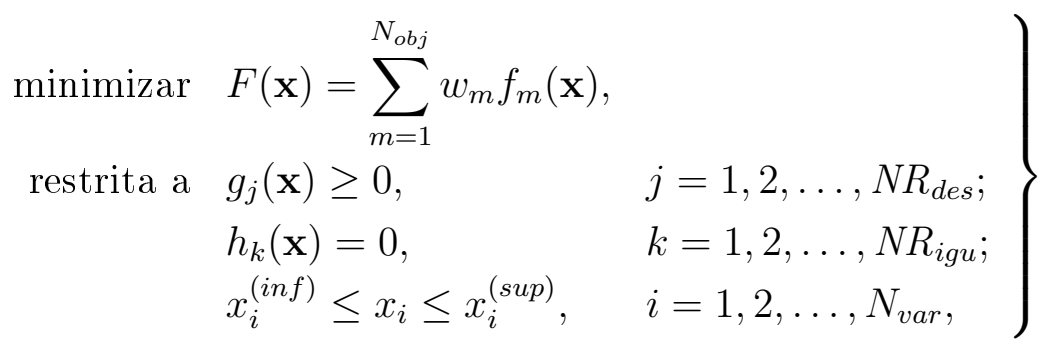

onde $w_{m} \in[0,1]$ é o peso para cada função objetivo $f_{m}$. Pode-se mostrar que a solução do problema na Equação 4.2 pertence ao conjunto Pareto-ótimo se os pesos são positivos para todos os objetivos. Além disso, é garantido que quando um MOOP é convexo (Deb, 2001), qualquer solução Pareto-ótima pode ser encontrada usando o método de somatório dos pesos, empregados diferentes combinações de valores de $w_{m}$.

Embora esse método seja simples, precisa de várias iterações para atingir toda a fronteira de Pareto. No caso de um MOOP não convexo, este método não é capaz de determinar todas as soluções. Além disso, a aplicação de vetores de pesos uniformemente distribuídos não garante que seja obtido um conjunto de soluções uniformemente distribuídas.

\subsubsection{Método de restrições $\varepsilon$}

Haimes et al. (1971 apud Deb, 2001), sugeriram reformular um MOOP considerando qualquer objetivo, mantendo restritos os demais objetivos com valores definidos pelo usuário. A formulação adotada é a seguinte:

$$
\left.\begin{array}{cll}
\operatorname{minimizar} & f_{u}(\mathbf{x}), & \\
\text { restrita a } & f_{m}(\mathbf{x}) \leq \varepsilon_{m}, & m=1,2, \ldots, N_{o b j} \text { e } m \neq u ; \\
& g_{j}(\mathbf{x}) \geq 0, & j=1,2, \ldots, N R_{\text {des }} ; \\
& h_{k}(\mathbf{x})=0, & k=1,2, \ldots, N R_{\text {igu }} ; \\
& x_{i}^{(L)} \leq x_{i} \leq x_{i}^{(U)}, \quad i=1,2, \ldots, N_{\text {var }},
\end{array}\right\}
$$

onde cada $\varepsilon_{m}$ definido pelo usuário representa um limite máximo para o valor de $f_{m}$. Seja um MOOP não convexo de dois objetivos $f_{1}$ e $f_{2}$. Escolhe-se $f_{2}$ e mantém-se $f_{1}$ com a restrição $f_{1} \leq \varepsilon_{1}$.

A Figura 4.3 apresenta o espaço de objetivos e vários valores para $\varepsilon_{1}$. O mínimo para $f_{2}$ depende da escolha do $\varepsilon$. Por exemplo, usando $\varepsilon_{1}^{c}$, o valor mínimo para $f_{2}$ é ponto C. Então, empregando valores diferentes de $\varepsilon$, encontra-se diferentes soluções Pareto-ótimas.

Desta forma, o método de restrições $\varepsilon$ pode ser usado para gerar as soluções Paretoótimas independentemente de o espaço de objetivos ser convexo, não convexo ou discreto (Deb, 2001). Este método necessita que a escolha do vetor $\varepsilon$ esteja em uma região factível para cada objetivo. Por exemplo, na Figura 4.3, se for escolhido $\varepsilon_{1}^{a}$, então nenhuma solução será obtida. Assim, como no somatório de pesos, são precisas vários iterações para 


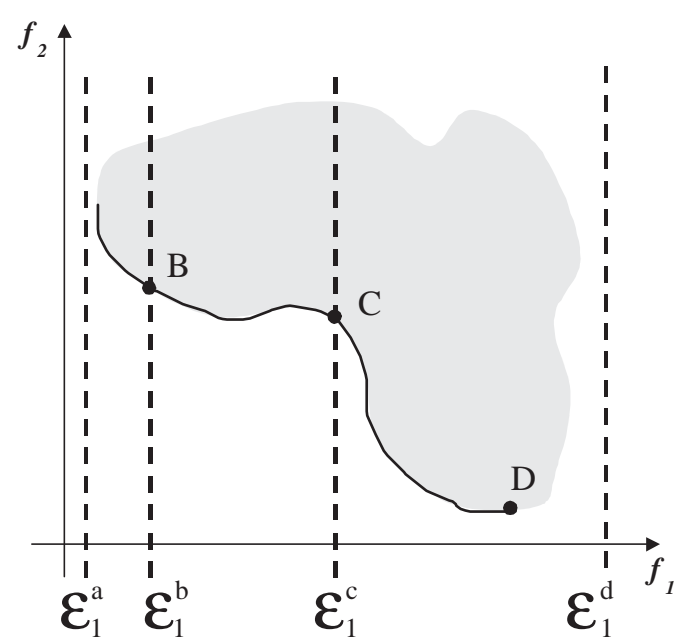

Figura 4.3: Método de restrições $\varepsilon$ (Deb, 2001).

determina a fronteira de Pareto e o uso de uma distribuição uniforme de $\varepsilon$ não garante que um conjunto de soluções com a mesma distribuição.

\subsubsection{Programação por metas}

Esta técnica tenta encontrar soluções que possam atingir uma meta predeterminada para uma ou mais funções objetivo. Caso não exista uma solução factível que alcance as metas para todos os objetivos, esta minimiza os desvios em relação às metas.

Considere uma função $f(\mathbf{x})$ para ser minimizada dentro do espaço de busca $S_{\text {fact }}$. Para cada objetivo é escolhido pelo usuário um valor meta $z$. Então, o problema é formulado para encontrar uma solução cujo valor em $f$ seja igual a $z$. Formalmente:

$$
\begin{aligned}
\text { meta } & (f(\mathbf{x})=z), \\
& \mathbf{x} \in S_{\text {fact }}
\end{aligned}
$$

Para resolver um problema de programação de metas, cada meta é convertida em uma restrição de igualdade. Busca-se, então, minimizar todos os desvios em relação as metas. Existem várias formas de trabalhar com esses problemas, as quais serão descritas a seguir:

- Programação de metas com pesos: para um problema com $N_{o b j}$ objetivos, formulase uma função somando os desvios para cada um dos $N_{o b j}$ objetivos. A forma geral é: 


$$
\left.\begin{array}{rlr}
\operatorname{minimizar} & \sum_{j=1}^{N_{o b j}}\left(\alpha_{j} \phi_{j}+\beta_{j} \eta_{j}\right) & \\
\text { restrita a } & f_{j}(\mathbf{x})-\phi_{j}+\eta_{j}=z_{j}, \quad j=1,2, \ldots, N_{o b j} \\
& \mathbf{x} \in S_{f a c t}, & \\
& \phi_{j}, \eta_{j} \geq 0, & j=1,2, \ldots, N_{o b j},
\end{array}\right\}
$$

onde $\alpha_{j}$ e $\beta_{j}$ são os pesos dos desvios positivo e negativo $\left(\phi_{j}\right.$ e $\eta_{j}$, respectivamente) para o $j$-ésimo objetivo, $z_{j}$ é a meta para a função $f_{j}$ e $S_{f a c t}$ é o espaço de decisão factível. As soluções obtidas por este método dependem consideravelmente da escolha dos valores para $\alpha_{j}$ e $\beta_{j}$. Além disso, segundo Deb (2001), este método possui dificuldades similares ao método do somatório dos pesos;

- Programação de metas lexicográficas: aqui as metas são organizadas em vários níveis de prioridade. Resolve-se seqüencialmente vários problemas de programação de metas. Inicialmente, as metas de primeira ordem de prioridade são consideradas na formulação do problema. Caso existam múltiplas soluções, as metas de segunda ordem de prioridade são consideradas formulando outro problema para minimizar apenas os desvios para as metas de segunda ordem. As metas de primeira ordem de prioridade são usadas como restrições. O processo continua com os demais níveis de prioridade até que seja encontrada uma única solução. Utilizando este método, é encontrada freqüentemente uma solução Pareto-ótima. A Figura 4.4 mostra um espaço de objetivos para as funções $f_{1}$ e $f_{2}$. Se $f_{1}$ é mais importante, minimiza-se $f_{1}$ primeiro e obtém-se as soluções das regiões $A B$ e $C D$ nas quais $f_{1}$ é mínima. Dado que existem múltiplas soluções, minimiza-se $f_{2}$ somente nas regiões $A B$ e $C D$ encontradas na iteração anterior. A solução é o ponto $D$, que corresponde ao mínimo para $f_{2}$. Então, $D$ é a solução para todo o problema de programação de metas lexicográficas.

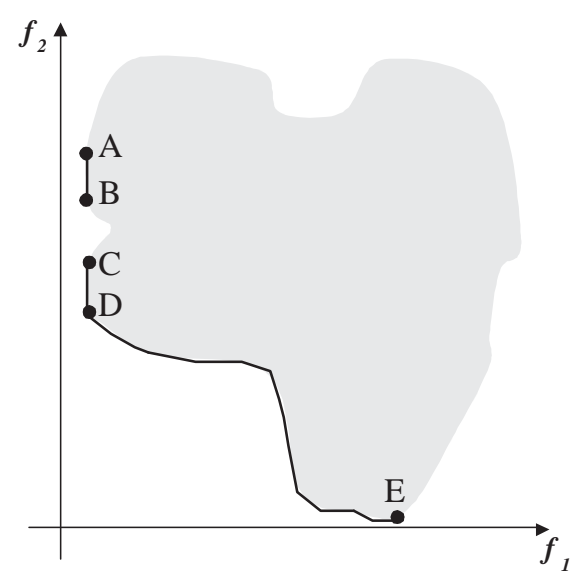

Figura 4.4: Método da programação de metas lexicográficas (Deb, 2001). 
- Programação de metas min-max: neste método é minimizado o máximo desvio em relação às metas. A formulação adotada é a seguinte:

$$
\left.\begin{array}{rlr}
\text { Minimizar } & \delta & \\
\text { restrita a } & \alpha_{j} \phi_{j}+\beta_{j} \eta_{j} \leq \delta, & j=1,2, \ldots, N_{o b j} \\
& f_{j}(\mathbf{x})-\phi_{j}+\eta_{j}=z_{j}, & j=1,2, \ldots, N_{o b j} \\
& \mathbf{x} \in S_{f a c t}, & \\
& \phi_{j}, \eta_{j} \geq 0, & j=1,2, \ldots, N_{o b j},
\end{array}\right\}
$$

onde $\delta$ é o desvio máximo para qualquer meta, $\phi_{j}$ e $\eta_{j}$ são os desvios positivos e negativos para cada objetivo, respectivamente e $\alpha_{j}$ e $\beta_{j}$ representam os pesos para cada desvio. Este método requer também a escolha dos pesos $\alpha_{j}$ e $\beta_{j}$.

\subsubsection{Vantagens e desvantagens das técnicas tradicionais}

A principal vantagem das técnicas tradicionais é que possuem provas de convergência que garantem encontrar as soluções Pareto-ótimas (Coello et al., 2002; Deb, 2001). Todas as técnicas descritas neste Capítulo reduzem um MOOP para um problema de objetivo simples. Cada técnica utiliza uma forma diferente de redução e introduz parâmetros adicionais. A escolha desses parâmetros afeta diretamente os resultados obtidos. Cada vez que os parâmetros são modificados, é necessário resolver um novo problema de otimização simples. Portanto, para encontrar cada solução Pareto-ótima, precisa-se solucionar um problemas de objetivos simples.

Alguns métodos não garantem soluções ao longo de toda a fronteira de Pareto. Se esta não é convexa, o método do somatório dos pesos não encontra certas soluções, independentemente dos pesos escolhidos.

Finalmente, todos as técnicas descritas precisam de parâmetros adicionais, tais como pesos, metas, e vetores de restrição. A distribuição uniforme destes parâmetros não garante a diversidade das soluções Pareto-ótimas. Porém, existem técnicas alternativas para tratar MOOPs. Dentre dessas técnicas, destacam-se os AEs (principalmente AGs) que apresentam vários aspectos positivos que motivam a aplicação dos mesmos. Na próxima Seção, será tratada a aplicação de AEs em MOOPs.

\subsection{Algoritmos evolutivos para problemas otimização multi-objetivo}

A primeira implementação de um MOEA (do inglês Multi-Objective Evolutionary Algorithm) foi proposta por Schaffer (1985). O modelo sugerido foi denominado VEGA (do 
inglês Vector Evaluated Genetic Algorithm). Schaffer fez uma modificação no AG convencional para avaliar cada objetivo separadamente. Contudo, o método proposto não permitia obter uma diversidade adequada nas soluções ao longo da fronteira de Pareto.

Goldberg (1989) propôs várias abordagens para estender a aplicações de AGs para MOOPs. Uma das propostas utiliza um procedimento para ordenação de soluções baseado no conceito de dominância. Neste método, o valor de aptidão para uma solução $i$ é proporcional ao número de soluções que $i$ domina. Desta forma, as soluções não dominadas são enfatizadas obtendo maior quantidade de cópias na lista de reprodução. Para manter a diversidade das soluções, Goldberg sugeriu o emprego de um método de compartilhamento (Goldberg, 1989), que permite levar em conta a densidade de soluções em uma vizinhança no espaço de busca. Assim, soluções que estejam melhor espalhadas na fronteira de Pareto têm um melhor valor de compartilhamento. Baseadas nessas idéias iniciais, foram propostos uma série de modelos de MOEAs.

A diferença fundamental dos MOEAs em relação aos AEs tradicionais é o operador de seleção, dado que a comparação entre duas soluções deve-se efeituar conforme o conceito de dominância de Pareto. Em alguns métodos, o valor de aptidão é proporcional à dominância da solução. Outros métodos utilizam apenas a dominância de Pareto e não calculam um valor de aptidão. A aplicação dos MOEAs para MOOPs apresenta três grandes vantagens com relação às técnicas tradicionais descritas na Seção 4.3 (Coello, 2001):

1. Não introduzem parâmetros adicionais no problema;

2. Trabalham diretamente com várias funções usando o conceito de dominância de Pareto;

3. Um conjunto diversificado de soluções pode ser encontrado apenas em uma execução do MOEA.

Os modelos de MOEA são classificados por Deb (2001) em dois tipos:

1. Não elitistas: são aqueles modelos que, como o próprio nome indica, não utilizam alguma forma de elitismo nas suas iterações;

2. Elitistas: são os modelos que empregam alguma forma o elitismo. Alguns modelos, como o SPEA (Zitzler e Thiele, 1998) e o PESA (Corne et al., 2000) (ver Tabela 4.1, que enumera os principais modelos de MOEAs), utilizam uma população externa onde são armazenadas as soluções não dominadas encontradas até o momento. Outros métodos, como o NSGA-II (Deb et al., 2000), combinam a população atual com a população anterior para preservar as melhores soluções de ambas. O estudo 
realizado por Zitzler et al. (2000) conclui que o elitismo melhora as soluções encontradas por um modelo MOEA. A partir deste trabalho, os novos modelos passam a incorporam alguma estratégia de elitismo.

Tabela 4.1: Diferentes modelos de MOEAs.

\begin{tabular}{|c|c|c|}
\hline Sigla & Nome do modelo & Elistista \\
\hline VEGA (Vector Evaluated Genetic Algorithm) & (Schaffer, 1985) & Não \\
\hline WBGA (Weight Based Genetic Algorithm) & (Hajela e Lin, 1992) & Não \\
\hline MOGA (Multiple Objective Genetic Algorithm) & $\begin{array}{l}\text { (Fonseca e Fleming, } \\
1993 \text { ) }\end{array}$ & Não \\
\hline NSGA (Non-Dominated Sorting Genetic Algorithm) & (Srinivas e Deb, 1994) & Não \\
\hline NPGA & et al., 1994) & Não \\
\hline PPES (Predator-Prey Evolution Strategy) & $\begin{array}{l}\text { (Laumanns et al., } \\
\text { 1998) }\end{array}$ & Não \\
\hline $\begin{array}{l}\text { REMOEA (Rudolph's Elitist Multi-Objective Evoluti- } \\
\text { onary Algorithm) }\end{array}$ & (Rudolph, 2001) & Sim \\
\hline $\begin{array}{l}\text { NSGA-II (Elitist Non-Dominated Sorting Genetic Al- } \\
\text { gorithm) }\end{array}$ & $\begin{array}{l}\text { (Deb et al., 2000; Deb } \\
\text { e Sundar, 2006) }\end{array}$ & Sim \\
\hline $\begin{array}{l}\text { SPEA, SPEA2 (Strenght Pareto Evolutionary Algo- } \\
\text { rithm) } 1 \text { e } 2\end{array}$ & $\begin{array}{l}\text { (Zitzler et al., 2001; } \\
\text { Zitzler e Thiele, 1998) }\end{array}$ & Sim \\
\hline TGA (Thermodynamical Genetic Algorithm) & (Kita et al., 1996) & Sim \\
\hline PAES (Pareto-Archived Evolutionary Strategy) & $\begin{array}{l}\text { (Knowles e Corne, } \\
\text { 1999) }\end{array}$ & Sim \\
\hline $\begin{array}{l}\text { MOMGA-I, MOMGA-II (Multi-Objective Messy Ge- } \\
\text { netic Algorithm) I e II }\end{array}$ & (Veldhuizen, 1999) & Sim \\
\hline Micro-GA (Multi-Objective Micro-Genetic Algorithm) & $($ Coello, 2001) & Sim \\
\hline $\begin{array}{l}\text { PESA-I, PESA-II (Pareto Envelope-Base Selection Al- } \\
\text { gorithm) I e II }\end{array}$ & $\begin{array}{l}\text { (Corne et al., 2001, } \\
2000)\end{array}$ & Sim \\
\hline
\end{tabular}

Na Seção 4.4.1 é apresentado detalhadamente o NSGA-II, um dos principais modelos elitistas de MOEAs encontrados na literatura (Zitzler et al., 2001).

\subsubsection{Algoritmo NSGA-II}

O algoritmo NSGA-II (do inglês Non-dominated Sorting Genetic Algorithm) (Deb et al., 2000) é baseado em uma ordenação elitista por dominância (Pareto ranking). Esse procedimento consiste em classificar as soluções de um conjunto $M$ em diversas fronteiras $\mathcal{F}_{1}, \mathcal{F}_{2}, \ldots \mathcal{F}_{k}$ conforme ao grau de dominância de tais soluções. Assim, a fronteira $\mathcal{F}_{1}$ contêm as soluções não dominadas de todo o conjunto $M$. A fronteira $\mathcal{F}_{2}$ possui as soluções não dominadas de $M-\mathcal{F}_{1}, \mathcal{F}_{3}$ contêm as soluções de $M-\left(\mathcal{F}_{1} \cup \mathcal{F}_{2}\right)$ e assim sucessivamente.

O procedimento de ordenação por dominância proposto por Deb et al. (2000) é mostrado no Algoritmo 5. Para cada solução $i$ contida em $P$ são calculados dois valores:

- $n d_{i}$, o número de soluções que dominam a solução $i$; 
- $U_{i}$, o conjunto de soluções que são dominadas pela solução $i$.

As linhas 1-7 do Algoritmo 5 calculam tais valores para as soluções em $M$. Além disso, as soluções com $n d_{i}=0$ estão contidas na fronteira $\mathcal{F}_{1}$. Seguidamente, as linhas 9-16 percorrem o conjunto de soluções dominadas $U_{i}$ para cada solução $i$ de $\mathcal{F}_{1}$. O contador $n d_{j}$ de cada solução $j$ em $U_{i}$ é diminuído em 1 . Se $n d_{j}=0$, então a solução $j$ pertence a seguinte fronteira (neste caso $\mathcal{F}_{2}$ ). A iteração das linhas 9-16 é repetido até que todas as soluções estejam classificadas em uma fronteira. A Figura 4.5 ilustra este procedimento aplicado a soluções que minimizam $f_{1}$ e $f_{2}$.

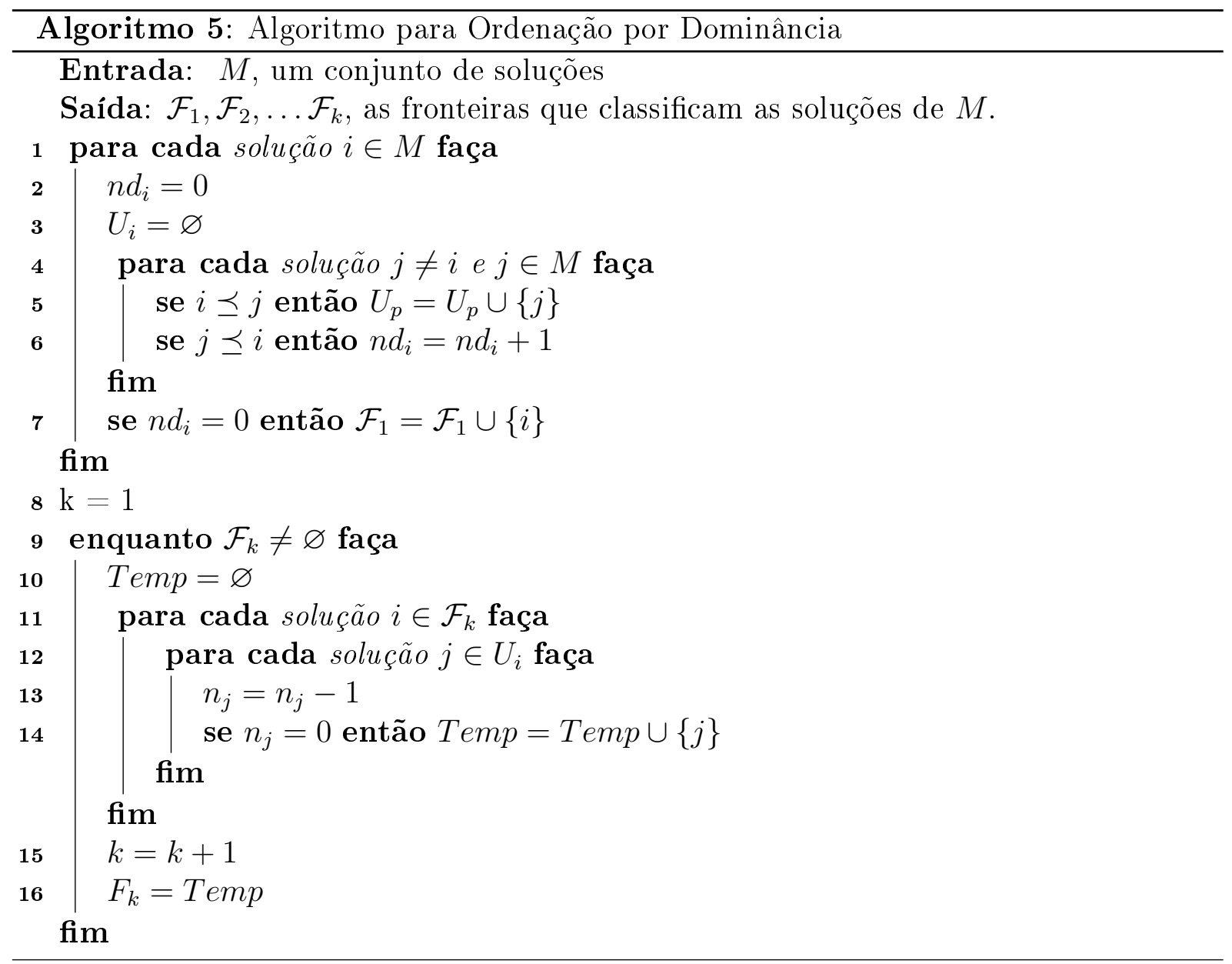

O algoritmo NSGA-II trabalha com duas populações, denotadas como $P$ e $Q$ de tamanho $N_{\text {ind }}$. Na primeira geração, os indivíduos inicias da população $P_{1}$ geram as soluções em $Q_{1}$ mediante a aplicação da seleção, recombinação e mutação. Nas seguintes iterações do algoritmo, é estabelecido um processo competitivo para preencher $N_{\text {ind }}$ vagas na população $P_{t+1}$ entre $2 N_{\text {ind }}$ indivíduos contidos em $R_{t}=P_{t} \cup Q_{t}$. Esta operação é realizada usando ordenação por dominância em $R_{t}$, encaminhando as soluções não dominadas contidas nas fronteiras diretamente para a próxima geração (elitismo).

Para garantir a diversidade na fronteira calculada o NSGA-II emprega uma estimativa da densidade das soluções que rodeiam cada indivíduo da população. Assim, calcula-se a 


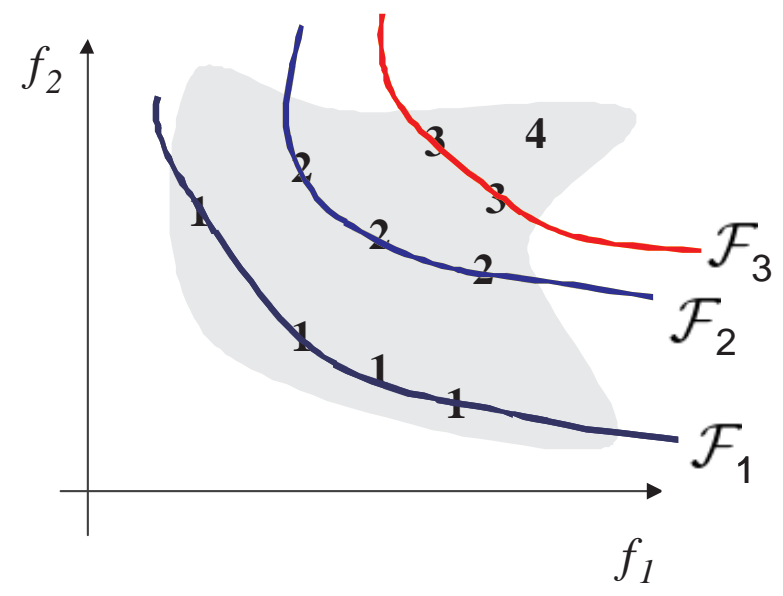

Figura 4.5: Ordenação por dominância (Deb, 2001).

média da distância das duas soluções adjacentes a cada indivíduo para todos os objetivos. Esse valor é denominado distância de multidão. O Algoritmo 6 mostra os passos a seguir para calcular tal valor, onde dist $_{i}$ é o valor da distância de multidão do $i$-ésimo indivíduo do conjunto $M$ (denotado como $\left.M_{i}\right)$ e $f_{m}\left(S_{i}\right)$ é o valor da $m$-ésima função objetivo para tal indivíduo.

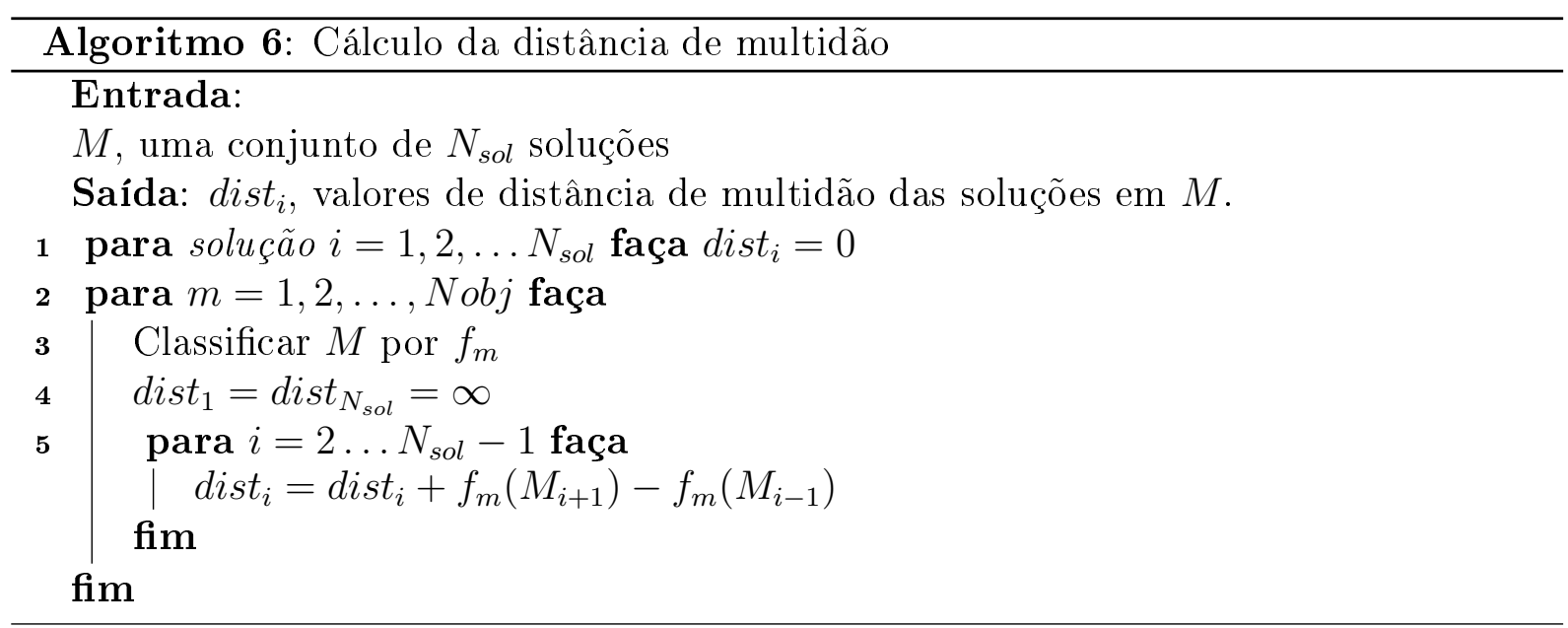

A aptidão de cada solução $i$ é determinada pelos seguintes valores:

1. $\operatorname{rank}_{i}=k$, o valor de ranking $i$ é igual ao número da fronteira $\mathcal{F}_{k}$ à qual pertence;

2. dist $_{i}$, o valor de distância de multidão de $i$.

O NSGA-II emprega um processo de seleção por torneio. Em tal abordagem, duas soluções são comparadas para escolher qual delas vai gerar descendentes na nova população. Uma solução $i$ é escolhida sobre uma solução $j$ se:

1. $i$ possui um ranking menor que $j$, ou seja, $\operatorname{rank}_{i}<\operatorname{rank}_{j}$; 
2. Se ambas as soluções possuem o mesmo ranking e $i$ possui um maior valor de distância de multidão (ou seja, $\operatorname{rank}_{i}=\operatorname{rank}_{j}$ e dist ${ }_{i}>d i s t_{j}$ ).

O cálculo da distância de multidão permite que as soluções melhor espalhadas passem a ocupar as últimas vagas disponíveis de $P_{i+1}$ garantindo a diversidade das soluções.

A seqüência de passos seguido pelo NSGA-II é descrita no Algoritmo 7. A Figura 4.6 mostra o esquema para uma iteração do NSGA-II.

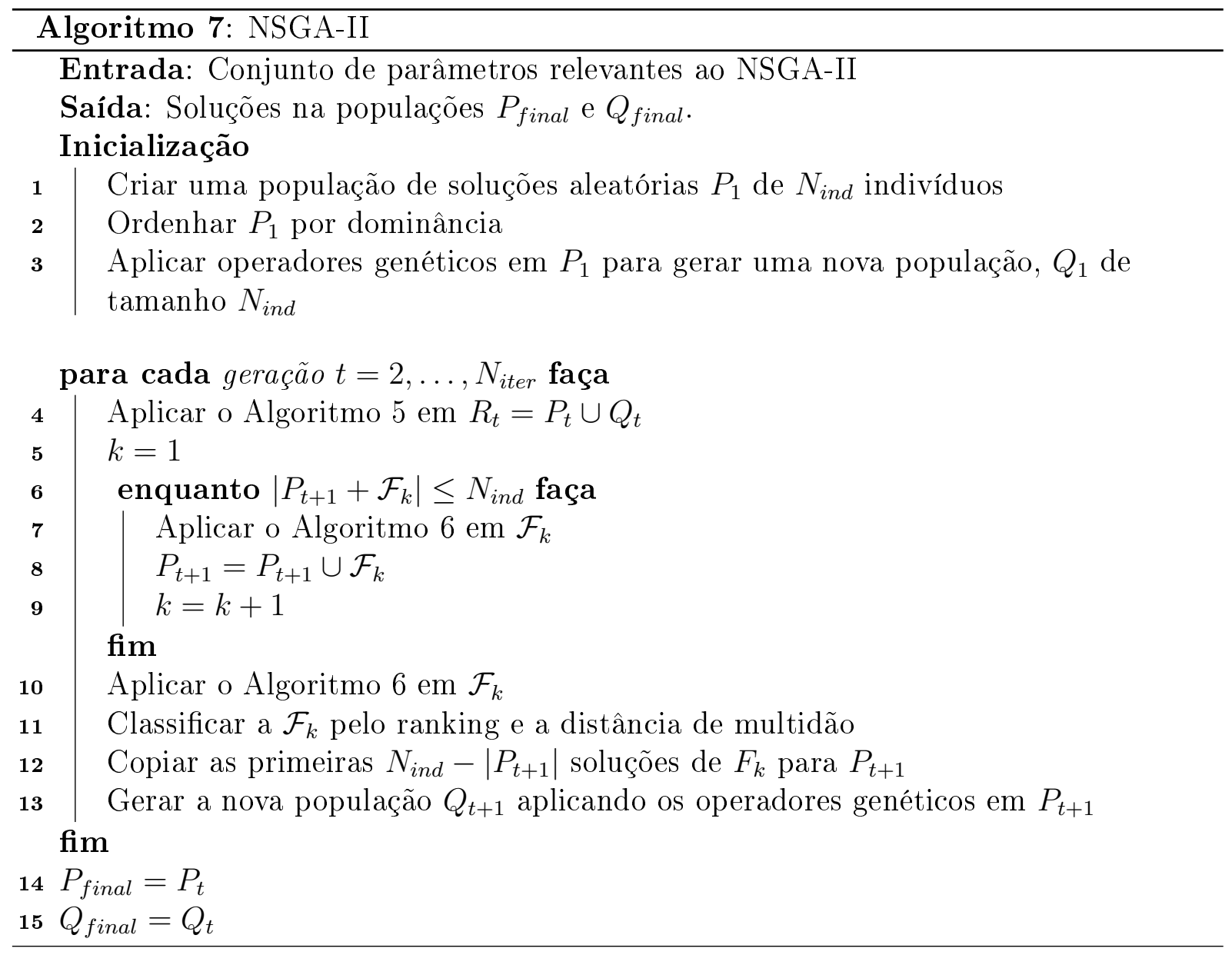

\subsection{Abordagens multi-objetivo aplicados à reconstru- ção filogenética}

Esta Seção apresenta dois trabalhos que aplicaram abordagens multi-objetivo em inferência filogenética.

Poladian e Jermiin (2006) estudam a utilização otimização multi-objetivo para determinar as soluções da fronteira de Pareto obtidas a partir de bancos de seqüências conflitantes (de Queiroz e Poe, 2001). Os autores construíram dois conjuntos de seqüências por simulação para 4 espécies de forma que as árvores resultantes da análise de 


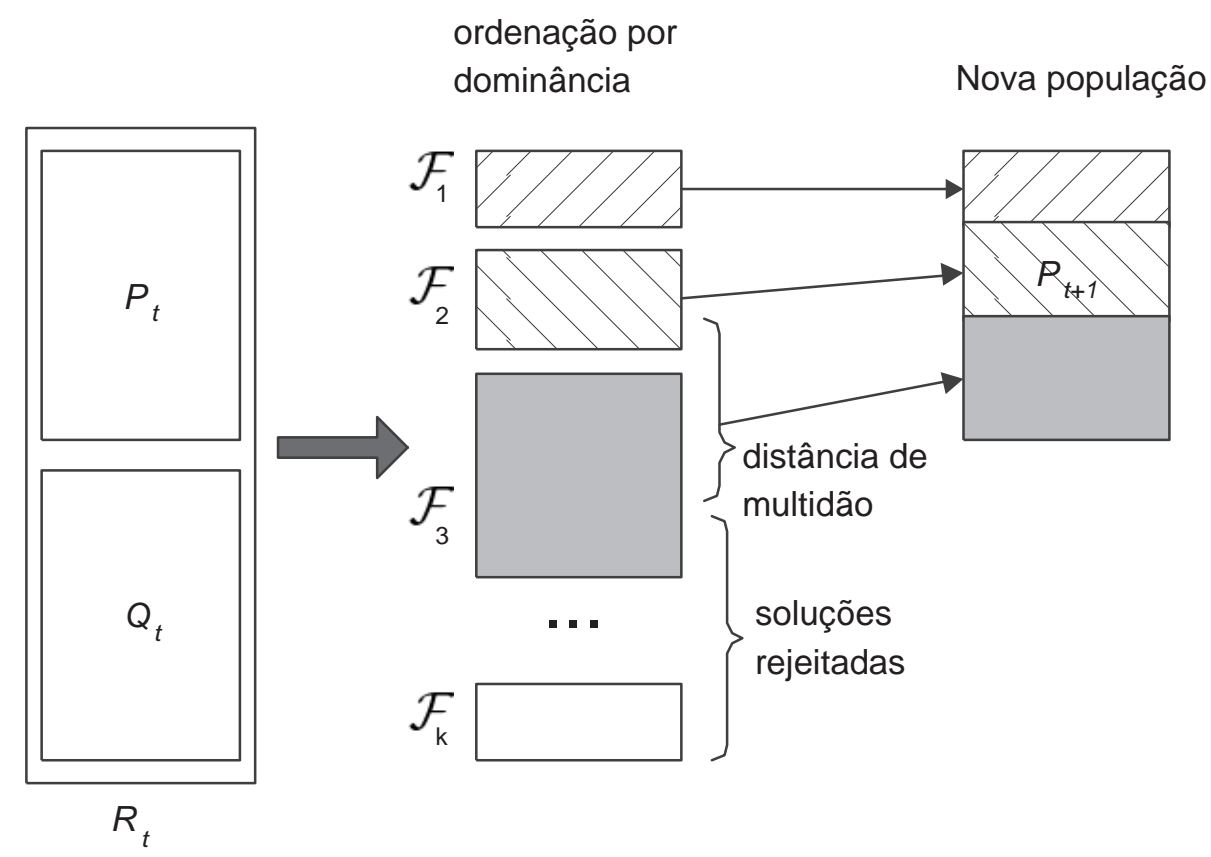

Figura 4.6: Esquema do modelo NSGA-II (Deb, 2001).

máxima verossimilhança em cada banco, por separado ou em conjunto, fossem diferentes. Foi empregado um MOEA para calcular a fronteira de Pareto resultante para avaliar a verossimilhança das topologias obtidas para os bancos simulados. As soluções mostraram diferenças topológicas e de comprimento de ramos que definiram três regiões da fronteira de Pareto. Os autores destacam a importância do trabalho porque mostra como a otimização multi-objetivo pode ajudar nos casos de bancos de dados conflitantes. Além disso, o estudo do problema de 4 seqüências, pode ser usado em combinação com métodos de inferência filogenética que trabalham com quartetos de espécies (Strimmer e von Haesler, 1996).

Coelho et al. (2007) apresentaram uma aplicação do algoritmo omni-aiNet (Coelho e Von Zuben, 2006) para o problema de filogenia considerando os critérios de evolução mínima (Edwards e Cavalli-Sforza, 1964) e mínimos quadrados (Fitch e Margoliash, 1967). O omni-aiNet (Coelho e Von Zuben, 2006) é uma abordagem de sistemas imunológicos artificias (De Castro e Timmis, 2002) para otimização de problemas com um ou vários objetivos. Uma vez obtida a fronteira de Pareto, uma das árvores Pareto-ótimas é escolhida como resultado final. Para esta tarefa, os autores empregaram dois técnicas de toma de decisões conhecidas como Programação de Compromisso (do inglês Compromise Programming) (Zeleny, 1973 apud Deb, 2001) e Taxa Marginal de Retorno (do inglês Marginal Rate of Return) (Deb, 2001; Miettinen, 1999). As árvores da Fronteira de Pareto escolhidas por ambas as técnicas mostraram-se melhores que a obtida pelo método NJ (Saitou e Nei, 1987). A comparação com o NJ é devida ao fato deste método considerar os critérios de evolução mínima e mínimos quadrados no algoritmo. 


\subsection{Considerações finais}

Neste Capítulo foram introduzidos os conceitos básicos otimização multi-objetivo. Apresentou-se o modelo geral para um MOOP e as principais diferenças em relação ao problema de otimização de objetivo simples. Além disso, foram descritas as técnicas tradicionais para resolver um MOOP, verificando as vantagens e desvantagens de cada uma.

Os AEs surgem como uma técnica alternativa para tratar os MOOPs, apresentando uma série de vantagens em relação às técnicas tradicionais. No decorrer deste capítulo foi explicada a utilização de AEs em MOOPs. Um dos principais modelos de MOEA, o NSGA-II, foi também descrito detalhadamente. Além disso, foi realizada uma revisão das principais abordagens multi-objetivo para reconstrução filogenética encontradas na literatura.

Como descrito no Capítulo 2, a aplicação de diversos métodos de reconstrução resulta em árvores filogenéticas com critérios de avaliação conflitantes entre sim. Por outro lado, no Capítulo 3 mostrou que o emprego de AEs em filogenia tem mostrado resultados relevantes. Tais fatos motivam a proposta de uma abordagem de MOEA do problema da inferência filogenética, a qual é explorada no próximo capítulo. 


\section{CAPÍTULO \\ 5 \\ Algoritmo evolutivo multi-objetivo para o problema de reconstrução de árvores filogenéticas}

\subsection{Introdução}

Este Capítulo apresenta o PhyloMOEA, que é o modelo de MOEA para o problema de reconstrução filogenética desenvolvido nesta pesquisa. O PhyloMOEA é baseado no NSGAII (Deb et al., 2000), um dos modelos de MOEA mais importantes descritos na literatura. Os critérios de otimalidade empregados pelo PhyloMOEA são a máxima parcimônia e máxima verossimilhança. Assim, o objetivo final é gerar um conjunto de soluções que representem um consenso entre tais critérios.

Este capítulo está dividido em duas seções. A seção 5.2 descreve detalhadamente o PhyloMOEA A Seção 5.3, apresenta-se as considerações finais sobre este Capítulo.

\subsection{PhyloMOEA}

O objetivo fundamental do PhyloMOEA é encontrar árvores na Fronteira de Pareto considerando os critérios de máxima parcimônia e máxima verossimilhança. A Figura 5.1 ilustra o funcionamento do PhyloMOEA destacando seus principais etapas e componentes. 


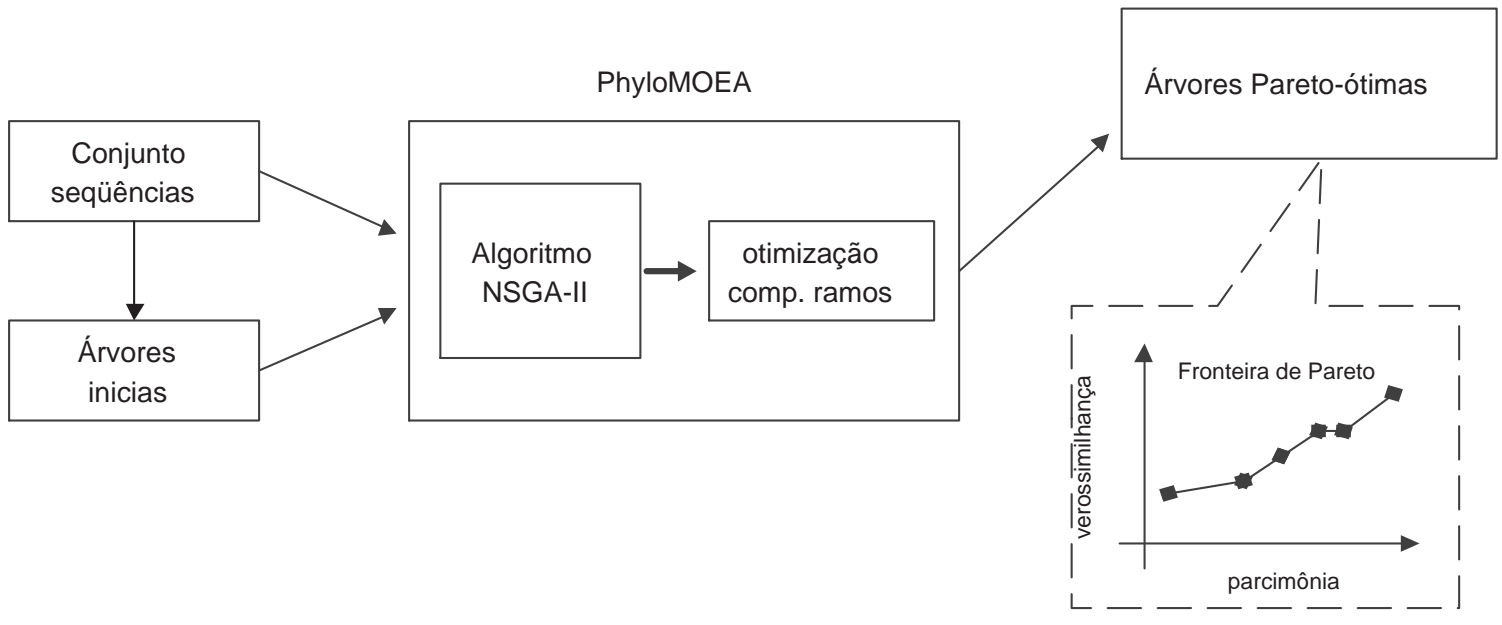

Figura 5.1: Ilustração do funcionamento do PhyloMOEA.

As Seções 5.2.1-5.2.5 apresentam características específicas do PhyloMOEA como representação de soluções, funções de aptidão, geração de soluções inicias, operadores de recombinação, mutação e otimização dos comprimentos de ramos.

\subsubsection{Representação de soluções}

Na literatura foram propostas várias formas para representar árvores filogenéticas como: estruturas de dados baseadas em listas de adjacências (Adachi e Hasegawa, 1996; Felsenstein, 2004), matriz de adjacência (Prado, 2002) ou arranjos de números inteiros (Cotta e Moscato, 2002). Dessas formas de representação, a estrutura baseada em grafos é a mais empregada por programas de inferência filogenética tais como PHYLIP (Felsenstein, 2000b), PAML (Yang, 1997), PHYML (Guindon e Gascuel, 2003), entre outros.

O PhyloMOEA emprega a estrutura de dados de lista de adjacências (Cormen, 2001) para a representação das árvores filogenéticas. Uma das razões para escolher tal representação é que existe uma grande variedade de implementações prontas com essa estrutura. Duas bibliotecas de código aberto na linguagem $\mathrm{C}++$ foram avaliadas: a BGL (Boost Graph Library) (Siek et al., 2002) a GTL (Graph Template Library) (Forster et al., 2004). Ambas as bibliotecas possuem implementações bastante completas de grafos, incluindo métodos eficientes para acesso a nós e ramos, assim como vários algoritmos comuns da teoria de grafos. A GTL mostrou-se como uma biblioteca que fornece uma forma mais clara e simples de programar. Por essas razões, a implementação do PhyloMOEA está baseada na biblioteca GTL. Deve-se ressaltar que o uso de grafos como estrutura de dados implica a inferência de árvores sem raiz que, como visto no Capítulo 2, reduz o espaço de busca com relação à inferência de árvores enraizadas.

Além das informações da topologia da árvore, a GTL permite associar informações aos nós e ramos do grafo (por exemplo comprimentos de ramos) que permitem uma 
representação de todos os parâmetros relevantes ao problema. A Figura 5.2 mostra a representação de uma árvore para o PhyloMOEA.

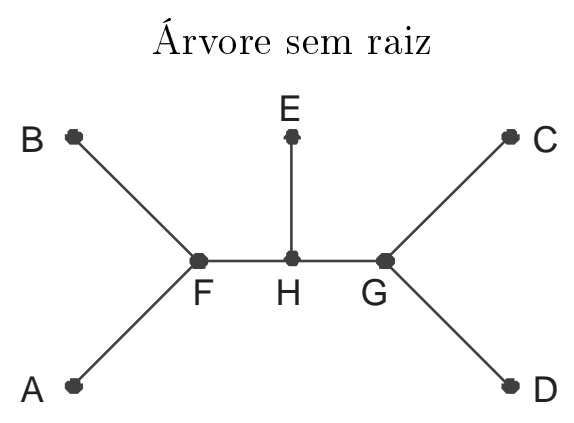

Representação interna
\begin{tabular}{|l|l|}
\hline Nós & Arestas \\
\hline A & $\longrightarrow \mathrm{F}$ \\
\hline $\mathrm{B}$ & $\longrightarrow \mathrm{F}$ \\
\hline $\mathrm{C}$ & $\longrightarrow \mathrm{G}$ \\
\hline $\mathrm{D}$ & $\longrightarrow \mathrm{G}$ \\
\hline $\mathrm{E}$ & $\longrightarrow \mathrm{H}$ \\
\hline $\mathrm{F}$ & $\longrightarrow \mathrm{A}, \longrightarrow \mathrm{B}, \longrightarrow \mathrm{H}$ \\
\hline $\mathrm{G}$ & $\longrightarrow \mathrm{C}, \longrightarrow \mathrm{D}, \longrightarrow \mathrm{H}$ \\
\hline $\mathrm{H}$ & $\longrightarrow \mathrm{F}, \longrightarrow \mathrm{G}, \longrightarrow \mathrm{E}$ \\
\hline
\end{tabular}

Figura 5.2: Representação interna empregada pelo PhyloMOEA para uma árvore sem raiz.

A estrutura de dados desenvolvida foi amadurecendo no decorrer da pesquisa possibilitando o aprimoramento da capacidade de calcular partições de cada árvore. Assim, empregou-se o algoritmo de Day (Day, 1985) que permite obter as partições das árvores com um custo ótimo em tempo de execução e na utilização de memória.

O PhyloMOEA emprega o formato Newick (Felsenstein, 2000a) para mostrar as árvores encontradas no final da execução do algoritmo. Nesse formato, uma árvore é representada por uma cadeia de caracteres terminada em ponto e virgula. Nessa cadeia, cada nó interno corresponde a um par de parênteses emparelhados. Tais parênteses podem estar aninhados conforme os níveis de profundida de árvore. Os descendentes do nó interno são separados por vírgula. As folhas da árvore são representadas pelo nome das suas espécies correspondentes. Os comprimentos de ramos são inseridos com dois pontos (:) após o nome da espécies (um nó folha), ou do parênteses fechado (no caso do nó interno), seguido de o valor de tal comprimento. Por exemplo, a árvore da Figura 5.2 corresponde a cadeia “((A,B),E, $(\mathrm{C}, \mathrm{D}))$ )" no formato Newick.

\subsubsection{Funções de aptidão}

O PhyloMOEA emprega os algoritmos de Fitch e Felsenstein apresentados no Capítulo 2 para calcular os valores de parcimônia e verossimilhança das soluções encontradas. O funcionamento de tais algoritmos foi apresentado em árvores com raiz. As mudanças requeridas para que esses algoritmos funcionem em árvores não enraizadas são apresentadas a seguir. 


\section{Cálculo de parcimônia}

No caso de árvores não enraizadas, o algoritmo de Fitch (Fitch, 1972) foi modificado conforme aos seguintes passos:

- Primeiramente, escolhe-se uma folha $u$ conetada a um nó interno $v$. O nó interno $v$ define uma subárvore que contém todos as folhas da árvore com exceção de $u$, que serve como raiz da árvore. Em outros termos, a árvore é pendurada pela folha $u$;

- A seguir, aplica-se o percurso pós-ordem (linhas 1-6) do Algoritmo 1 de cálculo de parcimônia (ver Capítulo 2) na subárvore com raiz em $v$;

- Se o estado do nó $u$ no sítio $j$ não está contido no conjunto de estados de $v\left(u_{j} \in \mathcal{S}_{v}\right)$, então incrementa-se o valor de parcimônia $\operatorname{Par}_{j}$.

Os passos descritos anteriormente são aplicados para cada sítio $j$ e, finalmente, obtemse o valor de parcimônia da árvore. A Figura 5.3 mostra o esquema das modificações aplicadas no algoritmo de Fitch. Vários trabalhos na literatura (Gladstein, 1997; Goloboff, 1996, 1999a; Ronquist, 1998) mostram como aumentar a eficiência do algoritmo de Fitch quando se trabalha com grandes bancos de seqüências. Tais trabalhos explicam basicamente como reaproveitar cálculos realizados anteriormente para encontrar o novo valor de parcimônia de soluções modificadas topologicamente, reduzindo bastante o número de vezes que executa-se o algoritmo de Fitch. O foco de desenvolvimento do PhyloMOEA foi o aumento de diversidade de soluções Pareto-ótimas. Assim, melhorias de desempenho não foram implementadas no modelo proposto, representando uma interessante linha de pesquisa futura.
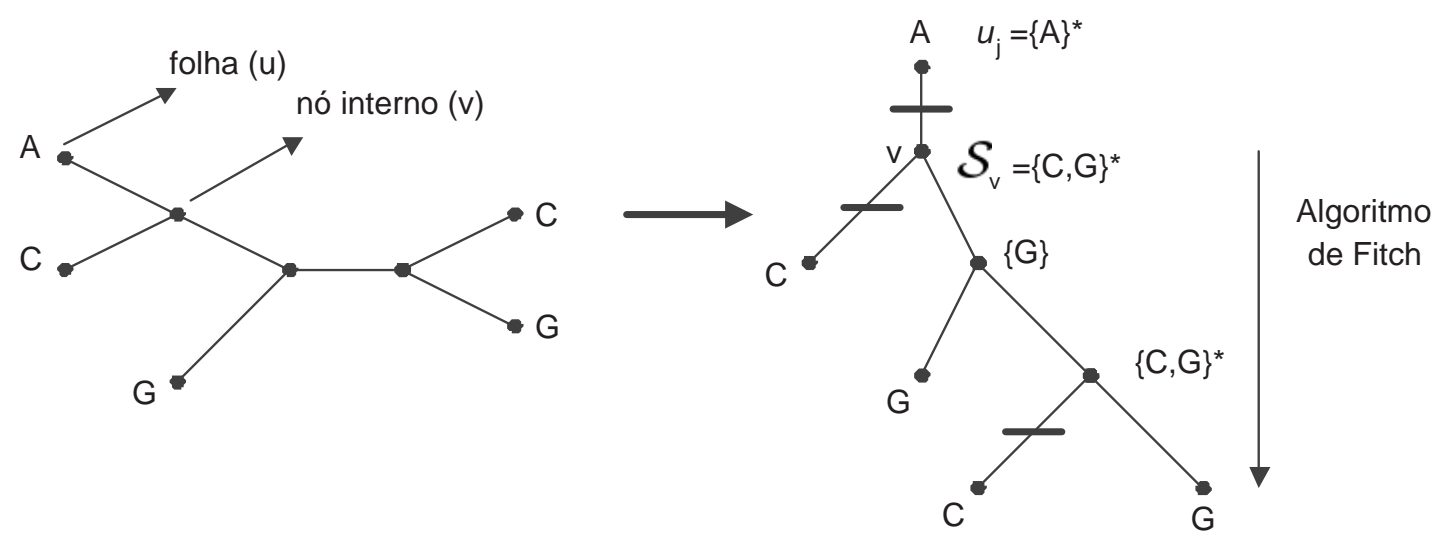

Figura 5.3: Algoritmo de Fitch para árvore sem raiz. 


\section{Cálculo de verossimilhança}

O cálculo da verossimilhança apresentado no Algoritmo 2 (ver Capítulo 2) pode ser também aplicado em árvores sem raiz devido a propriedade de reversibilidade dos modelos de substituição de seqüências. Por exemplo, considerando a árvore da Figura 5.4(a), tem-se que a verossimilhança para o sítio $j$ é determinada pela seguinte expressão (ver Equação 2.18 do Capítulo 2):

$$
L_{j}=\sum_{r_{j} \in \Omega} \pi_{r_{j}} L_{j}^{r}\left(r_{j}\right)
$$

A verossimilhança condicional do nó $r$ depende das subárvores dos nós $v$ e $s$ (ver Figura 5.4(a)). Pela Equação 2.16 temos que:

$$
L_{j}=\sum_{r_{j} \in \Omega} \sum_{v_{j} \in \Omega} \sum_{s_{j} \in \Omega} \pi_{r_{j}} \mathbf{P}_{r_{j}, v_{j}}\left(t_{r v}\right) \mathbf{P}_{r_{j}, s_{j}}\left(t_{r s}\right) L_{j}^{v}\left(v_{j}\right) L_{j}^{s}\left(s_{j}\right)
$$

Pela propriedade de reversibilidade (ver Equação 2.8 do Capítulo 2) tem-se que:

$$
\pi_{r_{j}} \mathbf{P}_{r_{j}, v_{j}}\left(t_{r v}\right)=\pi_{v_{j}} \mathbf{P}_{v_{j}, r_{j}}\left(t_{r v}\right)
$$

Substituindo a Equação 5.3 na Equação 5.2, tem-se que:

$$
L_{j}=\sum_{r_{j} \in \Omega} \sum_{v_{j} \in \Omega} \sum_{s_{j} \in \Omega} \pi_{v_{j}} \mathbf{P}_{v_{j}, r_{j}}\left(t_{r v}\right) \mathbf{P}_{r_{j}, s_{j}}\left(t_{r s}\right) L_{j}^{v}\left(v_{j}\right) L_{j}^{s}\left(s_{j}\right)
$$

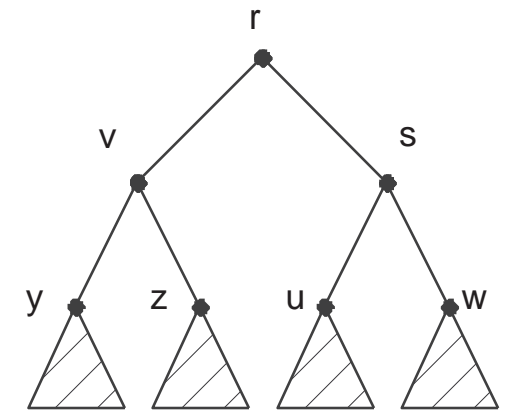

(a) Árvore com raiz

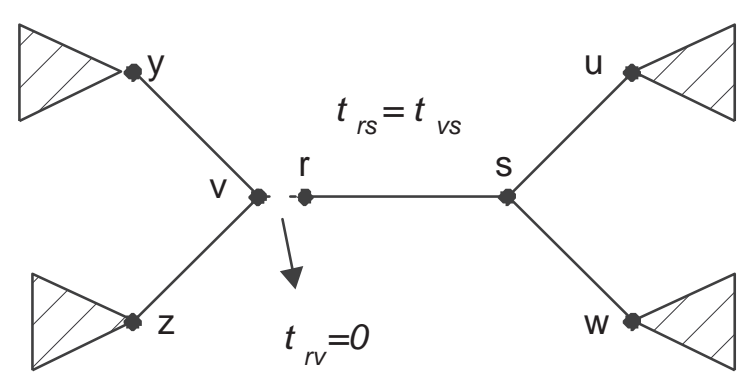

(b) Árvore sem raiz equivalente

Figura 5.4: Cálculo de verossimilhança em árvores com raiz e sem raiz.

A árvore da Figura 5.4(a) pode-se transformar em uma árvore sem raiz eliminando o nó $r$ e criando uma novo ramo $(v, s)$ com comprimento igual a $t_{r v}+t_{r s}$. Isso equivale a deslocar o nó $r$ próximo ao nó $v$, como mostrado na Figura 5.4(b) tal que $t_{r v}$ seja zero e $t_{r s}$ seja igual a $t_{v s}$. A equação de Chapman-Kolmogorov (Felsenstein, 2004) garante que: 


$$
\mathbf{P}_{v_{j}, s_{j}}\left(t_{r v}+t_{r s}\right)=\mathbf{P}_{v_{j}, r_{j}}\left(t_{r v}\right) \mathbf{P}_{r_{j}, s_{j}}\left(t_{r s}\right),
$$

ou seja, a raiz $r$ pode ser deslocada em qualquer posição do ramo $(v, s)$ sem alterar o valor de $L_{j}$. Substituindo $t_{r v}=0$ e $\mathbf{P}_{r_{j}, s_{j}}\left(t_{r s}\right)=\mathbf{P}_{v_{j}, s_{j}}\left(t_{v s}\right)$ na Equação 5.4 tem-se que:

$$
L_{j}=\sum_{r_{j} \in \Omega} \sum_{v_{j} \in \Omega} \sum_{s_{j} \in \Omega} \pi_{v_{j}} \mathbf{P}_{v_{j}, r_{j}}(0) \mathbf{P}_{v_{j}, s_{j}}\left(t_{v s}\right) L_{j}^{v}\left(v_{j}\right) L_{j}^{s}\left(s_{j}\right)
$$

O termo $\mathbf{P}_{v_{j}, r_{j}}(0)$ é igual a 1 se $r_{j}=v_{j}$ e 0 , caso contrário. Aplicando esse resultado na Equação 5.6 tem-se que:

$$
L_{j}=\sum_{v_{j} \in \Omega} \sum_{s_{j} \in \Omega} \pi_{v_{j}} \mathbf{P}_{v_{j}, s_{j}}\left(t_{v s}\right) L_{j}^{v}\left(v_{j}\right) L_{j}^{s}\left(s_{j}\right)
$$

Deve-se notar que as Equações 5.7 e 5.2 são equivalentes e, conseqüentemente, pode-se aplicar o Algoritmo 2 em árvores sem raiz, escolhendo um nó interno arbitrário como raiz da árvore.

Vários autores reportam problemas na precisão numérica no cálculo da verossimilhança quando se empregam bancos de dados que contém mais de 100 espécies (Guindon, 2003; Yang, 2000). Tal fenômeno foi confirmado nos experimentos realizados com o PhyloMOEA, os quais apresentaram grandes erros de precisão na verossimilhança. Isso é devido ao fato de que, em grandes bancos de dados, as verossimilhanças condicionais são muito pequenas para serem representadas em um computador comum. Para solucionar esse problema, implementou-se um procedimento de escalonamento descrito em (Guindon, 2003; Yang, 2000).

Considerando uma subárvore com raiz $r$ e filhos $v$ e $s$, a verossimilhança condicional dessa subárvore no sítio $j$ pode ser expressada como (ver Equação 2.16 do Capítulo 2):

$$
L_{j}^{r}\left(r_{j}\right)=\left[\sum_{v_{j} \in \Omega} \mathbf{P}_{r_{j}, v_{j}}\left(t_{r v}\right) L_{j}^{v}\left(v_{j}\right)\right] \times\left[\sum_{s_{j} \in \Omega} \mathbf{P}_{r_{j}, s_{j}}\left(t_{r s}\right) L_{j}^{s}\left(s_{j}\right)\right] .
$$

Se os valores de $L_{j}^{v}\left(v_{j}\right)$ e/ou $L_{j}^{s}\left(s_{j}\right)$ forem muito pequenos, pode ser difícil representar $L_{j}^{r}\left(r_{j}\right)$ no computador. Nesses casos, ao invés de calcular a verossimilhança condicional original, calcula-se a verossimilhança condicional escalonada, denotada como $L E_{j}^{r}\left(r_{j}\right)$, conforme à seguinte expressão:

$$
L E_{j}^{r}\left(r_{j}\right)=\left[\sum_{v_{j} \in \Omega} \mathbf{P}_{r_{j}, v_{j}}\left(t_{r v}\right) \frac{L_{j}^{v}\left(v_{j}\right)}{\rho_{j}(v)}\right] \times\left[\sum_{s_{j} \in \Omega} \mathbf{P}_{r_{j}, s_{j}}\left(t_{r s}\right) \frac{L_{j}^{s}\left(s_{j}\right)}{\rho_{j}(s)}\right],
$$

onde $\rho_{j}(v)=\max \left\{L_{j}^{v}\left(v_{j}\right)\right\}$ e $\rho_{j}(s)=\max \left\{L_{j}^{s}\left(s_{j}\right)\right\}$ são os fatores de escalonamento das verossimilhanças condicionais correspondentes aos nós $v$ e $s$, respectivamente. Ao dividir 
pelos fatores de escalonamento, as verossimilhança condicional volta a ser representável no computador.

Se $r$ é a raiz da árvore, a verossimilhança escalonada no sítio $j$ pode ser calculada como:

$$
L E_{j}=\frac{1}{\rho_{j}\left(v_{j}\right) \rho_{j}\left(s_{j}\right)} \sum_{r_{j} \in \Omega} \pi_{r_{j}} L_{j}^{r}\left(r_{j}\right) .
$$

O termo do somatório a equação 5.10 corresponde à verossimilhança original (não escalonada) no sítio $j$, denotada como $L_{j}$ (ver Equação 2.18 do Capítulo 2). Substituindo e aplicando logaritmo natural a ambos lados da Equação 5.10, temos:

$$
\ln \left(L_{j}\right)=\ln \left(L E_{j}\right)+\ln \left(\rho_{j}(u)\right)+\ln \left(\rho_{j}(w)\right)
$$

Dessa forma é possível voltar ao valor da verossimilhança original empregando a verossimilhança escalonada e os fatores de escalonamento sem ter os problemas de precisão numérica. O procedimento implementado no PhyloMOEA armazena os fatores de escalonamento para todas as subárvores e todos os sítios. Tais fatores são logo propagados até a raiz da árvore como mostrado na Equação 5.11 para calcular a verossimilhança original.

Sem a aplicação de tal método é impossível o emprego de bancos de seqüências maiores nos experimentos. Assim, os valores de verossimilhança obtidos pelo PhyloMOEA foram consistentes como os dos programas PHYML (Guindon e Gascuel, 2003) e PAML (Yang, 1997).

O cálculo do valor de verossimilhança para árvores obtidas a partir de grandes bancos de seqüências consome consideráveis recursos computacionais (Felsenstein, 2004; Swofford et al., 1996). Na literatura existem vários trabalhos que mostram como reduzir tal custo pela reordenação dos dados (Kosakovsky e Muse, 2004), paralelização do cálculo de verossimilhança (Stamatakis et al., 2002a,b; Stamatakis e Meier, 2004) ou aproximação numérica das probabilidades requeridas pelos modelos evolutivos (Pupko e Graur, 2002). Além disso, vários trabalhos mostram como aproveitar os cálculos previamente realizados quando modificações topológicas são realizadas nas árvores. Programas como PHYML (Guindon e Gascuel, 2003; Hordijk e Gascuel, 2005) ou RAX-ML (Stamatakis et al., 2005b) são exemplos de programas que reaproveitam cálculos anteriores.

O cálculo da verossimilhança no PhyloMOEA não implementa tais melhorias, devendo ser essas o foco de trabalhos futuros para aumentar a eficiência computacional do algoritmo atual. 


\subsubsection{Geração de soluções iniciais}

O PhyloMOEA implementa a geração aleatória de topologias iniciais utilizando o método de adição por passos (ver Capítulo 2). Nesse método a posição de inserção de uma nova espécies é escolhida aleatoriamente. Para os comprimentos de ramos são atribuídos valores aleatórios no intervalo [0; 0, 05] (Lewis, 1998).

A estratégia de geração de topologias aleatórias tem-se mostrado útil para bancos de seqüências muito pequenos. Para conjuntos de dados maiores as árvores geradas encontram-se muito afastadas das soluções ótimas. Isso prejudica consideravelmente a convergência do PhyloMOEA.

Uma forma de resolver este problema foi possibilitar a inserção de árvores geradas por outros programas na população inicial (no formato Newick). Assim, podem ser inseridas árvores resultantes das análises de máxima parcimônia, máxima verossimilhança ou árvores geradas utilizando bootstrap (Felsenstein, 1985). Tal procedimento é freqüentemente empregado na literatura referente a AEs (ver Capítulo 3) aplicados ao problema de reconstrução filogenética, como o GARLI (Zwickl, 2006), Ga-mt (Katoh et al., 2001), METAPIGA (Lemmon e Milinkovitch, 2002a) ou PARSIGAL (Moilanen, 1999), mostrando resultados relevantes.

\subsubsection{Operadores de recombinação e mutação}

O operador de recombinação implementado no PhyloMOEA é a troca de subárvores implementado no GAML (Lewis, 1998) (ver Capítulo 3). Dadas duas árvores pais $\tau_{1}$ e $\tau_{2}$, esse operador de recombinação segue os seguintes passos:

1. Escolhe uma subárvore $\tau_{1}$, denotada como $\tau_{1}^{\prime}$;

2. Remove as espécies contidas em $\tau_{1}^{\prime}$ da árvore $\tau_{2}$. A árvore resultante desta operação é denotada como $\tau_{2}^{\prime}$;

3. Escolhe um ramo de $\tau_{2}^{\prime}$ para inserir a subárvore $\tau_{1}^{\prime}$, resultando em uma nova árvore.

A Figura 5.5 mostra um exemplo do operador de recombinação. Existem dois tipos de operadores de mutação implementados no PhyloMOEA:

1. Mutação topológica: os operadores de mutação topológica implementados no PhyloMOEA são o NNI, SPR e TBR (ver Capítulo 2);

2. Modificação dos comprimentos de ramos: neste operador, uma parcela dos ramos são escolhidos para serem modificados. O novo comprimento é produto do seu valor anterior multiplicado por um fator calculado usando a distribuição Gama (Lewis, 1998). 


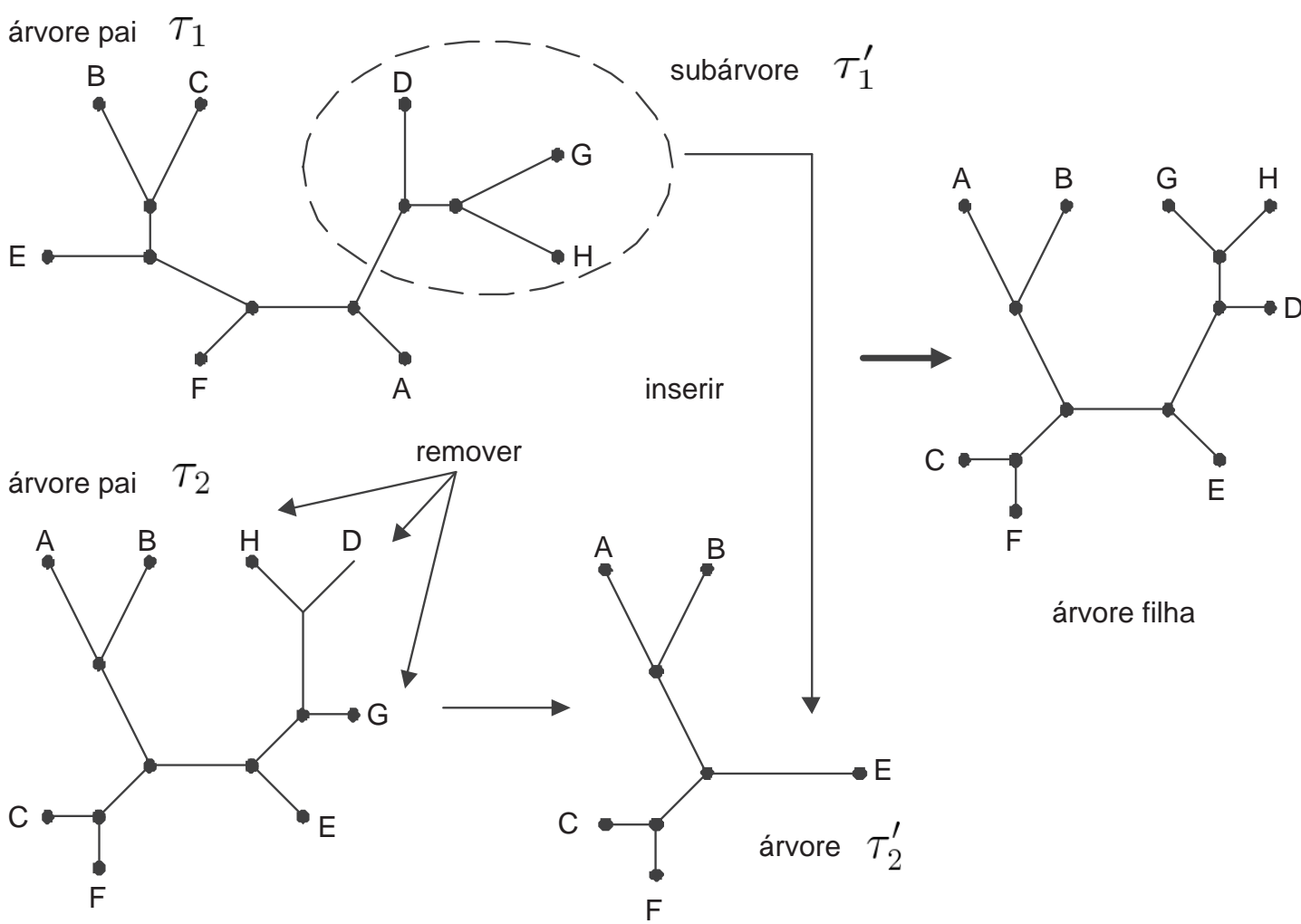

Figura 5.5: Operador de recombinação do PhyloMOEA.

\subsubsection{Otimização dos comprimentos dos ramos}

No final da execução do PhyloMOEA, espera-se que os valores de comprimento de ramos fornecidos sejam aproximações adequadas dos valores ótimos. Tais comprimentos podem ser melhorados iterativamente aplicando técnicas de otimização convencionais, como nos programas GA-mt (Lewis, 1998) e no METAPIGA (Lemmon e Milinkovitch, 2002a).

No PhyloMOEA, a otimização dos comprimentos de ramos é realizada usando o método de Newton para uma variável, tal como descrito no trabalho de Yang (2000). O algoritmo implementado nesse trabalho, faz a otimização dos comprimentos ramo por ramo. Da Equação 5.7 pode ser verificado que o valor de $L_{j}$ depende do apenas do comprimento de ramo $t_{v s}$, sendo que os demais ramos encontram-se fixados. Dessa forma, é possível calcular as primeiras e segundas derivadas de $L_{j}$ com relação a $t_{v s}$, conforme a seguinte equação:

$$
\begin{aligned}
L_{j}^{\prime} & =\frac{\delta L_{j}}{\delta t_{v s}}=\sum_{v_{j} \in \Omega} \sum_{s_{j} \in \Omega} \pi_{v_{j}} \mathbf{P}_{v_{j}, s_{j}}^{\prime}\left(t_{v s}\right) L_{j}^{v}\left(v_{j}\right) L_{j}^{s}\left(s_{j}\right), \\
L_{j}^{\prime \prime} & =\frac{\delta^{2} L_{j}}{\delta t_{v s}^{2}}=\sum_{v_{j} \in \Omega} \sum_{s_{j} \in \Omega} \pi_{v_{j}} \mathbf{P}_{v_{j}, s_{j}}^{\prime \prime}\left(t_{v s}\right) L_{j}^{v}\left(v_{j}\right) L_{j}^{s}\left(s_{j}\right),
\end{aligned}
$$

onde $\mathbf{P}_{v_{j}, s_{j}}^{\prime}\left(t_{v s}\right)$ e $\mathbf{P}_{v_{j}, s_{j}}^{\prime \prime}\left(t_{v s}\right)$ dependem do modelo de evolução de DNA escolhido. Para todas as $j$ posições das seqüências, as primeiras e segundas derivadas de $\ln L$ são: 


$$
\begin{aligned}
& \ln L^{\prime}=\frac{\delta \ln L}{\delta t_{v s}}=\sum_{j} \frac{L_{j}^{\prime}}{L_{j}} \\
& \ln L^{\prime \prime}=\frac{\delta^{2} \ln L}{\delta t_{v s}^{2}}=\sum_{j} \frac{L_{j} \cdot L_{j}^{\prime \prime}-\left(L_{j}^{\prime}\right)^{2}}{L_{j}^{2}} .
\end{aligned}
$$

Empregando a Equação 5.13 é possível melhorar iterativamente o valor de $t_{v s}$ utilizando o método de Newton. Assim, o novo valor do $t_{v s}$ (denotado como $t_{v s}^{\prime}$ ) é dado por:

$$
t_{v s}^{\prime}=t_{v s}+\alpha \frac{L^{\prime}}{L^{\prime \prime}}
$$

onde $L^{\prime} / L^{\prime \prime}$ é a direção Newton e $\alpha$ é o tamanho do passo.

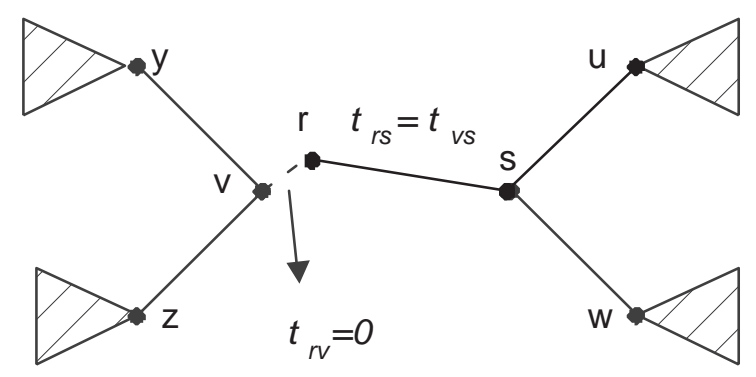

(a) Otimização de $t_{v s}$

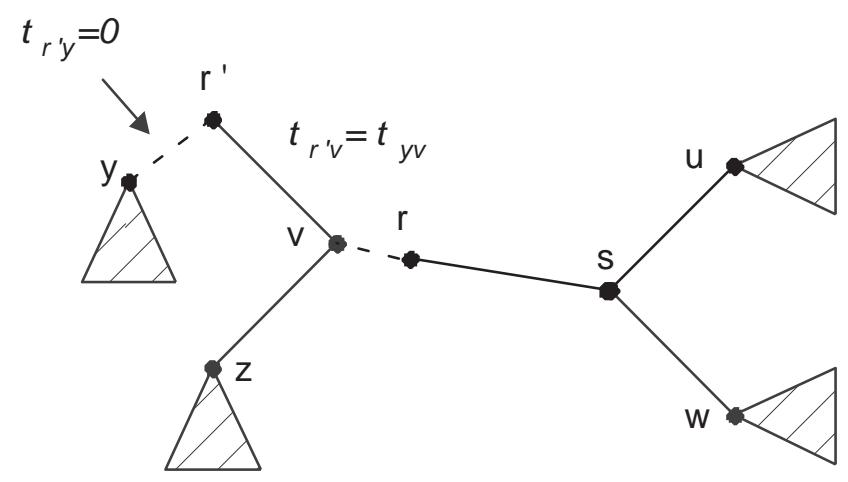

(b) Otimização de $t_{y v}$

Figura 5.6: Otimização de dois comprimentos de ramo.

Uma vez otimizado $t_{v w}$, procede-se com os demais ramos da árvore. A propriedade de reversibilidade do modelo de evolução de seqüências de DNA e a equação de ChapmanKolmogorov permitem que o cálculo da verossimilhança seja independente da nó escolhido como raiz (Felsenstein, 2004). Como visto na Seção 5.2.2, o valor de $L_{j}$ da Equação 5.7 corresponde a inserir um nó raiz $r$ no ramo $(v, s)$ tal que $t_{r v}=0$ e $t_{r s}=t_{v s}$ (ver Figura 5.6(a)). Para otimizar um novo ramo, por exemplo, o ramo $(v, y)$, deve-se criar uma nova raiz $r^{\prime}$, tal que $t_{r^{\prime} y}=0$ e $t_{r^{\prime} v}=t_{u v}$. O valor de $L_{j}$ para a nova topologia mostrada na Figura 5.6(b) é dada pela seguinte expressão: 


$$
L_{j}=\sum_{y_{j} \in \Omega} \sum_{v_{j} \in \Omega} \pi_{y_{j}} \mathbf{P}_{y_{j}, v_{j}}\left(t_{y v}\right) L_{j}^{y}\left(y_{j}\right) L_{j}^{v}\left(v_{j}\right)
$$

Deve-se observar que enquanto na Figura 5.6(a), o nó $v$ é a raiz da subárvore com descendentes $y$ e $z$, na Figura 5.6(b), o nó $v$ é a raiz da subárvore com descendentes $s$ e z. Assim, o significado da verossimilhança condicional de tal nó $\left(L_{j}^{v}\left(v_{j}\right)\right)$ tem um valor diferente nas Equações 5.7 e 5.15. Conseqüentemente, cada vez que se otimiza um novo ramo, é necessário também modificar as verossimilhanças condicionais no caminho entre a nova raiz $r^{\prime}$ e a antiga raiz $r$.

Na prática, os comprimentos de ramos não são independentes entre sim, ou seja, o resultado de otimizar um determinado ramo pode levar outros ramos otimizados anteriormente a não terem valores ótimos. Assim, vários ciclos de otimização envolvendo todos os ramos da árvore podem ser necessários (Yang, 2006). O Algoritmo 8 mostra o procedimento de otimização de ramos implementado no PhyloMOEA.

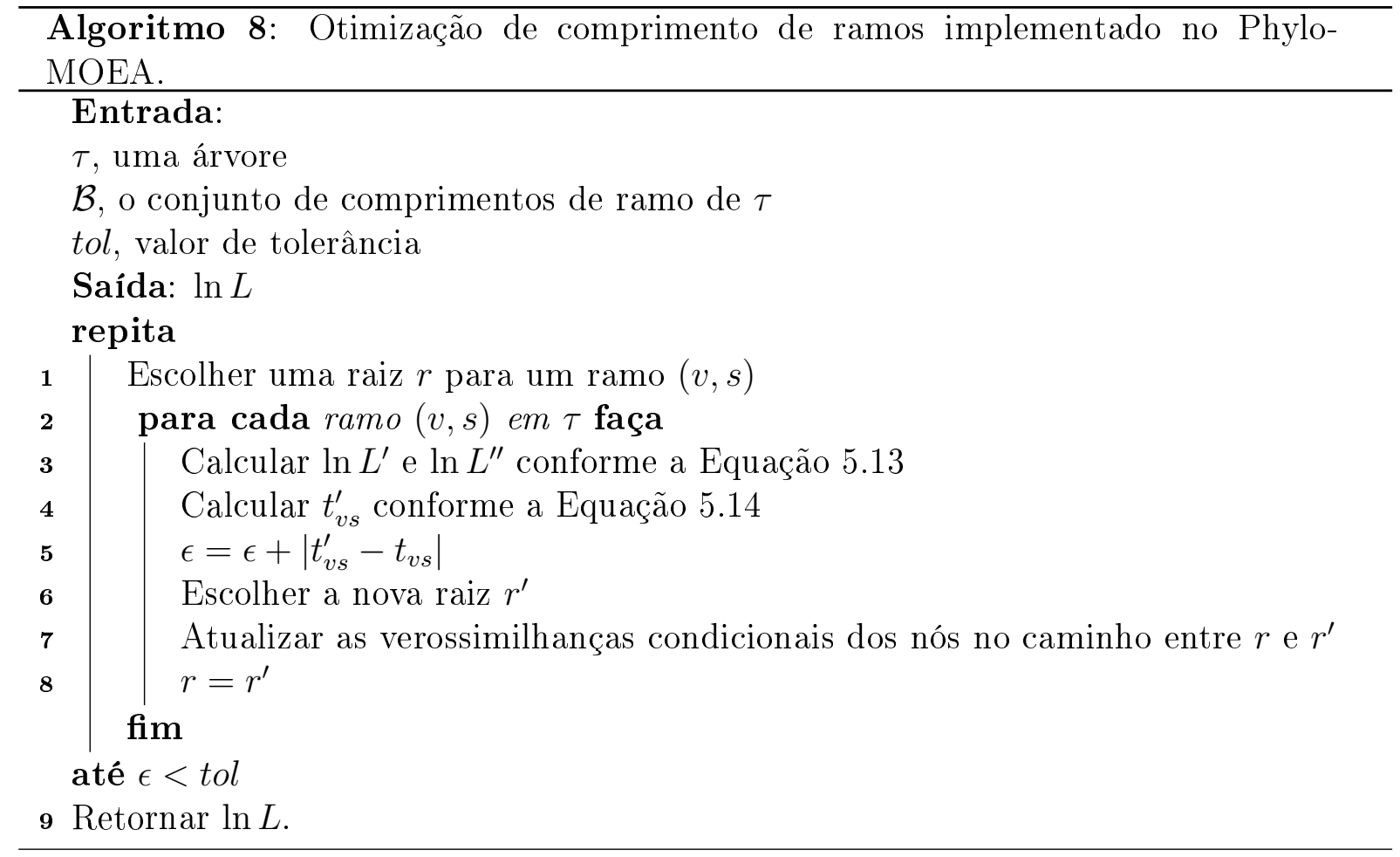

Várias outras técnicas de otimização clássica têm sido empregadas na otimização dos ramos como, por exemplo o, método de Newton para múltiplas variáveis (Weir, 1996), o método de otimização sem o emprego de derivadas (Brent, 1973) e de aproximações heurísticas (Hordijk e Gascuel, 2005). Porém, encontrar os valores ótimos para os comprimentos de ramos tem-se mostrado como um fator limitante na análise de máxima verossimilhança dado que é um processo que consume consideravelmente os recursos computacionais (Bryant et al., 2005). 


\subsection{Considerações finais}

Neste capítulo foi apresentado o modelo de MOEA para o problema de reconstrução de árvores filogenéticas. Os critérios de otimalidade empregados no PhyloMOEA são a máxima parcimônia e a máxima verossimilhança. Os detalhes da adaptação do NSGAII (Deb et al., 2000) para ser aplicado a filogenia foram também apresentados. O resultado da execução do PhyloMOEA é um conjunto de árvores Pareto-ótimas correspondentes a um compromisso entre os critérios de parcimônia e verossimilhança.

O desempenho do modelo proposto com diversos bancos de seqüências e a análise de resultados dos experimentos é discutido no Capítulo 6. 


\section{CAPÍTULO \\ 6 \\ Experimentos e resultados}

\subsection{Introdução}

Neste capítulo são apresentados os resultados da aplicação do PhyloMOEA para 4 bancos de seqüências de DNA. O objetivo dos experimentos é mostrar o desempenho de várias execuções do PhyloMOEA para encontrar um conjunto de árvores que representem um compromisso entre os critérios de máxima parcimônia e máxima verossimilhança.

As demais Seções deste capítulo estão organizadas como segue. A Seção 6.2 apresenta os conjuntos de teste empregados nos experimentos. A Seção 6.3 detalha as condições iniciais dos experimentos, enfatizando a geração de soluções iniciais e os parâmetros do PhyloMOEA empregados. A Seção 6.4 mostra os resultados das execuções do PhyloMOEA em cada banco de testes, destacando as melhores soluções encontradas, a avaliação estatística das topologias alternativas e a comparação desses resultados com os obtidos pelo programa Mr.Bayes (Ronquist et al., 2005). A Seção 6.5 mostra como a incorporação da taxa de heterogeneidade de sítios afeta os resultados das execuções do PhyloMOEA. Finalmente, a Seção 6.6 sintetiza os resultados mais relevantes deste Capítulo.

\subsection{Conjuntos de seqüências}

O PhyloMOEA foi testado com 4 bancos de seqüências de DNA, os quais foram empregados como bancos de teste de programas de vários inferência filogenética tais como: 
PHYML (Guindon e Gascuel, 2003), GAML (Lewis, 1998), RAxML (Stamatakis et al., 2005b), IQPNNI (Vinh e von Haeseler, 2004), e TNT (Goloboff et al., 2004).

1. O banco $r b c L \_55$ contendo 55 seqüências (de 1.314 nucleotídeos cada uma) do gen rbcL de cloroplasto de plantas (Lemmon e Milinkovitch, 2002a; Lewis, 1998);

2. O banco mtDNA_186 contendo 186 sequências de DNA mitocondrial humano (de 16.608 nucleotídeos cada uma) obtido do banco mtDB (The Human Mitochondrial genome Database (Ingman e Gyllensten, 2006));

3. O banco RDPII_218 contendo 218 seqüências de RNA procariótico (de 4.182 nucleotídeos) encontrado no projeto RDPII ( The Ribosomal Database Project II (Cole et al., 2005; Guindon e Gascuel, 2003; Stamatakis et al., 2005b; Vinh e von Haeseler, 2004));

4. O banco ZILLA_500 contendo 500 seqüências (de 1.428 nucleotídeos cada uma) do gen rbcL de plantas (Chase et al., 1993; Goloboff e Farris, 2001; Guindon e Gascuel, 2003; Stamatakis et al., 2005b; Vinh e von Haeseler, 2004).

Os bancos são apresentados em ordem crescente de número de espécies considerada, aumentando também a complexidade de busca topológica.

\subsection{Condições iniciais}

As soluções da população inicial do PhyloMOEA foram obtidas utilizando análises de parcimônia, verossimilhança e bootstrap (Felsenstein, 1985) (ver Capítulo 2). Como mencionado no Capítulo 5, o PhyloMOEA pode gerar soluções inciais aleatórias, porém usualmente tais soluções encontram-se muito longe da fronteira de Pareto. Isso retarda notavelmente a convergência do algoritmo sobretudo nos bancos de seqüências maiores. A análise de parcimônia foi efetuado com o programa NONA (Goloboff, 1999b); enquanto a análise de máxima verossimilhança foi efetuada empregando o programa RAxML-V (Stamatakis e Meier, 2004).

A inclusão de soluções geradas por meio da análise de bootstrap (Felsenstein, 1985) na população inicial possibilita que o algoritmo encontre facilmente soluções intermediárias entre os extremos da fronteira de Pareto. Para a análise de bootstrap (Felsenstein, 1985) foi empregado o programa PHYML (Guindon e Gascuel, 2003). Assim, as soluções iniciais correspondentes a população inicial do PhyloMOEA são:

- uma árvore gerada pelo NONA (máxima parcimônia);

- uma árvore gerada pelo RAxML-V (máxima verossimilhança); 
- As demais árvores geradas por bootstrap empregando o programa PHYML.

A Tabela 6.1 mostra os valores de parcimônia e verossimilhança para as soluções calculadas pelo NONA e RAxML-V para os 4 bancos de teste. Tais valores representam os pontos extremos (máxima parcimônia e máxima verossimilhança) da Fronteira de Pareto a ser pesquisada pelo PhyloMOEA.

Tabela 6.1: Resultados de máxima parcimônia e máxima verossimilhança obtidos pelo NONA e RAxML-V.

\begin{tabular}{|l|r|r|r|r|}
\hline \multirow{2}{*}{ Banco } & \multicolumn{2}{|c|}{ NONA } & \multicolumn{2}{c|}{ RAxML-V } \\
\cline { 2 - 5 } & Parcimônia & Verossimilhança & Parcimônia & Verossimilhança \\
\hline rbcL_55 & 4.874 & $-24.627,848$ & 4.894 & $-24.583,331$ \\
\hline mtDNA_186 & 2.438 & $-41.049,768$ & 2.450 & $-40.894,550$ \\
\hline RDPII_218 & 41.534 & $-170.831,121$ & 42.631 & $-156.595,873$ \\
\hline ZILLA_500 & 16.219 & $-87.361,484$ & 16.276 & $-86.993,826$ \\
\hline
\end{tabular}

A Tabela 6.2 mostra os parâmetros do PhyloMOEA empregados nos experimentos. Pode-se observar que o banco ZILLA_500 requer um maior número de iterações e tamanho de população devido a este banco conter um maior número de espécies, o que aumenta significativamente o espaço de busca. Para o cálculo da verossimilhança, emprega-se o modelo de substituição de seqüências HKY85 (Hasegawa et al., 1985) (ver Capítulo 2). Tal modelo é extensivamente empregado na literatura consultada (Guindon e Gascuel, 2003; Lemmon e Milinkovitch, 2002a; Lewis, 1998; Stamatakis e Meier, 2004).

Como visto no Capítulo 5, o PhyloMOEA possui os operadores de mutação topológica NNI, SPR e TBR. Os resultados de experimentos preliminares (não mostrados nesta Capítulo), não indicaram uma diferença significativa entre os três operadores. Assim, optou-se por operador NNI por ser a forma mais simples de modificação topológica. Os parâmetros de taxa de recombinação e mutação apresentados na Tabela 6.2 mostraram um desempenho adequado nos experimentos.

Tabela 6.2: Parâmetros do PhyloMOEA para os experimentos.

\begin{tabular}{|l|l|}
\hline Parâmetro & Valor \\
\hline Gerações & $500\left(r b c L \_55, m t D N A_{-} 186\right.$, e RDPII_218) \\
& $2.000\left(Z I L L A \_500\right)$ \\
Tamanho da População & $50\left(r b c L \_55, m t D N A \_186\right.$, e RDPII_218) \\
& e $100\left(Z \bar{I} L L A_{-} 500\right)$ \\
Taxa de Cruzamento & 0,8 \\
Taxa de Mutação & 0,05 \\
Operador de Mutação & NNI \\
Modelo Evolutivo & HKY85 \\
\hline
\end{tabular}




\subsection{Resultados das execuções do PhyloMOEA}

Devido à natureza estocástica dos AEs (De Jong, 2006), o PhyloMOEA foi executado 20 vezes por cada banco de teste. Tais execuções permitem observar a estabilidade e o comportamento do algoritmo. Para aumentar a quantidade de testes realizados foi utilizado um cluster de 5 nós, cada nó com um processador de dois núcleos Atlhon 64 com 2Gb de RAM, rodando o sistema operacional Rocks Linux.

A Tabela 6.3 mostra os melhores valores de parcimônia e verossimilhança obtidos nas execuções do PhyloMOEA. Além disso, é mostrada a média e o desvio padrão em cada caso. Os números indicados em negrito destacam os casos em que o PhyloMOEA conseguiu melhorar as árvores de máxima parcimônia e máxima verossimilhança. No caso do critério de parcimônia, apenas para o banco mtDNA_186 obteve-se resultados melhores em relação aos valores iniciais. No critério de verossimilhança, o PhyloMOEA melhorou esses valores para todos os bancos. No caso do banco 500_ZILLA a melhora foi mais significativa.

Tabela 6.3: Resumo dos resultados das execuções do PhyloMOEA.

\begin{tabular}{|l|r|c|c|c|}
\hline \multirow{2}{*}{ Banco } & \multicolumn{2}{|c|}{$\begin{array}{c}\text { Pontuação de } \\
\text { Parcimônia }\end{array}$} & \multicolumn{2}{c|}{$\begin{array}{c}\text { Pontuação de } \\
\text { Verossimilhança }\end{array}$} \\
\cline { 2 - 5 } & Melhor & Média $\pm \sigma$ & Melhor & Média $\pm \sigma$ \\
\hline$r b c L \_55$ & 4.874 & $4.874,00 \pm 0,00$ & $\mathbf{- 2 4 . 5 8 3 , 3 3 0}$ & $\mathbf{- 2 4 . 5 8 3 , 3 3 0} \pm 0,00$ \\
\hline$m t D N A \_186$ & $\mathbf{2 . 4 3 6}$ & $\mathbf{2 . 4 3 7 , 1 0} \pm 0,64$ & $\mathbf{- 4 0 . 8 9 4 , 3 4 3}$ & $\mathbf{- 4 0 . 8 9 4 , 5 2 8} \pm 0,06$ \\
\hline $218 \_R D P I I$ & 41.534 & $41.534,00 \pm 0,00$ & $\mathbf{- 1 5 6 . 5 9 5 , 8 5 0}$ & $\mathbf{- 1 5 6 . 5 9 5 , 8 5 0} \pm 0,00$ \\
\hline $500 \_Z I L L A$ & 16.219 & $16.219,00 \pm 0,00$ & $\mathbf{- 8 6 . 9 9 1 , 6 4 9}$ & $\mathbf{- 8 6 . 9 9 3 , 5 6 1} \pm 0,66$ \\
\hline
\end{tabular}

O PhyloMOEA encontra dois conjuntos de soluções:

- As Soluções Pareto-ótimas, ou seja, soluções que não são dominadas por nenhuma solução na população final;

- As Soluções Finais, as quais mantém todas as soluções não dominadas além daquelas que possuem valores iguais para o critério de parcimônia. Tais soluções são importantes uma vez que é possível que duas topologias possuam o mesmo valor de parcimônia e valores de verossimilhança diferentes. Nesse caso, se for aplicado o critério de dominância de Pareto, seria eliminada a solução com menor verossimilhança. Porém, ambas as soluções são relevantes do ponto de vista do critério de parcimônia e, portanto, são guardadas pelo PhyloMOEA.

A Tabela 6.4 mostra os valores máximo, média e desvio padrão do número de Soluções Pareto-ótimas e Finais encontradas pelo PhyloMOEA. Pode-se observar um comportamento estável em todas as execuções do algoritmo dado que os valores de desvio são relativamente pequenos. 
Tabela 6.4: Resumo do número de soluções encontradas nas execuções do PhyloMOEA.

\begin{tabular}{|l|r|c|r|r|}
\hline \multirow{2}{*}{ Banco } & \multicolumn{2}{|c|}{ Soluções Pareto-ótimas } & \multicolumn{2}{c|}{ Soluções Finais } \\
\cline { 2 - 5 } & Máximo & Média $\pm \sigma$ & Máximo & Média $\pm \sigma$ \\
\hline rbcL_55 & 10 & $7,05 \pm 1,39$ & 54 & $48,20 \pm 3,00$ \\
\hline mtDNA_186 & 12 & $9,05 \pm 1,23$ & 55 & $48,95 \pm 2,61$ \\
\hline $218 \_R D P I I$ & 35 & $28,75 \pm 2,97$ & 85 & $77,40 \pm 4,15$ \\
\hline $500 \_Z I L L A$ & 24 & $18.50 \pm 2.52$ & 121 & $102.40 \pm 7.99$ \\
\hline
\end{tabular}

As Figuras 6.1, 6.2, 6.3 e 6.4 mostram a fronteira de Pareto obtida de uma execução do PhyloMOEA para os bancos $r b c L \_55, m t D N A_{-}$186, RDPII_218 e ZILLA_500, respectivamente. $\mathrm{O}$ eixo horizontal representa a pontuação de parcimônia e o eixo vertical representa a pontuação de verossimilhança. Devido ao fato de que as pontuações de parcimônia são números inteiros, a Fronteira de Pareto é formada por pontos descontínuos. Tais pontos foram unidos por linhas para facilitar a visualização da fronteira. Se o intervalo de valores correspondentes a parcimônia for pequeno, são esperadas poucas soluções intermediárias entre os pontos extremos da fronteira. Tal fenômeno é observado nas Figuras 6.1 e 6.2. Isso é também indicado no número de soluções na fronteira de Pareto na Tabela 6.4. Por outro lado, se o intervalo for maior, como acontece para bancos maiores (RDPII_218 e ZILLA_500), existem várias soluções intermediárias, como observado nas Figuras 6.3 e 6.4, assim como na Tabela 6.4.

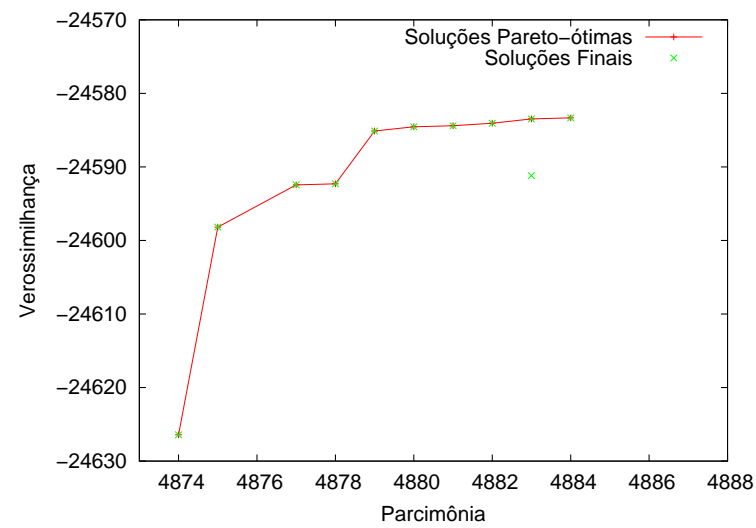

Figura 6.1: Soluções Pareto-ótimas banco $r b c L 55$.

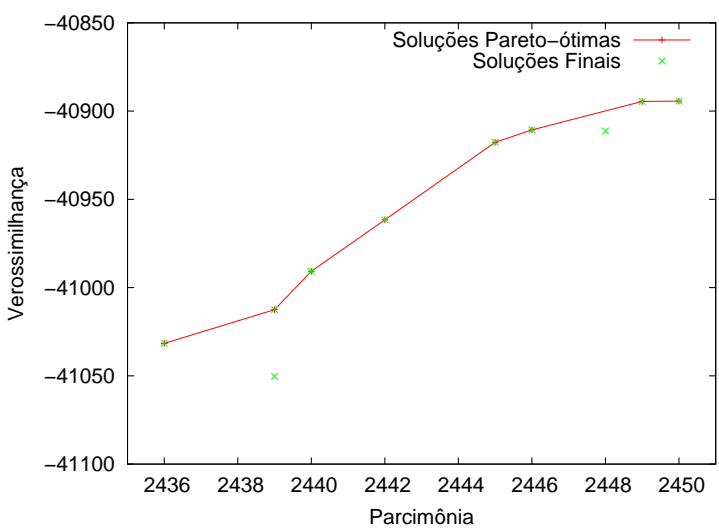

do Figura 6.2: Soluções Pareto-ótimas do banco $m t D N A_{-} 186$.

\subsubsection{Testes de árvores alternativas e clados}

O teste SH (Shimodaira e Hasegawa, 1999) (ver Capítulo 2) foi aplicado com os critérios de parcimônia e verossimilhança separadamente para o conjunto de soluções correspondentes a execução do PhyloMOEA com melhor resultado para cada banco. As Tabelas 6.5 e 6.6 mostram os resultados do teste SH para as Soluções Pareto-ótimas e as Soluções Finais, respectivamente. Os valores de tais tabelas referem-se ao número de soluções não 


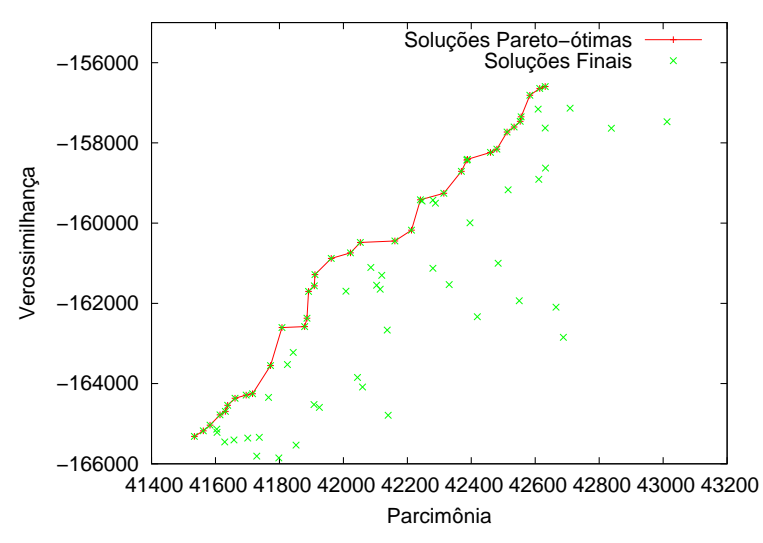

Figura 6.3: Soluções Pareto-ótimas banco RDPII_218.

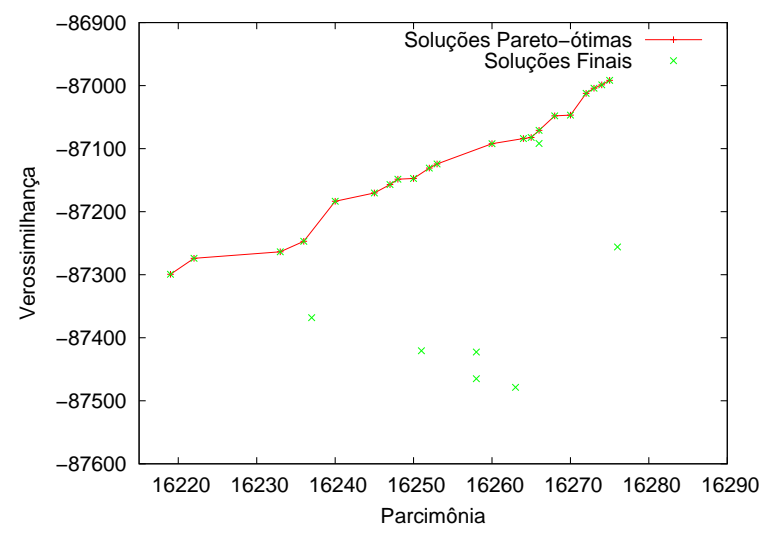

do Figura 6.4: Soluções Pareto-ótimas do banco ZILLA_500.

rejeitadas e soluções rejeitadas pelo teste SH aplicado com os critérios de parcimônia e verossimilhança.

Na Tabela 6.5 pode-se observar que não existem soluções Pareto ótimas rejeitadas para o banco $r b c L \_55$ nos critérios de parcimônia e verossimilhança. Isso indica que as pontuações das soluções intermediárias estão próximas aos dos pontos extremos (melhores soluções encontradas para cada critério) da fronteira e, portanto, o teste SH não rejeita tais soluções. No caso dos bancos RDPII_218 e ZILLA_500 existe um maior número de soluções rejeitadas uma vez que as pontuações das soluções intermediárias encontramse afastadas dos melhores pontuações para cada objetivo. Mesmo assim, em todos os casos existem soluções intermediárias que não são rejeitadas pelo teste SH para ambos os critérios.

Na Tabela 6.6 observa-se um alto número de Soluções Finais rejeitadas nos bancos $r b c L \_55, R D P I I \_218$ e ZILLA_500. No caso do banco mtDNA_186, existe um alto número de Soluções Finais não rejeitadas. Uma observação importante é que, o número de Soluções Finais não rejeitadas em todos os bancos de dados é maior que os mesmos valores para as Soluções Pareto-ótimas mostrados na Tabela 6.6. Esse resultado mostra que, de certa forma, o critério empregado para manter as soluções relevantes para o critério de parcimônia tornou-se útil para encontrar soluções relevantes para o critério de verossimilhança. Comparando os valores de ambas as Tabelas 6.5 e 6.6, verifica-se que o número de Soluções finais não rejeitadas é mais que o dobro, na maioria dos casos, do número de soluções Pareto-ótimas.

É importante ressaltar que o teste $\mathrm{SH}$ tem sido empregado em diferentes critérios de otimalidade separadamente. Ou seja, não é um teste desenvolvido com a finalidade de analisar soluções contendo múltiplos critérios. Porém, os resultados do teste SH mostraram que existem soluções intermediárias que são consistentes tanto com a solução de máxima parcimônia quanto com a solução de máxima verossimilhança. Portanto, o Phy- 
loMOEA foi capaz de encontrar árvores alternativas que representam um compromisso entre as melhores árvore para cada critério considerado separadamente.

Tabela 6.5: Resultados do teste SH para as Soluções Pareto-ótimas.

\begin{tabular}{|l|r|r|r|r|}
\hline \multirow{2}{*}{ Banco } & \multicolumn{2}{|c|}{$\begin{array}{c}\text { Teste SH } \\
\text { Parcimônia }\end{array}$} & \multicolumn{2}{c|}{$\begin{array}{c}\text { Teste SH } \\
\text { Verossimilhança }\end{array}$} \\
\cline { 2 - 5 } & Não Rejeitadas & Rejeitadas & Não Rejeitadas & Rejeitadas \\
\hline rbcL_55 & 10 & 0 & 10 & 0 \\
\hline mtDNA_186 & 8 & 0 & 4 & 4 \\
\hline RDPII_218 & 10 & 25 & 6 & 29 \\
\hline ZILLA_500 & 12 & 9 & 14 & 7 \\
\hline Total & 40 & 34 & 34 & 40 \\
\hline
\end{tabular}

Tabela 6.6: Resultados do teste SH para as Soluções Finais.

\begin{tabular}{|l|r|r|r|r|}
\hline \multirow{2}{*}{ Banco } & \multicolumn{2}{|c|}{$\begin{array}{c}\text { Teste SH } \\
\text { Parcimônia }\end{array}$} & \multicolumn{2}{c|}{$\begin{array}{c}\text { Teste SH } \\
\text { Verossimilhança }\end{array}$} \\
\cline { 2 - 5 } & Não Rejeitadas & Rejeitadas & Não Rejeitadas & Rejeitadas \\
\hline rbcL_55 & 16 & 37 & 17 & 36 \\
\hline mtDNA_186 & 37 & 8 & 22 & 23 \\
\hline RDPII_218 & 21 & 57 & 11 & 67 \\
\hline$Z I L L A \_500$ & 27 & 79 & 29 & 77 \\
\hline Total & 101 & 181 & 79 & 203 \\
\hline
\end{tabular}

O conjunto de árvores obtidas pelo PhyloMOEA nas Soluções Pareto-ótimas e nas Soluções Finais permitem calcular também o grau de suporte para cada ramo. Esses resultados podem ser comparados com os graus de suporte de ramos calculados utilizando a técnica de bootstrap (Felsenstein, 1985) ou com probabilidades posteriores dos ramos calculados por inferência Bayesiana (Lemmon e Milinkovitch, 2002a).

O grau de suporte do PhyloMOEA para cada clado é a freqüência de tais clados nas árvores das Soluções Pareto-ótimas e Soluções Finais. Para tal procedimento, foram empregadas as soluções da melhor execução do PhyloMOEA em cada banco de seqüências. Os resultados foram comparados com as probabilidades posteriores calculadas pelo programa Mr.Bayes (Huelsenbeck e Ronquist, 2003; Huelsenbeck et al., 2001). O Mr.Bayes foi executado com os 4 bancos de dados empregando os parâmetros padrões do programa, com exceção do modelo HKY85 (Hasegawa et al., 1985) e o número de iterações de 1.000.000 para os bancos $r b c L \_55$ e mtDNA_186, 1.500 .000 para o banco RDPII_218 e 2.000 .000 para o banco ZILLA_500. A saída do Mr.Bayes possui arquivos referentes ao estado da execução do algoritmo, árvore de consenso, probabilidade posterior das árvores iteradas e parâmetros do modelo evolutivo empregado (Ronquist et al., 2005).

O conjunto de ramos comuns para as soluções do PhyloMOEA e as soluções do Mr.Bayes foi classificado em várias classes para facilitar a análise: 
- Tipo I: o clado pertence apenas as árvores das soluções intermediárias, não estando presente nas árvores de máxima parcimônia ou máxima verossimilhança;

- Tipo II: o clado pertence apenas a árvore de máxima parcimônia;

- Tipo III: o clado pertence somente a árvore de máxima parcimônia e as árvores das soluções intermediárias;

- Tipo IV: o clado pertence apenas a árvore de máxima verossimilhança;

- Tipo V: o clado pertence somente a árvore de máxima verossimilhança e as árvores das soluções intermediárias;

- Tipo VI: o clado pertence apenas a árvore de máxima parcimônia e a árvore de máxima verossimilhança;

- Tipo VII. o clado encontra-se nas árvores de máxima parcimônia, verossimilhança e soluções intermediárias.

As Tabelas 6.7-6.14 mostram os resultados da comparação do PhyloMOEA com Mr.Bayes para as Soluções Pareto-ótimas e as Soluções Finais dos bancos $r b c L$ 55, mtDNA_186, RDPII_218 e ZILLA_500, respectivamente. Os números em negrito indicam os maiores graus de suporte do PhyloMOEA e do Mr.Bayes. O significado de cada coluna nessas tabelas é explicado a seguir:

- Tipo: o tipo de clado referido;

- Núm.: o número de clados encontrados para cada tipo;

- PMOEA: a média do grau de suporte para cada tipo de clado das árvores calculadas pelo PhyloMOEA;

- PBayes: o grau de suporte para cada tipo de clado obtida pelo Mr.Bayes;

- Dif.: o valor absoluto da diferença entre as colunas PMOEA e PBayes;

- DPars: para cada clado de um determinado tipo, calcula-se a diferença entre o valor de parcimônia da árvore a qual o clado pertence e a pontuação de máxima parcimônia encontrado. A média de tais valores é depois normalizada no intervalo $[0,1]$. Dpars é o valor normalizado;

- DVeross: obtido de forma similar a DPars, utilizando os valores de verossimilhança no lugar da parcimônia; 
- DTPars: para cada clado de um determinado tipo, calcula-se a distância topológica de Robinson-Foulds (Robinson e Foulds, 1979) entre a árvore de máxima parcimônia e a árvore a qual o clado pertence. A média de tais valores correspondente a DTPars;

- DTVeross: o cálculo é similar ao DTPars trocando os valores de parcimônia pelos de verossimilhança.

Os resultados mostram que os clados comuns dar árvores encontradas pelo PhyloMOEA e o Mr.Bayes pertencem aos tipos I, III, V e VII. Deve-se observar também que desses clados, apenas os de tipo V e VII mostram uma média de grau de suporte (colunas PMOEA e PBayes) alta tanto no PhyloMOEA como no Mr.Bayes. Ou seja, os clados comuns melhor suportados correspondem as árvores intermediárias e as árvores de máxima parcimônia e/ou máxima verossimilhança. Os valores de distância nas pontuações (colunas DPars e DVeross) mostram, na maioria dos casos, uma maior proximidade das árvores que contém tais tipos de clados com a árvore de máxima verossimilhança. Os valores de distância topológica (colunas DTPars e DTVeross) mostram também uma menor distância entre as árvores contendo os clados de tipo V e VII e a árvore de máxima verossimilhança.

Os clados de tipo I e III apresentam o menor valor nas colunas PMOEA e PBayes. A diferença entre os valores de ambas as colunas são também as maiores. Isso significa que, os clados correspondentes apenas às soluções intermediárias e/ou os clados correspondentes a árvore de máxima parcimônia são menos suportados pelo PhyloMOEA e pelo Mr.Bayes. Uma exceção acontece para o banco RDPII_218 (ver Tabelas 6.11 e 6.12), onde a probabilidade posterior é maior que $50 \%$ para os clados de tipo I e III. Os clados de tipo II aparecem apenas no banco $r b c L \_55$ (mostrado na Tabela 6.7), porém este tipo de clado é pouco suportado.

Os resultados das comparações realizadas entre os clados comuns do PhyloMOEA e o Mr.Bayes claramente favorecem aqueles clados que estão próximos à árvore de máxima verossimilhança. Tal resultado é o esperado, pois a inferência Bayesiana emprega o cálculo de verossimilhança e, quando as informações a priori não influenciam significativamente, os resultados concordam com os da máxima verossimilhança (Felsenstein, 2004).

Na última linha das Tabelas 6.7-6.14, encontra-se a somatória do número de clados de cada tipo e as médias correspondentes as demais colunas dessas tabelas. Em todos os casos, os clados de tipo V e VII apresentaram uma maior freqüência que os demais de tipos. A diferença das médias gerais do grau de suporte do PhyloMOEA e da probabilidade do Mr.Bayes é pequena na maioria dos casos. Além disso, as médias gerais das distâncias de pontuações e topológicas são também muito próximas.

As Figuras 6.5, 6.6, 6.7 e 6.8 mostram a relação do grau de suporte do PhyloMOEA (eixo vertical) e a probabilidade posterior do Mr.Bayes (eixo horizontal) dos clados do tipo 
V e VII para os bancos $r b c L_{-} 55, m t D N A_{-} 186, R D P I I \_218$ e $Z I L L A \_500$, respectivamente. A maior correspondência entre ambas as quantidades é observada para os clados do tipo VII, onde a maioria dos pontos estão concentrados e próximos da coordenada $[1,1]$ (maior grau de suporte para ambos os métodos) da reta (função identidade ilustrada por uma linha).

Tabela 6.7: Comparação dos resultados do PhyloMOEA e Mr.Bayes para as Soluções Pareto-ótimas do banco $r b c L \_55$.

\begin{tabular}{|r|r|r|r|r|r|r|r|r|}
\hline Tipo & Num. & PMOEA & PBayes & Dif. & DPars. & DVeross. & DTPars. & DTVeross. \\
\hline \hline I & 2 & 0,1500 & 0,2590 & 0,1090 & 0,3750 & 0,1869 & 0,1779 & 0,0913 \\
\hline II & 5 & 0,1000 & 0,1558 & 0,0558 & 0,0000 & 1,0000 & 0,0000 & 0,2500 \\
\hline III & 4 & 0,4500 & 0,4554 & 0,0054 & 0,2321 & 0,4613 & 0,1174 & 0,1408 \\
\hline V & 13 & 0,7231 & 0,7327 & 0,0096 & 0,6603 & 0,0708 & 0,2160 & 0,0392 \\
\hline VII & 39 & $\mathbf{1 , 0 0 0 0}$ & $\mathbf{0 , 9 6 5 1}$ & 0,0349 & 0,5300 & 0,1878 & 0,1865 & 0,0692 \\
\hline \hline Total. & 63 & 0,4846 & 0,5136 & 0,0429 & 0,3595 & 0,3814 & 0,1396 & 0,1181 \\
\hline
\end{tabular}

Tabela 6.8: Comparação dos resultados do PhyloMOEA e Mr.Bayes para as Soluções Finais do banco $r b c L \_55$.

\begin{tabular}{|r|r|r|r|r|r|r|r|r|}
\hline Tipo & Num. & PMOEA & PBayes & Dif. & DPars. & DVeross. & DTPars. & DTVeross. \\
\hline \hline I & 3 & 0,0755 & 0,4268 & 0,3513 & 0,4295 & 0,3207 & 0,2935 & 0,1693 \\
\hline III & 9 & 0,2558 & 0,2889 & 0,0332 & 0,4005 & 0,3459 & 0,1849 & 0,3245 \\
\hline V & 13 & 0,5544 & 0,7327 & 0,1783 & 0,3320 & 0,2440 & 0,2873 & 0,1387 \\
\hline VII & 39 & $\mathbf{0 , 8 8 2 4}$ & $\mathbf{0 , 9 6 5 1}$ & 0,0827 & 0,3654 & 0,2808 & 0,2669 & 0,1865 \\
\hline \hline Total & 64 & 0,4420 & 0,6034 & 0,1614 & 0,3818 & 0,2979 & 0,2582 & 0,2047 \\
\hline
\end{tabular}

Tabela 6.9: Comparação dos resultados do PhyloMOEA e Mr.Bayes para as Soluções Pareto-ótimas do banco $m t D N A_{-} 186$.

\begin{tabular}{|r|r|r|r|c|r|r|r|r|}
\hline Tipo & Num. & PMOEA & PBayes & Dif. & DPars. & DVeross. & DTPars. & DTVeross. \\
\hline \hline I & 8 & 0,1406 & 0,1900 & 0,0494 & 0,2411 & 0,8080 & 0,1192 & 0,1916 \\
\hline III & 14 & 0,3304 & 0,1886 & 0,1418 & 0,1709 & 0,8427 & 0,0751 & 0,1985 \\
\hline V & 34 & 0,6103 & 0,4472 & 0,1631 & 0,7339 & 0,1876 & 0,2039 & 0,0482 \\
\hline VII & 139 & $\mathbf{0 , 9 9 6 4}$ & $\mathbf{0 , 8 9 9 4}$ & 0,0970 & 0,5281 & 0,4162 & 0,1614 & 0,1000 \\
\hline \hline Total & 195 & 0,5194 & 0,4313 & 0,1128 & 0,4185 & 0,5636 & 0,1399 & 0,1346 \\
\hline
\end{tabular}

Tabela 6.10: Comparação dos resultados do PhyloMOEA e Mr.Bayes para as Soluções Finais do banco $m t D N A_{-} 186$.

\begin{tabular}{|r|r|r|r|r|r|r|r|r|}
\hline Tipo & Num. & PMOEA & PBayes & Dif. & DPars. & DVeross. & DTPars. & DTVeross. \\
\hline \hline I & 14 & 0,0492 & 0,1802 & 0,1310 & 0,3828 & 0,3554 & 0,1781 & 0,1791 \\
\hline III & 14 & 0,4381 & 0,1886 & 0,2495 & 0,3600 & 0,4252 & 0,0817 & 0,2497 \\
\hline V & 34 & 0,4471 & 0,4472 & 0,0002 & 0,3281 & 0,1916 & 0,2344 & 0,0890 \\
\hline VII & 139 & $\mathbf{0 , 9 5 7 3}$ & $\mathbf{0 , 8 9 9 4}$ & 0,0579 & 0,3403 & 0,3058 & 0,1627 & 0,1673 \\
\hline \hline Total & 201 & 0,4729 & 0,4289 & 0,1096 & 0,3528 & 0,3195 & 0,1642 & 0,1713 \\
\hline
\end{tabular}


Tabela 6.11: Comparação dos resultados do PhyloMOEA e Mr.Bayes para as Soluções Pareto-ótimas do banco RDPII_218.

\begin{tabular}{|r|r|r|r|c|r|r|r|r|}
\hline Tipo & Num. & PMOEA & PBayes & Dif. & DPars. & DVeross. & DTPars. & DTVeross. \\
\hline \hline I & 6 & 0,1619 & 0,6169 & 0,4550 & 0,6329 & 0,3825 & 0,3840 & 0,2858 \\
\hline III & 3 & 0,3905 & 0,5250 & 0,1345 & 0,1862 & 0,8031 & 0,1194 & 0,4933 \\
\hline V & 61 & 0,5251 & 0,7265 & 0,2014 & 0,7378 & 0,2547 & 0,4429 & 0,2000 \\
\hline VII & 78 & $\mathbf{0 , 9 8 9 7}$ & $\mathbf{0 , 8 5 9 0}$ & 0,1307 & 0,4941 & 0,4952 & 0,3039 & 0,3332 \\
\hline \hline Total & 148 & 0,5168 & 0,6818 & 0,2304 & 0,5127 & 0,4839 & 0,3126 & 0,3281 \\
\hline
\end{tabular}

Tabela 6.12: Comparação dos resultados do PhyloMOEA e Mr.Bayes para as Soluções Finais do banco RDPII_218.

\begin{tabular}{|r|r|r|r|r|r|r|r|r|}
\hline Tipo & Num. & PMOEA & PBayes & Dif. & DPars. & DVeross. & DTPars. & DTVeross. \\
\hline \hline I & 8 & 0,1122 & 0,7111 & 0,5989 & 0,4732 & 0,5009 & 0,3491 & 0,3780 \\
\hline III & 3 & 0,3974 & 0,5250 & 0,1276 & 0,2035 & 0,7734 & 0,1472 & 0,5059 \\
\hline V & 61 & 0,4548 & 0,7265 & 0,2717 & 0,5888 & 0,2810 & 0,4407 & 0,2304 \\
\hline VII & 78 & $\mathbf{0 , 9 6 8 6}$ & $\mathbf{0 , 8 5 9 0}$ & 0,1096 & 0,3992 & 0,5292 & 0,2959 & 0,3750 \\
\hline \hline Total & 150 & 0,4833 & 0,7054 & 0,2769 & 0,4162 & 0,5211 & 0,3082 & 0,3723 \\
\hline
\end{tabular}

Tabela 6.13: Comparação dos resultados do PhyloMOEA e Mr.Bayes para as Soluções Pareto-ótimas do banco ZILLA_500.

\begin{tabular}{|r|r|r|r|c|r|r|r|r|}
\hline Tipo & Num. & PMOEA & PBayes & Dif. & DPars. & DVeross. & DTPars. & DTVeross. \\
\hline \hline I & 4 & 0,0952 & 0,2358 & 0,1406 & 0,8274 & 0,2064 & 0,2297 & 0,0495 \\
\hline III & 65 & 0,3575 & 0,3302 & 0,0274 & 0,3008 & 0,7482 & 0,0865 & 0,1860 \\
\hline V & 99 & 0,6445 & 0,5472 & 0,0974 & 0,7605 & 0,2849 & 0,2095 & 0,0698 \\
\hline VII & 355 & $\mathbf{0 , 9 9 3 4}$ & $\mathbf{0 , 8 2 8 7}$ & 0,1648 & 0,6227 & 0,4264 & 0,1745 & 0,1046 \\
\hline \hline Total & 523 & 0,5227 & 0,4854 & 0,1075 & 0,6278 & 0,4165 & 0,1750 & 0,1025 \\
\hline
\end{tabular}

Tabela 6.14: Comparação dos resultados do PhyloMOEA e Mr.Bayes para as Soluções Finais do banco ZILLA_500.

\begin{tabular}{|r|r|r|r|c|r|r|r|r|}
\hline Tipo & Num. & PMOEA & PBayes & Dif. & DPars. & DVeross. & DTPars. & DTVeross. \\
\hline \hline I & 19 & 0,0323 & 0,2489 & 0,2166 & 0,5439 & 0,5033 & 0,2228 & 0,1184 \\
\hline III & 65 & 0,3218 & 0,3302 & 0,0084 & 0,3602 & 0,6075 & 0,1005 & 0,2177 \\
\hline V & 99 & 0,6403 & 0,5472 & 0,0931 & 0,4898 & 0,3836 & 0,2424 & 0,0879 \\
\hline VII & 355 & $\mathbf{0 , 9 7 5 0}$ & $\mathbf{0 , 8 2 8 7}$ & 0,1463 & 0,4518 & 0,4473 & 0,2037 & 0,1252 \\
\hline \hline Total & 538 & 0,4923 & 0,4887 & 0,1161 & 0,4614 & 0,4854 & 0,1923 & 0,1373 \\
\hline
\end{tabular}

\subsection{Incorporação da variação de taxas entre sítios}

Os cálculos de verossimilhança nos experimentos da Seção 6.4 não consideram a heterogeneidade da taxa de substituição (ASRV) entre os sítios (ver Capítulo 2). Vários autores 


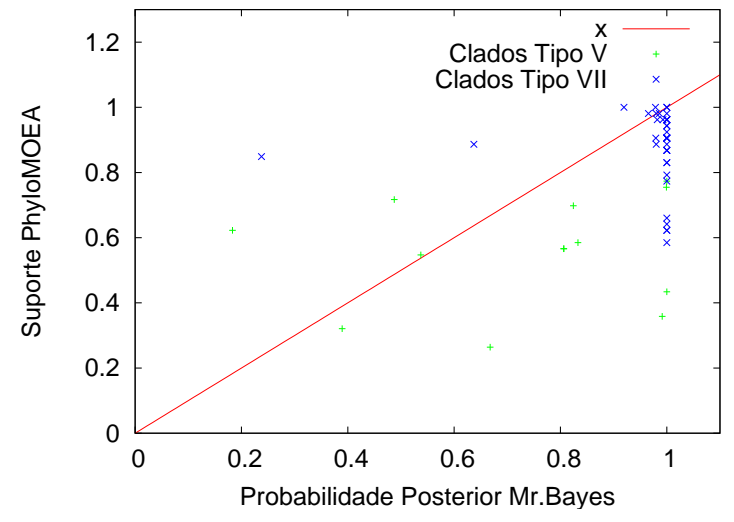

Figura 6.5: Grau de suporte do PhyloMOEA vs. Probabilidade Posterior do Mr.Bayes para as Soluções Pareto-ótimas do banco $r b c L \_55$.

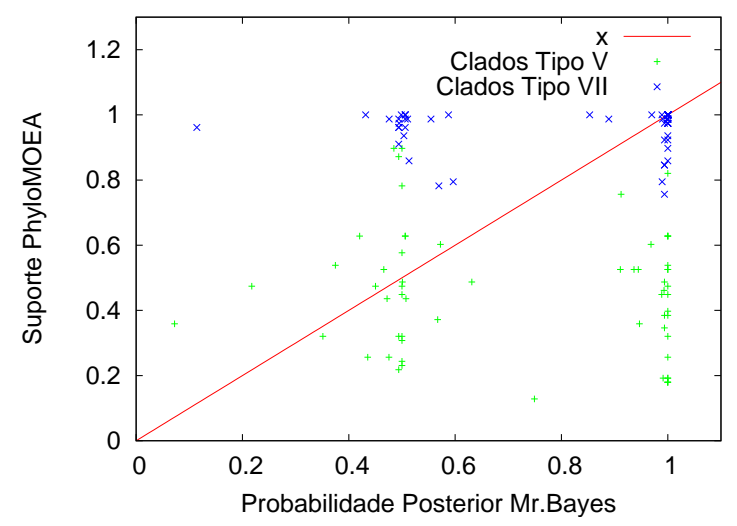

Figura 6.7: Grau de suporte do PhyloMOEA vs. Probabilidade Posterior do Mr.Bayes para as Soluções Pareto-ótimas do banco RDPII_218.

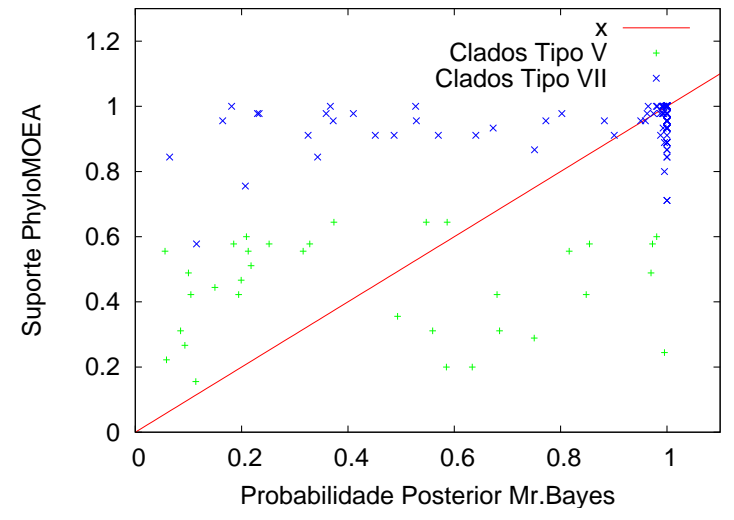

Figura 6.6: Grau de suporte do PhyloMOEA vs. Probabilidade Posterior do Mr.Bayes para as Soluções Pareto-ótimas do banco $m t D N A \_186$.

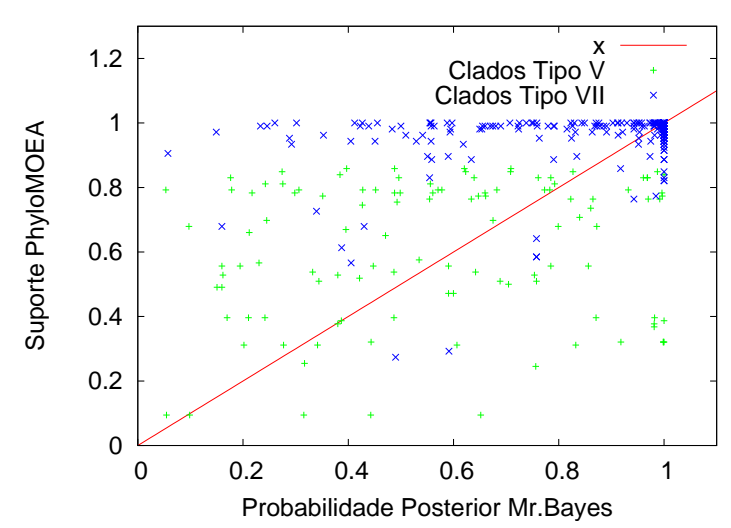

Figura 6.8: Grau de suporte do PhyloMOEA vs. Probabilidade Posterior do Mr.Bayes para as Soluções Pareto-ótimas do banco ZILLA_500.

assinalam que nos bancos de seqüências reais, os sítios evoluem com taxas diferentes (Felsenstein, 2004; Yang, 2006). Quando esse fator é empregado, os resultados da análise de verossimilhança podem ser sensivelmente melhorados (Yang, 2006).

Assim, no decorrer das pesquisas, incorporou-se o ASRV empregando a taxa de heterogeneidade Gama (ver Capítulo 2) no modelo HKY85, resultando no modelo HYK85 $+\Gamma$. A análise de máxima verossimilhança foi efetuada para cada banco de teste empregando o programa RAxML-V (Stamatakis e Meier, 2004) considerando o ASRV. Contudo, esse programa emprega uma aproximação do modelo HKY85 $+\Gamma$ denominado HKY85CAT (Stamatakis, 2006a). As soluções do RAxML-V foram submetidas a uma otimização dos comprimentos de ramos e parâmetros do modelo HKY85 $+\Gamma$ utilizando o PHYML (Guin- 
don e Gascuel, 2003). Portanto, a análise completa de verossimilhança é realizada pela combinação de RAxML-V+PHYML. Da mesma forma que nos experimentos da Seção 6.4, a soluções de máxima parcimônia são calculadas com o programa NONA e o restante das soluções iniciais é obtida pela análise de bootstrap empregando o PHYML (Guindon e Gascuel, 2003).

A Tabela 6.15 mostra os valores de parcimônia e verossimilhança para as soluções calculadas pelo NONA e RAxML-V+PHYML para os 4 bancos de teste. Deve-se observar que os valores de verossimilhança dessa tabela são significativamente melhores comparando com os valores correspondentes aos da Tabela 6.1. Ou seja, a incorporação de ASRV utilizando o modelo HYK85 $+\Gamma$ melhorou significativamente as pontuações de verossimilhança das soluções obtidas pelo NONA e RAxML-V+PHYML.

Além disso, as soluções calculadas pelo RAxML-V+PHYML mostraram pequenas variações na pontuação de parcimônia comparada aos valores mostrados na Tabela 6.1. Os valores de parcimônia de tais soluções pioraram para os bancos $m t D N A_{-} 186, R D P I I \_218$ e ZILLA_500. Esse resultado indica que os pontos extremos da fronteira para tais bancos encontram-se mais distantes.

Tabela 6.15: Resultados de máxima parcimônia e máxima verossimilhança obtidos pelo NONA e RAxML-V+PHYML (considerando o ASRV).

\begin{tabular}{|l|r|r|r|r|}
\hline \multirow{2}{*}{ Banco } & \multicolumn{2}{|c|}{ NONA } & \multicolumn{2}{c|}{ RAxML-V + PHYML } \\
\cline { 2 - 5 } & Parcimônia & Verossimilhança & Parcimônia & Verossimilhança \\
\hline rbcL_55 & 4.874 & $-21.989,580$ & 4.893 & $-21.889,844$ \\
\hline mtDNA_186 & 2.438 & $-40.010,941$ & 2452 & $-39.896,442$ \\
\hline RDPII_218 & 41.534 & $-147.794,345$ & 42.813 & $-134.696,535$ \\
\hline ZILLA_500 & 16.219 & $-81.880,193$ & 16.310 & $-81.018,060$ \\
\hline
\end{tabular}

Os parâmetros da execução do PhyloMOEA são os mesmos que os empregados na Seção 6.4 (ver Tabela 6.2). Os parâmetros $\kappa$ e $\alpha$ do modelo HKY85 $+\Gamma$ para os 4 bancos de teste são mostrados na Tabela 6.16. Tais valores foram obtidos com o programa PHYML a partir das árvores de máxima verossimilhança do RAxML.

Tabela 6.16: Parâmetros do modelo HKY $85+\Gamma$ para os experimentos.

\begin{tabular}{|c|r|c|}
\hline Banco & \multicolumn{1}{|c|}{$\alpha$} & $\kappa$ \\
\hline$r b c L \_55$ & 5,075 & 0,355 \\
\hline mtDNA_186 & 33,451 & 0,015 \\
\hline RDPII_218 & 2,719 & 0,533 \\
\hline ZILLA_500 & 3,890 & 0,950 \\
\hline
\end{tabular}




\subsubsection{Resultados das execuções do PhyloMOEA utilizando ASRV}

O PhyloMOEA foi executado apenas 10 vezes por cada banco de teste, devido ao aumento significativo de tempo de execução quando considera-se o ASRV. A Tabela 6.17 mostra os melhores valores de parcimônia e verossimilhança obtidos nas execuções do PhyloMOEA. Além disso, é mostrada a média e o desvio padrão em cada caso. Os números indicados em negrito mostram onde o PhyloMOEA conseguiu melhorar as árvores de máxima parcimônia e máxima verossimilhança em relação a população inicial (ver Tabela 6.15). Os resultados mostram uma pequena melhoria nos critérios de parcimônia e verossimilhança apenas para o banco $m t D N A_{-} 186$.

Tabela 6.17: Resumo dos resultados das execuções do PhyloMOEA considerando ASRV.

\begin{tabular}{|l|r|r|r|r|}
\hline \multirow{2}{*}{\multicolumn{1}{|c|}{ Banco }} & \multicolumn{2}{|c|}{$\begin{array}{c}\text { Pontuação de } \\
\text { Parcimônia }\end{array}$} & \multicolumn{2}{c|}{$\begin{array}{c}\text { Pontuação de } \\
\text { Verossimilhança }\end{array}$} \\
\cline { 2 - 5 } & Melhor & Média $\pm \sigma$ & \multicolumn{1}{c|}{ Melhor } & Média $\pm \sigma$ \\
\hline rbcL_55 & 4.874 & $4.874,00 \pm 0,00$ & $-21.889,844$ & $-21.889,844 \pm 0,00$ \\
\hline mtDNA_186 & $\mathbf{2 . 4 3 7}$ & $2.437,90 \pm 0,32$ & $\mathbf{- 3 9 . 8 9 6 , 4 4 1}$ & $-39.896,441 \pm 0,00$ \\
\hline RDPII_218 & 41.534 & $41.534,00 \pm 0,00$ & $-134.696,535$ & $-134.696,535 \pm 0,00$ \\
\hline ZILLA_500 & 16.219 & $16.219,00 \pm 0,00$ & $-81.018,060$ & $-81.018,060 \pm 0,00$ \\
\hline
\end{tabular}

A Tabela 6.18 mostra os valores máximo, médio e desvio padrão do número de Soluções Pareto-ótimas e Finais encontradas pelo PhyloMOEA. Pode-se observar um comportamento estável em todas as execuções do algoritmo, uma vez que os valores de desvio são relativamente pequenos. Comparados aos resultados mostrados na Tabela 6.4, encontrouse um maior número de soluções Pareto-ótimas para os bancos rbcL_55 e ZILLA_500 e um menor número delas nos bancos $m t D N A_{-} 186$ e RDPII_218. O número de Soluções Finais foi maior apenas no banco $R D P I I \_218$. Este resultado mostrou que, embora os valores de verossimilhança das soluções tenham melhorado, a diversidade das soluções foi afetada, embora levemente, tanto para as soluções Pareto-ótimas como para as Soluções Finais.

Tabela 6.18: Resumo do número de soluções encontradas nas execuções do PhyloMOEA considerando ASRV.

\begin{tabular}{|l|r|r|r|c|}
\hline \multirow{2}{*}{ Banco } & \multicolumn{2}{|c|}{ Soluções Pareto-ótimas } & \multicolumn{2}{c|}{ Soluções Finais } \\
\cline { 2 - 5 } & Máximo & \multicolumn{1}{c|}{ Média $\pm \sigma$} & Máximo & Média $\pm \sigma$ \\
\hline rbcL_55 & 13 & $10,30 \pm 1,49$ & 61 & $52,50 \pm 5,74$ \\
\hline mtDNA_186 & 10 & $8,50 \pm 1,43$ & 59 & $50,80 \pm 4,44$ \\
\hline RDPII_218 & 27 & $23,90 \pm 1,97$ & 80 & $77,40 \pm 3,03$ \\
\hline ZILLA_500 & 26 & $19,60 \pm 3,27$ & 71 & $63,10 \pm 4,58$ \\
\hline
\end{tabular}

As Figuras 6.9, 6.10, 6.11 e 6.12 mostram a fronteira de Pareto e algumas Soluções Finais obtidas de uma execução do PhyloMOEA para os bancos de teste $r b c L \_55$, $m t D N A_{-} 186, R D P I I \_218$ e ZILLA_500, respectivamente. 


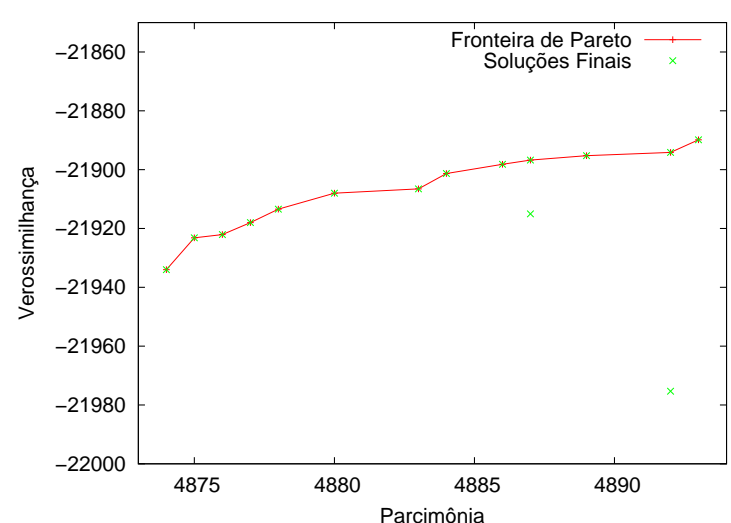

Figura 6.9: Soluções Pareto-ótimas do banco $r b c L \_55$.

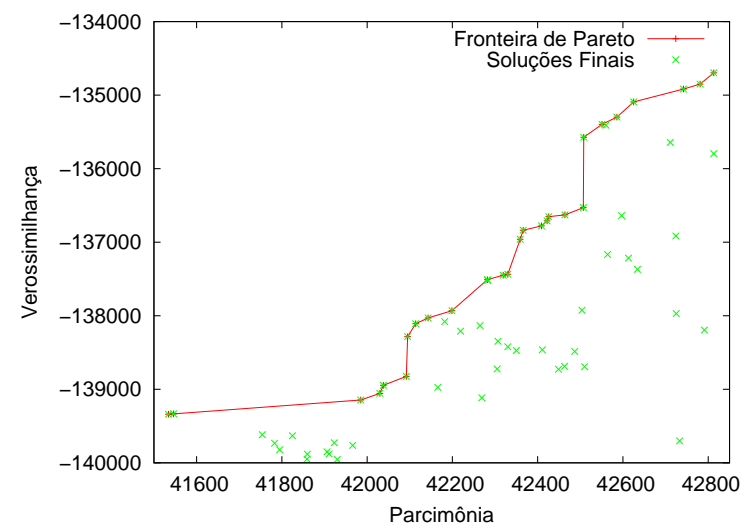
banco RDPII_218.

Figura 6.11: Soluções Pareto-ótimas do Figura 6.12: Soluções Pareto-ótimas do

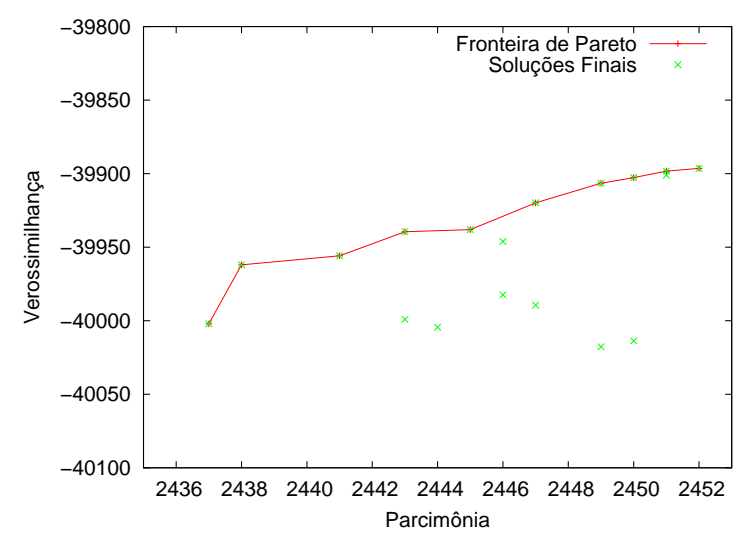

do Figura 6.10: Soluções Pareto-ótimas do banco $m t D N A_{-} 186$.

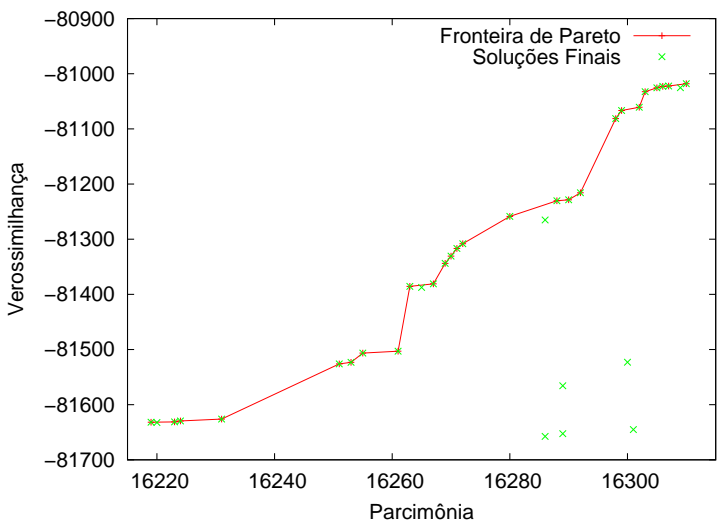
banco ZILLA_500.

\subsubsection{Testes de árvores alternativas para as soluções do Phylo- MOEA considerando ASRV}

Os resultados da fronteira de Pareto e as Soluções Finais fornecidas pelo PhyloMOEA (considerando ASRV) foram analisadas estatisticamente utilizando o teste SH (Shimodaira e Hasegawa, 1999). As Tabelas 6.19 e 6.20 mostram os resultados do teste SH para as Soluções Pareto-ótimas e as Soluções Finais, respectivamente. Tais tabelas apresentam o número de soluções não rejeitadas e soluções rejeitadas pelo teste SH aplicado com os critérios de parcimônia e verossimilhança.

Nas Tabelas 6.19 e 6.20 por um lado, mostram resultados semelhantes aos das Tabelas 6.5 e 6.6 (sem considerar ASRV). Para os bancos menores, poucas soluções são rejeitadas; enquanto para os bancos maiores o número de soluções rejeitadas é relativamente grande. Mesmo para os bancos maiores, o número de soluções não rejeitadas é significativo, revelando a importância das soluções do PhyloMOEA. 
Tabela 6.19: Resultados do teste SH para as Soluções Pareto-ótimas fornecidas pelo PhyloMOEA considerando ASRV.

\begin{tabular}{|l|r|r|r|r|}
\hline \multirow{2}{*}{ Banco } & \multicolumn{2}{|c|}{$\begin{array}{c}\text { Teste SH } \\
\text { Parcimônia }\end{array}$} & \multicolumn{2}{c|}{$\begin{array}{c}\text { Teste SH } \\
\text { Verossimilhança }\end{array}$} \\
\cline { 2 - 5 } & Não Rejeitadas & Rejeitadas & Não Rejeitadas & Rejeitadas \\
\hline rbcL_55 & 11 & 2 & 8 & 5 \\
\hline mtDNA_186 & 10 & 0 & 9 & 1 \\
\hline RDPII_218 & 2 & 25 & 4 & 23 \\
\hline ZILLA_500 & 9 & 17 & 8 & 18 \\
\hline Total & 32 & 44 & 29 & 47 \\
\hline
\end{tabular}

Tabela 6.20: Resultados do teste SH para as Soluções Finais fornecidas pelo PhyloMOEA considerando ASRV.

\begin{tabular}{|l|r|r|r|r|}
\hline \multirow{2}{*}{ Banco } & \multicolumn{2}{|c|}{$\begin{array}{c}\text { Teste SH } \\
\text { Parcimônia }\end{array}$} & \multicolumn{2}{c|}{$\begin{array}{c}\text { Teste SH } \\
\text { Verossimilhança }\end{array}$} \\
\cline { 2 - 5 } & Não Rejeitadas & Rejeitadas & Não Rejeitadas & Rejeitadas \\
\hline rbcL_55 & 19 & 40 & 18 & 41 \\
\hline mtDNA_186 & 41 & 13 & 29 & 25 \\
\hline RDPII_218 & 6 & 74 & 5 & 75 \\
\hline ZILLA_500 & 16 & 55 & 12 & 59 \\
\hline Total & 82 & 182 & 64 & 200 \\
\hline
\end{tabular}

Comparando as Tabelas 6.5 e 6.19, verifica-se que o total de soluções não rejeitadas para parcimônia (verossimilhança) são 40 e 32 (34 e 29), respectivamente. Das Tabelas 6.6 e 6.20, observa-se que o total de soluções não rejeitadas para parcimônia (verossimilhança) caem de 101 para 82 (79 para 64). Comparando-se as Tabelas 6.1 e 6.15 (com as soluções encontradas pelo NONA e RAxML-V), verifica-se que os pontos extremos estão mais próximos de uma forma geral na Tabela 6.15, que foi obtida considerando o ASRV. Claramente, o menor número de soluções não rejeitadas está relacionado com o menor intervalo entre os pontos extremos nos cálculos utilizando ASRV.

Os resultados do teste SH mostraram, mais uma vez, que existem soluções intermediárias que são consistentes com a solução de máxima parcimônia e a solução de máxima verossimilhança. Portanto, o PhyloMOEA foi capaz de encontrar árvores alternativas que representam um compromisso entre as melhores árvores para cada critério.

As Tabelas 6.21-6.28 mostram os resultados da comparação do PhyloMOEA com o Mr.Bayes para as Soluções Pareto-ótimas e as Soluções Finais dos bancos rbcL_55, mtDNA_186, RDPII_218 e ZILLA_500 respectivamente. As colunas de tais tabelas possuem o mesmo significado que os das colunas das Tabelas 6.7-6.14 (ver Seção 6.4).

Os resultados mostram que os tipos de clados usualmente encontrados correspondem aos tipos I, III, V e VII. Todos esses tipos de clados pertencem as soluções intermediárias, podendo ou não estar na árvores de máxima parcimônia e/ou máxima verossimilhança. Os clados de tipo V e VII possuem, em geral, os melhores valores de suporte e a menor di- 
ferença entre tais graus quando se comparam os resultados do PhyloMOEA e o Mr.Bayes. Isso significa que, os clados com maior suporte e probabilidade posterior, são aqueles que pertencem às soluções intermediárias e a árvore de máxima verossimilhança. Na maioria dos casos, as distâncias de pontuação e topológicas em relação à a parcimônia são maiores que as distâncias referentes a verossimilhança.

Os clados de tipo III, embora sejam bem suportados pelo phyloMOEA, não possuem o mesmo suporte pelo Mr.Bayes. Dessa forma, a diferença de grau de suporte de ambos os programas é considerável. Outros tipos de clados não possuem valores de suporte altos em nenhum dos programas. Conseqüentemente, os clados correspondentes apenas às soluções intermediárias e os clados correspondentes à árvore de máxima parcimônia são menos suportados pelo PhyloMOEA e pelo Mr.Bayes. A diferença das médias gerais do grau de suporte do PhyloMOEA e da probabilidade do Mr.Bayes é pequena na maioria dos casos. Além disso, as médias gerais das distâncias de pontuações e topológicas são também muito próximas.

As Figuras 6.13, 6.14, 6.15 e 6.16 mostram a relação do grau de suporte do PhyloMOEA e a probabilidade posterior do Mr.Bayes dos clados do tipo V e VII para os bancos rbcL_55, mtDNA_186, RDPII_218 e ZILLA_500 respectivamente. A maior correspondência entre ambas as quantidades é observada para os clados de tipo VII, onde a maioria dos pontos estão concentrados na região direita da função identidade.

Os resultados da comparação entre o PhyloMOEA e o Mr.Bayes realizada nesta Seção são similares aos obtidos na Seção 6.4. Assim, os valores mostrados das Tabelas 6.21-6.28 são próximos dos mostrados nas Tabelas 6.7- 6.14, encontrando-se pequenas diferenças nos graus de suporte em alguns casos. Como esperado, o resultado das comparações realizadas entre o PhyloMOEA e o Mr.Bayes favorece aqueles clados que estão próximos à árvore de máxima verossimilhança.

Tabela 6.21: Comparação dos resultados (considerando ASRV) do PhyloMOEA e Mr.Bayes para as Soluções Pareto-ótimas do banco $r b c L \_55$.

\begin{tabular}{|r|r|r|r|r|r|r|r|r|}
\hline Tipo & Num. & PMOEA & PBayes & Dif. & DPars. & DVeross. & DTPars. & DTVeross. \\
\hline \hline I & 1 & 0,2308 & 0,3535 & 0,1228 & 0,5439 & 0,2091 & 0,1154 & 0,0385 \\
\hline III & 2 & 0,6538 & 0,1471 & 0,5067 & 0,3090 & 0,4973 & 0,0573 & 0,0647 \\
\hline V & 6 & 0,5897 & 0,7648 & 0,1750 & 0,6287 & 0,1978 & 0,0970 & 0,0312 \\
\hline VII & 46 & $\mathbf{0 , 9 9 5 0}$ & $\mathbf{0 , 9 2 2 9}$ & 0,0721 & 0,4325 & 0,3926 & 0,0722 & 0,0519 \\
\hline \hline Total & 55 & 0,6173 & 0,5471 & 0,2192 & 0,4785 & 0,3242 & 0,0855 & 0,0466 \\
\hline
\end{tabular}


Tabela 6.22: Comparação dos resultados (considerando ASRV) do PhyloMOEA e Mr.Bayes para as Soluções Finais do banco $r b c L \_55$.

\begin{tabular}{|r|r|r|r|r|r|r|r|r|}
\hline Tipo & Num. & PMOEA & PBayes & Dif. & DPars. & DVeross. & DTPars. & DTVeross. \\
\hline \hline I & 18 & 0,0231 & 0,1797 & 0,1566 & 0,3775 & 0,3478 & 0,2340 & 0,2147 \\
\hline III & 2 & 0,5492 & 0,1471 & 0,4021 & 0,3848 & 0,3876 & 0,2135 & 0,2457 \\
\hline V & 6 & 0,4912 & 0,7648 & 0,2735 & 0,4310 & 0,3599 & 0,2460 & 0,1840 \\
\hline VII & 46 & $\mathbf{0 , 8 1 4 6}$ & $\mathbf{0 , 9 2 2 9}$ & 0,1082 & 0,3828 & 0,3537 & 0,2162 & 0,2050 \\
\hline \hline Total & 72 & 0,4696 & 0,5036 & 0,2351 & 0,3940 & 0,3623 & 0,2274 & 0,2123 \\
\hline
\end{tabular}

Tabela 6.23: Comparação dos resultados (considerando ASRV) do PhyloMOEA e Mr.Bayes para as Soluções Pareto-ótimas do banco mtDNA_186.

\begin{tabular}{|r|r|r|r|c|r|r|r|r|}
\hline Tipo & Num. & PMOEA & PBayes & Dif. & DPars. & DVeross. & DTPars. & DTVeross. \\
\hline \hline I & 10 & 0,2091 & 0,1903 & 0,0187 & 0,3282 & 0,2927 & 0,1627 & 0,1446 \\
\hline II & 5 & 0,0909 & 0,2148 & 0,1239 & 0,0000 & 1,0000 & 0,0000 & 0,2295 \\
\hline III & 13 & 0,3776 & 0,1834 & 0,1942 & 0,2389 & 0,5245 & 0,0910 & 0,1759 \\
\hline IV & 2 & 0,0909 & 0,0696 & 0,0213 & 1,0000 & 0,0000 & 0,2295 & 0,0000 \\
\hline V & 35 & 0,6182 & 0,3627 & 0,2555 & 0,7092 & 0,0897 & 0,2002 & 0,0628 \\
\hline VII & 138 & $\mathbf{0 , 9 9 6 0}$ & $\mathbf{0 , 8 7 3 0}$ & 0,1230 & 0,5347 & 0,2354 & 0,1655 & 0,1021 \\
\hline \hline Total & 203 & 0,3971 & 0,3156 & 0,1228 & 0,4685 & 0,3570 & 0,1415 & 0,1192 \\
\hline
\end{tabular}

Tabela 6.24: Comparação dos resultados (considerando ASRV) do PhyloMOEA e Mr.Bayes para as Soluções Finais do banco mtDNA_186.

\begin{tabular}{|r|r|r|r|r|r|r|r|r|}
\hline Tipo & Num. & PMOEA & PBayes & Dif. & DPars. & DVeross. & DTPars. & DTVeross. \\
\hline \hline I & 101 & 0,0299 & 0,1435 & 0,1136 & 0,2775 & 0,2998 & 0,2017 & 0,1789 \\
\hline III & 18 & 0,3002 & 0,1922 & 0,1080 & 0,2532 & 0,3457 & 0,1344 & 0,2335 \\
\hline V & 37 & 0,4789 & 0,3468 & 0,1320 & 0,2980 & 0,2478 & 0,2302 & 0,1083 \\
\hline VII & 138 & $\mathbf{0 , 9 5 1 6}$ & $\mathbf{0 , 8 7 3 0}$ & 0,0785 & 0,2847 & 0,2946 & 0,1953 & 0,1603 \\
\hline \hline Total & 294 & 0,4401 & 0,3889 & 0,1081 & 0,2783 & 0,2970 & 0,1904 & 0,1703 \\
\hline
\end{tabular}

Tabela 6.25: Comparação dos resultados (considerando ASRV) do PhyloMOEA e Mr.Bayes para as Soluções Pareto-ótimas do banco RDPII_218.

\begin{tabular}{|r|r|r|r|r|r|r|r|r|}
\hline Tipo & Num. & PMOEA & PBayes & Dif. & DPars. & DVeross. & DTPars. & DTVeross. \\
\hline \hline I & 15 & 0,1544 & 0,3119 & 0,1576 & 0,7163 & 0,3176 & 0,5432 & 0,2168 \\
\hline III & 10 & 0,4053 & 0,5405 & 0,1353 & 0,4087 & 0,7618 & 0,3293 & 0,4221 \\
\hline V & 127 & 0,5864 & 0,8174 & 0,2310 & 0,7423 & 0,2770 & 0,5655 & 0,1903 \\
\hline VII & 74 & $\mathbf{0 , 9 9 6 8}$ & $\mathbf{0 , 9 6 5 6}$ & 0,0312 & 0,6096 & 0,4589 & 0,4791 & 0,2855 \\
\hline \hline Total & 226 & 0,5357 & 0,6589 & 0,1387 & 0,6192 & 0,4538 & 0,4793 & 0,2787 \\
\hline
\end{tabular}


Tabela 6.26: Comparação dos resultados (considerando ASRV) do PhyloMOEA e Mr.Bayes para as Soluções Finais do banco RDPII_218.

\begin{tabular}{|r|r|r|r|c|r|r|r|r|}
\hline Tipo & Num. & PMOEA & PBayes & Dif. & DPars. & DVeross. & DTPars. & DTVeross. \\
\hline \hline I & 48 & 0,0398 & 0,3279 & 0,2881 & 0,5049 & 0,4500 & 0,4652 & 0,3564 \\
\hline III & 10 & 0,4366 & 0,5405 & 0,1039 & 0,3389 & 0,6436 & 0,3143 & 0,4834 \\
\hline V & 127 & 0,4830 & 0,8174 & 0,3344 & 0,5786 & 0,2995 & 0,5506 & 0,2452 \\
\hline VII & 74 & $\mathbf{0 , 9 6 6 8}$ & $\mathbf{0 , 9 6 5 6}$ & 0,0012 & 0,4665 & 0,4673 & 0,4446 & 0,3611 \\
\hline \hline Total & 259 & 0,4815 & 0,6629 & 0,1819 & 0,4722 & 0,4651 & 0,4437 & 0,3615 \\
\hline
\end{tabular}

Tabela 6.27: Comparação dos resultados (considerando ASRV) do PhyloMOEA e Mr.Bayes para as Soluções Pareto-ótimas do banco ZILLA_500.

\begin{tabular}{|r|r|r|r|r|r|r|r|r|}
\hline Tipo & Num. & PMOEA & PBayes & Dif. & DPars. & DVeross. & DTPars. & DTVeross. \\
\hline \hline I & 14 & 0,0842 & 0,1477 & 0,0634 & 0,7040 & 0,3398 & 0,1837 & 0,0727 \\
\hline III & 64 & 0,3261 & 0,2820 & 0,0441 & 0,4364 & 0,6837 & 0,1106 & 0,1448 \\
\hline V & 118 & 0,6554 & 0,5946 & 0,0608 & 0,7371 & 0,3031 & 0,1903 & 0,0648 \\
\hline VII & 374 & $\mathbf{0 , 9 9 6 4}$ & $\mathbf{0 , 9 1 3 3}$ & 0,0832 & 0,6523 & 0,4063 & 0,1682 & 0,0869 \\
\hline \hline Total & 570 & 0,5155 & 0,4844 & 0,0629 & 0,6325 & 0,4332 & 0,1632 & 0,0923 \\
\hline
\end{tabular}

Tabela 6.28: Comparação dos resultados (considerando ASRV) do PhyloMOEA e Mr.Bayes para as Soluções Finais do banco ZILLA_500.

\begin{tabular}{|r|r|r|r|r|r|r|r|r|}
\hline Tipo & Num. & PMOEA & PBayes & Dif. & DPars. & DVeross. & DTPars. & DTVeross. \\
\hline \hline I & 113 & 0,0117 & 0,1891 & 0,1775 & 0,4707 & 0,4205 & 0,1853 & 0,1247 \\
\hline III & 63 & 0,3474 & 0,2764 & 0,0710 & 0,3545 & 0,5688 & 0,1178 & 0,1827 \\
\hline IV & 119 & 0,6128 & 0,6035 & 0,0093 & 0,4865 & 0,2878 & 0,2196 & 0,0769 \\
\hline VII & 373 & $\mathbf{0 , 9 7 5 1}$ & $\mathbf{0 , 9 1 1 3}$ & 0,0638 & 0,4429 & 0,3870 & 0,1845 & 0,1140 \\
\hline \hline Total & 668 & 0,4868 & 0,4951 & 0,0804 & 0,4386 & 0,4160 & 0,1768 & 0,1246 \\
\hline
\end{tabular}

\subsection{Considerações finais}

Neste Capítulo foram apresentados os resultados da aplicação do PhyloMOEA em 4 bancos de seqüências de DNA usualmente empregados para avaliar programas de inferência filogenética. Os resultados indicaram que o modelo proposto apresentou um desempenho e uma estabilidade adequadas em várias execuções do modelo para cada banco de teste. O PhyloMOEA foi capaz de gerar soluções da fronteira de Pareto que representam alternativas intermediárias relevantes entre as árvores de máxima parcimônia e verossimilhança. Para obter melhores resultados, é preciso que soluções iniciais resultantes das análises de máxima parcimônia e máxima verossimilhança sejam incluídas na população inicial do PhyloMOEA. Caso contrário, o método desenvolvido mostra-se relativamente lento para os casos em que as soluções iniciais encontram-se muito longe da Fronteira de 


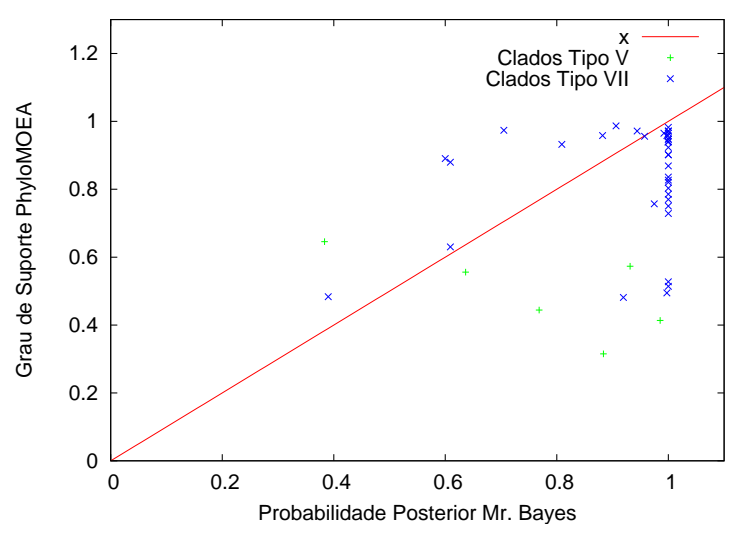

Figura 6.13: Grau de suporte do PhyloMOEA vs. Probabilidade Posterior do Mr.Bayes para as Soluções Pareto-ótimas do banco $r b c L \_55$.

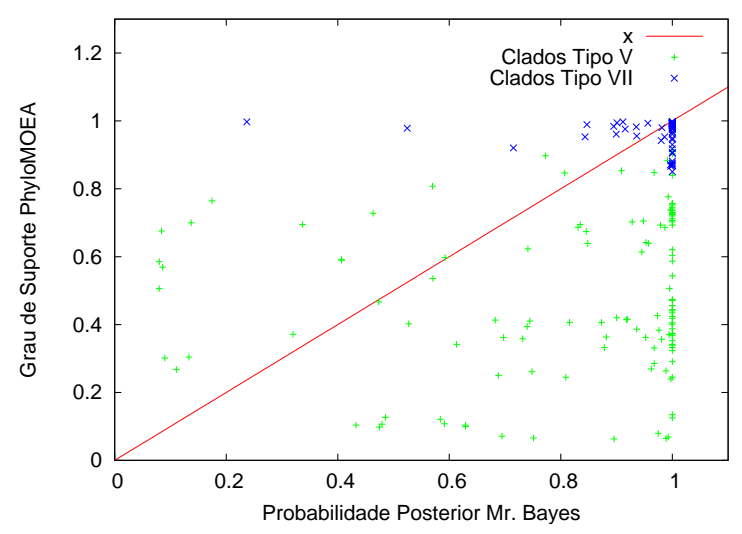

Figura 6.15: Grau de suporte do PhyloMOEA vs. Probabilidade Posterior do Mr.Bayes para as Soluções Pareto-ótimas do banco RDPII_218.

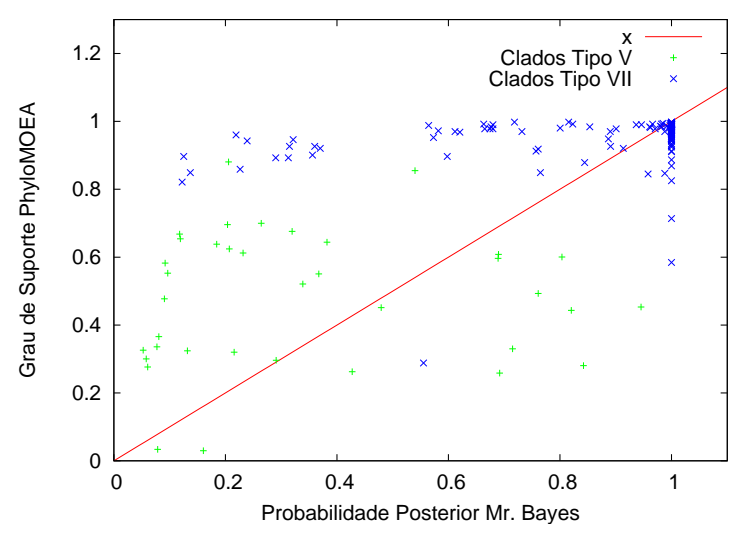

Figura 6.14: Grau de suporte do PhyloMOEA vs. Probabilidade Posterior do Mr.Bayes para as Soluções Pareto-ótimas do banco $m t D N A \_186$.

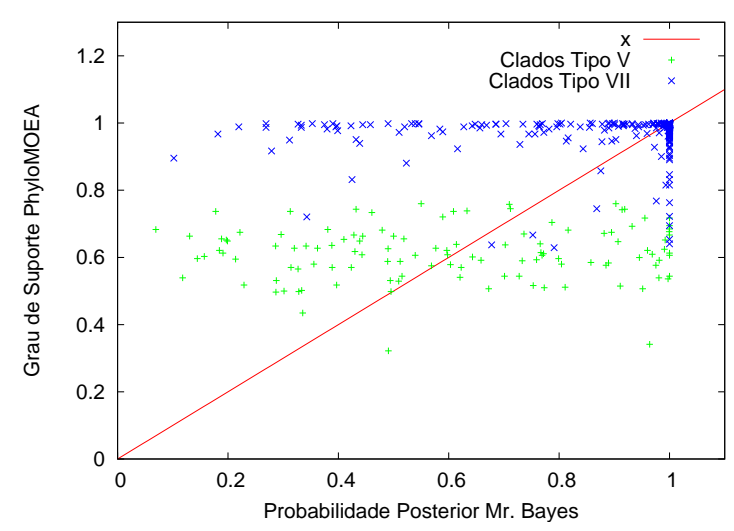

Figura 6.16: Grau de suporte do PhyloMOEA vs. Probabilidade Posterior do Mr.Bayes para as Soluções Pareto-ótimas do banco ZILLA_500.

Pareto. Além disso, em alguns casos, o PhyloMOEA foi capaz de melhorar as soluções iniciais de máxima parcimônia e máxima verossimilhança obtidas por outros programas de inferência filogenética.

A incorporação das taxas heterogeneidade entre sítios, utilizando o modelo $\mathrm{HKY} 85+\Gamma$, melhorou significativamente a verossimilhança da soluções iniciais fornecidas ao PhyloMOEA, assim como os resultados finais. Além disso, o número de soluções intermediárias não rejeitadas manteve-se em um nível significativo. Portanto, o PhyloMOEA considerando o ASRV, pode encontrar soluções melhores, bem como pode fornecer uma diversidade de soluções com compromisso adequado entre parcimônia e verossimilhança. 
O teste $\mathrm{SH}$ realizado com as árvores correspondentes às Soluções Pareto-ótimas e Soluções Finais do PhyloMOEA também mostrou que o modelo proposto foi capaz de encontrar árvores que são consistentes com os critérios de máxima verossimilhança e máxima parcimônia. Finalmente, os resultados obtidos pelo PhyloMOEA para cada banco foi comparado com os resultados do programa de inferência Bayesiana Mr.Bayes. Mostrou-se que, os graus de suporte dos clados calculados com o PhyloMOEA concordam razoavelmente com as probabilidades posteriores dos clados obtidas pelo Mr.Bayes.

As conclusões finais deste trabalho de pesquisa e as propostas de trabalho futuras são exploradas no Capítulo 7. 


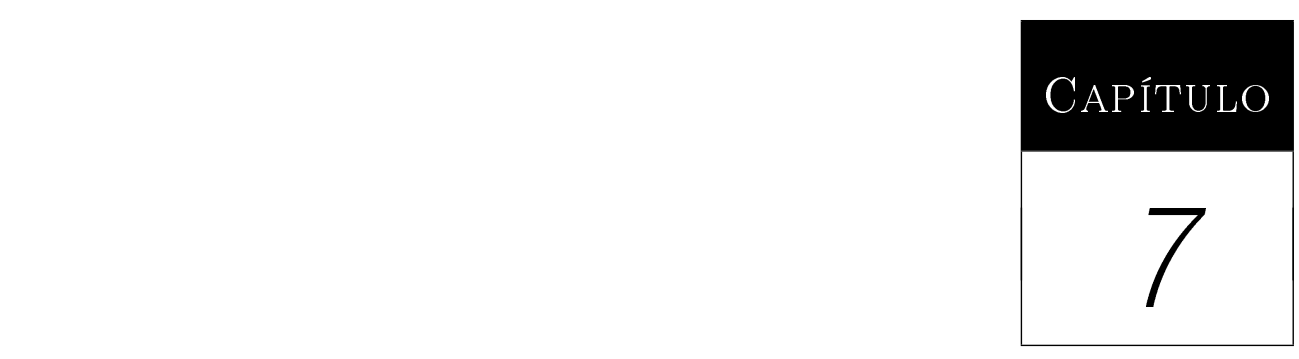

Conclusões e trabalhos futuros

No decorrer do deste trabalho apresentou-se o problema de reconstrução de árvores filogenéticas como um dos principais da área da bioinformática. Diversos métodos para reconstruir a árvore que melhor representa a história das espécies envolvidas na análise têm sido propostas nesta área de pesquisa. A máxima parcimônia e a máxima verossimilhança são dois dos principais métodos de reconstrução filogenética empregados pelos pesquisadores. Tais métodos definem critérios de otimalidade para avaliar as diferentes soluções no espaço de busca. Os algoritmos de Fitch (Fitch, 1972) e Felsenstein (Felsenstein, 1981a) permitem determinar as pontuações de parcimônia e verossimilhança, respectivamente. Contudo, a procura da árvore de máxima parcimônia ou máxima verossimilhança no espaço de busca é uma tarefa complexa. O tamanho de espaço de busca, o qual cresce rapidamente com o número de espécies analisados, impede a aplicação de métodos de busca exata para determinar a solução ótima para conjuntos de dados de tamanho mediano e grande. Assim, para tal tarefa são empregados métodos de busca baseados em heurísticas que, embora não garantam encontrar uma solução ótima, têm apresentado desempenho satisfatório na prática.

Os AEs constituem uma das principais heurísticas empregadas na reconstrução de árvores filogenética. Esses algoritmos representam um conjunto de técnicas que tem por base simular princípios da genética e evolução natural. Neste contexto, os AGs têm-se destacado para resolver tanto problemas de otimização quanto problemas de aprendizado de máquina. O problema de reconstrução filogenética pode ser formulado como um problema de otimização empregando um critério de otimalidade para avaliar as árvores no espaço de busca de topologias. A utilização de AEs em filogenia tem se mostrado como 
uma aplicação importante obtendo resultados comparáveis aos principais programas de inferência filogenética como PHYLIP e o PAUP*. Foi realizada uma revisão extensiva dos principais trabalhos da aplicação de AEs em filogenia, focando principalmente os trabalhos que empregaram como critério de otimalidade a máxima parcimônia e máxima verossimilhança.

Os AEs podem ser aplicados em problemas de otimização com vários objetivos a serem atingidos simultaneamente. Em tais problemas de otimização multi-objetivo (MOOPs), usualmente os objetivos a serem otimizados são conflitantes entre sim, ou seja, se um objetivo é melhorado usualmente outro objetivo é prejudicado. Isso significa que em tais casos, não existe apenas uma solução ótima, mais sim um conjunto de soluções denominadas Pareto-ótimas que representam um compromisso entre os objetivos do problema. Os AEs têm sido empregados satisfatoriamente em MOOPs, apresentando várias vantagens com relação a outras técnicas de otimização para este tipo de problemas.

Uma série de trabalhos apresentados na revisão bibliográfica mostra que o emprego de diferentes métodos de reconstrução filogenética para um conjunto de dados têm resultado em árvores conflitantes. Assim, uma abordagem multi-objetivo da reconstrução filogenética surge como uma alternativa viável para incorporar diversos critério de otimalidade usualmente empregados neste problema. Esta abordagem representa a principal motivação do presente trabalho de tese.

Neste trabalho foi desenvolvido o PhyloMOEA, um abordagem de MOEA para o problema de reconstrução de árvores filogenéticas baseado no modelo NSGA-II (Deb et al., 2000). Os principais componentes do PhyloMOEA foram apresentados detalhadamente. Os critérios considerados pelo PhyloMOEA são a máxima parcimônia e a máxima verossimilhança. O resultado da execução do modelo proposto é um conjunto de árvores Pareto-ótimas correspondentes a um compromisso entre os critérios considerados.

Para avaliar o conjunto de árvores obtidos pelo PhyloMOEA empregou-se o teste estatístico SH, que permite determinar se as soluções encontradas não são significativamente piores que as árvores de máxima parcimônia e máxima verossimilhança. Determinar soluções Pareto-ótimas que não sejam rejeitas pelo teste SH é um indicador de que as árvores encontradas com o PhyloMOEA são consistentes com os critérios considerados. É importante notar que as árvores encontradas não podem ser diretamente comparadas com as encontradas por outros programas de inferência filogenética, dado que esses programas consideram apenas um critério (parcimônia ou verossimilhança).

Uma outra forma de validar os resultados dos experimentos é comparar com métodos de inferência filogenética que permitam trabalhar com um conjunto de árvores alternativas. Para esse propósito podem ser empregados métodos de amostragem como bootstrap ou o método de inferência bayesiana. Assim, optou-se por comparar os graus de suporte dos clados pertencentes as árvores do PhyloMOEA com a probabilidade posterior dos 
clados das árvores encontradas pelo programa Mr.Bayes. Procurou-se analisar a natureza das correspondência e diferença entre ambos os valores.

Os experimentos testaram o desempenho do PhyloMOEA em 4 bancos de seqüências de DNA que têm sido freqüentemente empregados na literatura. Devido ao comportamento estocástico dos AEs, o PhyloMOEA foi executado várias vezes para cada banco. Os resultados indicaram que o modelo proposto teve um desempenho satisfatório e um comportamento estável em todas as execuções. Além disso, O PhyloMOEA foi capaz de gerar soluções da fronteira de Pareto que representam árvores alternativas entre as soluções de máxima parcimônia e verossimilhança. Contudo, para obter resultados aceitáveis, é preciso que soluções inicias sejam incorporadas na população inicial. Assim, foi realizado uma análise previa de máxima parcimônia e máxima verossimilhança para cada banco de dados. Adicionalmente, outras árvores foram obtidas utilizando a análise de bootstrap. A inclusão de tais árvores melhora consideravelmente o tempo de execução e os resultados obtidos pelo modelo proposto. O PhyloMOEA foi capaz, em alguns dos experimentos, de encontrar árvore melhores considerando cada critério separadamente.

A incorporação das taxas heterogeneidade entre sítios, utilizando o modelo HKY85 $+\Gamma$, melhorou significativamente as pontuações de verossimilhança da soluções inicias, assim como os resultados finais do PhyloMOEA. Contudo, os cálculos de verossimilhança requeridos por este modelo, aumentam significativamente o tempo de execução do PhyloMOEA. Observou-se também que o número de soluções encontradas foi levemente diminuído com o emprego desta abordagem.

O teste SH realizado nas Soluções Pareto-ótimas e Soluções Finais do PhyloMOEA mostrou que o modelo proposto foi capaz de encontrar árvores que são consistentes com os critérios de máxima verossimilhança e máxima parcimônia. Embora em alguns casos o teste rejeitou certa porcentagem considerável das soluções, encontrou-se sempre árvores consistentes com os critérios considerados.

Os clados correspondentes as árvores encontradas pelo PhyloMOEA foram comparadas aos clados calculados pelo programa de inferência Bayesiana Mr.Bayes. Mostrou-se que, os graus de suporte dos clados calculados com o PhyloMOEA concordam razoavelmente com as probabilidades posteriores dos clados obtidas pelo Mr.Bayes. Propou-se uma classificação de clados conforme a sua presença em árvores de máxima parcimônia, máxima verossimilhança e soluções intermediárias. Calculou-se a média das distâncias de pontuação e topológica entre as topologias contendo cada tipo de clado e as pontuações das árvores de máxima parcimônia e máxima verossimilhança. Mostrou-se que os clados que pertencem tanto às soluções intermediárias quanto às árvores de máxima parcimônia e máxima verossimilhança possuem um maior grau de suporte do PhyloMOEA e do Mr.Bayes. As distâncias topológicas e de pontuação para esse tipo de clados encontram-se mais próximos do ponto de máxima verossimilhança. 
Resultados parciais decorrentes das pesquisas relativas ao presente trabalho foram publicadas em dois congressos internacionais (Cancino e Delbem, 2007b,c):

- Cancino, W. e Delbem, A.C.B. "A Multi-Objective Evolutionary Approach for Phylogenetic Inference", in "Fourth International Conference on Evolutionary MultiCriterion Optimization (EMO 2007). LNCS vol. 4403, pp. 428-442, 2007;

- Cancino, W. e Delbem, A.C.B., "Multi-Criterion Phylogenetic Inference using Evolutionary Algorithms", in IEEE Symposium on Computational Intelligence and Bioinformatics and Computational Biology, 200\%. CIBCB '0\%. pp. 351 - 358, 2007. Neste último evento realizou-se a apresentação oral do trabalho e o mesmo ganhou o prêmio de Best Student Paper.

Além disso, uma versão estendida de tais trabalhos foi aceita para publicação na revista "International Journal of Information Technology and Intelligent Computing" (Cancino e Delbem, 2007a), o qual é respaldado pelo IEEE.

Embora os resultados obtidos pelo PhyloMOEA sejam encorajadores, ainda existem vários aspectos que merecem ser atendidos em pesquisa futura como:

- O desempenho do PhyloMOEA pode ser melhorado em diversos aspectos, principalmente no emprego de heurísticas de busca local (Guindon e Gascuel, 2003; Stamatakis e Meier, 2004) para uma melhor convergência do algoritmo. Se as soluções iniciais são pobremente estimadas, o PhyloMOEA poderia requerer várias horas de execução e não atingir resultados razoáveis;

- O cálculo da verossimilhança é um fator que influi fortemente no desempenho do PhyloMOEA. No algoritmo proposto empregou-se o algoritmo de Felsenstein para tal cálculo. Tal algoritmo reduz drasticamente o número de operações necessárias, mas ainda pode ser lento para grandes bancos de seqüências. Além disso, a natureza dos AEs exige muitas avaliações das soluções na população. Assim, o aumento do desempenho do cálculo da verossimilhança influenciaria fortemente o desempenho do PhyloMOEA. Na literatura, foram propostas várias técnicas para aumentar a performance de tais cálculos, as quais são empregadas em programas filogenéticos mais recentes (Larget e Simon, 1998; Pond e Muse, 2004; Stamatakis e Meier, 2004).

- O PhyloMOEA não otimiza os parâmetros do modelo de substituição de seqüências empregado no cálculo da verossimilhança. Isso restringe o modelo a ser utilizado quando são requeridos vários parâmetros. Esses valores podem ser otimizados simultaneamente com as soluções no decorrer das iterações do PhyloMOEA;

- O método proposto emprega o modelo de parcimônia mais simples, isto é, o algoritmo de Fitch, que trabalha com custos unitários para cada troca de estado. Porém, 
existem vários outros modelos de parcimônia que podem ser adequados conforme o banco de seqüências empregado. A inclusão desses modelos pode melhorar os resultados (Felsenstein, 2004; Swofford et al., 1996);

- Diversas técnicas de paralelização de MOEAs têm sido propostas na literatura (Coello et al., 2002; Veldhuizen et al., 2003). Tais abordagens podem ser facilmente implementados no PhyloMOEA visando melhorar o desempenho do modelo proposto.

Usualmente, os pesquisadores empregam diversas técnicas de reconstrução filogenética para analisar os seus dados moleculares. Assim, um programa que permita sintetizar os resultados da aplicação de vários métodos de reconstrução pode resultar em um aporte muito significativo na área.

Em resumo, pode-se dizer que a pesquisa proposta foi realizada a contento, uma vez que o PhyloMOEA tem obtido resultados condizentes com o esperado, bem como a comunidade científica da área tem se mostrado bastante receptiva ao tratamento multiobjetivo para filogenia proposto neste trabalho. 


\section{Referências Bibliográficas}

Adachi, J.; Hasegawa, M. MOLPHY version 2.3. Programs for Molecular Phylogenetics Based on Maximum Likelihood. in ishiguro. Computer Science Monographs 28, The Institute of Statistical Mathematics, Tokyo, 1996.

Ayala, F. Evolving: the theory and processes of organic evolution. Menlo Park, Calif: Benjamin/Cummings Pub. Co., 1979.

Blagojevic, F.; Stamatakis, A.; Antonopoulos, C.; Nikolopoulos, D. Raxmlcell: Parallel phylogenetic tree inference on the cell broadband engine. In: Parallel and Distributed Processing Symposium, 200\%. IPDPS 200\%. IEEE International, 2007, p. $1-10$.

Brauer, M. J.; Holder, M. T.; Dries, L. A.; Zwickl, D. J.; Lewis, P. O.; Hillis, D. M. Genetic algorithms and parallel processing in maximum-likelihood phylogeny inference. Molecular Biology and Evolution, v. 19, n. 10, p. 1717-1726, 2002.

BRENT, R. Algorithms for minimization without derivatives. Englewood Cliffs, NJ: Prentice-Hall, 1973.

Bruno, W.; Socci, N.; Halpern, A. Weighted neighbor joining: A likelihoodbased approach to distance-based phylogeny reconstruction. Molecular Biology and Evolution, v. 17, n. 1, p. 189-197, 2000.

Bryant, D.; Galtier, N.; Poursat, M. Likelihood calculation in molecular phylogenetics. In: Gascuel, O., ed. Mathematics of Evolution and Phylogeny, cáp. 2, Oxford University Press, p. 33-62, 2005.

Cancino, W.; Delbem, A. Inferring phylogenies by multi-objective evolutionary algorithms. International Journal of Information Technology and Intelligent Computing, v. 2, n. 2, 2007a. 
Cancino, W.; Delbem, A. Multi-criterion phylogenetic inference using evolutionary algorithms. In: Computational Intelligence and Bioinformatics and Computational Biology, 200\%. CIBCB '0\%. IEEE Symposium on, 2007b, p. 351 - 358.

Cancino, W.; Delbem, A. A multi-objective evolutionary approach for phylogenetic inference. In: Evolutionary Multi-Criterion Optimization, Springer Berlin / Heidelberg, 2007c, p. 428-442 (Lecture Notes in Computer Science, v.4403).

Cavalli-Sforza, L.; Edwards, A. Phylogenetic Analysis: Models and Estimation Procedures. Evolution, v. 21, n. 3, p. 550-570, 1967.

Cavender, J.; Felsenstein, J. Invariants of phylogenies in a simple case with discrete states. Journal of Classification, v. 4, p. 57-71, 1987.

Chase, M.; Soltis, D.; Olmstead, R.; Morgan, D.; Les, D.; Mishler, B.; Duvall, M.; Price, R.; Hills, H.; Qiu, Y.; Kron, K.; Rettig, J.; Conti, E.; Palmer, J.; Manhart, J.; Sytsma, K.; Michaels, H.; Kress, W.; Karol, K.; Clark, W.; Hedren, M.; Gaut, B.; Jansen, R.; Kim, K.; Wimpee, C.; Smith, J.; Furnier, G.; Strauss, S.; Xiang, Q.; Plunkett, G.; Soltis, P.; Swensen, S.; Williams, S.; Gadek, P.; Quinn, C.; Eguiarte, L.; Golenberg, E.; Learn, G.; Graham, S.; Barrett, S.; Dayanandan, S.; Albert, V. Phylogenetics of seed plants - an analysis of nucleotide-sequences from the plastic gene rbcl. Annals of the Missouri Botanical Garden, v. 80, n. 3, p. 528-580, 1993.

Coelho, G.; Silva, A.; Zuben, F. Evolving phylogenetic trees: A multiobjective approach. In: Advances in Bioinformatics and Computational Biology, Springer Berlin / Heidelberg, 2007, p. 113-125 (Lecture Notes in Computer Science, v.4643/2007).

Coelho, G.; Von Zuben, F. Omni-ainet: An immune-inspired approach for omni optimization. In: Artificial Immune Systems, 2006, p. 294-308.

Coello, C. A Short Tutorial on Evolutionary Multiobjective Optimization. In: ZitzLer, E.; Deb, K.; Thiele, L.; Coello, C. A. C.; Corne, D., eds. First International Conference on Evolutionary Multi-Criterion Optimization, Springer-Verlag., 2001, p. 21-40 (Lecture Notes in Computer Science, v.1993).

Coello, C.; Veldhuizen, D. V.; LAmont, G. Evolutionary algorithms for solving multi-objective problems. Genetic algorithms and evolutionary computation ; 5 . New York: Kluwer Academic, 2002.

Cole, J.; Chai, B.; Farris, R.; Wang; Kulam, S.; McGarrell, D.; Garrity, G.; TIEDJE, J. The Ribosomal Database Project (RDP-II): Sequences and Tools for High-throughput rRNA Analysis. Nucleic Acids Research, v. 33, p. D294-D296, 2005. 
COngDon, C. GAPHYL: An evolutionary algorithms approach for the study of natural evolution. In: Genetic and Evolutionary Computation Conference (GECCO-2002), 2002.

Congdon, C.; Greenfest, E. GAPHYL: A Genetic Algorithm Approach to Cladistics. In: Freitas, A. A.; Hart, W.; Krasnogor, N.; Smith, J., eds. Data Mining with Evolutionray Algorithms, 2000, p. 85-88.

Congdon, C.; Septor, K. J. Phylogenetic trees using evolutionary search: Initial progress in extending GAPHYL to work with genetic data. In: SARKER, R.; REYnolds, R.; AbBass, H.; Tan, K. C.; McKay, B.; Gedeon, T., eds. Congress on Evolutionary Computation (CEC-2003), IEEE Press, 2003, p. 320-326.

Cormen, T. Introduction to algorithms. 2nd ed. ed. Cambridge, Mass: MIT Press, 2001.

Corne, D.; Jerram, N.; Knowles, J.; OAtes, M. PESA-II: Region-based Selection in Evolutionary Multiobjective Optimization. In: Spector, L.; Goodman, E. D.; Wu, A.; Langdon, W.; Voigt, H.-M.; Gen, M.; Sen, S.; Dorigo, M.; Pezeshr, S.; Garzon, M. H.; Burke, E., eds. Proceedings of the Genetic and Evolutionary Computation Conference (GECCO'2001), San Francisco, California: Morgan Kaufmann Publishers, 2001, p. 283-290.

Corne, D.; Knowles, J.; OAtes, M. The Pareto Envelope-based Selection Algorithm for Multiobjective Optimization. In: Schoenauer, M.; Deb, K.; Rudolph, G.; Yao, X.; Lutton, E.; Merelo, J. J.; Schwefel, H.-P., eds. Proceedings of the Parallel Problem Solving from Nature VI Conference, Paris, France: Springer., 2000, p. 839-848 (Lecture Notes in Computer Science, v.1917).

Cotta, C.; Moscato, P. Inferring Phylogenetic Trees Using Evolutionary Algorithms. In: Merelo, J., ed. Parallel Problem Solving From Nature VII, Springer-Verlag, 2002, p. $720-729$.

DAY, W. Optimal algorithms for comparing trees with labeled leaves. Journal of Classification, v. 2, n. 1, p. 7-28, 1985.

De Castro, L.; Timmis, J. Artificial immune systems: a new computational intelligence approach. London: Springer, 2002.

DE JonG, K. Evolutionary computation: a unified approach. Cambridge, Mass: MIT Press, 2006.

DEB, K. Multi-objective optimization using evolutionary algorithms. New York: John Wiley \& Sons, 2001. 
Deb, K.; Agrawal, S.; Pratab, A.; Meyarivan, T. A Fast Elitist Non-Dominated Sorting Genetic Algorithm for Multi-Objective Optimization: NSGA-II. KanGAL report 200001, Indian Institute of Technology, Kanpur, India, 2000.

DeB, K.; Sundar, J. Reference point based multi-objective optimization using evolutionary algorithms. In: GECCO '06: Proceedings of the 8th annual conference on Genetic and evolutionary computation, New York, NY, USA: ACM, 2006, p. 635-642.

Edwards, A.; Cavalli-Sforza, L. Reconstruction of evolutionary trees. In: J., H. V. . M., ed. Phenetic and Phylogenetic Classification, Systematics Association, p. 67-76, 1964.

FARRIS, J. A successive approximations approach to character weighting. Systematic Zoology, v. 18, p. 374-385, 1969.

FARRIS, J. Methods for computing wagner trees. Systematic Zoology, v. 19, n. 1, p. 83-92, 1970.

FARRIS, J. Estimating phylogenetic trees from distance matrices. American Naturalist, v. 106, n. 951, p. 645-668, 1972.

FARRIS, J. Hennig86 documentation. Distribuido pelo autor., 1988.

Disponível em: http://www.cladistics.org/education/hennig86.html (Acessado em 11/2007)

Felsenstein, J. Maximum-likelihood and minimum-steps methods for estimating evolutionary trees from data on discrete characters. Systematic Zoology, v. 22, n. 3, p. 240-249, 1973a.

Felsenstein, J. Maximum-likelihood estimation of evolutionary trees from continuous characters. American Journal of Human Genetics, v. 25, p. 471-492, $1973 \mathrm{~b}$.

Felsenstein, J. Evolutionary Trees from DNA Sequences: A Maximum Likelihood Approach. Journal of Molecular Evolution, v. 17, p. 368-376, 1981a.

Felsenstein, J. Evolutionary trees from gene frequencies and quantitative characters: Finding maximum likelihood estimates. Evolution, v. 35, n. 6, p. 1229-1242, 1981b.

Felsenstein, J. Confidence Limits on Phylogenies: An Approach Using the Bootstrap. Evolution, v. 39, n. 4, p. 783-791, 1985.

Felsenstein, J. The newick tree format. 2000a.

Disponível em: http://evolution.genetics.washington.edu/phylip/newicktree. html 
Felsenstein, J. PHYLIP (Phylogeny Inference Package). $2000 \mathrm{~b}$.

Disponível em: http://evolution.genetics.washington.edu/phylip.html

Felsenstein, J. Inferring phylogenies. Sunderland, Massachusetts: Sinauer, 2004.

Fitch, W. Toward Defining the Course of Evolution: Minimum Change for a Specific Tree Topology. Systematic Zoology, v. 20, n. 4, p. 406-416, 1972.

Fitch, W. A non-sequential method for constructing trees and hierarchical classifications. Journal of Molecular Evolution, v. 4, n. 18, p. 30-37., 1981.

Fitch, W.; Margoliash, E. Construction of phylogenetic trees. Science, v. 155, p. 279-284, 1967.

Fogel, L. Autonomous automata. Industrial Research, v. 4, n. 1, p. 14-19, 1962.

Fogel, L.; OWens, A.; WALsh, M. Artificial intelligence through simulated evolution. New York: Wiley, 1966.

Fonseca, C.; Fleming, P. Genetic Algorithms for Multiobjective Optimization: Formulation, Discussion and Generalization. In: Forrest, S., ed. Proceedings of the Fifth International Conference on Genetic Algorithms, University of Illinois at UrbanaChampaign, San Mateo, California: Morgan Kauffman Publishers, 1993, p. 416-423.

Forster, M.; Pick, A.; Raitner, M.; Bachmaier, C. Gtl - graph template library documentation. University of Pasdau, 2004.

Disponível em: http://infosun.fmi.uni-passau.de/GTL/ (Acessado em 11/2007)

Futuyma, D. Biologia evolutiva. Riberão Preto, SP: Sociedade Brasileira de Genética, 1992.

Gascuel, O. BIONJ: An Improved Version of the NJ Algorithm Based on a Sample Model of Sequence Data. Molecular Biology and Evolution, v. 14, n. 7, p. 685-695, 1997.

Geist, A.; Beguelin, A.; Dongarra, J.; Jiang, W.; Manchek, R.; Sunderam, V. Pvm: Parallel virtual machine a users' guide and tutorial for networked parallel. MIT Press, 1994.

Gladstein, D. Efficient incremental character optimization. Cladistics, v. 13, p. 21-26, 1997.

Gogarten, J.; Lewis, P. O. Computer methods in molecular evolution. Lecture Notes. University of Connecticut, 2002.

Disponível em: http://carrot.mcb.uconn.edu/mcb372/index2.html (Acessado em $11 / 2007)$ 
GOLDBERG, D. Genetic algorithms in search, optimization, and machine learning. Reading, MA: Addison-Wesley Publishing Company, Inc., 1989.

Goldman, N. Phylogenetic information and experimental design in molecular systematics. Proceedings of the Royal Society of London Series B-Biological Sciences, v. 265, n. 1407 , p. $1779-1786,1998$.

Goldman, N.; Anderson, J.; Rodrigo, A. Likelihood-based tests of topologies in phylogenetics. Systematic Biology, v. 49, n. 4, p. 652-670, 2000.

Goloboff, P. Character optimization and calculation of tree lengths. Cladistics, v. 9, n. 4, p. 433-436, 1993.

GolobofF, P. Methods for faster parsimony analysis. Cladistics, v. 12, n. 3, p. 199-220, 1996.

Goloboff, P. Analyzing large data sets in reasonable times: Solutions for composite optima. Cladistics, v. 15, n. 4, p. 415-428, 1999a.

Goloboff, P. NONA (no name) ver. 2. Distribuido pelo author, 1999b.

Disponível em: http://www.cladistics.com/aboutNona.htm (Acessado em 11/2007)

Goloboff, P.; FARris, J. Methods for quick consensus estimation. Cladistics, v. 17, n. 1, p. S26-S34, 2001.

Goloboff, P.; Farris, J.; Nixon, K. Tnt. Cladistics, v. 20, n. 1, p. 84-84, 2004.

Graur, D.; LI, W.-H. Fundamentals of molecular evolution. 2 ed. Sinauer, 2000.

Guindon, S. Méthodes et algorithmes pour l'approche statistique en phylogénie. Tese de Doutoramento, U.F.R. Sciences de Montpellier. Université de Montpellier II, 2003.

Guindon, S.; Gascuel, O. A Simple, Fast, and Accurate Algorithm to Estimate Large Phylogenies by Maximum Likelihood. Systematic Biology, v. 5, n. 52, p. 696-704, 2003.

Haimes, Y.; Lasdon, L.; Wismer, D. On a bicriterion formulation of the problems of integrated system identification and system optimization. IEEE Transactions on Systems, Man, and Cybernetics, v. 1, n. 3, p. 296-297, 1971.

Hajela, P.; Lin, C. Y. Genetic search strategies in multicriterion optimal design. Structural Optimization, v. 4, p. 99-107, 1992.

Handl, J.; Kell, D.; KNowles, J. Multiobjective Optimization in Computational Biology and Bioinformatics. IEEE Transactions on Computational Biology and Bioinformatics, v. 4, n. 2, p. 289-292, 2006. 
Hartigan, J. Minimum mutation fits to a given tree. Biometrics, v. 29, n. 1, p. 53-65, 1973.

Hasegawa, M.; Kishino, H.; Yano, T. Dating of the Human-Ape Splitting by a Molecular Clock of Mitochondrial DNA. Journal of Molecular Evolution, v. 22, p. $160-174,1985$.

Haupt, R.; Haupt, S. Practical genetic algorithms. New York: Wiley, 1998.

Hendy, M.; Penny, D. Branch and bound algorithms to determine minimal evolutionary trees. Mathematical Biosciences, v. 60, p. 133-142, 1982.

Hendy, M.; Penny, D. Spectral analysis of phylogenetic data. Journal of Classification, v. 10, p. 5-24, 1993.

Hillis, D.; Bull, J.; White, M.; Badgett, M.; Molineux, I. Experimental phylogenetics - generation of a known phylogeny. Science, v. 255, n. 5044, p. 589-592, 1992.

Holland, J. Adaptation in natural and artificial systems. University of Michigan Press, 1975.

Holland, J. Adaptation in natural and artificial systems: an introductory analysis with applications to biology, control, and artificial intelligence. Complex adaptive systems, 1st mit press ed. ed. Cambridge, Mass: MIT Press, 1992.

Hordisk, W.; Gascuel, O. Improving the efficiency of SPR moves in phylogenetic tree search methods based on maximun likelihood. Bioinformatics, v. 21, n. 24, p. $4338-4347,2005$.

Horn, J.; Nafpliotis, N.; GoldBerG, D. A Niched Pareto Genetic Algorithm for Multiobjective Optimization. In: Proceedings of the First IEEE Conference on Evolutionary Computation, IEEE World Congress on Computational Intelligence, Piscataway, New Jersey: IEEE Service Center, 1994, p. 82-87.

Huelsenbeck, J. Performance of Phylogenetic Methods in Simulation. Systematic Biology, v. 44, p. 17-48, 1995.

Huelsenbeck, J.; Ronquist, F. MrBayes: Bayesian inference of phylogeny. Bioinformatics, v. 17, p. 754-755, 2001.

Huelsenbeck, J.; Ronquist, F. Mrbayes 3: Bayesian phylogenetic inference under mixed models. Bioinformatics, v. 19, p. 1572-1574, 2003. 
Huelsenbeck, J.; Ronquist, F.; Nielsen, R.; Bollback, J. Bayesian inference of phylogeny and its impact on evolutionary biology. Science, v. 294, p. 2310-2314, 2001.

Ingman, M.; Gyllensten, U. mtDB: Human Mitochondrial Genome Database, a Resource for Population Genetics and Medical Sciences. Nucleic Acids Research, v. 34, p. D749-D751, 2006.

Jin, L.; NeI, M. Limitations of the Evolutionary Parsimony Method of Phylogenetic Analysis. Molecular Biology and Evolution, v. 7, p. 82-102, 1990.

JobB, G. $\quad$ Treefinder manual. 2007.

Disponível em: http://www.treefinder.de/ (Acessado em 11/2007)

Jones, D.; TAYlor, W.; Thorton, J. The rapid generation of mutation data matrices from protein sequences. Computer Applications in the Biosciences, v. 8, p. 275-282, 1992.

Jukes, T.; CAntor, C. Mammalian protein metabolism. In: Evolution of protein molecules, Academic Press, p. 21-120, 1969.

Katoh, K.; Kuma, K.; Miyata, T. Genetic Algorithm-Based Maximum-Likelihood Analysis for Molecular Phylogeny. Journal of Molecular Evolution, v. 53, p. 477-484, 2001.

Kishino, H.; Hasegawa, M. Evaluation of the maximum likelihood estimate of the evolutionary tree topologies from DNA sequence data, and the branching order in hominoidea. Journal of Molecular Evolution, v. 4, p. 170-179, 1989.

Kita, H.; Yabumoto, Y.; Mori, N.; Nishikawa, Y. Multi-Objective Optimization by Means of the Thermodynamical Genetic Algorithm. In: VoIgT, H.-M.; EBELing, W.; Rechenberg, I.; Schwefel, H.-P., eds. Parallel Problem Solving from Nature-PPSN IV, Berlin, Germany: Springer-Verlag, 1996, p. 504-512 (Lecture Notes in Computer Science, v.1).

Knowles, J.; Corne, D. The Pareto Archived Evolution Strategy: A New Baseline Algorithm for Multiobjective Optimisation. In: 1999 Congress on Evolutionary Computation, Washington, D.C.: IEEE Service Center, 1999, p. 98-105.

Kosakovsky, S.; Muse, S. Column sorting: Rapid calculation of the phylogenetic likelihood function. Systematic Biology, v. 53, n. 5, p. 685-692, 2004.

Kuhner, M.; Felsenstein, J. A Simulation Comparison of Phylogeny Algorithms under Equal and Unequal Evolutionary Rate. Molecular Biology and Evolution, v. 11, p. 459-468, 1994. 
LAKE, J. A rate-independent technique for analysis of nucleic acid sequences: Evolutionary parsimony. Molecular Biology and Evolution, v. 4, p. 167-191, 1987.

LARget, B.; Simon, D. Faster likelihood calculations on trees. Relatório Técnico, Department of Mathematics and Computer Science. Duquesne University, 1998.

Larget, B.; Simon, D. Markov chain monte carlo algorithms for the bayesian analysis of phylogenetic trees. Molecular Biology and Evolution, v. 16, n. 6, p. 750-759, 1999.

Laumanns, M.; Rudolph, G.; Schwefel, H. A Spatial Predator-Prey Approach to Multi-Objective Optimization: A Preliminary Study. In: EIBEN, A. E.; SchOENAuer, M.; Schwefel, H.-P., eds. Parallel Problem Solving From Nature - PPSN V, Amsterdam, Holland: Springer-Verlag, 1998, p. 241-249.

Lemmon, A. R.; Milinkovitch, M. C. The Metapopulation Genetic Algorithm: An Efficient Solution for the Problem of Large Phylogeny Estimation. In: Proceedings of the National Academy of Sciences, 2002a, p. 10516-10521.

Lemmon, A. R.; Milinkovitch, M. C. Supporting information for lemmon and milinkovitch(2002). 2002b.

Disponível em: http://www.ulb.ac.be/sciences/ueg/pdf_files/Lem\&Milinko_02_ supp_data.pdf (Acessado em 11/2007)

LEwIs, P. O. A Genetic Algorithm for Maximum-Likelihood Phylogeny Inference Using Nucleotide Sequence Data. Molecular Biology and Evolution, v. 15, n. 3, p. 277-283, 1998.

Li, S.; PeArl, D.; Doss, H. Phylogenetic tree construction using markov chain monte carlo. Journal of the American Statistical Association, v. 95, n. 450, p. 493-508, 2000.

MAK, T.; LAM, K. High speed GAML-based phylogenetic tree reconstruction using hw/sw codesign. In: Proceeding of the Computational Systems Bioinformatics (CSB'03), IEEE Press, 2003, p. 470-473.

Matsuda, H. Construction of phylogenetic trees from amino acid sequences using a genetic algorithm. In: Pacific Symposium on Biocomputing '96, World Scientific, 1996, p. $512-523$.

Mau, B.; Newton, M. Phylogenetic inference for binary data on dendograms using markov chain monte carlo. Journal of Computational and Graphical Statistics, v. 6, n. 1, p. 122-131, 1997.

Michalewicz, Z. Genetic algorithms + data structures = evolution programs. 3rd rev. and extended ed. ed. Berlin: Springer-Verlag, 1996. 
Michener, C.; SokAl, R. A quantitative approach to a problem in classification. Evolution, v. 11, p. 130-162, 1957.

Miettinen, K. Nonlinear multiobjective optimization, v. 12 de International Series in Operations Research \& Management Science. Boston: Kluwer Academic Publishers, 1999.

Mollanen, A. Searching for Most Parsimonious Trees with Simulated Evolutionary Optimization. Cladistics, v. 15, p. 39-50, 1999.

Mollanen, A. Simulated evolutionary optimization and local search: Introduction and application to tree search. Cladistics, v. 17, p. S12-S25, 2001.

Morrison, D. A. Phylogenetic tree-building. International Journal of Parasitology, v. 26, n. 6, p. 589-617, 1996.

NeI, M.; Kumar, S. Molecular evolution and phylogenetics. Oxford University Press, 2000.

Nei, M.; Takezaki, N.; Sitnikova, T. Assessing molecular phylogenies. Science, v. 267, p. 253-255, 1994.

NiXON, K. The parsimony ratchet, a new method for rapid parsimony analysis. Cladistics, v. 15, n. 4, p. 407-414, 1999.

Olsen, G.; Matsuda, H.; Hagstrom, R.; Overbeek, R. fastDnAml: A tool for construction of phylogenetic trees of DNA sequences using maximun likelihood. Computer Applications in the Biosciences, v. 10, n. 1, p. 41-48, 1994.

Page, R. D. M.; Holmes, E. C. Molecular evolution: A phylogenetic approach. Blackwell Science Ltd., 1998.

PEer, Y. Phylogeny inference based on distance methods. In: SAlEmi, M.; VANDAmme, A., eds. The Phylogenetic Handbook: A Practical Approach to DNA and Protein Phylogeny, cáp. 5, Cambridge University Press, p. 101-136, 2003.

Penny, D.; Hendy, M.; Henderson, I. Reliability of evolutionary trees. In: Cold Spring Harbor Symposium on Quantitative Biology, 1987, p. 857-862.

Poladian, L.; Jerminn, L. Multi-Objective Evolutionary Algorithms and Phylogenetic Inference with Multiple Data Sets. Soft Computing, v. 10, n. 4, p. 359-368, 2006.

Pond, S. K.; Muse, S. Column Sorting: Rapid Calculation of the Phylognetic Likelihood Function. Systematic Biology, v. 53, n. 5, p. 685-592, 2004. 
PRADO, O. Computação evolutiva empregada na reconstrução de Árvores filogenéticas. Dissertação de Mestrado, DCA-FEEC/Unicamp, 2002.

Press, W.; Flannery, B.; Teukolsky, S.; Vetterling, W. Numerical recipes in c: the art of scientific computing. 2nd ed. ed. Cambridge: Cambridge University Press, 1992.

Pupko, T.; Graur, D. Fast computation of maximum likelihood trees by numerical approximation of amino acid replacement probabilities. Computational Statistics $\&$ Data Analysis, v. 40, p. 285-291, 2002.

Queiroz, K.; Poe, S. Philosophy and phylogenetic inference: a comparison of likelihood and parsimony methods in the context of karl popper's writings on corroboration. Systematic Biology, v. 50, n. 3, p. 305-321, 2001.

Quesne, W. L. A method of selection of characters in numerical taxonomy. Systematic Zoology, v. 18, p. 201-205, 1969.

Quesne, W. L. Compatibility analysis and its applications. Zoological Journal of the Linnean Society, v. 74, p. 267-275, 1982.

Rannala, B.; YANG, Z. Probability distribution of molecular evolutionary trees: A new method of phylogenetic inference. Journal of Molecular Evolution, v. 43, n. 3, p. 304-311, 1996.

RECHEnberG, I. Cybernetic solution path of an experimental problem. Relatório Técnico 1122, Royal Aircraft Establishment, Library Translation Number 1122, Franborough, UK., 1965.

Reijmers, T.; Wehrens, R.; Daeyaert, F.; Lewi, P.; Buydens, L. Using genetic algorithms for the construction of phylogenetic trees: Application to g-protein coupled receptor sequences. Biosystems, v. 49, p. 31-43, 1999.

Rich, E.; Knight, K. Artificial intelligence. 2nd ed. ed. New York: McGraw-Hill, 1991.

RIDley, M. Evolution. 2nd ed. ed. Cambridge, Mass., USA: Blackwell Science, 1996.

Robinson, D.; Foulds, L. Comparison of weighted labelled trees. In: Combinatorial mathematics VI, Springer, 1979, p. 119-126 (Lecture Notes in Mathematics, v.748).

Rogers, J.; Swofford, D. A fast method for approximating maximun likelihoods of phylogenetic trees from nucleotide sequences. Systematic Biology, v. 47, n. 1, p. 77-89, 1998. 
Rokas, A.; Wiliams, B.; King, N.; Carroll, S. Genome-Scale Approaches to Resolving Incongrounce in Molecular Phylogenies. Nature, v. 425, n. 23, p. 798-804, 2003.

Ronquist, F. Fast fitch-parsimony algorithms for large data sets. Cladistics, v. 14, n. 4, p. 386-400, 1998.

Ronquist, F.; Huelsenbeck, J.; Mark, P. Mrbayes 3.1 manual. School of Computer Science. Florida State University, 2005.

Rudolph, G. Evolutionary Search under Partially Ordered Fitness Sets. In: Proceedings of the International NAISO Congress on Information Science Innovations (ISI 2001), ICSC Academic Press: Millet/Sliedrecht, 2001, p. 818-822.

Russell, S.; Norvig, P. Artificial intelligence: a modern approach. Prentice Hall series in artificial intelligence. Englewood Cliffs, N.J: Prentice Hall, 1995.

Russo, C.; TAKezaki, N.; NeI, M. Efficiencies of different genes and different treebuilding methods in recovering a known vertebrate phylogeny. Molecular Biology and Evolution, v. 13, n. 3, p. 525-536, 1996.

Rzhetsky, A.; NeI, M. A simple method for estimating and testing minimum-evolution trees. Molecular Biology and Evolution, v. 9, p. 945-967, 1992.

Saitou, N.; Imanishi, T. Relative efficiencies of the fitch-margoliash, maximumparsimony, maximun-likelihood, minimum evolution, and neighbor-joining methods of phylogenetic tree construction in obtaining the correct tree. Molecular Biology and Evolution, v. 6, p. 514-525, 1989.

Saitou, N.; NeI, M. The Neighbor-Joining Method: A New Method for Reconstructing Phylogenetic Trees. Molecular Biology and Evolution, v. 4, n. 4, p. 406-425, 1987.

SANKOFF, D. Minimal mutation trees of sequences. SIAM Journal of Applied Mathematics, v. 28, p. 35-42, 1975.

SANKOFF, D. Simultaneous Solution of the RNA Folding, Alignment and Proto-Sequence Problems. SIAM Journal on Applied Mathematics, v. 45, n. 5, p. 810-825, 1985.

Sattath, S.; Tversky, A. Additive similarity trees. Psychometrika, v. 42, p. 319-345, 1977.

Schaffer, J. Multiple Objective Optimization with Vector Evaluated Genetic Algorithms. In: Genetic Algorithms and their Applications: Proceedings of the First International Conference on Genetic Algorithms, Lawrence Erlbaum, 1985, p. 93-100. 
SCHWEFEL, H. Projekt mhd-staustrahlrohr: Experimentelle optimierung einer zweiphasendüse, teil $i$. Relatório Técnico 11.034/68, 35, AEG Forschungsinstitut, Berlin, 1968.

Setubal, J.; MeIDANIS, J. Introduction to computational molecular biology. International Thomson, 1997.

Shimodaira, H. An approximately unbiased test of phylogenetic tree selection. Systematic Biology, v. 51, n. 3, p. 492-508, 2002.

Shimodaira, H.; Hasegawa, M. Likelihood-Based Tests of Topologies in Phylogenetics. Molecular Biology and Evolution, v. 16, n. 8, p. 1114-1116, 1999.

SieK, J.; LeE, L.; Lumsdaine, A. The boost graph library: User guide and reference manual. Addison-Wesley, Pearson Education Inc., 2002.

Disponível em: http://www.boost.org/libs/graph/doc/index.html (Acessado em $11 / 07)$

Skourikhine, A. Phylogenetic tree reconstruction using self-adaptive genetic algorithm.

In: 1st IEEE International Symposium on Bio-Informatic and Biomedical Engineering (BIBE 2000), IEEE Press, 2000, p. 193-199.

Sourdis, J.; NeI, M. Relative efficiencies of the maximum parsimony and distancematrix methods in obtaining the correct phylogenetic tree. Molecular Biology and Evolution, v. 5, p. 298-311, 1988.

Srinivas, N.; DeB, K. Multiobjective Optimization Using Nondominated Sorting in Genetic Algorithms. Evolutionary Computation, v. 2, n. 3, p. 221-248, 1994.

Stamatakis, A. An efficient program for phylogenetic inference using simulated annealing. In: 19th IEEE International Parallel and Distributed Processing Symposium (IPDPS'05), 2005.

Stamatakis, A. Phylogenetic models of rate heterogeneity: a high performance computing perspective. In: Parallel and Distributed Processing Symposium, 2006. IPDPS 2006. 20th International, 2006a, p. 8 pp.

StamatAkis, A. Raxml-vi-hpc: Maximum likelihood-based phylogenetic analyses with thousands of taxa and mixed models. Bioinformatics, v. 22, n. 21, p. 2688-2690, 2006b.

Stamatakis, A.; Ludwig, T.; Meier, H. Raxml-ii: a program for sequential, parallel and distributed inference of large phylogenetic. Concurrency and ComputationPractice \& Experience, v. 17, n. 14, p. 1705-1723, 2005a. 
Stamatakis, A.; Ludwig, T.; Meier, H. RAxML-III: A fast program for maximum likelihood based inference of large phylogenetic trees. Bioinformatics, v. 21, n. 4, p. 456-463, 2005b.

Stamatakis, A.; Ludwig, T.; Meier, H.; Wolf, M. Accelerating parallel maximun likelihood-based phylogenetic tree calculations using subtree equality vectors. In: CD, P., ed. 15th IEEE/ACM Supercomputing Conference (SC2002), Baltimore, Maryland, 2002a.

Stamatakis, A.; Ludwig, T.; Meier, H.; Wolf, M. AxMl: A fast program for sequential and parallel phylogenetic tree calculations based on the maximun likelihood method. In: Proceedings of 1st IEEE Computer Society Bioinformatics Conference (CSB2002), Palo Alto, California, 2002b, p. 21-28.

Stamatakis, A.; Meier, H. New Fast and Accurate Heuristics for Inference of Large Phylogenetic Trees. In: 18th IEEE/ACM International Parallel and Distributed Processing Symposium (IPDPS2004), 2004.

Strimmer, K.; Haeseler, A. Nucleotide substitution models. In: Salemi, M.; Vandamme, A., eds. The Phylogenetic Handbook: A Practical Approach to DNA and Protein Phylogeny, cáp. 4, Cambridge University Press, p. 72-100, 2003.

Strimmer, K.; HAesler, A. Quartet puzzling: A quartet maximum-likelihood method for reconstructing tree topologies. Molecular Biology and Evolution, v. 13, p. 407-514, 1996.

SunG, W.-K. Lecture 7: Phylogenetic trees reconstruction. 2002.

Disponível em: http://www.comp.nus.edu.sg/ ksung/cs5238/2002Sem1/note/ note_taking_list.htm (Acessado em 11/2007)

Swofford, D. PAUP* Phylogenetic Analisys Using Parsimony. CSIT Florida State University, 2000.

Swofford, D.; Olsen, G.; Waddell, P.; Hillis, D. Phylogeny Reconstruction. In: Molecular Systematics, 3 ed, cáp. 11, Sinauer, p. 407-514, 1996.

Swofford, D.; Sullivan, J. Phylogeny inference based on parsimony and other methods using paup*. In: SAlemi, M.; VAndamme, A., eds. The Phylogenetic Handbook: A Practical Approach to DNA and Protein Phylogeny, cáp. 7, Cambridge University Press, p. 160-206, 2003.

SyWERDA, G. Uniform crossover in genetic algorithms. In: Proceedings of the third international conference on Genetic algorithms, Morgan Kaufmann Publishers Inc., 1989, p. 2-9. 
Tateno, Y.; Takezaki, N.; Nei, M. Relative Efficiences of the Maximum-Likelihood, Neighbor-Joining, and Maximum Parsimony Methods when Substitution Rate Varies with Site. Molecular Biology and Evolution, v. 11, p. 261-267, 1994.

Templeton, A. Phylogenetic inference from restriction endonuclease cleavage site maps with particular reference to the evolution of humans and the apes. Evolution, v. 37, n. 2, p. 221-244, 1983.

Tuffley, C.; Steel, M. Links between maximum likelihood and maximum parsimony under a simple model of site substitution. Bulletin of Mathematical Biology, v. 59, n. 3, p. 581-607, 1997.

Veldhuizen, D. V. Multiobjective Evolutionary Algorithms: Classifications, Analyses, and New Innovations. Tese de Doutoramento, Department of Electrical and Computer Engineering. Graduate School of Engineering. Air Force Institute of Technology, WrightPatterson AFB, Ohio, 1999.

Veldhuizen, D. V.; Zydallis, J.; Lamont, G. Considerations in engineering parallel multiobjective evolutionary algorithms. IEEE Transactions on Evolutionary Computation, v. 7, n. 2, p. $144-173,2003$.

Vinh, L.; HAESELER, A. Iqpnni: Moving fast through tree space and stopping in time. Molecular Biology and Evolution, v. 21, n. 8, p. 1565-1571, 2004.

WeIR, B. Genetic data analysis ii. Sinauer, 1996.

YANG, Z. Maximum-Likelihood Estimation of Phylogeny from DNA Sequences when Substitution Rates Differ over Sites. Molecular Biology and Evolution, v. 10, n. 6, p. 1396-1401, 1993.

YANG, Z. Maximum-likelihood phylogenetic estimation from DNA sequences with variable rates over sites: Approximate methods. Journal of Molecular evolution, v. 39, n. 3, p. 306-314, 1994.

YAnG, Z. PAML: A Program Package for Phylogenetic Analysis by Maximum Likelihood. Computer Applications in Biosciences, v. 13, n. 5, p. 555-6, 1997.

YANG, Z. Maximum Likelihood Estimation on Large Phylogenies and Analysis of Adaptative Evolution in Human Influenza Virus A. Journal of Molecular Evolution, v. 51, n. 5, p. 423-432, 2000.

YANG, Z. Computational molecular evolution. Oxford series in ecology and evolution. Oxford: Oxford University Press, 2006. 
Zeleny, M. Compromise programming. In: Cochrane, J.; Zeleny, M., eds. Multiple Criteria Decision Making, University of South Carolina Press, 1973, p. 262301.

Zitzler, E.; Deb, K.; Thiele, L. Comparison of Multiobjective Evolutionary Algorithms: Empirical Results. Evolutionary Computation, v. 8, n. 2, p. 173-195, 2000.

Zitzler, E.; Laumanns, M.; Thiele, L. SPEA2: Improving the Strength Pareto Evolutionary Algorithm. Relatório Técnico 103, Computer Engineering and Networks Laboratory (TIK), Swiss Federal Institute of Technology (ETH) Zurich, Gloriastrasse 35, CH-8092 Zurich, Switzerland, 2001.

Zitzler, E.; Thiele, L. An Evolutionary Algorithm for Multiobjective Optimization: The Strength Pareto Approach. Relatório Técnico 43, Computer Engineering and Communication Networks Lab (TIK), Swiss Federal Institute of Technology (ETH), Zurich, Switzerland, 1998.

ZWICKL, D. Genetic algorithm approaches for the phylogenetic analysis of large biological sequence datasets under the maximum likelihood criterion. Tese de Doutoramento, Faculty of the Graduate School. University of Texas., 2006. 